\title{
Distributional impacts of public policies : essays in ex- ante and ex-post evaluation
}

Citation for published version (APA):

Salanauskaite, L. (2012). Distributional impacts of public policies : essays in ex-ante and ex-post evaluation. [Doctoral Thesis, Maastricht University]. Boekenplan. https://doi.org/10.26481/dis.20121005ls

Document status and date:

Published: 01/01/2012

DOI:

10.26481/dis.20121005ls

Document Version:

Publisher's PDF, also known as Version of record

\section{Please check the document version of this publication:}

- A submitted manuscript is the version of the article upon submission and before peer-review. There can be important differences between the submitted version and the official published version of record.

People interested in the research are advised to contact the author for the final version of the publication, or visit the DOI to the publisher's website.

- The final author version and the galley proof are versions of the publication after peer review.

- The final published version features the final layout of the paper including the volume, issue and page numbers.

Link to publication

\footnotetext{
General rights rights.

- You may freely distribute the URL identifying the publication in the public portal. please follow below link for the End User Agreement:

www.umlib.nl/taverne-license

Take down policy

If you believe that this document breaches copyright please contact us at:

repository@maastrichtuniversity.nl

providing details and we will investigate your claim.
}

Copyright and moral rights for the publications made accessible in the public portal are retained by the authors and/or other copyright owners and it is a condition of accessing publications that users recognise and abide by the legal requirements associated with these

- Users may download and print one copy of any publication from the public portal for the purpose of private study or research.

- You may not further distribute the material or use it for any profit-making activity or commercial gain

If the publication is distributed under the terms of Article $25 \mathrm{fa}$ of the Dutch Copyright Act, indicated by the "Taverne" license above, 
DISTRIBUTIONAL IMPACTS OF PUBLIC POLICIES

ESSAYS IN EX-ANTE AND EX-POST EVALUATION 


\section{(C) Lina Salanauskaite}

All rights reserved. No part of this publication may be reproduced, stored in a retrieval system, or transmitted in any form, or by any means, electronic, mechanical, photocopying, recording or otherwise, without the prior permission in writing, from the author.

ISBN 9789086662753

Cover picture Karaliu pasaka (Kings' Fairy Tale) by Lithuanian painter Mikalojus Konstantinas Čiurlionis

Publisher Boekenplan, Maastricht NL. www.boekenplan.nl 


\section{Distributional Impacts of Public Policies}

Essays in Ex-Ante and Ex-Post Evaluation

Dissertation

to obtain the joint degree of Doctor at Maastricht University and at the University of Antwerp,

on the authority of the Rector Magnificus Prof. dr. L.L.G. Soete in accordance with the decision of the Board of Deans, to be defended in public at Maastricht University on Friday 5 October 2012, at $10.00 \mathrm{hrs}$

By

Lina Salanauskaite 


\section{Supervisor:}

Prof. Dr. Chris de Neubourg

\section{Co-Supervisors:}

Dr. Gerlinde Verbist (University of Antwerp, Belgium)

Dr. Raymond Wagener (Inspection Générale de la Sécurité Sociale, Luxembourg)

\section{Assessment committee:}

Prof. Dr. Wim Groot (chairman)

Prof. Dr. Diana de Graeve (University of Antwerp, Belgium)

Dr. Franziska Gassmann

Prof. Dr. Hans Maarse

Prof. Dr. Cathal O’Donoghue (Teagasc, Ireland) 
ŠIĄ KNYGA SKIRIU SAVO TÉVAMS 



\section{Acknowledgments}

The ancient phrase, "A journey of a thousand miles starts with one step" could not be more right. The first step is a deciding one. However, after it - there are still 999 steps to be made. The journey of writing this dissertation has been just like that: a hefty decision when starting it and a long way in completing it. This "journey", however, could not have been possible without the guidance and the help of many people who in one or another way have contributed in the preparation and completion of this thesis.

First and foremost, my utmost gratitude goes to my supervisors - Chris de Neubourg, Gerlinde Verbist and Raymond Wagener. Your support and encouragement I will never forget!

Thank you to the reading committee members Dr. Franziska Gassmann, Prof. Dr. Diana de Graeve, Prof. Dr. Wim Groot, Prof. Dr. Hans Maarse and Prof. Dr. Cathal O'Donoghue for their comments and stimulus in improving this manuscript.

My big thanks also go to Denis de Crombrugghe - you have been my inspiration as I "hurdled" along the challenges of econometrics.

Thank you for the support of numerous other people, both in Maastricht and Antwerp universities, especially Mindel van de Laar, Annemarie Rima, Mieke Drossaert, Celine Duijsens, Susan Roggen, Bea Cantillon, Karel van den Bosch, Tim Goedeme, Tim van Rie, Ive Marx, Ninke Mussche ... - your research comments, administrative and personal support has cleared away so many obstacles for me.

I am also eternally grateful for the friendship of so many people I have met during this journey and in Maastricht. Actually, if one could allocate where the first step towards this PhD degree has been made - without the doubt I would point to the master programme of Social Protection Financing (SPF). Both the content and the people of this programme have changed my life dramatically. Many thanks go to Jessica, Robert, Mirtha, Patricia, David, Nader, Agnieszka, Waty, Fifi, Florian, Jin Jing and many other groupmates, SPF alumni, ILO lecturers and support staff our ways have crossed in so many important ways, that I can barely remember the times I did not know you!

I would also like to thank my PhD groupmates - Melissa, Britta, Zina, Denisa, Frieda, Hao, Bianca, Michal, Pascal - as well as other students at Maastricht Graduate School of Governance, especially Sonila, Judith, Metka, Maha and Cheng, 
ii

for their unconditional friendship and so many beautiful moments together. My special thanks also go to the comrades from the UNU-MERIT: my dearest housemate Asel, and then Marion, Semih, Abraham, Flavia, Eze and many others I have got to know on the "MGSoG/MERIT friendship" terrace of Bilserbaan 53b.

My sincere thanks also go to the number of many other friends, both in Lithuania and abroad - Giedré, Rasa, Kristina, Vytautas, Erwin, Yvette, Alex and the many others that are so dear to me. I am also grateful for the new friendship of so many people in Antwerp, and especially my housemates in Sanderusstraat. Without this opportunity of being a "guest" housemate, without your support and great dinners we share every week, I would be so much more lost in the complicated Belgian landscape!

Finally, I thank my family. I thank my family in Lithuania for simply providing their love and unreserved trust in me, no matter how far away journeys I have made. I promise I will not pursue another $\mathrm{PhD}$, though being far away from home is perhaps irreversible. My heart also goes to my new family in Belgium - your warm welcome and support has been of the highest importance to me.

And last but not least, I thank my husband Alain, for without your love and continuous encouragement this journey would have been so much different. It has been our destiny to meet in Maastricht, and every day I thank for being together. I also thank for our little daughter Maria being born - having you born this May has given me an extra boost of energy and motivation of finalising this thesis. This year is truly a happy ending of this and a start of yet another journey...

Thank you all so much!

Lina Salanauskaitė

Mürringen, Belgium. 


\section{Table of contents}

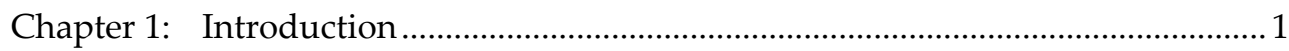

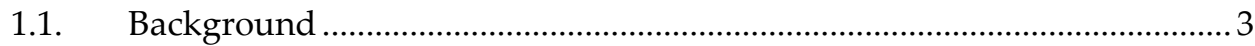

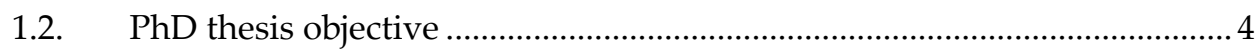

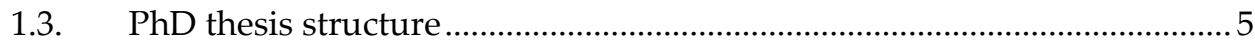

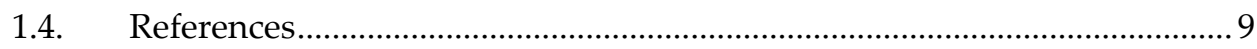

Chapter 2: Employment and Healthcare Use: A Conceptual Framework .............. 11

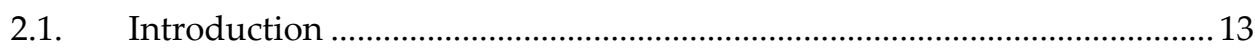

2.2. Contextual factors and conceptual models of healthcare use ....................14

2.3. Institutional healthcare determinants......................................................... 19

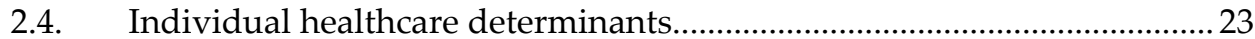

2.5. Employment as a determinant of healthcare use: a conceptual model....26

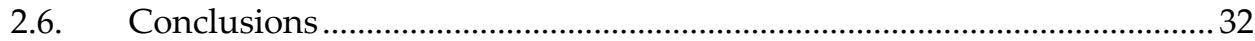

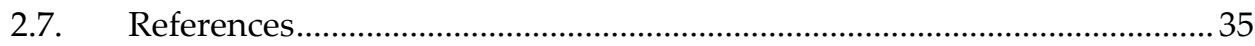

Chapter 3: Employment and Healthcare Use: Insights from Luxembourg Social

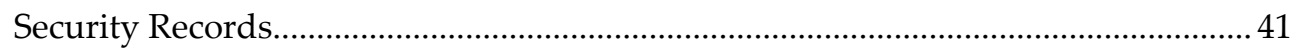

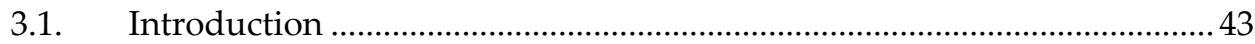

3.2. Review of Luxembourg social settings...................................................... 44

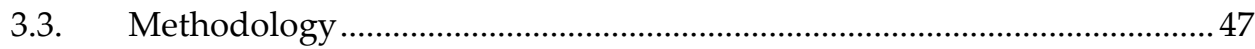

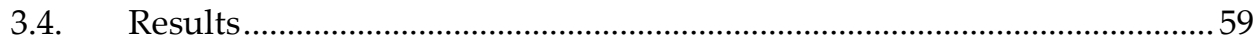

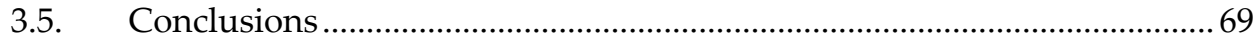

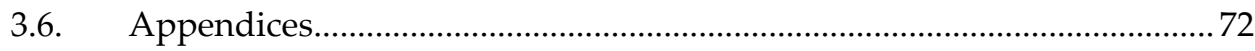

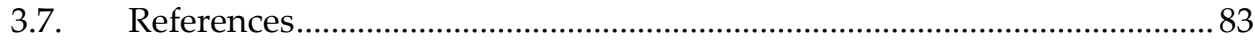

Chapter 4: Tax-Benefit Microsimulation in European Transition Countries: A

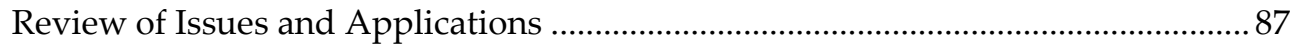

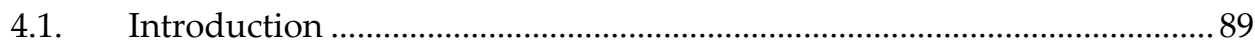

4.2. Microsimulation modelling for public policy analysis ............................... 90

4.3. MSMs in European transition countries........................................................ 94

4.4. Issues behind MSM construction and use ....................................................99

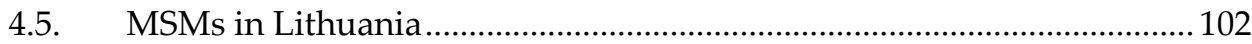


iv

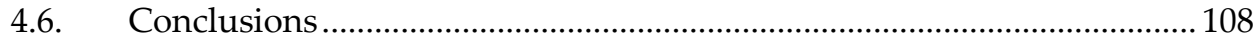

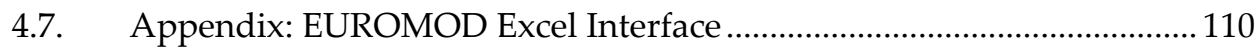

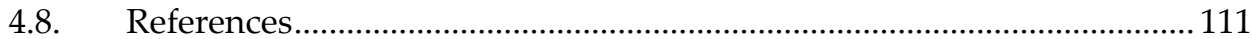

Chapter 5: Family Allowances' Reform in Lithuania: Microsimulation of its

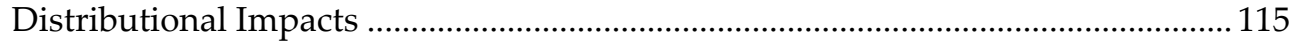

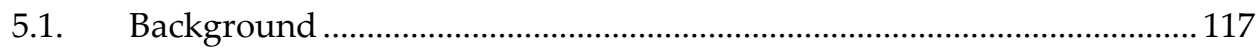

5.2. Combating Child Poverty: a European and a Lithuanian concern ........ 118

5.3. The Lithuanian family policy reform of 2004: main strands .................. 121

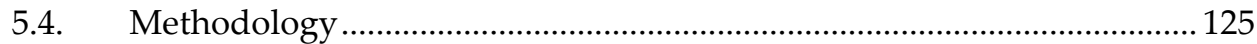

5.5. Distributional impacts of family and child benefits reform ................... 128

5.6. Poverty and inequality before and after the reform .............................. 135

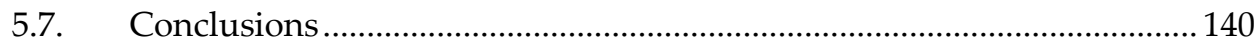

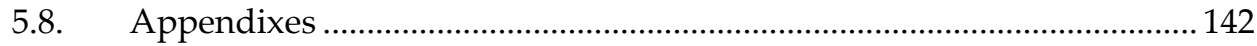

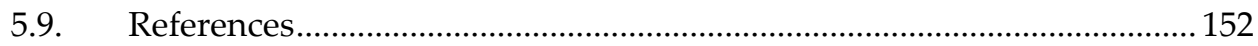

Chapter 6: Is the Neighbour's Grass Greener? Comparing Family Support in Lithuania and Four Other New Member States ...................................................... 155

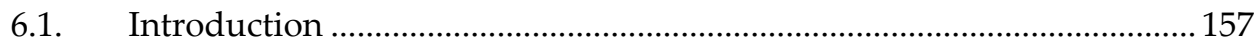

6.2. Child poverty and family support systems: existing evidence ............... 158

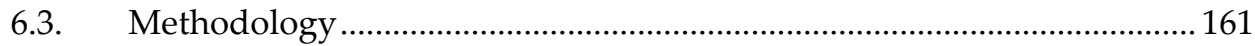

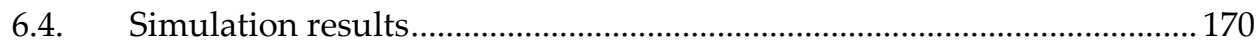

6.5. Conclusions and policy recommendations ......................................... 176

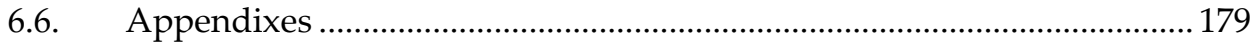

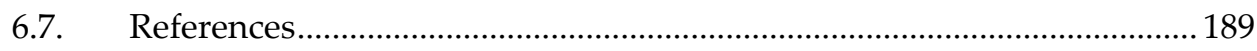

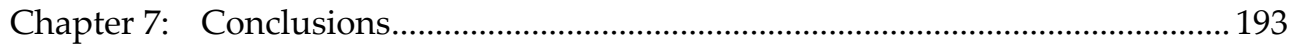

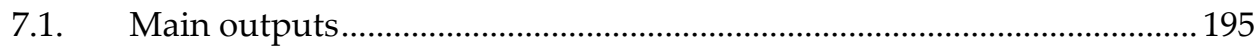

7.2. Evidence on distributional impacts of public policies ........................... 196

7.3. Conclusions on the use of methodologies in public policy studies........ 199

7.4. Conclusions on the data needs for distributional public policy studies 200

7.5. Lessons for Public Policy Design .......................................................... 202

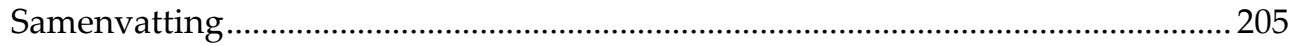

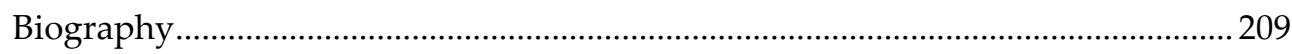




\section{List of figures}

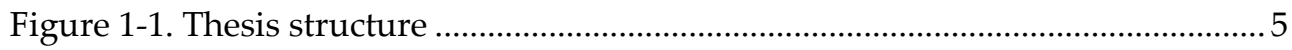

Figure 2-1. Contextual influences of individual healthcare utilization ....................... 18

Figure 2-2. Conceptual framework - employment and healthcare use ...................... 31

Figure 3-1. Observed versus negative binomial distributions.......................................52

Figure 4-1. MSMs in transition countries …………………………………….... 97

Figure 4-2. GINI in transition countries, 1989-2006................................................... 100

Figure 4-3. Democracy and knowledge ranking in transition countries.................. 101

Figure 5-1. The simulation framework …………………...................................... 127

Figure 5-2. Average yearly equivalised household income by household types

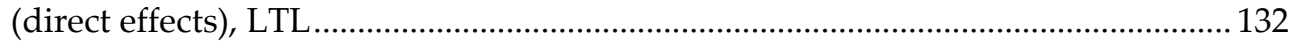

Figure 5-3. Average yearly equivalised household income change due to direct and indirect effects (by household types), LTL ………………........................................ 134

Figure 5-4. Poverty changes: implications for total population ................................ 136

Figure 5-5. Inequality changes: implications for total population ............................ 136

Figure 5-6. Poverty changes (\%): implications for selected household groups...... 137

Figure 5-7. Inequality changes (\%): implications for selected household groups.. 138 Figure 6-1. Poverty among different households with children in the selected

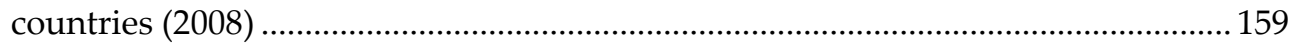

Figure 6-2. Generosity of family transfers and (child) poverty in the EU, 2007..... 160

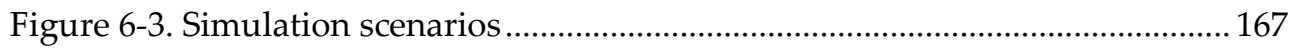


vi

\section{List of tables}

Table 3-1. Summary statistics of dependent variables............................................50

Table 3-2. The hurdle model results - determinants of prime interest.....................60

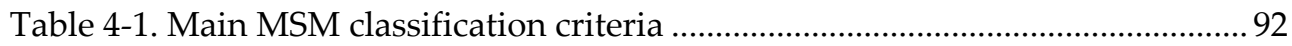

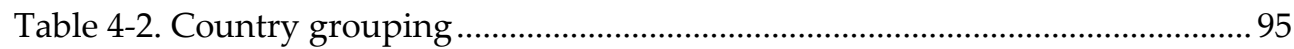

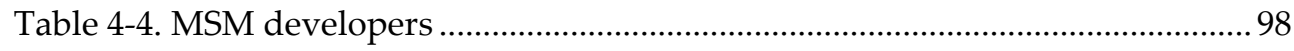

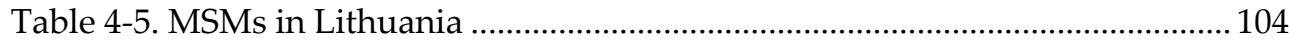

Table 5-1. State spending on non-contributory family policy measures................. 123

Table 5-2. Family benefits: simulation versus administrative data......................... 130

Table 6-1. EUROMOD included policies \& datasets of the selected countries ...... 161

Table 6-2. State annual expenses \& beneficiaries of 'transfers to children' ............. 165

Table 6-3. Poverty headcount and gap in pre- and post- transfer systems............. 172

Table 6-4. Poverty headcount and gap under the "borrowed" policies................... 174

Table 6-5. Poverty headcount and gap, swapping Lithuanian policies into four

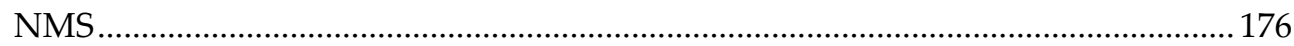


Chapter 1: Introduction 



\subsection{Background}

Public policy design currently receives a special attention from policymakers and social stakeholders alike, in light of developments brought about by the economic and financial turmoil that started in 2008. In the EU, the crisis is seen as the sharpest economic contraction since its establishment (DG ECFIN, 2009), though degrees of countries' vulnerability are highly varied. For example, among the earliest and hardest hit countries are the new EU member states, with the Baltic states $^{1}$ being among those the most affected (Gardó \& Martin, 2010).

Finding adequate public policy responses able to counteract crisis influences is a major challenge. Many different approaches are being proposed, often including interventions of international financial institutions but also responses achieved solely via national policy measures. In any case, policy packages chosen to combat budget deficits are highly varied across the countries, both in terms of overall budgetary size and changes in specific policy aims or parameters. Their distributional impacts are often not well known and undergo intense public discussion. That is not surprising; after all, the way a number of public policies are designed has an influence on each of our chances for a better living.

A question on how to reduce/reallocate public expenditure given the new economic and social challenges is thus one of the biggest governments' concerns. Furthermore, if public spending cuts are to be made, the least "painful way" would be by eliminating (identified) inefficiencies and by aiming at the most effective and sustainable use of available resources. Identifying them is a challenge on its own. Furthermore, central to such policy optimization is the knowledge of distributional consequences. A number of questions are associated with it: which population groups should be targeted; what type of people (would) benefit or lose because of certain policy designs and redesigns; how to change the policy structure as to achieve the most effective use of the available resources, etc. To gain such insights, adequate distributional policy analyses should be made, often, though, against the odds of time.

Aside the pressures of the economic crisis, many other - stimulating rather than restricting - factors are responsible for the ever-rising interests in linking policy making to the research evidence on whether and how policies work (e.g. Sanderson, 2002). Based on Amann (2000), "expansion and availability of the relevant social science knowledge, the demand for greater public-accountability or the enthusiasm on the part of government for systematic and well-focused

\footnotetext{
${ }^{1}$ Lithuania, Latvia and Estonia
} 
evidence" are behind the surging interest in developing evidence-based-policies. Improvements in data availability and quality are of high importance too.

As Fischer, Miller, \& Sidney (2007) note, "although policy advice-giving is as old as government itself, the increasing complexity of modern society dramatically intensifies the decision makers' need for information". Diversified and complex information sources must be analysed in order to extract such relevant information. Additionally, timely policy evaluations are particularly challenging, not the least because of up-to-date data shortages and availability of ready-to-use analytical policy tools. For example, many recent structural reforms are based not on the current, but on the previously accumulated research knowledge of actual and potential distributional policy impacts.

Aside plentiful limitations, one could also note that policy analysis adequate data is becoming ever-more available, partially due to new technologies and new capacities to collect and analyse data originating from diverse sources. Actually, in the last 20 to 30 years, availability of high quality micro level data - which is central for distributional policy impacts' analysis - has increased dramatically. In parallel, data and policy analysis techniques became more comprehensive too. Altogether, this enables making richer and more accurate statements on diverse public policy issues. Numerous challenges though still remain.

\subsection{PhD thesis objective}

Broadly, this $\mathrm{PhD}$ thesis aims at supporting policy advice in the effective and efficient attainment of policy goals. Specifically, it aims at providing new empirical evidence on the distributional impacts for one monetary and one in-kind public policy, namely state cash support to families and public healthcare. These policies are analysed given the national and international perspectives and present ex-post, ex-ante and hypothetical policy analysis insights. Furthermore, the thesis goes beyond a pure empirical analysis type and explores the relevant methods for a comprehensive empirical micro-data analysis underlying the policy advice needs. We aim to show what factors are important for a systematic analysis of the distributional impact of public policies. Furthermore, we aim to show what methods could be employed for gaining comprehensive empirical evidence on such policies' distributional impacts. 


\subsection{PhD thesis structure}

The two selected public policies form the two policy themes and thus the two major parts of this dissertation (see Figure 1-1). They also influence selection of methodological and data discussion topics.

Figure 1-1. Thesis structure

Theme I:

Disparities in healthcare use: accounting for employment influences

Chapter 2. Conceptual framework: employment influences on healthcare use

Chapter 3. Ex-post policy analysis: employment influences on healthcare use in Luxembourg

\section{Theme II:}

Distributional impacts of family cash support measures: a microsimulation approach

Chapter 4. Policy analysis tools: tax-benefit microsimulation models in the European transition countries

\section{Chapter 5. Ex-post and ex-ante} policy analysis:

family allowances' reform in Lithuania

Chapter 6. Hypothetical policy analysis: family cash support in Lithuania and four other new EU member states

\section{Source: own presentation}

Both cash and in-kind programs are equally important public expenditures tools. In some countries, the non-cash benefits exceed public spending on cash benefits (e.g. Marical, D'Ercole, Vaalavuo, \& Verbist, 2006). The in-kind policy we analyse, healthcare provision, represents one of the biggest shares of public expenditures often more than 5\% of the country's GDP (Salanauskaite \& Verbist, 2010). Cash support to families with children, as the cash program we study, also makes a bulky share of public expenses - from about $1 \%$ to more than $2 \%$ of the country's GDP, based on the information collected in the OECD Family Database (OECD, 2011). Here, cash support to families covers both benefits and tax breaks (i.e. tax credits), though information on the latter item is highly scattered across the countries.

As public policies are reflections of national politics and national socio-economic settings, geographical coverage is an important aspect of any empirical policy analysis. In this dissertation, healthcare utilisation analysis is conducted based on the Luxembourg case study. Family cash policies are explored within the context of the new EU member states (NMS), and particularly Lithuania. Both country and region specific selections are related to highly under-explored, though, particularly interesting policy and socio-economic settings. 
Distributional policy analysis relies on the availability of the adequate micro-data. Therefore, each of the two dissertation themes also makes a specific contribution to the underlying micro-data use. In the first theme, the new empirical evidence is primarily obtained via the use of a newly developed social security database. In the second theme, survey-based micro-data is enriched using a tax-benefit microsimulation model. We present both themes - their motivation, specific research objectives, policy and scientific relevance - in more detail below.

\section{Theme I - Disparities in healthcare use: accounting for employment influences}

The first theme explores distributional impacts of Luxembourg's national healthcare system, i.e. utilisation of healthcare services in relation to diverse employment characteristics. This policy question is still under-explored within the wider literature in general and Luxembourg in particular. Luxembourg is particularly interesting to explore as a case study, given its broad national healthcare coverage and one of the most ethnically diverse and mobile employment markets in the world.

In Chapter 2 of this thesis, we develop a conceptual framework explaining how both individual and contextual level employment characteristics influence the individual's use of healthcare services. Individual characteristics are among the most often recognised healthcare use determinants. Various contextual factors, aside the features of the healthcare system per se receive a much lower attention, though are increasingly recognised as an important source of variation in healthcare use. Employment, as an array of both individual and contextual factors, lacks a comprehensive acknowledgment too. In this conceptual study, we pool multidisciplinary insights, namely the social risk management theory and the existing conceptual frameworks of healthcare use, to suggest a more comprehensive accounting for these diverse determinants' types. The proposed structure of determinants is then immediately applied to depict how an array of employment characteristics influences healthcare utilisation. A better understanding of employment, as a determinant of healthcare use, could enable more adequate policy responses in reducing unequal healthcare consumption.

In Chapter 3, we present empirical evidence on how employment characteristics influence healthcare utilisation. For this, we explore actual healthcare utilisation in Luxembourg, an ex post policy analysis type, and rely on the (retrospective, year 2006) administrative social security records. This dataset is also enriched with selected external information: Luxembourg tax-benefit microsimulation model's information on household disposable income and diverse macro-level information on healthcare policy settings and socio-economic environment. In comparison to the survey data on healthcare utilisation, the obtained dataset permits a much 
more comprehensive accounting for diverse determinants of healthcare utilisation - in line with the framework proposed in Chapter 2. In particular, we are able to take a deeper look into employment related influences. Furthermore, we can highlight the role of nationality - as it turns out a crucial factor. Luxembourg is thus an interesting case study, as it is one of the most ethnically diverse labour markets in the world. It should also be noted, that the utilised dataset is specifically structured for this particular empirical study and offers a new, unique and unexploited information source for conducting healthcare use analysis.

\section{Theme II - Distributional impacts of family cash support measures: a microsimulation approach}

The second theme of this thesis addresses distributional issues of national cashbased tax and benefit policies. Specifically, it aims at providing knowledge on how effective are family support measures in Lithuania in terms of their ability to combat (child) poverty. As policy effectiveness is often better judged in comparison to certain thresholds, we first focus solely on the Lithuanian case and then analyse its family support system in comparison to the systems of the four other new EU member states. Given complexity and inter-linkages of diverse tax and benefit policies, as well as numerous limitations of available survey data - we employ the microsimulation method to obtain information on the potential distribution of diverse family support measures. The tax-benefit microsimulation models are highly suitable for complex national policy analyses; however, they need to be specifically developed given a certain country's policy settings. Therefore, in this theme, we not only conduct empirical analysis, but also provide a wider discussion on the tax-benefit microsimulation models and their availability for distributional policy analysis within a wider European transition region.

Actually, analyses of distributional impacts of public policies are still particularly rare in Lithuania. Various reasons can be cited. Among them, restrictions of distributional policy analyses in the "soviet" times due to fear of breaking the "equality" myth (Davies, 2009). The distributional analysis and its relevant analytical instruments have become more "popular" since then, but still to a lesser degree than in numerous other (more developed) countries.

Additionally, given the lack of microsimulation tools to analyse the major Lithuanian family policy reform of 2004, we develop our own partial static microsimulation model LitFAMOD. A number of this model's features were later integrated into EUROMOD - the EU-wide tax-benefit microsimulation model. The latter model enables Lithuanian tax-benefits' system analysis of 2008 policies and in a cross-country perspective. Both models are primarily based on the representative EU-SILC survey data for Lithuania. 
In Chapter 4, we determine how widespread tax-benefit microsimulation models (MSM) are in the European transition countries. This group of transition countries is composed of 10 new EU member states plus 13 other countries of South-Eastern Europe and the Commonwealth of Independent States. This review note documents the existing microsimulation tools in these countries and discusses the major development initiatives, model types, as well as obstacles behind the (sluggish) construction and use of MSM for distributional policy analyses. As some of these reasons are necessarily country specific, Lithuania - the country with the highest recorded MSM incidence - is used as an illustrative case study.

Chapter 5 explores to what extent the Lithuanian family benefit system is able to combat poverty among families with children - one of the major system aims. Family benefits were reformed extensively since 1990's, with the major reform implemented in 2004. The latter reform entails a shift from means-tested benefits to a more universal system. Due to budget constraints, implementation of the full reform design has been postponed till 2008. No distributional impact analysis of this reform, either of its initial or final designs, has yet been implemented. Furthermore, given that many families with children live on incomes close to the at-risk-of poverty threshold, we also analyse how entitlements to family allowances interact with the social assistance system. We evaluate if gains from the newly designed family benefits' system are not foregone due to respective losses in social assistance benefits.

Microsimulation also permits analysis of hypothetical policy reforms and designs a policy issue tackled within Chapter 6 of this thesis. Here, we further explore the Lithuanian family benefit system. To evaluate the effectiveness of its design, we employ an international comparison. First, we note that the at-risk-of-poverty rates of both large and single parent families are extremely high in Lithuania (more than $45 \%$ ) despite the state continuously recognising these household types as major poverty reduction targets. This contrasts with most other EU countries, where at least one of these household types has a better income position. Second, we also note that family policies in a few other new member states of the EU, namely Hungary, Slovenia, the Czech Republic and Estonia, are much more effective in combating child poverty. This point to potential gains if the Lithuanian system were re-designed along the policy parameters of these countries. Using microsimulation, we "swap" these countries policies into Lithuanian microsettings and vice versus. Such an exercise provides policy relevant evidence on how a policy would perform, given different country's socio-economic and demographic settings. 


\subsection{References}

Amann, R. (2000). Foreword. In H. T. O. Davies, S. M. Nutley \& P. C. Smith (Eds.), What Works?: Evidence-based Policy and Practice in Public Services. University of Bristol: Policy Press.

Bago d'Uva, T., Jones, A. M. \& van Doorslaer, E. (2009). Measurement of Horizontal Inequity in Health Care Utilisation Using European Panel Data. Journal of Health Economics, 28(2), 280-289.

Davies, J. B. (2009). Combining Microsimulation with CGE and Macro Modelling for Distributional Analysis in Developing and Transition Countries. International Journal of Microsimulation, 2(1), 49-65.

DG ECFIN. (2009). Economic Crisis in Europe: Causes, Consequences and Responses. The European Commission series on European Economy 7/2009.

Fischer, F., Miller, G. \& Sidney, M. S. (2007). Handbook of Public Policy Analysis: Theory, Politics, and Methods: CRC Press.

Gardó, S. \& Martin, R. (2010). The Impact of the Global Economic and Financial Crisis on Central, Eastern and South-Eastern Europe: A Stock-Taking Exercise. European Central Bank, Occasional Paper Series, No. 114.

Hurst, J., Siciliani, L. \& OECD Secretariat. (2004). Tackling Excessive Waiting Times for Elective Surgery. In OECD Health Project (Ed.), Towards high-performing health systems: policy studies (pp. 207-263): OECD.

Marical, F., D'Ercole, M. M., Vaalavuo, M. \& Verbist, G. (2006). Publicly-provided Services and the Distribution of Resources. OECD Social, Employment and Migration Working Papers, DELSA/ELSA/WD/SEM(2006)14.

OECD. (2011a). The Balance of Family Policy Tools - Benefit Packages, Spending by Age and Families with Young Children. In Doing Better for Families: OECD Publishing.

OECD. (2011b). OECD Family Database: OECD, Paris.

Salanauskaite, L. \& Verbist, G. (2010). Broadening the Income Concept: How and Why to Construct Non-Cash Resource Needs Adjusted Equivalence Scales? [Electronic Version]. FLEMOSI Disccusion Paper No. 2 from http://www.flemosi.be

Sanderson, I. (2002). Evaluation, Policy Learning and Evidence-Based Policy Making. Public Administration, 80(1), 1-22. 



\section{Chapter 2: Employment and Healthcare Use: A Conceptual Framework}

The working version of this chapter has been presented at:

- CRISS and INEQ project's 2007 Summer school on "Inequality: Mechanisms, Effects and Policies": June 17-23, Siena.

- $\quad$ ECINEQ 2007 Conference: July 12-14; Berlin.

- $\quad$ ESPANET 2007 Conference: September 20 - 22, Vienna. 



\subsection{Introduction}

In 1948, the Universal Declaration of Human Rights² stated that "everyone has the right to a standard of living adequate for the health and well-being of himself and of his family, including food, clothing, housing and medical care and necessary social services..." By now many countries have acknowledged significance of (equal) healthcare access. Nevertheless, accessibility remains an issue both in the countries with universal health insurance or national healthcare systems and in the countries with other types of health care systems.

Impediments to healthcare use occur due to many factors. Individual characteristics and the constrained health policy design are among the most often quoted causes (e.g. Gulliford et al., 2002; Hurst \& Jee-Hughes, 2001; Mooney, Hall, Donaldson, \& Gerard, 1991; Wagstaff \& van Doorslaer, 2000a; Wagstaff \& van Doorslaer, 2000b). Changes within many of these factors are difficult to achieve: individuals might have certain health needs; adjustments in health care policy design are often restricted and lagged due to intricate political processes; there is a lack of adequate policy tools or knowledge on the sources of the access impediments. Thereby, a growing interest recently falls on the modifiable factors of healthcare use (i.e. the factors which could be more easily altered by certain public actions, such as income situation, job prospects, access to health insurance, etc.). As Andersen (1995) explains, "to be useful for promoting access, a variable must also be considered mutable, or point to policy changes that might bring about behavioural change".

Employment related merits and constraints represent an important ray of the modifiable factors, with literature pointing to various links between employment (type) and healthcare use. On the other hand, under-exploration of employment related influences on healthcare use is also stressed. Furthermore, studies tend to analyse single or selected influences, rather than structurally reviewing overall/varied employment effects. Precise pathways, through which influences occur, are rarely documented too. As Gleason \& Kneipp (2004) note, few studies yet evaluate "the extent to which employment may interfere specifically with accessing illness care or preventive care". Also, diverse contextual as compared to individual determinants receive a considerably lower attention (Kirby \& Kaneda, 2006; Phillips, Morrison, Andersen, \& Aday, 1998). Following Andersen (1995) and Lipscomb, Loomis, McDonald, Argue, \& Wing (2006), this reflects the overall failure in yet defining the role and scope of institutional factors on healthcare

\footnotetext{
2 Article, 25, the Universal Declaration of Human Rights, adopted and proclaimed in 1948.
} 
utilization.

Complexities in conceptualization, access to adequate empirical data are partially responsible for the up to date negligence of employment related influences. Lack of conceptual frameworks, which could be used for the empirical evaluation of (diverse) employment related healthcare influences, is a restrictive factor too.

This chapter aims at contributing to two under-explored questions. First, we explore existing evidence and then structurally present diverse employments influences on healthcare use. For this, we develop a conceptual framework of employment related influences in healthcare use. No general conceptual model of this type yet exists, though important contributions are made by a few studies, especially Andersen (1968), Gleason \& Kneipp (2004) and Lipscomb, Loomis, McDonald, Argue, \& Wing (2006). Second, we explore the role of various contextual (employment) factors, as the healthcare use determinants. As the role of these determinants is still under-explored in the healthcare literature, we exploit the social risk management theory (de Neubourg, 2002; Holzmann \& Jørgensen, 2001) - a theory proposed and applied by the social protection studies, but not yet applied within the field of healthcare research. This conceptual approach acknowledges the interrelated role of various institutions in managing individual risks, such as becoming ill (Sigg \& Behrendt, 2002). A comparable recognition is yet lacking in the health or healthcare use studies.

The chapter is structured as follows. Section 2.2 provides the overview of the conceptual frameworks of healthcare use. The focus is on the frameworks suggesting a comprehensive structure of the diverse lists of healthcare use determinants. The following section explores the role of institutional determinants in healthcare use. The social risk management perspective is applied here. Links to employment influences are made if relevant. Section 2.4 sketches through the types of individual determinants. Here, the most widely acknowledged determinants are discussed. The next section discusses the specific pathways through which a vector of employment characteristics influences healthcare utilisation. The conceptual model of employment influences on healthcare use is presented. The final section presents conclusions.

\subsection{Contextual factors and conceptual models of healthcare use}

What are the contextual factors? In a number of different social science fields this group of determinants covers a wide range of macro descriptions of environment 
in which individuals reside and behave (Johnson, Phillips Shively, \& Stein, 2002). Often, terms "contextual", "macro", "aggregate", "institutional", "external" are used interchangeably. No strict definition of contextual variables exists within the field of healthcare analysis too, however usually the list of potential factors is defined more narrowly compared to the other disciplines. Furthermore, factors linked to the healthcare system dominate the list of recognised contextual factors. We explain this observation in more detail. Furthermore, we suggest on how to more comprehensively account for the contextual factors, using the theory of social risk management.

\section{The behavioural model(s) of healthcare use}

A number of conceptual frameworks have been suggested for discussion of healthcare use and its determinants. Usually they focus on explanation of certain aspects. For example, in Grossman's (1972) economic model of health demand, health is seen as a capital stock; a purchase of healthcare - as an investment in health. Here, the demand for healthcare is shown to increase with wages. The model's focus is on the selected number of determinants, such as age, income, education. Healthcare is treated as the most important input in the health investment function. Other influences are mentioned arbitrarily and are not modelled due to difficulties of empirical measurement. Many other economic models, are extensions (Muurinen, 1982) and/or criticisms (e.g. Cropper, 1977) of the Grossman's model and have been developed afterwards. They do not explore the structuring of various determinants' lists too.

Conceptual models, which do focus on structuring and acknowledging roles of the diverse lists of healthcare determinants, also exist. Among them, one of the earliest and the most influential conceptual frameworks of healthcare use is Andersen's (1968) "behavioural model of families' use of health services" (hereinafter referred to as the behavioural model of healthcare use $)^{3}$.

A number of this model's extensions have been suggested, with the direct advancements provided in Aday \& Andersen's (1974) framework on access to medical care, Andersen's (1995) "revisited" version of the model or Phillips et al. (1998) study on "understanding the context of healthcare utilisation". An adaptation of these frameworks is also Gleason and Kneipp's (2004) model, which provides our study important support on employment related constraints in the use of (primary) healthcare. Other significant frameworks exist, with a notable contribution for health rather than healthcare analysis made by Lipscomb et al.

\footnotetext{
${ }^{3}$ As noted by Andersen (1995), the model was not the first initiative of a kind, but it has integrated a number of ideas on "how's" and "why's" of healthcare use.
} 
(2006). The findings of this and many other studies are used throughout this study. The Andersen's model and its relevant versions/extensions provide the key conceptual frame in both discussing the role of contextual determinants and depicting the specific pathways though which employment has an effect on individual healthcare utilisation.

The behavioural model of healthcare use discusses the role of three major groups of individual determinants: predisposing, enabling and need factors. The contextual (without using the title) influences are also discussed, but with a lower degree of attention ${ }^{4}$. In response to criticism and suggestions, this original classification of major determinants' lists within the model has been revised (Phillips et al., 1998). Among the most important adjustments is Aday \& Andersen's (1974) distinguishing of "the health care delivery system", which refers to two components: resources (labour and capital) and organization. In Andersen's (1995) study, the definition of environment appears. Environment consists of the healthcare system and external environmental factors. In the further extension of the model, namely Phillips et al. (1998) study, an even more comprehensive classification is used. Here, in addition to environment, provider-related factors are distinguished. Healthcare delivery system characteristics, external environmental and community-level enabling variables are listed as environmental factors. Provider-related factors refer to provider characteristics and patient factors that could be influenced by providers. The focus of this classification nevertheless falls short on giving a wider/more precise role to the factors outside the healthcare field. In particular, the role of institutional arrangements is mainly linked to the healthcare system.

Studies following this classification did not make any further structural changes. Little progress has also been made in a comprehensive use of both individual and environmental factors within the empirical studies. Approximately half of existing research includes some environmental or provider-related variables, as Phillips et al. (1998) point out; however, their overall influence is rarely acknowledged and captured. The latter study also warns that such unsystematic inclusion or exclusion of contextual variables in addition to individual determinants of healthcare use could "lead to biased and misleading results and to large amounts of unexplained variance that hamper the understanding of utilization behaviour".

\footnotetext{
${ }^{4}$ At the time of the initial model's proposal, as noted by Andersen \& Newman (1973), few studies analysed the relationship between general societal forces, the health service system and the population use of healthcare services.
} 


\section{Healthcare determinants and theory of social risk management}

Multidisciplinary perspective could bring advantages in restructuring and acknowledging (missing/institutional) categories of contextual variables in the healthcare analysis field. The theory of social risk management ${ }^{5}$ offers precisely this capacity: it allows recognising and classifying societal institutional settings from the perspective of managing diverse individual risks. Here, the list of risks covers such basic needs, as access to housing and utilities, food, social participation or our focus variable - health. This theory has been used for the explanation of diverse household and individual behaviours and risks. For example, migration as a household livelihood strategy (Hagen-Zanker, Siegel, \& de Neubourg, 2009) or analysis of labour market transitions (Schmid, 2006) have been conceptualised using the theory. The application concerning health related risks has not yet been done.

The main idea of the social risk management, as defined by Holzmann \& Jørgensen (2001), is that all individuals are exposed to numerous risks, such as illness (i.e. a natural risk) or unemployment (i.e. man-made risk). Consequently they need an access to various institutions to manage the simultaneous or separate occurrence of these risks. In response, societies have developed various institutions, which help by preventing, mitigating or coping with these risks. Five major society institutions, also called Welfare Pentagon, are recognised as the key players: family, markets, social networks, membership institutions and public authorities (de Neubourg, 2002). According to the theory, actual use of the Welfare Pentagon depends on the strength and development of a certain institution within a particular society. In practice people deal with their risks by addressing a few institutions rather than using a single institution at a time. Following Sigg \& Behrendt (2002), the theory overcomes the "artificial analytical separation" of social protection from the other policy fields and acknowledges important policy inter-links.

As such, the social risk management theory offers complementarities to the behavioural model of healthcare use: it provides a more structured way of discussing institutional contextual factors. By this, explicit separation of the institutional contextual influences is made, while important role of the other groups of determinants - remaining contextual (external) ${ }^{6}$ and individual level factors - is still explicitly recognised. The Welfare Pentagon, just like the

\footnotetext{
${ }^{5}$ Emerged around 2000, simultaneously proposed by Holzmann \& Jørgensen (2001) and de Neubourg (2002) in the field of social protection studies.

${ }^{6}$ For example, the share of ethnic minorities within the region or pollution and crime level, would mainly reflect external environmental factors, as defined by Phillips et al. (1998).
} 
aforementioned healthcare use models, recognises various interlinks between the different groups and levels of determinants.

The re-classification of contextual level determinants in line with the social risk management theory is stylized within Figure 2-1. Five major institutional factors' groups, namely family, markets, social networks, membership institutions and public authorities, are marked P1-5. They incorporate such Phillips et al. (1998) described contextual variables' groups as health services' system, provider-related or community level factors, though with a different annotation. As such, healthcare system and non-healthcare institutional settings are assigned more equal weights as determinants of healthcare use.

Figure 2-1. Contextual influences of individual healthcare utilization

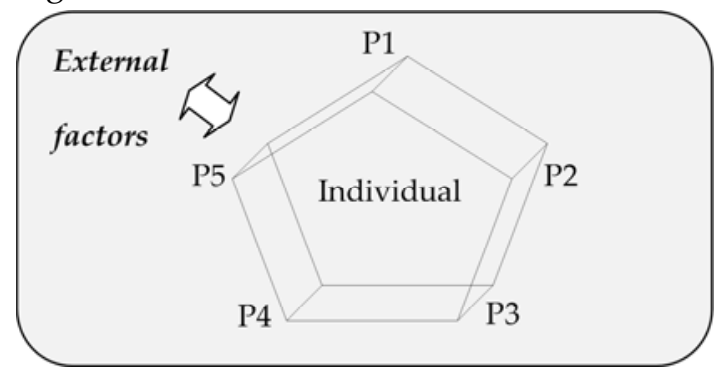

Note: P1-P5 = Institutional factors

Source: own adaptation of Welfare Pentagon framework

Welfare Pentagon, as depicted in Figure 2-1, represents multi-layered influences between the individual and contextual factors. An individual reaches for the Welfare Pentagon and is influenced by certain external factors in making healthcare use choices. External factors shape the way how Welfare Pentagon is formed and functions (i.e. poverty situation in the region might imply a higher presence of NGO's, charity organisations or state organisations, aiming at improving socio-economic settings). At the same time, institutions also interact and influence external factors. Additionally, Pentagon institutions affect each other, producing combined effects. For example, public institutions affect the way markets organize healthcare provision or the way through which labour markets function (so that people could be remunerated for their work and obtain healthcare services or healthcare insurance). This presentation of Pentagon inter-links corresponds to Phillips et al. (1998) observation that contextual factors often interact with other factors, which directly or indirectly influence healthcare utilization.

A note should also be made on the meaning of an individual being the primary unit of the analysis. This corresponds to Andersen's (1995) suggestion to shift the 
behavioural model of the healthcare use from the household to an individual unit analysis level. This is done to account both for heterogeneity of family members in seeking healthcare services and because of complexities in developing family summary measures, such as "family health status". Aside the healthcare studies, comparable arguments are made. For example, Hagen-Zanker, Siegel \& de Neubourg (2009) point out that households, as well as their members, have different initial endowments, definitions of needs, and degrees of risk aversion. Hence, their access to Welfare Pentagon is diverse because some people lack required assets (social or material) to ensure beneficial relation with a corresponding institution. As a result, the use of each five Welfare Pentagon institutions is different for each household and for each household member. A comparable argument could also be extended to the household members reacting to or using the settings of the external factors.

\subsection{Institutional healthcare determinants}

The role of each Welfare Pentagon's institution is reviewed in this section. It should be noted, that this study does not attempt to analyse or provide new evidence regarding the discussed determinants. Instead, it focuses on structuring the existing knowledge using the perspective of the theory of social risk management. Furthermore, our attention falls on highlighting the role of employment related institutional influences.

\section{Family}

Family is a specific type of a social network, described by the intensity of the relationship of its members: birth or marriage, cohabitation, kinship or promises of commitment. According to Lewis et al. (1976), many of the stresses and strains that affect people's lives, and many of the supports that they depend on, are found within the family structures. Belonging to a family is an important criterion for many administrative arrangements too, including healthcare access.

For example, entitlement to health insurance, which facilitates access to healthcare, is often based on the family and family willingness to provide for it - especially if a person cannot acquire it through the labour market. Depending on the available health insurance products, this could mean coverage for a dependent child, spouse or partner, a parent or relative of the 1st, 2nd or 3rd degree of the insured person. On the other hand, access to health insurance could also be restricted due to family history. For example, a study by Lapham, Kozma, \& Weiss (1996) showed that more than $20 \%$ of the uninsured people in the US believe they were refused health 
insurance because of the insurance company's knowledge of genetic disorders in the family.

Families also have a strong influence in directly shaping the individual use of healthcare services (e.g. Gravlee, Dressler, \& Bernard, 2005; Krieger, Williams, \& Moss, 1997). First, they can act as providers. For example, they can provide healthcare services when giving birth at home, nursing a person, giving the first aid, etc. Second, family social and material assets play a role. This concerns attitudes towards seeking healthcare services, lack of knowledge on the healthcare system structure, language barriers, availability of economic resources, family care giving traditions, etc. (Infeld, Gordon, \& Harper, 1995). Third, stresses and strains experienced within the family affect person's behaviour. For example, Fairbrother et al. (2005) shows that family social turbulence, economic hardship or parental ill health reduce parents' confidence and ability to obtain healthcare for their children or other family members.

\section{Markets}

Different types of markets exist: product and service markets, capital markets, labour markets, etc. They have different roles in either providing healthcare or shaping healthcare demand.

Healthcare services or healthcare insurance are offered due to functioning product and service markets (e.g. Maynard, 1991). Capital markets are used to obtain funds, needed for the development of healthcare services and institutions (e.g. Gershberg, Grossman, \& Goldman, 1999). Labour markets provide individuals with employment and income generation capacity, which is necessary for purchasing healthcare services or having healthcare access via health insurance plans. In addition, labour markets ensure that health professionals have jobs and can perform their duties. We focus on describing the role of labour markets in more details due to its direct link with our variable of interest - employment.

Participation in the labour market does not necessarily ensure access to health insurance, even if this pathway is a leading route for gaining affordable access to healthcare services. For example, research shows that even if health insurance is provided by an employer at a subsidized price (i.e. as in the US), the actual take-up decision is highly related to the final costs borne by an employee (e.g. Cutler, 2002). This corresponds to the argument of the social risk management theory stating that the actual use of any institution depends on the role that institution plays in a particular society.

Formal employment compared to informal employment usually allows easier healthcare access (e.g. by health insurance). However, falling employment and, 
thus shrinking tax revenue, is often seen as a barrier to develop employment-based national healthcare coverage in many developing and transition countries (Bennett, Creese, \& Monasch, 1998). On the other hand, health insurance for people working informally is less available due to difficulties of capturing and adequately taxing their work income. Based on Bennett et al. (1998), community financing programmes and different types of pre-payment and credit schemes are increasingly used to offer health insurance for those working in the informal labour markets.

Employment within a certain occupational sector also affects accessibility to health services. For instance, Bashshur et al. (1994) observes that the shift in the US labour market from manufacturing to service sector resulted in a decline in health insurance provision and thus access to healthcare.

Inflexible and long working hours could directly affect a person's capacity in managing access to healthcare. For instance, research in the US shows that visiting a doctor could be less feasible due to difficulties in obtaining employer's permission of leave during morning hours - the most often offered time for appointments (i.e. Cristancho et al, 2008).

Unemployment is found to have contradicting influences on healthcare use. On the one hand, it enables healthcare seeking due to lesser time constraints. On the other hand, it could impede access to healthcare, especially if the labour market related social insurance status is lost. Many other links between unemployment and healthcare utilisation exist. For example, lack of employment is linked to unmet healthcare needs, especially among those who have psychological concerns (Ahs \& Westerling, 2006).

\section{Public institutions}

A number of public institutions are linked to facilitating and/or directly providing access to healthcare. For example, healthcare access could be ensured because of state credited health insurance contributions for the inactivity time (i.e. maternity leave). Many heterogeneous designs of subsidized health insurance schemes (i.e. for elderly, children or people receiving social assistance) also exist. Research indicates that some of these vulnerable populations might be even better protected than employees due to state provisions. For instance, Hayward et al. (1988) find that working-age adults in the 1990's had less access to medical care than the elderly due to favourable arrangements provided by the US social insurance programme Medicare. 
Public institutions have the utmost effect not only on the demand, but also on the supply side of the healthcare system. For example, educational institutions provide medical education and thus form the quantity and knowledge capacity of the medical personnel. Moreover, much healthcare demand is dependent on the authoritative advice of the doctor. Actually, as the existing research suggests, available medical resources could become a perfect predictor for the magnitude of services consumed (Lewis et al., 1976). Public institutions also influence supply of conventional versus alternative, public versus private healthcare services.

According to Aday \& Andersen (1974), public institutions, especially those operating in the healthcare field, decide on financing, education, manpower and organization of the healthcare system. This consequently results in numerous system characteristics: volume and distribution of labour and capital, organization of the entry, etc. In general, public institutions influencing design of the healthcare system are interlinked in so many numerous ways that any policy change within the scope of their activities has a broad implication on an individual's healthcare seeking behaviour.

\section{Membership institutions}

Membership institutions are institutions based on solidarity and formal rules. They include organizations, such as healthcare insurance companies, sickness funds, or labour unions. The role of health insurance for people working in the formal and informal labour markets has already been mentioned. Many other influences and types of institutions are also important.

For example, membership institutions, as health and wellbeing centres, affect healthcare seeking behaviour through membership related information. They could raise awareness on legislative issues, access to care or on societal and ethical perspectives of, for example, equitable healthcare access (e.g. Kauffman Foundation Convention Center, International Society for Equity in Health, etc.). What's more, membership institutions are very often established to actively converse with the healthcare system. In such a case, they have ability to influence the development of professional standards, review and raise public understanding on health and health access issues, or provide support and authoritative information to their members (e.g. American Diabetes Association, the Dutch Association of Occupational Health, etc.).

\section{Social networks}

Social networks are viewed as social structures, which consist of both individuals and organizations. They are formed because of common values, friendship, kinship or mutual activities. Social networks, just like membership institutions, are based 
on the principle of solidarity, but do not have a formal structure or regulations attached to their existence.

Social networks are often thought of having a diminishing or a more segmented role in the developed countries. This is mainly due to people's ability to manage their risks through the relatively more developed Welfare Pentagon institutions, such as markets or public organizations. The greater transience of community life has caused many of the traditional, informal sources of help to break down in the developed industrialized countries: when an illness strikes, the resources of family or long-term friends are less available for assistance (e.g. Lewis et al., 1976).

Nevertheless, the influence of social networks cannot be underestimated in both developed and developing countries. It's here that health related behaviour or knowledge is learnt and acquired. For example, recent research in psychology field acknowledges that work relations, as a part of the non-kin social networks, are highly under-explored with respect to their influence on health and healthcare access (e.g. Neyer \& Lehnart, 2006). Work relations could influence healthcare use via knowledge, shortfall of time, lack or increased support to seek healthcare, etc.

Furthermore, both work or non-work related social networks can provide many positive effects, such as social support, self-esteem, identity and perceptions of control or access to other social-networks (i.e. Cattell, 2001). For example, research indicates that the often reported inequity favouring the rich in specialists' care utilization is likely related to strong social networks and higher social status, rather than any specific delivery system's characteristics or income situation itself (Chandola, Ferrie, Sacker, \& Marmot, 2007). Community factors are also found to play an important role in improving access to healthcare (e.g. Hendryx, Ahern, Lovrich, \& McCurdy, 2002).

\subsection{Individual healthcare determinants}

The above presented Welfare Pentagon model takes into account that individual differences exist in terms of how and whether or not to seek healthcare services. This theory does not focus though on explaining the role of individual level determinants in managing the risks of becoming ill. For this, we rely on the insights offered by the "behavioural model of healthcare uses". Aside shortly reviewing the role of each determinants' group, we also aim at highlighting multidisciplinary insights on the diverse roles of employment related individual healthcare determinants. Where relevant, we touch upon interactions between different individual factors, as well as individual and contextual factors. 


\section{Predisposing factors}

Among the individual determinants of healthcare access, predisposing factors refer to immutable and mutable factors. They are defined not as direct causes of utilization, but rather as determinants of the propensity to use such services. Immutable predisposing factors, such as age, gender or genetic inheritance, determine predisposition of certain health conditions. Mutable factors include characteristics, such as religion, values, smoking habits, level of physical activity, nutritional habits, sleeping rhythm, or even type of personality (Aday \& Andersen, 1974; ISO, 2002; Krieger, 1999; Krieger et al., 1997).

For example, hostile individuals are reported to create more interpersonal conflicts in their lives and to have lower levels of social support. Consequently this affects their ability to utilize social (i.e. workplace, family, etc.) networks for a better (e.g. timely, appropriate, affordable) healthcare access (e.g. Wiebe \& Forenberry, 2006). Some of the other predisposing factors, such as smoking or level of physical activity, might also be linked to personality type, since one personality type individuals might choose to cope with the stress by smoking and others by exercising. As Wiebe \& Forenberry (2006) explain, personality also works in conjunction with the enabling determinants of health (i.e. socioeconomic status) and influence the expression of disease vulnerability.

\section{Enabling factors}

Enabling factors are usually factors defined on the individual level. However, they could also refer to community means that influence the individual's propensity to use services (Lewis et al., 1976).

The enabling individual factors are closely related to socioeconomic and sociocultural characteristics of the population. They refer to such variables as income, education, literacy, occupational status and occupational stability, unemployment, ethnicity, racial stratification, migration status or social class (e.g. Eschbach, YongFang, \& Goodwin, 2006; Krieger et al., 1997; Wagstaff, van Doorslaer, \& Watanabe, 2003; Winkleby, Jatulis, Frank, \& Fortmann, 1992). The enabling or restricting nature of these variables is quite well documented for a number of socio-economic variables, especially income, education or gender. Many of the employment related influences receive comparatively lower attention.

For example, numerous findings point to the inequitable utilization of healthcare services, and especially secondary care services, related to person's income status (e.g. van Doorslaer \& Koolman, 2004; van Doorslaer, Koolman, \& Jones, 2004; van Doorslaer et al., 2000). On the other hand, many studies also indicate that income related inequality in healthcare use might not be captured well enough. This is 
caused by lack of data on out of pocket payments, lack of information on regional disparities, lack of supply side information or lack of information about the health status (e.g. Billings et al., 1993; Gornick et al., 1996; van Doorslaer, Masseria, \& Koolman, 2006).

Persons with higher educational level are found to use more preventive services and are more likely to take advantage of the new medical programs. Lewis (1994) also reports that people from higher social classes are more likely to better describe their problems and to seek specialized assistance. In contrast, people with lower social status are more likely to enter healthcare system late in their illness and are more likely to provide vague and undefined symptoms.

Gender, as a social category, is also found to have an influence on healthcare seeking behaviour. Some studies report that women tend to use more healthcare services than men, even if adjustment for need is taken into account. The explanation of greater utilization encloses such factors, as worse perception of health status or lower embarrassment in expressing pain or asking for help (e.g. Lewis et al., 1976; Redondo-Sendino, Guallar-Castillon, Banegas, \& RodriguezArtalejo, 2006). Women are also traditionally considered to use more of the healthcare services during office hours due to more flexible job arrangements. They also use more preventive healthcare services, while men are observed to use more of emergency help services.

\section{Need factors}

Need factors is the third group of the individual determinants of the healthcare access. They refer to illness level and could be defined as perceived by individual or evaluated by the medical personnel. Need-factors have a direct impact on the type, purpose, location or timing of healthcare use.

Lots of studies use self-assessed health status (SAH) as one of main health needs' indicators, as it usually includes overall evaluation (i.e. poor vs. excellent) of the health status (e.g. van Doorslaer \& Koolman, 2004; van Doorslaer, Masseria, Labour and Social Affairs Committee, \& Organisation for Economic Co-operation and, 2004). SAH is considered to be a central key to the management of illness because it provides reflection of shifts in actual health status (Williams, 2006). On the other hand, research indicates (e.g. van Doorslaer et al., 2000) that a crude measurement, like $\mathrm{SAH}$, might lead to a lack of precision in estimates. An alternative would be a health status evaluation conducted by the medical professionals. 
A number of other health need related factors, such as age or gender, are also routinely analysed (van Doorslaer, Koolman et al., 2004). Other commonly used need factors include biomass index, chronic diseases, functional status, cognitive deficit or health related quality of life. Some diseases indicate a specific health need, which could be captured from a person's behaviour to use specific service: asthma, arthritis, diabetes mellitus, Parkinson's disease, cancer (at any site), etc.

Many links between the enabling/predisposing factors and health needs are documented. Some studies use enabling factors as predictors of the health needs. The rationale behind such a decision is observation that many health needs vary by culture, ethnicity, socioeconomic status, geographic location, etc. Predisposing factors, such as tobacco and alcohol consumption, are also used to indicate the need for healthcare (Redondo-Sendino et al., 2006).

\subsection{Employment as a determinant of healthcare use: a conceptual model}

\section{Underlying frameworks}

The proposed model is an extension of the two major frameworks tracing the complex employment influences on healthcare and health. The first framework is Gleason \& Kneipp's (2004) model on employment constraints in healthcare utilization. As mentioned before, the latter framework is an adaptation of the behavioural model of healthcare use and aims at evaluating "the extent to which employment may interfere specifically with accessing illness care or preventive care". The second framework is Lipscomb's et al. (2006) conceptual model of work and health disparities (in the United States). This model traces pathways, though which work, as a broad concept, contributes to creating health inequalities. Aside building on the structures of these two frameworks, our model also accounts for institutional influences, as suggested by the theory of social risk management and explained in the Section 2.2 of this study.

A few major alterations and extensions of these three frameworks are suggested by this study. Gleason \& Kneipp's (2004) model focuses on three major employment constraints: availability of paid sick leave as an employment benefit, job flexibility, and availability of after-hours primary healthcare services. Lipscomb's et al. (2006) conceptual model provides a much broader understanding of work related influences. It also depicts causal pathways linking work and health outcomes (healthcare use is not addressed). Theory of social risk management proposes a structural way of accounting for diverse institutional influences in managing individual health risks. Our proposed model takes a step further: it illustrates the 
complex process through which work, as a broad and multi-level array of influences, relates to the employee's decision of (one-time or multiple) healthcare utilisation.

\section{Major settings and assumptions}

A person's employment or work (see Figure 2-2) is treated as a multi- dimensional characteristic. On the individual level, it is a point of reference to a number of employment related harms, duties, constraints and benefits. Examples are salary or in-kind benefits, time spent at work, access to social networks and occupational exposures. In addition to monetary income and in-kind benefits, work also associates with many non-material factors, such as degree of subordination, autonomy, control, job flexibility, or security. On the contextual level, employment influences accumulate for a given job place, family, community or geographical location. In addition to this, workplace healthcare plans and many other public policies represent a vector of contextual employment influences.

Work is a starting point of the framework. The final step is utilization of healthcare services. Other factors and processes are displayed to depict (causal) links between a person's (current) employment and a person's choice of using healthcare services. Health needs and healthcare services are assumed to be generic. The framework focuses on employment rather than unemployment related links to healthcare utilization. This is because pathways and exposures to risks are rather different for these two labour market statuses.

The starting point of the model is placed at a certain point in time $t$. This indicates any time in a person's working career, assuming that the individual "currently" has a job. As such, occupational history influences a current job position. Nevertheless, the dynamic dimension of the model is simplified to two points in time: present (it could also be past) time $t$ and time $t+1$. This indicates time needed for a potential alteration of health status due to exposures, use of healthcare services or other influences, including potential occurrence of disease or changes within the contextual settings. Utilization per se has no certain marked position within the set time frame $[t ; t+1]$, and in so doing depicts individual differences. Individual differences could be an immediate or delayed response to the symptoms, with respect to the healthcare seeking behaviour and the differences in timing of provision of healthcare services.

The determinants of healthcare utilisation and work are listed and structured on the left side of the framework. They present three levels of analysis: 1) individual, 2) family and social network, and 3) policy and external environment level. The individual factors (i.e. level one) that influence a person's initial health and 
occupational choice are listed on the bottom left side of the model. Levels two and three explicitly cover the previously discussed Welfare Pentagon institutions. External contextual factors, like physical environment or area socio-economic potential, are placed under the level three. This is done because of two reasons. First, external contextual factors are closer linked to certain institutional determinants (e.g. social policy rules are related to poverty level). Second, we wish to explicitly portray household and social network related influences.

The model also acknowledges that all levels of analysis undergo a continuous change as well as reciprocal influences. Furthermore, they represent significant effects on the person's current job status (work) and the level of health needs as experienced at the time of a certain employment. For example, family processes influence the predisposing and enabling background of the individual. Families and social networks are also important "filters" for many contextual influences. Public policies influence family formation.

Empirical evidence confirms various inter-links. Members of certain ethnicities are often found to live in the economically disadvantaged or environmentally polluted areas. They are disproportionately employed in manual professions or in hazardous work environments (e.g. Dressler, Oths, \& Gravlee, 2005; Krieger, 1999; Krieger et al., 1997). A person's ability to choose a job position might be limited by such a living environment given his knowledge of workplace related benefits and occupational exposures, as well as his perceived medical needs, professional abilities and wishes. The situation also implicitly points to circular links, because people's activities, educational and work options bring high returns to the area's wellbeing level too.

\section{Explanation of pathways}

The model presents two main directions of pathways (i.e. horizontal and vertical), through which personal choices and contextual factors influence employee's healthcare seeking behaviour (see Figure 2-2).

The horizontal pathway depicts how work is related to health risks and needs. As WHO (2006) indicates, many occupational health problems arise from new information technologies and automation, new chemical substances, physical energies or biotechnologies, transfer of hazardous technologies, rising psychological workload, problems related to growing mobility of worker populations, occurrence of various new occupational diseases, etc. According to this report, the highest health risk industries are mining, forestry, construction and agriculture. One-fifth to one-third of workers within these sectors may suffer occupational injury or disease annually. On the other hand, service and office jobs 
increasingly contain high psychological stressors and ergonomic problems, which cause job dissatisfaction and affect health and productivity.

Health status might be altered, depending on the intensity and duration of work related exposures and stressors, as well as individual susceptibility to the health risks. The model also depicts that the worry of health status might occur before the actual appearance of the symptoms of illness. This could be linked to the knowledge of occupational health risks. The worry about health in combination with an individual's propensity to seek care could lead to a decision to use preventive healthcare services. However, if a person is not risks averse, he or she might wait till the appearance of specific ill health symptoms. The severity of the symptoms influences if a person seeks an immediate or an unhurried request for healthcare services. Some workplaces also acknowledge certain symptoms as related to work environment without the medical evaluation. Examples are red eyes or breathing problems. Often, workplaces voluntarily aim to remove the responsible catalysts of such health problems. Then, healthcare utilisation would not be realised. If catalysts could not be removed, access to lighter duty work could be offered. This consequently affects a person's need to use or not to use healthcare.

In general, a change in (perceived or evaluated) health while being employed leads to different working abilities. This depicts a circular link between employment type and health. Depending on the job and the nature of the related health changes, an individual might need to choose a different work: continue working full time, but in a different job position; lose some ability to work; become unable to work in the original job duty, etc.

The vertical pathway traces influences on healthcare use by work related benefits and constraints. In addition to this, the vertical pathway depicts multi-level influences.

Work and health needs are linked not only via horizontal pathways. Depending on the job nature, people might bring chemical or psychosocial effects from work to their families (i.e. vertical pathway). On the other hand, family and social networks influence a person's perception of the symptoms, knowledge of the treatments, as well as responsibility and ability to seek healthcare.

Material and non-material attributes of a person's employment have both been proved to have a direct impact on health and healthcare seeking abilities (e.g. Marmot \& Wilkinson, 2001). Their effects within the model are placed within the family level of determinants. We make this vertical link from the individual to the family level, as we believe that individual capacity to pay for healthcare is formed on the household, rather than on the individual level. For example, many women have little or no personal income, but live in a high income household. As such, 
household income is a better measure of an individual's ability to pay and access healthcare than an individual income level (Kupek, Dooley, Whitaker, Petrou, \& Renton, 1999; Nguyen \& Häkkinen, 2006; van Doorslaer, Koolman et al., 2004). Furthermore, numerous public policies are designed to account for and increase household's abilities in reaching healthcare.

A number of non-monetary benefits are associated with participation in the labour market. Among them is healthcare insurance. As already mentioned, access to healthcare insurance can differ if a person works in the informal or formal labour market. Based on WHO (1995), information on the benefits of healthcare system is also very difficult to disseminate among the workers of the informal sector or among the self-employed. Furthermore, there are significant differences in insurance benefits per employment sector or company and these gaps are widening. This has been shown by studies on workplace related healthcare insurance plans in the US (e.g. Lipscomb et al., 2006). Furthermore, health insurance could be organized publicly or privately. Private insurance plans could completely replace public insurance plans, provide additional coverage for services excluded from the public insurance scheme or increase a choice of provider and timing of service of provision.

Overall, monetary and non-monetary returns to work (in combination with the other individual and institutional determinants) create a specific healthcare-seeking behaviour and influence the demand for healthcare services. The observed utilization rates are the result of the supply side factors too.

The supply side of healthcare services could either enhance or impede healthcare utilization through five major dimensions: the financial and non-financial costs, the quality of services, the spatial distribution of services, the information on availability and effectiveness of services, and the quantity and types of services. For example, the quality of healthcare services might be low due to limited medical education on specific occupation related risks. Lack of appropriate assessment of occupational history might lead to an inadequate treatment and to an underestimation of the life-course effects (e.g. Chaix, Isacsson, Rastam, Lindstrom, \& Merlo, 2007; Lipscomb et al., 2006; Liukkonen, Virtanen, Kivimaki, Pentti, \& Vahtera, 2004). Lipscomb et al. (2006) also report that supply of healthcare services and perception on healthcare seeking may be distorted by employer engagement in the provision of healthcare services or employer's preferences on healthcare providers and insurers. 


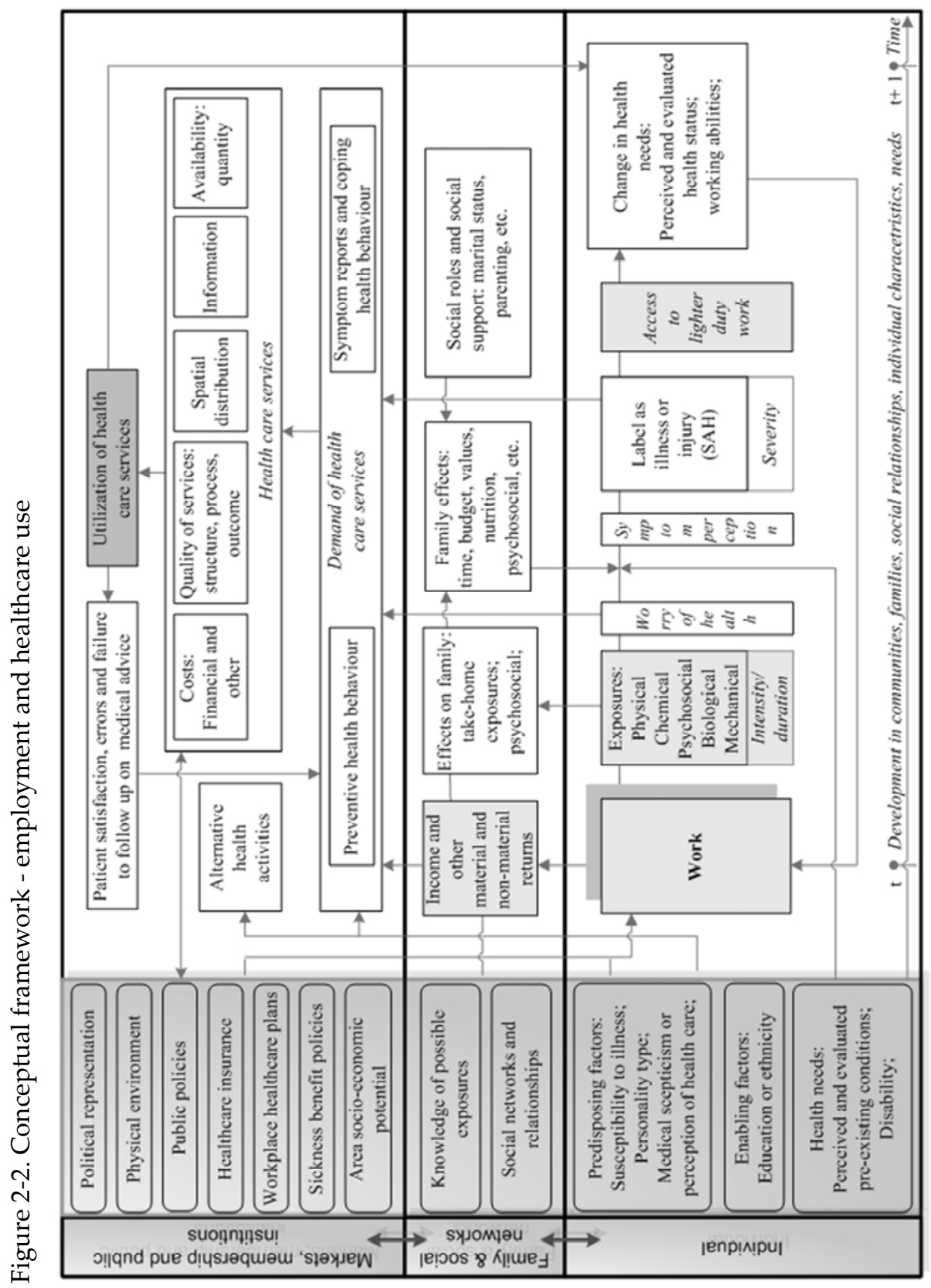


Overall, public and workplace policies might mediate the relationship between work exposures and the treatment of work related illnesses and injuries. They might also create inequalities in healthcare use. For example, the self-employed or the employed in the informal sector might not be covered through national healthcare plans or might only be covered for major risks. It is also observed that employees concerned about becoming unemployed, are less likely to speak up about their rights to healthcare access and are less likely to seek medical care (Lipscomb et al., 2006).

The model also acknowledges that contextual determinants, such as public polices, political representation or area socio-economic potential, have a significant influence on the healthcare supply. For example, politically "disempowered" regions and groups are found to lack provision of the services (Mobarak, Rajkumar, \& Cropper, 2004). Lipscomb et al. (2006) also reports that unionized workers are more likely to have health insurance if compared to the non-unionized workers.

The last element of the model is the eventual utilization of healthcare services: an outcome variable of the discussed processes and needs. After the first contact is made, a person might also decide to a follow up on a medical advice or not. This depends on the needs, individual characteristics, received care quality or advice by the medical professional. Finally, the model depicts that, depending on the received healthcare, a person might be exposed to new working abilities and seek different job options.

\subsection{Conclusions}

Quite a few empirical studies explain employment related determinants of healthcare use. General frameworks for the study of healthcare use behaviour also exist. As such, the concepts presented in this study are not new. However, they extend into the yet un-explored areas and make a few conceptual contributions.

In this study, we show that there is a lot of un-pooled and multi-disciplinary evidence on employment influences in healthcare use. What is missing is a structural approach in accounting for the overall employment influences and tracing the specific channels of its influences. We therefore propose a conceptual framework which depicts through which direct and indirect routes employment, as an array of multi-level factors, impacts an individual healthcare use. Furthermore, our acknowledgment of diverse institutional influences, relying on the theory of social risk management, enables a better understanding of a differentiated healthcare use. This also highlights the role of diverse public policies beyond the impacts of the healthcare system per se. 
Historically frameworks for analysing the determinants of healthcare utilization have been highly focused on the role of individual factors, which has resulted in neglecting institutional influences. Moreover, most of the occurring empirical or theoretical researches focus on a selective number of separate institutional factors. In contrast, we argue that the social risk management theory sets up better theoretical grounds for drawing a complete and comparative picture of pathways through which all types of existing societal institutional arrangements have a role in an individual's ability to satisfy occurring health needs. We suggest distinguishing between the two major groups of contextual influences in healthcare use: institutional and external (or non-institutional) factors. Institutional factors refer to the Welfare Pentagon: families, markets, social networks, membership institutions and public authorities. Such classification acknowledges the role of the healthcare system and goes beyond it.

We apply the proposed contextual determinants' structure for the development of a conceptual framework of employment related influences in healthcare use. Healthcare utilization is depicted in this model as an outcome of a process in which a person - and specifically an employee - goes through various stages of health and healthcare need assessments and is continuously influenced by diverse external and institutional factors. Employment characteristics refer to income and other material and non-material returns to work, workplace rules, occupational sector regulations or overall employment choices available within the region of the residence (in a broad sense). All these factors are shown to be interlinked with certain other contextual and individual determinants of healthcare use.

Overall, throughout the study we highlight the following employment and healthcare use links:

- Labour markets provide easier access to employment. Consequently they create better possibilities of acquiring healthcare services. A better labour market functioning (i.e. collection of tax revenue) also guarantees a more stable healthcare system financing, and thus a better healthcare supply.

- Employment provides easier access to diverse public institutions. Consequently it provides easier access to healthcare services at times of inactivity or extraordinary health needs (i.e. via state credited health insurance contributions, subsidized health insurance schemes, paid sick leave, etc.).

- Compared to informal employment, formal employment usually allows having easier access to health insurance schemes, and, thus, facilitates access to healthcare services.

- Diverse returns to work - income, fringe benefits, vacation time, etc. - affect a person's need for and ability to use healthcare services. For example, a specific 
job could reflect an employer's choice in the provision of healthcare services and insurers.

- Healthcare use varies by occupational sectors. This is related to the available health insurance plans (i.e. service versus manual sectors), to flexibility of job arrangements (i.e. using healthcare during office hours); to differences in occupational health exposures (i.e. injuries, work related diseases, induced disability), etc.

- Public and workplace policies on (occupational) health standards and services can mediate relations between the work exposures and the use of healthcare services.

- Work relations, as a type of social networks, have both negative and positive effects on healthcare use through positive or negative social support.

- Current employment is endogenously related to a person's occupational history, and thus to the previous occupational exposures, as well as current and past health status.

This study proposed complex accounting for employment influences in healthcare use might be difficult to capture in empirical studies. However, the suggested structure and explicit references to potential multi-level influences provide a more systematic way for carrying empirical analyses. The review of overall influences also serves as a valuable explanation for sources of (often) unexplained variation. Further research is needed to define the scope of influence of these links within certain national socio-economic and cultural settings. Further research is also needed to test if observed differences in employment (types) lead to inequitable (unjust) use of healthcare services. If such evidence is established, further actions could be called upon with respect to relevant social policy design improvements. 


\subsection{References}

Aday, L. A. \& Andersen, R. (1974). A Framework for the Study of Access to Medical Care. Health Services Research 9(3), 208-220.

Ahs, A. M. \& Westerling, R. (2006). Health Care Utilization Among Persons Who Are Unemployed or Outside the Labour Force. Health Policy, 78(2-3), 178193.

Andersen, R. (1968). A Behavioral Model of Families' Use of Health Services Chicago: Center for Health Administration Studies, University of Chicago, Research Series No. 25.

Andersen, R. \& Newman, J. F. (1973). Societal and Individual Determinants of Medical Care Utilization in the United States. Milbank Memorial Fund Quarterly 51(1), 95-124.

Andersen, R. M. (1995). Revisiting the Behavioral Model and Access to Medical Care: Does It Matter? Journal of Health and Social Behavior, 36(1), 1-10.

Bashshur, R. L., Homan, R. K. \& Smith, D. G. (1994). Beyond the Uninsured: Problems in Access to Care. Medical Care, 32(5), 409-419.

Bennett, S., Creese, A. \& Monasch, R. (1998). Health Insurance Schemes for People Outside Formal Sector Employment (No. 16): WHO/ARA, Geneva.

Billings, J., Zeitel, L., Lukomnik, J., Carey, T. S., Blank, A. E. \& Newman, L. (1993). Impact of Socioeconomic Status on Hospital Use in New York City. Health Affairs, 12(1), 162-173.

Cattell, V. (2001). Poor People, Poor Places, and Poor Health: the Mediating Role of Social Networks and Social Capital. Social Science and Medicine, 52(10), 1501-1516.

Chaix, B., Isacsson, S. O., Rastam, L., Lindstrom, M. \& Merlo, J. (2007). Income Change at Retirement, Neighbourhood-Based Social Support, and Ischaemic Heart Disease: Results From the Prospective Cohort Study "Men Born in 1914". Social Science \& Medicine, 64(4), 818-829.

Chandola, T., Ferrie, J., Sacker, A. \& Marmot, M. (2007). Social Inequalities in Self Reported Health in Early Old Age: Follow-up of Prospective Cohort Study. BMJ, 334(7601), 990.

Cropper, M. L. (1977). Health, Investment in Health, and Occupational Choice. The Journal of Political Economy, 1273-1294.

Cutler, D. (2002). Employee Costs and the Decline in Health Insurance Coverage. Frontiers in Health Policy Research, 6, 27-54.

de Neubourg, C. (2002). The Welfare Pentagon and the Social Management of Risks. In R. Sigg \& C. Behrendt (Eds.), Social Security in the Global Village New Brunwick and London: Transaction Publishers. 
Dressler, W. W., Oths, K. S. \& Gravlee, C. C. (2005). Race and Ethnicity in Public Health Research: Models to Explain Health Disparities. Annual Review of Anthropology 34(1), 231-252.

Eschbach, K., Yong-Fang, K. \& Goodwin, J. S. (2006). Ascertainment of Hispanic Ethnicity on California Death Certificates: Implications for the Explanation of the Hispanic Mortality Advantage. American Journal of Public Health, 96(12), 2209-2215.

Fairbrother, G., Kenney, G., Hanson, K. \& Dubay, L. (2005). How Do Stressful Family Environments Relate to Reported Access and Use of Health Care by Low-Income Children? Medical Care Research Review, 62(2), 205-230.

Gershberg, A. I., Grossman, M. \& Goldman, F. (1999). Health Care Capital Financing Agencies: the Intergovernmental Roles of Quasi-Government Authorities and the Impact on the Cost of Capital. National Bureau of Economic Research: NBER Working Paper No. 7221.

Gleason, R. P. \& Kneipp, S. M. (2004). Employment-Related Constraints: Determinants of Primary Health Care Access? Policy Politics Nursing Practice, 5(2), 73-83.

Gornick, M. E., Eggers, P. W., Reilly, T. W., Mentnech, R. M., Fitterman, L. K., Kucken, L. E., et al. (1996). Effects of Race and Income on Mortality and Use of Services among Medicare Beneficiaries. The New England Journal of Medicine, 335(11), 791:199.

Gravlee, C. C., Dressler, W. W. \& Bernard, H. R. (2005). Skin Color, Social Classification, and Blood Pressure in Southeastern Puerto Rico. American Journal of Public Health, 95(12), 2191-2197.

Grossman, M. (1972). The Demand for Health: a Theoretical and Empirical Investigation. NBER Occasional Papers No. 119.

Gulliford, M., Figueroa-Munoz, J., Morgan, M., Hughes, D., Gibson, B., Beech, R., et al. (2002). What Does Access to Health Care Mean? Journal of Health Services Research \& Policy 7(3), 186-188.

Hagen-Zanker, J., Siegel, M. \& de Neubourg, C. (2009). Strings Attached: the Impediments to Migration in Albania and Moldova. Southeast European and Black Sea Studies, 9(4), 459-479.

Hayward, R. A., Shapiro, M. F., Freeman, H. E. \& Corey, C. R. (1988). Inequities in Health Services Among Insured Americans. Do Working-age Adults Have Less Access to Medical Care than the Elderly? The New England Journal of Medicine, 318(23), 15107-11512.

Hendryx, M. S., Ahern, M. M., Lovrich, N. P. \& McCurdy, A. H. (2002). Access to Health Care and Community Social Capital. Health Services Research, 37(1), 87-104. 
Holzmann, R. \& Jørgensen, S. (2001). Social Risk Management: A New Conceptual Framework for Social Protection, and Beyond. International Tax and Public Finance, 8(4), 529-556.

Hulshof, C., Verbeek, J., van Dijk, F., van der Weide, W. \& Braam, I. (1999). Evaluation Research in Occupational Health Services: General Principles and a Systematic Review of Empirical Studies. Occupational Environmental Medicine, 56(6), 361-377.

Hurst, M. \& Jee-Hughes, M. (2001). Performance Measurement and Performance Management in OECD Health Systems. DELSA/ELSA/WD: OECD.

Infeld, D. L., Gordon, A. K. \& Harper, B. C. (Eds.). (1995). Hospice Care and Cultural Diversity: The Haworth Press.

ISO. (2002). Health Informatics - Health Indicators Conceptual Framework (Technical Specification - Working Draft): International Organization for Standardization (ISO).

Johnson, M., Phillips Shively, W. \& Stein, R. M. (2002). Contextual Data and the Study of Elections and Voting Behavior: Connecting Individuals to Environments. Electoral Studies, 21(2), 219-233.

Kirby, J. B. \& Kaneda, T. (2006). Access to Health Care: Does Neighborhood Residential Instability Matter? Journal of Health and Social Behavior, 47(2), 142-155.

Krieger, N. (1999). Embodying Inequality: A Review of Concepts, Measures, and Methods for Studying Health Consequences of Discrimination. International Journal of Health Services 29(2), 295-352.

Krieger, N., Williams, D. R. \& Moss, N. E. (1997). Measuring Social Class in US Public Health Research: Concepts, Methodologies, and Guidelines. Annual Review of Public Health 18(1), 341-378.

Kupek, E., Dooley, M., Whitaker, L., Petrou, S. \& Renton, A. (1999). Demographic and Socio-economic Determinants of Community and Hospital Services Costs for People with HIV/AIDS in London. Social Science $\mathcal{E}$ Medicine, 48(10), 1433-1440.

Lapham, E. V., Kozma, C. \& Weiss, J. O. (1996). Genetic Discrimination: Perspectives of Consumers. Science, 274(5287), 621-624.

Lewis, C. E., Fein, R. \& Mechanic, D. (1976). A Right to Health: The Problem of Access to Primary Medical Care: John Wiley\&Sons, Inc. .

Lewis, J. R. (1994). Patient Views on Quality Care in General Practice: Literature Review. Social Science E Medicine, 39(5), 655-670.

Lipscomb, H. J., Loomis, D., McDonald, M. A., Argue, R. A. \& Wing, S. (2006). A Conceptual Model of Work and Health Disparities in the United States. International Journal of Health Services : Planning, Administration, Evaluation, $36(1), 25-50$. 
Liukkonen, V., Virtanen, P., Kivimaki, M., Pentti, J. \& Vahtera, J. (2004). Social Capital in Working Life and the Health of Employees. Social Science $\mathcal{E}$ Medicine, 59(12), 2447-2458.

Marmot, M. \& Wilkinson, R. G. (2001). Psychosocial and Material Pathways in the Relation Between Income and Health: a Response to Lynch et al. BMJ, 322(7296), 1233-1236.

Maynard, A. (1991). Developing the Health Care Market. The Economic Journal, 101(408), 1277-1286.

Mobarak, A. M., Rajkumar, A. S. \& Cropper, M. L. (2004). The Political Economy of Health Services Provision and Access in Brazil: Institute of Behavioural Science, University of Colorado

Mooney, G., Hall, J., Donaldson, C. \& Gerard, K. (1991). Utilisation as a Measure of Equity: Weighing Heat? Journal of Health Economics, 10(4), 475-480.

Muurinen, J. M. (1982). Demand for Health: A Generalised Grossman Model. Journal of Health Economics, 1(1), 5-28.

Neyer, F. J. \& Lehnart, J. (2006). Personality, Relationships, and Health: A Dynamic-transactional Perspective. In M. E. Vollrath (Ed.), Handbook of Personality and Health (pp. 195-213): John Wiley\& Sons, Ltd. .

Nguyen, L. \& Häkkinen, U. (2006). Choices and Utilization in Dental Care: Public vs. Private Dental Sectors, and the Impacts of a Two-Channel Financed Health Care System. The European Journal of Health Economics, 7(2 ), 99-106.

Phillips, K. A., Morrison, K. R., Andersen, R. \& Aday, L. A. (1998). Understanding the Context of Healthcare Utilization: Assessing Environmental and Provider-related Variables in the Behavioral Model of Utilization. Health Services Research, 33(3 Pt 1), 571.

Redondo-Sendino, A., Guallar-Castillon, P., Banegas, J. \& Rodriguez-Artalejo, F. (2006). Gender differences in the utilization of health-care services among the older adult population of Spain. BMC Public Health, 6(1), 155.

Schmid, G. (2006). Social Risk Management Through Transitional Labour Markets. Socio-Economic Review, 4(1), 1-33.

Sigg, R. \& Behrendt, C. (2002). Chapter 1. Social Security in the Global Village: Mapping the Issues. In R. Sigg \& C. Behrendt (Eds.), Social Security in the Global Village. New Brunwick and London: Transaction Publishers.

van Doorslaer, E. \& Koolman, X. (2004). Explaining the Differences in IncomeRelated Health Inequalities Across European Countries. Health Economics, 13(7), 609-628.

van Doorslaer, E., Koolman, X. \& Jones, A. M. (2004). Explaining Income-related Inequalities in Doctor Utilisation in Europe. Health Economics, 13(7), 629647. 
van Doorslaer, E., Masseria, C. \& Koolman, X. (2006). Inequalities in Access to Medical Care by Income in Developed Countries. OECD Health Equity Research Group, 174(2), 177-183.

van Doorslaer, E., Wagstaff, A., van der Burg, H., Christiansen, T., de Graeve, D., Duchesne, I., et al. (2000). Equity in the delivery of health care in Europe and the US. Journal of Health Economics, 19(5), 553-583.

van Doorslaer, E. K. A., Masseria, C., Labour and Social Affairs Committee, E. \& Organisation for Economic Co-operation and, D. (2004). Income-related Inequality in the Use of Medical Care in 21 OECD Countries: Organisation for Economic Co-operation and Development.

Wagstaff, A. \& van Doorslaer, E. (2000a). Chapter 34: Equity in Health Care Finance and Delivery. In A. J. Culyer \& J. P. Newhouse (Eds.), Handbook of Health Economics (Vol. 1, Part B, pp. 1803-1862): Elsevier.

Wagstaff, A. \& van Doorslaer, E. (2000b). Measuring and Testing for Inequity in the Delivery of Health Care. The Journal of Human Resources, 35(4), 716-733.

Wagstaff, A., van Doorslaer, E. \& Watanabe, N. (2003). On decomposing the causes of health sector inequalities with an application to malnutrition inequalities in Vietnam. Journal of econometrics, 112(1), 207-223.

WHO. (1995). Global Strategy on Occupational Health for All: The Way to Health at Work. Retrieved from http://www.who.int/occupational_health/globstrategy/en/

WHO. (2006). The World Health Report 2006: Working Together for Health. Retrieved. from.

Wiebe, D. J. \& Forenberry, K. T. (2006). Mechanisms Relating Personality and Health In M. E. Vollrath (Ed.), Handbook of Personality and Health (pp. 137156): John Wiley\& Sons, Ltd. .

Williams, P. G. (2006). Personality and Illness Behaviour. In M. E. Vollrath (Ed.), Handbook of Personality and Health (pp. 157-173): John Wiley\& Sons, Ltd. .

Winkleby, M. A., Jatulis, D. E., Frank, E. \& Fortmann, S. P. (1992). Socioeconomic status and health: how education, income, and occupation contribute to risk factors for cardiovascular disease. American Journal of Public Health, 82(6), 816-820. 



\section{Chapter 3: Employment and Healthcare Use: Insights from Luxembourg Social Security Records}

The working version of this chapter has been presented at:

- Seminar, University of Antwerp: September 13, 2007.

- $\quad$ ESPANET 2007 Conference: September 20 - 22, Vienna.

- $\quad$ REDIS project meeting: June 16, 2008, Luxembourg. 



\subsection{Introduction}

Recent empirical studies increasingly document larger public healthcare spending and at the same time widening variation in healthcare use, especially found on the grounds of diverse socio-economic characteristics. A number of studies call for an attention to further explore links between the socio-economic characteristics and healthcare use (i.e. 2009; Goyder et al., 2005; Jiménez-Martín, Labeaga, \& MartínezGranado, 2004; Menendez, Benach, Muntaner, Amable, \& O'Campo, 2007; Pohlmeier \& Ulrich, 1995; van Doorslaer, Koolman, \& Puffer, 2002; van Doorslaer, Masseria, \& OECD Health Equity Research Group, 2004). A better understanding of healthcare use determinants, as socio-economic characteristics, could lead to easier implementable (compared to health system changes) public policy responses.

Employment, as an array of diverse occupational and job characteristics, is a particularly interesting socio-economic determinant of healthcare utilisation. Employment characteristics relate to monetary and non-monetary returns, both on individual and contextual levels (see Chapter 2 of this thesis). However, studies on its overarching impact on healthcare utilisation are rare, and if so, are often dominated by focus on income related aspects.

In this study, we aim to empirically test which and how employment characteristics explain individual differences in healthcare use. For this purpose, we focus on Luxembourg study case. We use micro-level administrative social security data of 2006, which provide both individual healthcare utilisation rates and diverse socio-economic characteristics. We focus on exploring one general and one specific healthcare type: ambulatory and dentist care.

Why is it interesting to investigate Luxembourg for studying employment related influences? The country is one of the most ethnically diverse and mobile employment markets in the world. However, due to its high commuter labour force and thus inflated GDP levels, many international empirical studies exclude Luxembourg as an outlier. Other studies exclude Luxembourg due to a lack of relevant data. As a result, healthcare utilisation pattern in this EU country is largely under-explored.

We structure this Chapter in the following way. First, we review Luxembourg country social settings, with a specific attention paid on certain labour market features and healthcare system description. Second, we present methodological structure of the paper: data in use and empirical model details. Third, we present 
and discuss empirical study results. Finally, we conclude and discuss potential future research, as well as some policy implications.

\subsection{Review of Luxembourg social settings}

\section{Population and the labour market}

The Grand Duchy of Luxembourg is situated in between Belgium, France and Germany. Administratively, it is divided into 12 cantons and 116 communes (i.e. an equivalent of municipalities) ${ }^{7}$. Luxembourg City, the country's capital, has a population of around 82000 inhabitants. The national language of Luxembourg is a West Germanic language Luxembourgish. In addition, French and German languages are also officially used for judicial and administrative purposes.

Luxembourg is often quoted to be one of the most prosperous world economies, attracting numbers of foreign workers to seek better economic opportunities. Mainly due to economic immigration, the country's population increased from around 340 thousands of people in 1970 to around 469 thousands in 2006. In the latter year, foreign origin residents constituted $41 \%$ of the overall population, making it one of the highest foreign origin resident rates observed worldwide (i.e. STATEC, 2010) ${ }^{8}$. The largest foreign nationality groups include Portuguese (15\%), French (5\%), Italians (4\%), Belgians $(4 \%)$, Germans $(2 \%)$, as well as immigrants from former Yugoslavia or Cape Verde ${ }^{9}$. Most of the foreign nationals have been attracted to Luxembourg due to its immense economic growth ${ }^{10}$, especially in such sectors, as financial or IT services, transport and communication industries (STATEC, 2003).

Close ties between the economic growth and migration have also resulted in intense ethnic disparities within the economy. For example, STATEC (2003) observes that around $40 \%$ of the working population with Luxembourg nationality works in the public and parapublic administration. These jobs predominantly require holding of Luxembourg nationality. Foreign workers dominate such sectors as construction (only 15\% of Luxembourgers employed), retail, hotels or food service (only 10\% of Luxembourgers employed). For specific nationalities,

\footnotetext{
7 Unless otherwise stated, information reference date is January 1, 2006.

${ }^{8}$ According to the UN (2006) estimates, each working day Luxembourg also receives a cross-border workforce, which constitutes around $40 \%$ of the resident working population.

${ }^{9}$ Percentage of total resident population, 2006 estimates (STATEC, 2010).

${ }^{10}$ From the mid-1980s until 2000, the average GDP real growth rate was more than $5 \%$, far exceeding the rates observed in other EU countries except of Ireland (STATEC, 2003).
} 
Portuguese are, for example, reported to dominate the construction sector, while Germans are mainly employed in financial and business services.

\section{Healthcare system organization}

Luxembourg's health care system is based on three fundamental principles: compulsory social health insurance, free choice of provider for patients and compulsory provider compliance with the fixed set of fees for services (UN, 2006). The insured people pay pre-defined co-payments for the national health services, with the levels ranging from $0 \%$ to $100 \%$ depending on the healthcare service (WHO, 2006). Overall, out-of-pocket expenditure ${ }^{11}$ in Luxembourg is reported to be among the lowest in OECD countries, at $1.5 \%$ of final household consumption (OECD, 2009).

Statutory health insurance covers $99 \%$ of Luxembourg population ${ }^{12}$ and is managed by the Union of Sickness Funds (called National Health Fund as of 2009), as well as nine occupational sickness funds (Kerr, 1999). The sickness funds are responsible for the reimbursement of the health care expenses incurred by the insured person ${ }^{13}$ and in principle act as agencies for direct contact with the insured members. People are assigned automatically to a respective occupational sickness fund according to their professional group or employer ${ }^{14}$. By law, a membership with a specific sickness fund should not involve any differences with respect to healthcare access. The Union of Sickness Funds is in charge of all other administrative responsibilities regarding healthcare insurance financing.

Based on the OECD (2009) data, 59.4\% of Luxembourg population had a complementary private healthcare insurance in 2007 (i.e. to cover hospital copayments, pre- and post-operative and, convalescence costs, dental prostheses, surgical treatment abroad, etc.). Mossialos \& Thomson (2002) report that the

\footnotetext{
${ }_{11}$ According to the OECD definition of out-of pocket expenditure, the term should cover cost-sharing (i.e. co-payments), self-medication and other expenditure paid directly by private households.

${ }^{12}$ Civil servants and employees of European and international institutions have their own health insurance funds. Based on OECD (2009) data, 97.9\% of Luxembourg population was covered by public health insurance in 2007.

13 Other functions of sickness funds include: payment of the flat-rate maternity benefit, reimbursement for the funeral allowances, administering cash benefits for sickness, etc.

${ }^{14}$ The mentioned sickness funds are: 4 sickness funds for the employees of the private sector (i.e. for manual workers or the blue-collar workers - $\mathrm{CMO}$; for white-collar workers of the private sector CMEP; for self-employed - CMPI; the sickness fund for the agricultural sector - CMAGR); 2 sickness funds for the employees of the public sector (i.e. for civil servants and state employees - CMFEP; for civil servants and employees of local authorities - CMFEC); 3 enterprise funds (i.e. for ARBED company's manual workers - CMOA; for ARBED white-collar workers - CMEA; the Luxembourg Railways Medical Insurance Association - EMCFL).
} 
population which does not have a complementary health insurance are mainly foreigners and construction workers.

\section{Healthcare use in Luxembourg: existing evidence}

Few studies discuss (social) determinants of healthcare use in Luxembourg, and if so, the obtainable evidence is often highly lagged in time. The most often quoted reasons behind Luxembourg case exclusion relate to unavailability of relevant comparative data, small survey sample size or Luxembourg's outlier position with respect to a number of income indicators.

For example, a recent study on healthcare utilisation inequities in Europe (i.e. Bago d'Uva et al., 2009), excludes Luxembourg analysis due to a limited number of available $\mathrm{ECHP}^{15}$ survey data waves. The same reason is mentioned regarding Luxembourg exclusion in van Doorslaer, Masseria, \& OECD Health Equity Research Group (2004) or Schulz (2004). A study by Hurst \& Siciliani (2004) reports that Luxembourg does not have significant waiting problems for elective surgeries. However, it excludes Luxembourg from further comparisons with the other OECD countries due to the small implemented survey size for Luxembourg (i.e. OECD Waiting Time Project) and large cross-boundary people flows.

The ECHP data for 1996, Luxembourg included, is used in van Doorslaer, Koolman, \& Jones (2004) cross-sectional study on the sources of inequalities in the use of GP and specialist services. This study points to high and significant pro-rich inequity in total specialist visits in all studied countries (i.e. 12 EU member states), except Luxembourg and Belgium. Luxembourg is hereby referred to as a "somewhat special case because of its small size (and sample), the lack of academic hospitals, the high degree of cross-border care delivery and the unclear distinction between a specialist and a general practitioner". This study however suggests that income is significant and negatively related in explaining subsequent specialist visits in Luxembourg. Furthermore, lower income groups are found to use more of GP services compared to higher incomes: both in terms of likeliness to seek and the frequency of using. Previously, Doorslaer et al. (2002) noticed that preferential treatment of lower income groups via certain co-payment reductions or exemptions could explain a (slightly) higher healthcare utilisation among lower

\footnotetext{
15 European Community Household Panel is a cross-national longitudinal survey focusing on household income and living conditions, including health characteristics (EPUNET, 2003). Full ECHP data format for these countries has actually been collected for 1994-1996, and then for remaining ECHP data collection years (1997-2001) replaced by an ECHP format derived national surveys, called PSELL in Luxembourg case.
} 
income groups in Luxembourg (also in Belgium, Ireland and Spain). The latter observation, though, has not yet been confirmed in the latter study.

Aside income driven inequalities in healthcare use, we are not aware of other studies exploring a wider array of employment influences on healthcare use given Luxembourg local settings.

\subsection{Methodology}

\section{Data and selected population}

The study uses a newly developed micro database from the Luxembourg social security records - the Social Security Data Warehouse (SSDW). SSDW is constructed by the Inspection Générale de la Sécurité Sociale (IGSS) and pools information from diverse operational files of the country's social security system. In 2006 SSDW data there are diverse social security records of 462323 residents of Luxembourg ${ }^{16}$.

Information regarding the healthcare use is available in relation to the compulsory healthcare insurance system: how many times and what types of services have been used and reported to the national health insurance system. Utilisation of services covered by private insurance are not reimbursed through occupational sickness funds and are therefore not observed in this dataset.

Household is constructed using two sources of information: registers of marriage and information on family benefits. Thereby, the constructed household refers more to a nuclear family definition - children and people in charge of them (i.e. parents, foster care givers, etc.) - rather than to a usual survey type household construct.

We focus on the analysis of the population aged 18 to 55, which is identified as having a status of an employee within the social security dataset ${ }^{17}$. The social security records are most reliable precisely for these people due to the payments of social security contributions, taxes, etc. Students, self-employed, unemployed people or people who have no affiliation with any identifiable employer are excluded from the further analysis. The selected lower age threshold aligns with

\footnotetext{
${ }^{16}$ Non-resident commuting population of Luxembourg is not included in the dataset. Information on the people working for multinational organizations, such as the EU, is also excluded, unless the latter people are identified as beneficiaries of the social security system through co-insurance plans.

${ }^{17}$ Due to age selection 209825 observations are dropped; due to job status selection 80765 observations are dropped.
} 
the age of majority ${ }^{18}$. The upper age threshold (55 years) is chosen to closely associate with an average working career ending age - 57 years (i.e. Goerens, 2006) ${ }^{19}$. We also exclude records of people who have no identification of the employment sector (42 observations dropped) and no distinction of the working class category (4102 observations dropped). Additionally, we exclude cases, which do not have an identified residence place (11 observations), as well as some extreme values with respect to the hours worked per month and the income levels (total of 62 observations). This result in 167446 cases of the final employee population (hereinafter referred to as the 'selected population' or 'employees').

Luxembourg social security records contain information on personal gross salaries, but not on the household disposable income. We consider that disposable household income is a better measure of individual's ability to pay and access healthcare than the personal gross employment income. Thereby, this study uses an external project REDIS outcome variable - the Luxembourg tax-benefit microsimulation model simulated household disposable income ${ }^{20}$. The gross salary level is utilised as an additional job characteristic.

In addition to the SSDW and REDIS data, we also obtain and organise the external aggregate information on the selected socio-economic settings of the country. This information mainly relates to municipality (i.e. commune) level characteristics, such as population density, unemployment level and regional economic underdevelopment. Furthermore, based on STATEC (2004) data, we construct variables indicating commune density of doctors (both general practitioners and specialists) and dentists.

Despite the richness of the SSDW and additional sources' data, it is noteworthy mentioning some major limitations of this dataset. For example, information on a potential cross-border healthcare or private insurance is not included. The data also collects information on the "facts", while the reasons (e.g. as in survey data) behind the observed choices are unknown (i.e. the reasons for working fewer hours/months). We also do not have time-related information, such as years in

\footnotetext{
${ }^{18}$ The age of majority is defined by the law and implies the full assumption of all the legal (adulthood) rights.

19 The legal retirement age threshold is 65 years for both men and women.

${ }^{20}$ The project REDIS, a joined CEPS / INSTEAD and Inspection Générale de la Sécurité Sociale project is co-financed by the FNR within the multi-annual programme "Living tomorrow in Luxembourg". It explores the coherence and distributional effects of Luxembourg social transfers (i.e. direct taxes, social contributions and social benefits in cash) through the use of microsimulation models. The project uses the anonymised administrative micro-data as an input into the microsimulation model. The Luxembourg module of EUROMOD - the EU wide tax-benefit microsimulation model - is specifically adapted to this dataset for simulating the disposable household income. More information on EUROMOD could be found at http://www.iser.essex.ac.uk/euromod.
} 
employment, or an indication of the educational level of the workforce. The latter factor is often considered as an important determinant of healthcare use. In this study we have to rely on the education related determinants, such as an occupational category/sector, gross salary level or age. For example, based on de Broeck (2008), women in Luxembourg are noted to have on average a lower educational level than men, but this is changing for the younger generations. Women aged 20 to 24 are observed to have a completed secondary education more often than men.

\section{Empirical model}

\section{Dependent variables}

Our dependent variables are two types of healthcare service utilisations: 1) the number of yearly (ambulatory and stationary) GP and specialist visits and 2) the number of yearly dentist visits. The GP and specialist visits mainly refer to the consultation type of visits, such as questioning of the patient, a clinical exam or related therapeutic prescriptions (technical types of contacts, such as surgery or radiology, are not included). We further on refer to this utilisation category as "consultations" or "ambulatory care". Visits to dentists cover both general and "technical" services mainly due to a more technical nature of the dental care per se. We further on refer to this utilisation category as "dentist visits" or "dental care".

The dependent variables have been selected based on the multiple rationales. First, our main interest is to explore how employment relates to general and specific type of healthcare. Second, consultations are not split into more specific components of general practitioner and specialist services due to a rather unclear distinction between the two categories in Luxembourg, as already noted by Doorslaer, Koolman, \& Jones (2004). Third, the SSDW dataset is not yet fully adapted for healthcare research analysis, with this study being the first attempt of a kind. Many other variables, while interesting to explore, are not yet available due to the database's continuous technical development and time constraints.

The selected dependent variables have numerous other strengths if compared to the survey reported variables. For example, surveys collected healthcare use information has been often criticised due to recall errors (e.g. Bago d'Uva, 2006) or too short (i.e. selected months) surveyed periods (e.g. Pohlmeier \& Ulrich, 1995). This has often caused limited variance and large excess of zero observations (i.e. non-use) in the dependent variables. For example, Pohlmeier \& Ulrich (1995) note that $90 \%$ of the respondents did not report visiting a general practitioner or a specialist more than three times during the used survey quarter. The SSDW dataset provided healthcare use variables refer to the entire course of 2006, ensuring a large variation within the dependents variables. 
Table 3-1. Summary statistics of dependent variables

\begin{tabular}{|c|c|c|c|c|c|}
\hline & & \multicolumn{2}{|c|}{ Consultations } & \multicolumn{2}{|c|}{ Dentist visits } \\
\hline & & All population & Employees & All population & Employees \\
\hline \multirow{11}{*}{$\begin{array}{l}\text { Number } \\
\text { of counts } \\
\text { per year }\end{array}$} & 0 & $20.36 \%$ & $16.47 \%$ & $48.77 \%$ & $43.79 \%$ \\
\hline & 1 & $10.15 \%$ & $12.06 \%$ & $6.22 \%$ & $4.60 \%$ \\
\hline & 2 & $9.86 \%$ & $11.43 \%$ & $10.04 \%$ & $10.82 \%$ \\
\hline & 3 & $9.21 \%$ & $10.31 \%$ & $7.37 \%$ & $8.58 \%$ \\
\hline & 4 & $8.22 \%$ & $9.00 \%$ & $4.78 \%$ & $5.51 \%$ \\
\hline & 5 & $7.17 \%$ & $7.78 \%$ & $3.68 \%$ & $4.36 \%$ \\
\hline & 6 & $6.06 \%$ & $6.43 \%$ & $2.94 \%$ & $3.47 \%$ \\
\hline & 7 & $4.98 \%$ & $5.09 \%$ & $2.37 \%$ & $2.78 \%$ \\
\hline & 8 & $4.22 \%$ & $4.27 \%$ & $2.00 \%$ & $2.31 \%$ \\
\hline & 9 & $3.49 \%$ & $3.33 \%$ & $1.62 \%$ & $1.96 \%$ \\
\hline & $10>=$ & $16.28 \%$ & $13.83 \%$ & $10.21 \%$ & $11.82 \%$ \\
\hline \multicolumn{2}{|c|}{ Total population } & $462,323=100 \%$ & $167,446=100 \%$ & $462,323=100 \%$ & $167,446=100 \%$ \\
\hline \multicolumn{2}{|c|}{ Max. number of visits } & 120 & 69 & 243 & 161 \\
\hline \multicolumn{2}{|l|}{ Variance } & 31.52 & 24.32 & 40.03 & 41.48 \\
\hline \multicolumn{2}{|l|}{ Mean } & 5.07 & 4.77 & 3.36 & 3.79 \\
\hline \multicolumn{2}{|c|}{ Conditional mean* } & 6.37 & 5.71 & 6.55 & 6.75 \\
\hline \multicolumn{2}{|c|}{ Conditional variance ${ }^{*}$} & 31.32 & 23.74 & 57.18 & 53.85 \\
\hline
\end{tabular}

Given that a contact has taken place $\left(y_{i}>=1\right)$

Source: own presentation

Table 3-1 displays the summary statistics of the dependent variables. We present both total and the selected population figures. Despite similar trends in healthcare service utilisation, employees are shown to be more "preventive" users of both ambulatory and dentist care - they have fewer observations of the non-use in comparison to the total population. A couple major differences between the employees' utilisation of consultations and dentist care also exist. First, fewer employees seek dentist services (56\%) compared to ambulatory consultations $(84 \%)$. Second, if seeking healthcare, employees use dental care more frequently (mean of visits 6.74 versus 5.71 respectively).

\section{Model selection}

The above reported distributions point to a large proportion of people having no visits, a majority of people having up to 10 visits per year and a smaller share of people reporting a very frequent use of healthcare visits $(>=10)$. The summary statistics also point to variances being considerably larger than means: variance of consultations (among employees) is 5 times larger than the mean, and variance of dentist visits - 11 times larger than the mean.

Variance exceeding the mean (i.e. over-dispersion feature), large number of zeros and the presence of the long right tail are commonly observed in many diverse 
healthcare utilisation applications (e.g. Hidayat \& Pokhrel, 2010; Pohlmeier \& Ulrich, 1995; van Doorslaer, Koolman et al., 2004). The usual way to account for such a distributional pattern is via zero-inflated models, such as zero-inflated negative binomial distribution (ZINB), or via hurdle models, often described as a two - part model in the count data literature ${ }^{21}$.

Figure 3-1 graphically displays how well negative binomial distribution (i.e. indicated as "neg binom prob" on the graph) fits the distribution of observed values. It shows a relatively close match, except of larger deviations occurring around the observational value of "one". Such a break in distributional pattern is quite typical for healthcare use data and is often explained by two rather than one data generation processes. Both zero inflated and hurdle models could be exploited to deal with such distribution, as they both recognize a different data generation process behind zero and positive count values. However, it has been shown in the literature that the hurdle mode is a more suitable empirical model specification for the healthcare data analysis. This is due to its closer match with an underlying economic theory (i.e. a principal-agent theory), as well as due to the often high proportion of zeros that remains un-explained after over-dispersion specification in the zero inflated models, such as zero inflated Poisson model (e.g. JiménezMartín et al., 2004; Jones et al., 2007). The hurdle model, initially proposed by Mullahy (1986), assumes that zero and non-zero observations of the dependent count variable come from two different data generating processes and are modelled independently, as the first stage is more related to a person's choice to see a doctor, when the second stage refers to both patient and doctor induced use of healthcare services. Following van Doorslaer, Koolman, et al. (2004) the doctor role is significant due to the prescribed follow-ups, referrals to the other specialists, etc.

The recent academic research also points to the potential use of a finite mixture (latent class) models or combined latent class hurdle models as potentially outperforming econometric specifications compared to hurdle models (e.g. Bago d'Uva, 2006; Deb \& Trivedi, 2002; Jones et al., 2007). Finite mixture (FM) models stress that differences exist between infrequent and frequent users rather than users and no-users, as in the hurdle models. Deb \& Trivedi (2002) argues that FM models are better suited to analyse healthcare utilisation data, given that it usually represents individuals at different times of their sickness episodes.

\footnotetext{
${ }^{21}$ Poisson, the most common count data model, is not suitable in this case due to its requirement on conditional mean being equal to conditional variance (e.g. Jones, Rice, Bago d'Uva, \& Balia, 2007).
} 
Figure 3-1. Observed versus negative binomial distributions: employee population
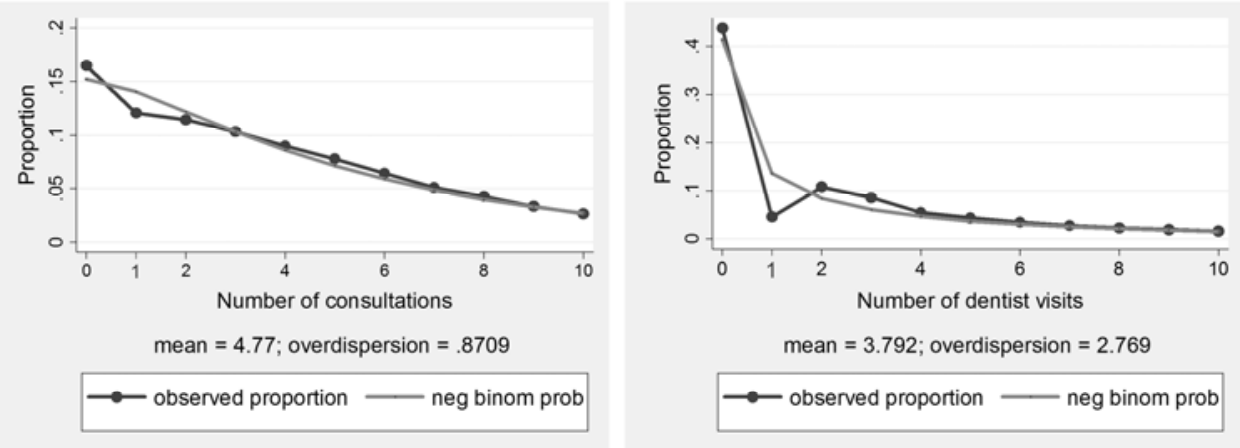

Source: own presentation

Critical notes on the use of FM models also exist. Jiménez-Martín et al (2004) present mixed empirical findings with respect to hurdle versus FM model use and suggest a hurdle model for the analysis of the annual data of specialist visits, while a FM model - for GP visits. This is due to the observation that specialist visits are usually related to one sickness episode and, therefore, hurdle models might fit the underlying data generation process better. The latent class models are also being criticized for their statistical rather than (economic) theory approach, as well as usually low ability of splitting population into more than two or three number of (latent) classes (i.e. Jochmann \& Leon-Gonzalez, 2004; Jones et al., 2007).

We choose the hurdle model as the primary framework for this analysis ${ }^{22}$. First, the hurdle model provides the best theoretical fit with supply and demand related influences in healthcare utilisation and aligns with the proposed theoretical framework on employment related influences in healthcare use (see Chapter 2 of this thesis). Second, as obtained data is cross-sectional (i.e. 2006 year), the possibility of testing a combination of a hurdle and a finite-mixture model, which would combine advantages of both latent and hurdle class models, as proposed by Bago d'Uva (2006), is excluded. Following Jones et al. (2007), such a combination in the cross-sectional context poses identification problems. Third, we use an extensive list of objectively evaluated health status covariates, including indication on sickness episodes. As the disease evaluations are done by doctors, we treat this

\footnotetext{
${ }^{22}$ For comparative purposes, we do attempt to estimate a zero inflated negative binomial model (the Vuong test results are significantly in favour of this rather than a standard negative binomial model). We allow the zero inflated probability to be dependent on the full covariate list. Due to the high number of parameters, this model is not able to converge. When the zero inflation probability part is set to constant, we do acquire comparable results to hurdle. However, in such a case we cannot offer an explanation behind the zero generating process.
} 
as an additional evidence of supply side effects in healthcare utilisation process (i.e. relying on a principal-agent theory).

\section{Hurdle model specification}

We denote $y_{i}$ (where $i=1, \ldots, N$ is the count data) two respective utilisation variables: ambulatory visits or dentist care. We estimate separate hurdle models for each of them. Following the hurdle model set-up, as discussed by Gurmu (1998), we divide $y_{i}$ into a binary and positive count variables: $y_{i}$ with $\mathrm{i}=0$ or 1 and $y_{i}$ with $\mathrm{i}$ ranging from 1 to some maximum value. We denote a ray of all explanatory variables as $x_{i}$. Explanatory variables $x_{i}$ are selected to be the same across two model stages, however their estimated impacts $\beta$ are allowed to be different.

We use a logit model to analyse the binary yivariable. Here, the log-likelihood for the binary choice, following Jones et al. (2007), is equal to:

$\log L_{1}=\sum_{y=0} \log \left[1-P_{1}(y>0 \mid x)\right]+\sum_{y>0} \log \left[P_{1}(y>0 \mid x)\right]$, where $P_{1}$ denotes logit distribution.

Within the second stage of the hurdle model, we employ a zero truncated negative binomial (NB) model to analyse the positive count of yi. The log likelihood for the positive count is expressed as:

$\log L_{2}=\sum_{y>0} \log \left[P_{2}(y \mid x, y>0)\right]$, where $P_{2}$ denotes a truncated at zero NB2 distribution ${ }^{23}$.

The log-likelihood of the hurdle model is equal to the sum of the two separate loglikelihood functions $\log L_{1}+\log L_{2}$. We estimate this set-up of the hurdle model using STATA software.

\section{Determinants}

We rely on the same list of covariates for the analysis of both ambulatory and dentist care. This allows highlighting if employment-related impacts are diverse or analogous for different healthcare types. Furthermore, the existing literature provides more (if any) evidence on employment influences for ambulatory rather than dental care. The list of associated hypotheses regarding the latter healthcare is, therefore, particularly limited.

Overall, the selected determinants refer to an extensive list of factors ${ }^{24}$ covering both individual and contextual level influences (see the entire list of determinants and summary statistics in Appendix 1). In the following sections we describe the

\footnotetext{
${ }^{23}$ In the NB2 specification, the conditional variance is expressed as a quadratic function of the mean (e.g. Greene, 2008).

${ }^{24}$ As noted before, administrative data has its own limitations. This highly shapes the final list of covariates. The final list of included determinants follows the Chapter 4 proposed structure and refers to both individual (enabling, need, predisposing) and contextual (institutional and external) influences.
} 
main employment attributes and the associated hypotheses. We also review a potential role of nationality and briefly introduce the other control factors.

\section{Employment characteristics and associated hypotheses}

Our prime interest variable is employment. This refers to an array of diverse factors, distinguished across the individual and contextual level influences (although the two can overlap). Individual employment determinants cover monthly number of working hours, number of months worked per year, unemployment, occupational category, membership within a specific occupational sickness fund, gross salary level and (cash) bonuses. Contextual determinants refer to the occupational sector, regional economic and unemployment characteristics, as well as workplace attributes. Disposable income is also accounted for, but at the family rather than at the individual level. Additionally, a family's at-risk-of poverty status is considered. We briefly discuss each of these determinants.

A dummy variable is used to indicate if a person has worked full 12 months (fullyear ${ }^{25}$ ) - the predominant job type in Luxembourg (about $90 \%$ of the selected population). Based on the existing research evidence, one could expect that people in seasonal (temporary) or transitory employment are less likely to use healthcare compared to those in a year-round employment (e.g. Schorr, 1990). According to EUROFOUND information (Wlodarski, 2010), temporary work in Luxembourg traditionally applies more to industrial and construction sectors. Many young people also have short term-contracts for the "entry" positions.

We account for a contractual nature of jobs following observations of substantial frequency peaks at certain thresholds. Three variables are created: working part time, (part_time; $<=80$ hours per month, $8 \%$ of population), full-time (full_time; $80 \%$ of population) and over-time (over_time $>176$ hours per month; $12 \%$ of population). Two primary healthcare utilisation effects could be associated. On the one hand, higher work intensity could cause more stress and exposures to occupational hazards, and, therefore, induce seeking more of healthcare services, and particularly ambulatory services. On the other hand, a high(er) work intensity could also be related to limited available time for both ambulatory visits and dentist care. Parttime jobs could be related to higher financial insecurity and reflect selectivity into the jobs (i.e. working mothers). Based on Wlodarski (2010), people working parttime in Luxembourg are usually those who provide domestic services, fill in replacement positions (i.e. teaching) or are the temporary agency workers. They could be both low and high skilled employees, such as cleaners or IT consultants. If so, diverse healthcare use effects could be expected.

\footnotetext{
${ }^{25}$ Here and further on: parentheses provided titles in the Italic font refer to the variables' names.
} 
To specifically account for any unemployment time within the year of analysis we use a dummy variable, which indicates an unemployment benefit receipt (unempl; 3\% of all employees). Based on international evidence, such as Yuen \& Balarajan's (1989) study on Britain, men in unemployment but seeking work have higher GP utilisation rates compared to those in employment. On the other hand, lower utilisation of healthcare services could also be expected, especially if financial strains pertain to the time in unemployment. For example, this type of negative association between unemployment and dental care use is observed in Finland (Nguyen, Häkkinen, \& Rosenqvist, 2005).

Four occupational categories are distinguished: blue-collar (bluecollar; $40 \%$ of all employees), white-collar (whitecollar; $41 \%$ of all employees) workers, civil servants (civil; $17 \%$ of all employees) and other types of employees (othercategory; $2 \%$ of all employees). Occupational categories refer to different job profiles and duties. Based on Luxembourg survey of occupational stress ${ }^{26}$ (Wlodarski, 2006), blue-collar workers experience three times higher stress levels compared to senior managers. Consequently, this could signal a higher healthcare use. International research shows diversified trends of healthcare use in relation to the occupational category. For example, a study by Whitehead, Evandrou, Haglund, \& Diderichsen (1997) finds a higher use combined GP and outpatient visits by non-manual employees in Sweden, whereas manual workers tend to use more of GP services, but less of specialist care in the UK. In both countries, no socio-economic differences in healthcare use were observed in 1970s and 1980s, pointing to a rather recent appearance of disparities.

We also distinguish among employees' membership with an occupational sickness fund (CMO, CMEP, etc.). As mentioned before, allocation to a sickness fund is automatically determined by the job position. We therefore mainly refer to this variable as an additional indication of a socio-professional classification (e.g. working in private or public sector; civil, white-collar or blue-collar workers; employment with a specific company, as ARBED ${ }^{27}$, etc.). Some (unobserved) administrative differences might also exist between the sickness funds influencing differentiated healthcare utilisation (e.g. via health knowledge dissemination). Generally, we do not expect to see large differences in healthcare utilisation patterns across the funds' members, unless the constructed variables refer stronger to the underlying socio-professional classification rather than the membership per se.

\footnotetext{
${ }^{26}$ Occupational stress is caused by such factors as 'change', 'demands of others', 'lack of control', 'physical environment', 'frustration', 'work organisation', etc.

27 As a result of mergers of companies: Arcelor and ArcelorMittal as of 2002 and 2006 respectively.
} 
Employment within different occupational sectors is accounted for. The corresponding variables are constructed in relation to NACE codes and refer to 11 sectors (n_sector $X$ ), such as manufacturing, hotels and restaurants, public administration work, work at the community level organisations, etc. Hypotheses with respect to occupational sector influences are rather limited due to lack of empirical evidence, especially given Luxembourg settings. Generally, we expect people in healthcare sector to use more of healthcare services due to work related health knowledge and social contacts within the healthcare sector. Occupational sectors, such as business activities, might also indicate higher utilisation of healthcare services due to more flexible personal time management. Transport or construction sectors are expected to reveal less of healthcare utilisation due to more stringent time (and geographical location) constraints for contacting healthcare specialists. The sectors (i.e. trade, cleaning, hotels, restaurants and catering) with the highest occupational stress (Wlodarski, 2006) are expected to use more of healthcare too. On the contrary, the sectors with the lowest reported stress levels (i.e. manufacturing, teaching, the public sector or financial services) should then associate with the reduced healthcare use. Overall, we expect the same occupational sector to have similar impacts for using either ambulatory or dental care.

We are also interested to see if an economic potential of the residence area has an impact on the healthcare use. Two municipal level variables are constructed. The first one points to the areas of very high unemployment (high_unempl; 15\% of all employees) - 1.5 times higher than the country average (5.4\%). The second one indicates economically deprived areas (deprived; $21 \%$ of all employees) and is created based on the EC (2006) information on regional aid provision to the economically disadvantaged areas. Increasing international research evidence points to lower probabilities of healthcare use among people living in the disadvantaged neighbourhoods (Kirby \& Kaneda, 2005).

The number of employees in the company describes a workplace (i.e. work environment, occupational health standards, etc.) and also refers to the extent of a social network potentially acquirable via the job. We distinguish among six company types: one person (onep_firm; $4 \%$ of all employees), micro (micro_firm, 12\% of all employees), small (small_firm; $27 \%$ of all employees), medium (medium_firm; $21 \%$ of all employees), large (large_firm; $8 \%$ of all employees) and very large (vlarge firm, $28 \%$ of all employees) companies. Following Goerens (2006) report on Luxembourg, working (health related) conditions have been improved in many workplaces. Most changes, however, occurred in the large companies (more than 250 people) and least changes - in the small (fewer than 20 people) companies. Better working conditions could relate to lower healthcare needs. On the other hand, more 
stringent working (time) regulations within the larger companies could create constraints in seeking healthcare.

The logarithm of the equivalised household's disposable income (ln_eqdinc) is used as an indication of the person's monetary well-being. Overall, we expect higher income levels to be strongly associated with a higher use of dentist services in Luxembourg. This relates to numerous cross-country observations on significant pro-rich dentist care utilisation. Income, on the other hand, is often reported to be negatively associated with the use of GP services. As our dependent variable on consultations pools information on both GP and specialist services, the direction of the income effect is ambiguous, especially given that the higher use of specialist services is usually observed for the higher income families. We also check the impact of living at-risk-of-poverty (poor; $10 \%$ of all employees). A relative poverty concept is used to create this dummy variable, with poverty line defined as $60 \%$ of median equivalised household disposable income. The expected effect follows income related observations.

Five gross salary levels, based on the quintile distribution of gross salaries, are also constructed (quintileX). They indicate low to high paid jobs and refer to an array of material and non-material returns to work (e.g. low to high skilled jobs, managerial positions, etc.). We also use an opportunity of working with a social security dataset to discuss the potential influence of bonuses: usually surveys do not include or do not contain enough observations on bonus receipts. Indication of bonus receipts (bonus; $73 \%$ of all employees) covers both material (i.e. income) and non-material returns from work too. The non-material aspects relate to potential over-time, extra-ordinary efforts at work, a higher managerial position, a more active use of the workplace's social network, etc. To better capture some of these effects, we indicate if a person received bonus is very ( $h$ bonus; $>=$ mean gross salary) or moderately high ( $m$ bonus; $>=0.6^{*}$ mean gross salary). If the income effect is dominant, we are going to observe the same pattern of influences as already discussed for household disposable income. Negative influences are not to be excluded too.

\section{Nationality influences}

Aside the direct role of employment, we are also interested in highlighting the healthcare use variation in relation to the ethnic background. In the fore-presented (default) hurdle model, employment influences on healthcare use are evaluated controlling for nationalities' effects. As a sensitivity analysis, we also implement a modification: we exclude nationalities in the used determinants' list. The aim is to see if, which and how employment influences would be altered. 
Such a sensitivity analysis on the links between nationality and employment is due to our previous observations of an ethnically segregated Luxembourg labour market. We distinguish between 15 nationality groups, with the largest nationality being Luxembourgish (53\% of all employees). Other large nationality groups are Portuguese (22\%), French (6\%), Italian (4\%), Belgian (4\%), German (2\%), various nationalities of former Yugoslavia (2\%) and Cape Verde. Our expectations on either higher or lower healthcare utilisation by non-Luxembourgish nationals are quite limited ${ }^{28}$. Aside cultural differences (i.e. cultural norms, but also language) a geographical proximity to the homeland could play a role. If so, non-EU nationalities would be noted to have a comparable utilisation to the Luxembourgish people, whereas those living close to the homelands would be expected to have a lower use of healthcare services, at least because of potential use of the cross-border care. If nationality is not controlled for, (some of) it related effects would be potentially "absorbed" by the employment characteristics.

\section{Other control factors}

We use an extensive list of objectively evaluated individual health needs' estimators: 1) sickness leave duration, 2) a number of sickness episodes per year, and 3) an array of different disease diagnostics ${ }^{29}$, which are constructed in relation to the International Disease Code (ICD) classification. The three covered categories of health needs are recognised as hardest to obtain, however, the most influential predictors of healthcare use. For example, the lack of data on sickness episodes have been often recognised as a serious issue for a hurdle model specification, annual data analysis or overall unexplained heterogeneity (e.g. Pohlmeier \& Ulrich, 1995; van Doorslaer, Koolman et al., 2004). Few empirical studies though yet exist using sickness leave or disease diagnostic code information. In addition to these three groups, maternity and disability variables are constructed on the basis of respective benefit receipts. Aside informing on the health needs, they also reflect the design of the state transfers.

\footnotetext{
${ }^{28}$ Few studies explore immigration background and healthcare utilisation patterns in Europe. The existing research points to either higher use rates among immigrants versus native-born individuals or provides with no conclusive evidence (e.g. Muñoz de Bustillo \& Antón, 2009; Solé-Auró, Guillén, \& Crimmins, 2009)

${ }^{29}$ Health status variables are often considered as endogenous variables in healthcare utilisation studies, especially if subjective health status measurements are used. This study relies on the objectively evaluated health needs. Furthermore, instrumental or lagged variables, which are often used to correct for endogeneity in health (e.g. van Doorslaer, Koolman et al., 2004) were not obtainable within this study scope. Thereby, following arguments provided by van Ourti (2004) - only mixed evidence available regarding endogeneity of the health status variables and a limited scope of the lagged variables in correcting endogeneity problem - we choose not to account for endogeneity issues in this study. This potential caveat is to be solved in the follow-up researches.
} 
We also control for family arrangements, such as household size (on average 2.5 people), family status (i.e. single, married, separated or widowed) and some specific household types (i.e. single parents with children, a family with a newborn child, a person taking care of the dependent). A number of (other) municipality level descriptions are included using STATEC data. They are constructed in order to capture environmental, administrative, political and other socio-economic aspects of the person's surroundings. Municipal densities (i.e. municipal population/doctors) of ambulatory care providers and dentists are also controlled for.

Additionally, we include control variables for gender, age (age and age squared), as well as age related employment (i.e. volatile jobs at the very young ages) and gender influences. Some other interaction terms referring to occupational specificities are covered too. For example we control for situations where a person works full year and is still noted to receive an unemployment benefit (presumably technical unemployment or other unknown/administrative reasons). A dummy variable is also used to control for cases with no disposable income. Some occupational sectors' specificities are taken into account by interactions with working hours.

\subsection{Results}

Here, we discuss the role of employment characteristics and nationality in healthcare use. Table 3-2 reports the associated hurdle model coefficients. Bolded coefficients are significant at $p=<0.05$. Coefficients of the other explanatory variables are reported in Appendix 2. 
Table 3-2. The hurdle model results - determinants of prime interest

\begin{tabular}{|c|c|c|c|c|c|c|c|c|}
\hline & \multicolumn{4}{|c|}{ Consultations } & \multicolumn{4}{|c|}{ Dentist visits } \\
\hline & \multicolumn{2}{|c|}{ Part I } & \multicolumn{2}{|c|}{ Part II } & \multicolumn{2}{|c|}{ Part I } & \multicolumn{2}{|c|}{ Part II } \\
\hline & Estimate & S.E. & Estimate & S.E. & Estimate & S.E. & Estimate & S.E. \\
\hline \multicolumn{9}{|c|}{ Employment characteristics: } \\
\hline fullyear & 0.630 & 0.040 & 0.102 & 0.014 & 0.573 & 0.032 & -0.102 & 0.025 \\
\hline unempl & 0.622 & 0.101 & 0.179 & 0.033 & 0.258 & 0.077 & -0.066 & 0.062 \\
\hline over_time & 0.163 & 0.070 & -0.021 & 0.021 & 0.039 & 0.048 & 0.014 & 0.035 \\
\hline part_time & -0.318 & 0.062 & -0.064 & 0.024 & -0.178 & 0.052 & -0.068 & 0.042 \\
\hline bluecollar & -0.414 & 0.171 & -0.393 & 0.040 & -0.086 & 0.101 & -0.158 & 0.070 \\
\hline civil & -0.770 & 0.196 & -0.314 & 0.043 & 0.055 & 0.118 & 0.161 & 0.076 \\
\hline othercategory & -0.643 & 0.128 & -0.445 & 0.029 & -0.267 & 0.073 & -0.176 & 0.048 \\
\hline quintile1 & 0.321 & 0.040 & 0.097 & 0.010 & 0.007 & 0.024 & 0.055 & 0.017 \\
\hline quintile2 & 0.043 & 0.027 & 0.019 & 0.007 & -0.064 & 0.018 & 0.048 & 0.012 \\
\hline quintile4 & 0.042 & 0.025 & -0.007 & 0.007 & 0.045 & 0.018 & -0.014 & 0.012 \\
\hline quintile5 & -0.179 & 0.030 & -0.077 & 0.009 & 0.074 & 0.022 & -0.059 & 0.014 \\
\hline bonus & -0.020 & 0.021 & -0.070 & 0.006 & 0.003 & 0.015 & -0.001 & 0.011 \\
\hline h_bonus & -0.200 & 0.081 & 0.052 & 0.034 & -0.348 & 0.069 & 0.076 & 0.050 \\
\hline m_bonus & -0.088 & 0.065 & 0.012 & 0.024 & -0.099 & 0.052 & 0.034 & 0.035 \\
\hline ln_eqdinc & 0.324 & 0.023 & 0.037 & 0.008 & 0.328 & 0.018 & -0.061 & 0.013 \\
\hline poor & -0.327 & 0.035 & -0.062 & 0.010 & -0.138 & 0.025 & 0.001 & 0.019 \\
\hline n_mine_man_ut & 0.016 & 0.042 & 0.001 & 0.013 & 0.129 & 0.029 & 0.009 & 0.021 \\
\hline n_construction & -0.132 & 0.042 & -0.025 & 0.013 & -0.029 & 0.029 & -0.017 & 0.022 \\
\hline n_trade & 0.053 & 0.037 & -0.003 & 0.011 & 0.107 & 0.026 & -0.039 & 0.018 \\
\hline n_hotels_rest & 0.038 & 0.049 & -0.066 & 0.015 & 0.188 & 0.035 & 0.106 & 0.025 \\
\hline n_transport & 0.272 & 0.046 & 0.126 & 0.014 & 0.162 & 0.033 & -0.029 & 0.023 \\
\hline n_financial & 0.232 & 0.035 & 0.107 & 0.011 & 0.222 & 0.026 & -0.021 & 0.018 \\
\hline n_public & 0.592 & 0.041 & 0.272 & 0.012 & 0.198 & 0.028 & 0.009 & 0.019 \\
\hline n_education & 0.012 & 0.087 & 0.071 & 0.029 & 0.150 & 0.067 & -0.113 & 0.045 \\
\hline n_health & -0.066 & 0.042 & 0.009 & 0.011 & 0.189 & 0.027 & -0.053 & 0.018 \\
\hline n_community & 0.231 & 0.058 & 0.026 & 0.016 & 0.256 & 0.039 & -0.056 & 0.026 \\
\hline n_household & 0.343 & 0.111 & -0.018 & 0.026 & 0.417 & 0.064 & -0.103 & 0.043 \\
\hline n_other & 0.111 & 0.074 & 0.028 & 0.022 & 0.190 & 0.052 & 0.028 & 0.037 \\
\hline onep_firm & -0.078 & 0.055 & -0.014 & 0.018 & -0.048 & 0.042 & -0.055 & 0.030 \\
\hline micro_firm & 0.001 & 0.034 & -0.026 & 0.010 & 0.041 & 0.024 & 0.023 & 0.016 \\
\hline small_firm & -0.017 & 0.028 & -0.031 & 0.008 & 0.033 & 0.019 & -0.017 & 0.013 \\
\hline med_firm & -0.003 & 0.028 & -0.017 & 0.008 & -0.024 & 0.019 & -0.044 & 0.012 \\
\hline large_firm & 0.016 & 0.034 & -0.009 & 0.010 & -0.052 & 0.024 & -0.009 & 0.016 \\
\hline CMEP & -0.328 & 0.169 & -0.403 & 0.039 & 0.109 & 0.100 & -0.275 & 0.069 \\
\hline CMFEP & 0.739 & 0.212 & 0.081 & 0.049 & 0.257 & 0.129 & -0.449 & 0.087 \\
\hline CMPI & 0.172 & 0.206 & -0.174 & 0.056 & 0.349 & 0.140 & -0.244 & 0.094 \\
\hline CMOA & 0.158 & 0.101 & -0.086 & 0.028 & -0.132 & 0.065 & -0.004 & 0.049 \\
\hline EMCFL & 1.284 & 0.222 & 0.301 & 0.052 & 0.243 & 0.137 & -0.351 & 0.091 \\
\hline CMFEC & 1.005 & 0.217 & 0.177 & 0.050 & 0.359 & 0.133 & -0.416 & 0.089 \\
\hline CMAGR & 0.186 & 0.260 & -0.146 & 0.077 & 0.535 & 0.194 & -0.046 & 0.119 \\
\hline CMEA & -0.393 & 0.185 & -0.381 & 0.047 & 0.250 & 0.116 & -0.301 & 0.079 \\
\hline deprived & 0.027 & 0.024 & 0.010 & 0.006 & -0.065 & 0.016 & 0.039 & 0.011 \\
\hline high_unempl & 0.005 & 0.037 & 0.019 & 0.010 & -0.053 & 0.025 & 0.009 & 0.017 \\
\hline
\end{tabular}




\begin{tabular}{|c|c|c|c|c|c|c|c|c|}
\hline & \multicolumn{4}{|c|}{ Consultations } & \multicolumn{4}{|c|}{ Dentist visits } \\
\hline & \multicolumn{2}{|c|}{ Part I } & \multicolumn{2}{|c|}{ Part II } & \multicolumn{2}{|c|}{ Part I } & \multicolumn{2}{|c|}{ Part II } \\
\hline & Estimate & S.E. & Estimate & S.E. & Estimate & S.E. & Estimate & S.E. \\
\hline \multicolumn{9}{|l|}{ Nationality: } \\
\hline Portugal & -0.186 & 0.026 & -0.081 & 0.007 & -0.327 & 0.017 & 0.077 & 0.012 \\
\hline France & -0.537 & 0.031 & -0.105 & 0.011 & -0.589 & 0.023 & 0.022 & 0.017 \\
\hline Italy & -0.179 & 0.041 & 0.004 & 0.012 & -0.175 & 0.029 & 0.051 & 0.020 \\
\hline Belgium & -0.759 & 0.036 & -0.133 & 0.013 & -0.727 & 0.028 & 0.029 & 0.021 \\
\hline Germany & -0.722 & 0.046 & -0.133 & 0.016 & -0.508 & 0.036 & -0.032 & 0.026 \\
\hline f_Yugoslavia & 0.041 & 0.063 & -0.075 & 0.015 & -0.387 & 0.037 & 0.126 & 0.028 \\
\hline UK & -0.871 & 0.069 & -0.204 & 0.029 & -0.802 & 0.058 & -0.112 & 0.046 \\
\hline Netherlands & -0.639 & 0.082 & -0.126 & 0.030 & -0.365 & 0.065 & -0.117 & 0.047 \\
\hline CapeVerde & -0.437 & 0.100 & -0.145 & 0.028 & -0.710 & 0.066 & -0.072 & 0.053 \\
\hline Spain & -0.265 & 0.099 & -0.053 & 0.030 & -0.496 & 0.070 & -0.058 & 0.052 \\
\hline Denmark & -0.293 & 0.121 & -0.034 & 0.040 & -0.409 & 0.092 & -0.128 & 0.064 \\
\hline Tajikistan & -0.230 & 0.129 & -0.174 & 0.055 & -1.162 & 0.121 & -0.102 & 0.108 \\
\hline Poland & -0.746 & 0.131 & -0.222 & 0.049 & -0.518 & 0.103 & 0.378 & 0.079 \\
\hline Sweden & -0.930 & 0.118 & -0.170 & 0.052 & -0.979 & 0.104 & -0.159 & 0.086 \\
\hline other_nation & -0.500 & 0.043 & -0.144 & 0.015 & -0.608 & 0.033 & 0.040 & 0.025 \\
\hline \multicolumn{9}{|c|}{ Other explanatory variables (see Appendix 2) } \\
\hline & \multicolumn{2}{|c|}{$\log L=-56685.89$} & \multicolumn{2}{|c|}{$\log L=-350630.99$} & \multicolumn{2}{|c|}{$\log L=-106190.64$} & \multicolumn{2}{|c|}{$\log L=-264640.63$} \\
\hline & \multicolumn{4}{|c|}{ Hurdle $\log L=-407316.88$} & \multicolumn{4}{|c|}{ Hurdle $\log L=-370831.27$} \\
\hline & \multicolumn{2}{|c|}{$\mathrm{N}=167446$} & \multicolumn{2}{|c|}{$\mathrm{N}=139866$} & \multicolumn{2}{|c|}{$\mathrm{N}=167446$} & \multicolumn{2}{|c|}{$\mathrm{N}=94114$} \\
\hline
\end{tabular}

Note: 'Estimates' refer to the coefficients as obtained from each part of the hurdle model.

\section{Employment influences}

Overall, we find that employment characteristics are relevant sources of influences in healthcare use. Their impacts, though, could present both comparable and opposing impacts given one or another healthcare type, and for a contact or a subsequent healthcare use. For example, we observe that employment characteristics are more significant in explaining the probability rather than the frequency of dentist visits. The effect is less apparent for ambulatory care. We also note that individual level determinants, such as work intensity or occupational category, are more significant in explaining the use of ambulatory rather than dental care. Contextual factors (i.e. economic deprivation, unemployment level, occupational sector), on the other hand, are found to be particularly important in predicting the probability of the (first) dental contact. Furthermore, probability of seeking healthcare, be it consultations or dental care, is rather uniformly influenced by the same employment characteristics. However, a more notable divergence in the effects of different employment attributes appears when explaining the frequency of utilisation. We discuss these observations in more detail.

An all year-round employment in comparison to fewer months at work relates to a higher probability of both contacting and using ambulatory care. The same effect is noted for contacting dental services. However, the full-year employment implies a 
lower frequency of dental care utilisation. This finding comes with a degree of surprise. Our initial expectations were associated with temporary or "entry" work positions (i.e. work, associated with less than full-time employment) implying a reduced use of healthcare.

Any unemployment time experienced during the year of analysis is associated with a higher probability of contacting and using ambulatory care. The same directional effect is also observed for contacting dental care, but no significant effect is noted for explaining the frequency of dental care utilisation. Our initial hypothesis suggested that people in search of work also use more of healthcare. In this study, no precise link however could be established between the receipt of an unemployment benefit and employment search. Our findings, on the other hand, do not endorse the reverse prospect of people in receipt of an unemployment also having higher financial strains. Based on this hypothesis, we should have observed a lower healthcare utilisation rate.

Working over-time in comparison to full-time increases a probability of a contact to ambulatory care. The effect is negligible in explaining the overall dental and the frequency of ambulatory care. Working part-time significantly decreases both the probability and the frequency of consultations. A similar negative effect is also noted for the probability of having a dentist visit. The effect is though insignificant for the frequency of dental visits. Overall, the direction of the over-time effect corresponds to our expectation that a higher stress and exposures to the occupational hazards increases a probability and a frequency of consultations. The part-time work effect is also in line with the initial hypothesis. It arguably suggests that part-time job related (financial) insecurity reduces the likelihood of a more active utilisation of healthcare services. It could also pertain to fewer occupational exposures when working less.

An occupational category has a higher role in explaining ambulatory rather than the dental care. We note that in comparison to white-collar workers all other occupational groups have a lower probability of seeking consultations. For dental care, the same directional effect is only noted among the workers without a clear indication of occupational category. The civil servants and blue-collar workers do not disclose significant differences from the white-collar workers in seeking dental care. An occupational category has a somewhat smaller, but a rather similar effect in explaining the frequency of consultations too: all other occupational groups have a lower use of ambulatory care in comparison to white-collar workers. A diverging role is though noted for the dental care: civil servants tend to use dental services most frequently, "followed" by white-collar, blue-collar and other types of workers respectively. As such, our expectations regarding the occupational 
category are partially not-fulfilled. We have expected a more clear-cut segregation of healthcare use among the manual and non-manual categories. This applies for dental, but not for ambulatory care.

The gross salary level has a different directional effect in explaining the contact to ambulatory and dental care. People with the lowest salary levels use consultations more often in comparison to those with the middle range salaries (i.e. the third quintile), whereas those with the top salaries (i.e. the fifth quintile) - more often. The opposite effect is observed for dental care: people with the highest salaries (both fifth and the fourth quintiles) seek dental care more often compared to those with the middle range salaries, while the second quintile is found to have a lowered tendency of contacts. The gross salary has a similar role though in explaining the frequency of both ambulatory and dental care. Namely, the lower salaried people have a slightly higher use of services in comparison to the middle and the very top salaries.

Overall, the receipt of a bonus does not have a large explanatory power, and if so the effect is negative (i.e. in explaining the subsequent use of ambulatory care). High (in comparison to low) bonuses are observed having a negative effect in seeking both ambulatory and dental care. Interestingly, the latter observation aligns to the negative high gross salary effect noted for ambulatory care, but not for dental care. A few explanations could emerge regarding the negative effect of top bonuses. This could signal a differentiated use of health services among the people with the very top remuneration packages. For example, these people might tend to use the cross-border rather than Luxembourg healthcare - information on which is not provided in our dataset. Additionally, given that a negative bonus effect is the strongest in explaining a contact rather than a frequency of healthcare use, it could point to different preventive care behaviour.

An increase in family income is associated with an increasing probability of a contact - both for consultations and dental care. The effect on the frequency of the use is however divergent: higher family disposable income has a positive effect on the use of consultations, but a negative effect on the use of dental care. These effects are observed given controls for the lowest family incomes: we note that living in a family at-risk-of poverty has a significantly negative effect on seeking both consultations and dentist services.

In summary, our expectation that a higher income level, be it gross salary, bonus or disposable income, is going to be associated with a higher use of at least dentist services is only partially met. While overall an increase in a family's disposable income is associated with a higher probability of seeking ambulatory and dentist care, varied top/low income effects are also noted for these two healthcare types. 
Arguably, they reveal different behaviours at the ends of income distributions and also point to different non-monetary influences pertaining to diverse remuneration schemes.

Employment with a specific occupational sector reveals to be a strong determinant of the healthcare contact, especially for the dental services. Additionally, this determinant has often opposite directional impacts in explaining the use of dental and ambulatory care. The reference category here is working in the business sector. We find that all other sectors are associated with a higher probability of having at least one dental service per year. For consultations, the construction sector is noted to have a lower contact probability than the business sector, and all the other sectors - either a comparable or a higher contact. An occupational sector has also a somewhat more limited but still a significant role in determining the frequency of healthcare use. Furthermore, the sector impacts are highly divergent in explaining the use of ambulatory and dental care. For consultations, the pattern is actually rather similar to the one noted above: in comparison to the business sector, working in the construction, plus in the hotels and restaurants' sector, implies a lower use of consultations. For dental care, most sectors, except of the hotels and restaurants, are associated with a lower use of dental services. As such, the sector influence in determining the contact and the frequency of usage is highly different for dental care. We also note that the sectors which do not have significantly different dental care usage (in comparison to the business sector) are mining and manufacturing, construction, transport, financial or even public sector. Precisely these sectors, except of mining and manufacturing, have the strong explanatory powers for the frequency of ambulatory care. Other reverse effects are also present. The sectors, such as trade, health or household work, show insignificant effects for ambulatory, but not for dental care. Working in the hotels and restaurants is noted to increase dental, but to decrease ambulatory care usage. The same reverse directional effect is also noted for the educational sector.

Overall, our initial hypotheses regarding the occupational sector role in Luxembourg are mainly rejected. First, people working in, for example, the healthcare sector do not tend to use more services in comparison to most other sectors. Second, among the sectors with the noted higher occupational stress exposures, only work in the household sector is related to a higher probability of contacting both ambulatory and dental care. Third, the sectors with the lowest stress levels (i.e. manufacturing, teaching, the public sector or financial services) have an increased, rather than reduced, use of ambulatory care, and mainly an insignificant or decreasing impact on the use of the dental services. 
The company size does not display any significant effect on the decision to contact any of the two healthcare services. The only exception is that working in a large compared to the very large company has a negative effect on making the first contact for the dental services. A more significant differentiation by the company size is noted though for the frequency of utilisation: employment with the very large companies (almost) uniformly associates with a higher use of ambulatory care. The effect is less significant but still comparable for dentist care too. As such, our expectation that employment in the very large companies could relate to more rigorous working hours or better working (at least healthcare wise) conditions and thus reduce healthcare use - is not approved. Instead, it seems that working in the very large companies creates higher demand or better settings for a more frequent use of, as a minimum, ambulatory care.

Membership with a certain occupational sickness fund, just like a work in a specific occupational sector, has a highly diverse utilisation effect on ambulatory and dentist services. Our main reference category here is $\mathrm{CMO}$ - a fund for manual or blue-collar workers of the private sector. Two affiliations are found to have a lower than the CMO probability of seeking ambulatory care: both are the private sector funds for white-collar workers, namely CMEA and CMEP. For dental care, the lower probability of a contact is only noted for the CMOA fund members ARBED's fund for manual workers. As such, the lowest probability of seeking dental care is associated with the manual workers of the private sector. All other affiliations imply either higher or insignificant difference in contacting both ambulatory and dentist care. CMEA and CMEP membership also implies a lower use of ambulatory care, once the first contact has been made. The same directional effect is also observed for CMOA and CMPI (i.e. a fund for self-employed). Membership with the CMFEC, a fund for civil servants and employees of local authorities, and the EMCFL (a medical insurance association of the Luxembourg Railways) reveals a higher utilisation of ambulatory care. For dental care, no fund is associated with a higher utilisation rate than observed for the CMO. In summary, our analysis shows that there exists a differentiated use of healthcare services across the members of occupational sickness funds - a finding we were uncertain about, when setting the initial hypotheses. Given controls for income levels, occupational sector and category (among others), this shows disparities across the private and public sectors, as well as other (yet) un-captured occupational features.

Finally, two included contextual factors - living in the economically deprived or high unemployment areas - have no significant effect on either contacting or using ambulatory care. Living in these residential areas though has a significant and negative effect on initiating the contact with dentists. On the other hand, once the 
first contact is made, living in the deprived areas is associated with a higher use of dental services. As such, our findings do not support our initial expectation of a reduced use of healthcare services in the economically deprived areas. The findings are actually mixed and depend on the healthcare service type.

\section{Nationality influences}

In comparison to Luxembourgish people, all foreign nationals have a lower probability of seeking either ambulatory or dental care. The same holds for the frequency of ambulatory care use. A couple nationalities, though, are noted to have a more frequent use of dental care in comparison to Luxembourgish people.

Overall, we have expected that the probability of a contact would be lower for nationalities of Luxembourg neighbouring countries, such as France, Belgium or Germany. This is confirmed for all three countries. Furthermore, the probability of a contact, be it consultations or dental care, is also lower for all other ethnic groups. It is likely that such a lower overall contact with the Luxembourg healthcare system is due to language barriers or a possibility of using services in the homeland/ across the border. The observation is rather surprising, though, as some of the foreign nationals have been living in Luxembourg since about 1970's, and assimilation effect could have been expected.

The frequency of ambulatory care use reveals a few other interesting observations. Workers with the southern European EU background, as Italy and Spain, do not have a significantly different utilisation of ambulatory care in comparison to Luxembourgish. So are Danish. All other nationalities have a lower use of ambulatory care in comparison to Luxembourg nationals. This comes rather unexpectedly, given that substituting Luxembourg healthcare with homeland services is quite cumbersome given geographical proximity or travel costs, at least for nationals of far-away and non-EU countries, as Tajikistan or Cape Verde.

The frequency of dental care use has a different pattern in comparison to ambulatory care use. First, less sharp divergences from the Luxembourg nationals are traced. Second, Portuguese, Italians, former Yugoslavian nationals and particularly Polish are found to have a higher (than Luxembourgish) dental care use. Only three nationalities, namely of the UK, Denmark and the Netherlands, are still noted to have a lower use. The remaining nationalities, even those with the neighbouring home states (i.e. Germany, Belgium and France) have a comparable to Luxembourgish dental care utilisation. This implies, that potentially the crossborder dental care (in contrast to ambulatory care) utilisation is of less importance/convenience. As such, this finding contradicts our initial expectation regarding geographical proximity to Luxembourg - it seems to have a healthcare 
use reducing effects for ambulatory care, but not for dental care. The quality of dental care might be an answer; however this study does not have any means to confirm this. Cultural norms seem to play a larger role too.

\section{Employment "absorbed" nationality effects}

How much does nationality interact with the diverse employment characteristics? As part of the sensitivity analysis, we run the same hurdle model - however, omitting a control for the nationality variables. Employment related coefficients of this limited hurdle model are presented in Appendix 3. Here, we highlight the major observations.

For seeking ambulatory care, we notice large changes regarding explanation of income, occupational sector, occupational sickness fund and a company size (other effects are mainly the same, especially in terms of the directional effects). Without the control for nationality, one could claim that all gross salary levels are significant in explanation of the first contact. So is the receipt of top bonuses. Employment in the construction sector, on the other hand, would reveal a less significant variation, whereas the work in the healthcare or community services would show positive and significant influence on the ambulatory care use. People working in the "one-employee" companies appear to have significantly lower probabilities in seeking ambulatory care if compared to those working in the very large companies.

For the frequency of the ambulatory care use, we observe analogous changes as discussed for the contact of the use. Additionally, we note that without controlling for nationality, the membership with the CMFEP occupational sickness fund (i.e. for civil servants and state employees) reveals a positive and significant influence on the healthcare use.

For seeking dentist care, the changes of employment impacts are also mainly analogous to those observed for ambulatory care. However, even stronger results are noted regarding the explanatory power of the bonus variables. For example, even the receipt of a bonus would signal a significant and positive explanatory relation. Explanation of the frequency of the dental care use in principle would not change (except of relatively small size effects) with or without inclusion of the nationality variables.

How is nationality related to the employment variables that reveal the biggest coefficient changes? From the data, we learn that higher incomes/bonuses are 
mostly ${ }^{30}$ received by Luxembourgish people and in particular a few EU member nationals, such as the UK, Denmark and Sweden. At the same time, very few nationals of Portugal, former Yugoslavia, Cape Verde, Tajikistan or Poland are noted to receive any such high remuneration.

Construction sector shows a reverse pattern to remuneration for pooling certain nationalities. Here, we find very few Luxembourgish, French, Belgians, Brits, Dutch, Danish or Swedish workers, but a high over-representation of workers from Portugal and the former Yugoslavia. The healthcare and community services do not have a very high over-representation of a certain nationality, but employment of nationals from the UK, Denmark, Sweden and Tajikistan is particularly low. Actually, nationals from the UK, Denmark and Sweden primarily take jobs in the financial sector ${ }^{31}$. Tajikistan and Cape Verde nationals are extremely self-selected to work in the restaurants and hotels sector ${ }^{32}$.

Ethnic background of employees also varies by company size. For example, for one-employee companies, Portuguese, Dutch, Cape Verdeans, Tajik or Polish are overrepresented as compared to the average in the population at large. ${ }^{33}$ The medium size companies are over-represented by the nationals of the UK, Denmark and Sweden. The very large companies, our reference category for tracing the company size influences, have consistently lower shares of all nationalities, except of Luxembourgish.

The occupational sickness fund CMFEP provides health insurance to civil servants and state employees. Nationality wise, it is highly dominated by Luxembourgish people (consistently low shares of all other nationalities are recorded). The same observation holds for EMCFL - the Luxembourg Railways Medical Insurance Association. CMOA, the occupational sickness fund for ARBED's manual workers, has a dominant share of two nationalities - Italy and Luxembourg. For the latter

\footnotetext{
${ }^{30}$ Over/under-representation of the nationality in relation to a certain employment characteristic is determined in the following way: if share of the nationality within the selected category (i.e. top quintile of the gross salary level) over the share of this nationality in the total population is more than 1.5 - we refer to it as a large over-representation; if the share of the nationality within the specific category over the share of this nationality in the total population is less than 0.5 - we refer to the ethnic group as largely under-represented.

${ }^{31}$ The over-representation ratios for these nationalities reach such extreme heights, as 4.5, 6.3 and 6.2 respectively. These are the highest over-representation ratios among all nationalities.

32 The over-representation ratios for these two nationalities are extremely high: more than 15.5 and 5.1 respectively. Some other nationalities, as French or Italians, display the next highest over-representation shares, but with somewhat lower heights of 2.7 and 2.2 respectively.

${ }^{33}$ The over-representation is particularly large for Tajik employees of one-person companies, with a ratio of 4 .
} 
membership, most of the other nationalities (except of French) are highly underrepresented.

\subsection{Conclusions}

This study is the first empirical investigation linking healthcare utilisation and employment characteristics in Luxembourg. The contribution of this chapter to the wider literature is twofold. On the one hand, it provides an innovative strategy for using administrative data to study health care utilisation in relation to employment characteristics. It uses an extremely rich set of cross-sectional data of the Luxemburg-resident population. The data were specifically assembled for this project from various public institutions by the Inspection Générale de la Sécurité Sociale. Our dataset refers to individual level records for the entire calendar year of 2006, allowing us to analyse individual's health status and detailed health care utilisation. Analysed healthcare refers to the residents' use of services covered by the national health insurance system. One limitation of the study is that we do not observe cross-border health care or health services covered by private insurance even if used by the resident population.

We further enrich this micro-level data by more aggregate information on, for example, economic and health infrastructure at the municipality level. The administrative nature of the data (i.e. no recall error) and the exhaustive nature of information allow accounting for both individual and contextual influences - with more than 100 parameters included. One particularly interesting aspect is also the availability of detailed information on nationality.

On the other hand, it provides innovative evidence on the link between employment characteristics and observed disparities in ambulatory and dental care utilisation. Our results highlight five key findings.

First, both individual and aggregate employment characteristics play a significant role in determining health care use. These effects are particularly strong and significant in determining contact with healthcare providers rather than the frequency of use - particularly for dental care. In addition, individual level employment attributes are notably more influential in explaining the use of ambulatory care whereas contextual parameters have a stronger role for dental care.

Second, employment characteristics have effects of varying amplitude and sometimes of opposite sign for ambulatory and dental care usage. Our results reveal that opposite signed effects are rather common for determining the 
frequency of health care usage, whereas they are less common regarding (the first) access to care. We find that belonging to the top gross salary quintile has a negative effect for seeking ambulatory care but a positive effect for dental care - the only significant opposite-signed determinant of access. We find negative effects for frequency of dental care use but positive effects for ambulatory care for characteristics such as full-year work (as opposed to seasonal), household disposable income or employment in the educational sector. The opposite holds true for civil servants.

Third, specific employment attributes reveal both expected and unexpected influences on healthcare use. Two major expectations are confirmed: full-year and overtime work unsurprisingly increase ambulatory care use, and blue-collar workers use significantly less dental services. We find an array of unexpected but significant effects. For example, workers of the business sector are noted to have the lowest overall ambulatory care use, whereas our expectation was an increased utilisation rate due to more flexible time management. Workers of the very large companies, on the other hand, have unexpectedly the highest ambulatory care usage - in spite of generally favourable workplace safety regulations as reported in the literature. Similarly, people working in the healthcare sector do not tend to use more healthcare services in comparison to other sectors. We also note that utilisation varies significantly across occupational sickness funds - showing the need for a further investigation of the solidarity mechanisms between funds.

Fourth, nationality is an important source of variation in healthcare use. We find that foreign nationality is always associated with lower probability of seeking both ambulatory and dental care. For the frequency of utilisation of ambulatory services, a similar result is found. For dental services, nationals of Portugal, Italy, former Yugoslavia and particularly Polish have a higher frequency of utilisation than Luxembourg nationals.

Fifth, the inclusion of both nationality and detailed employment information in our dataset allows us to isolate these two effects. Our results indicate that nationality is a powerful driver of behaviour in addition to employment characteristics. This finding also has implications regarding the wider literature - which generally relies on less complete data sources. Our sensitivity analysis reveals that the exclusion of nationality leads to an overestimated role of income parameters and an under-estimation of non-monetary employment influences - with the ensuing policy implications.

Our analysis reveals several areas for future research. Aside a number of limitations already mentioned in this Chapter, the dataset, for example, could be expanded by including information on education level or by adding additional 
years of observations. Additional analysis could also be conducted, such as the inclusion of separate indicators of health needs for different types of healthcare services or the detailed exploration of the driving forces (i.e. occupational stress, financial strains, etc.) behind the observed employment influences. Information on (any) preferential treatment of certain population groups when setting the rates of co-payments would be interesting to explore in more detail, especially given the varied income effects for ambulatory and dental care observed in this study. Equity considerations could be further explored too. 


\subsection{Appendices}

\section{Appendix 1. Description and summary statistics of explanatory variables}

We list determinants of prime interest (i.e. main employment and nationality effects) and other control variables. Overall, we follow the determinants' structure as proposed in Chapter 2 of this thesis.

\begin{tabular}{|c|c|c|c|c|c|}
\hline Variable name & Short description ${ }^{[1]}$ & Mean & $S E$ & Min & $\operatorname{Max}$ \\
\hline \multicolumn{6}{|c|}{ Employment related factors } \\
\hline quintile1 & Quintile 1, gross salary & 0.20 & 0.40 & 0.00 & 1.00 \\
\hline quintile2 & Quintile 2, gross salary & 0.20 & 0.40 & 0.00 & 1.00 \\
\hline quintile $3 *[2]$ & Quintile 3, gross salary & 0.20 & 0.40 & 0.00 & 1.00 \\
\hline quintile4 & Quintile 4, gross salary & 0.20 & 0.40 & 0.00 & 1.00 \\
\hline quintile5 & Quintile 5, gross salary & 0.20 & 0.40 & 0.00 & 1.00 \\
\hline bonus & Receipt of a bonus & 0.73 & 0.45 & 0.00 & 1.00 \\
\hline h_bonus & $\begin{array}{l}\text { Bonus is }>=35847 \text { (mean gross } \\
\text { salary) }\end{array}$ & 0.01 & 0.07 & 0.00 & 1.00 \\
\hline m_bonus & $\begin{array}{l}\text { Bonus is }>=0.6 \times \text { mean gross } \\
\text { salary }\end{array}$ & 0.01 & 0.10 & 0.00 & 1.00 \\
\hline fullyear & 12 months of work & 0.91 & 0.29 & 0.00 & 1.00 \\
\hline unempl & $\begin{array}{l}\text { Receipt of an unemployment } \\
\text { benefit }\end{array}$ & 0.03 & 0.17 & 0.00 & 1.00 \\
\hline over_time & Work hours per month $>176$ & 0.12 & 0.32 & 0.00 & 1.00 \\
\hline full_time* & $80<=$ hours per month $<=176$ & 0.80 & 0.40 & 0.00 & 1.00 \\
\hline part_time & Hours per month $<80$ & 0.09 & 0.28 & 0.00 & 1.00 \\
\hline whitecollar & $\begin{array}{l}\text { Occupational category: white- } \\
\text { collar worker }\end{array}$ & 0.41 & 0.49 & 0.00 & 1.00 \\
\hline bluecollar & $\begin{array}{l}\text { Occupational category: blue- } \\
\text { collar worker }\end{array}$ & 0.40 & 0.49 & 0.00 & 1.00 \\
\hline civil & $\begin{array}{l}\text { Occupational category: civil } \\
\text { servant }\end{array}$ & 0.17 & 0.38 & 0.00 & 1.00 \\
\hline othercategory & $\begin{array}{l}\text { Occupational category: } \\
\text { undefined }\end{array}$ & 0.01 & 0.11 & 0.00 & 1.00 \\
\hline n_business & Sector: business activities & 0.11 & 0.31 & 0.00 & 1.00 \\
\hline n_mine_man_ut & Sector: mining, manufacturing & 0.09 & 0.28 & 0.00 & 1.00 \\
\hline n_construction & Sector: construction & 0.10 & 0.30 & 0.00 & 1.00 \\
\hline n_trade & Sector: trade activities & 0.11 & 0.31 & 0.00 & 1.00 \\
\hline n_hotels_rest & Sector: hotels and restaurants & 0.05 & 0.21 & 0.00 & 1.00 \\
\hline n_transport & Sector: transportation & 0.07 & 0.26 & 0.00 & 1.00 \\
\hline n_financial & Sector: financial activities & 0.11 & 0.31 & 0.00 & 1.00 \\
\hline n_public & Sector: public services & 0.20 & 0.40 & 0.00 & 1.00 \\
\hline n_education & Sector: educational services & 0.01 & 0.09 & 0.00 & 1.00 \\
\hline n_health & Sector: healthcare services & 0.09 & 0.28 & 0.00 & 1.00 \\
\hline n_community & Sector: community services & 0.03 & 0.17 & 0.00 & 1.00 \\
\hline n_household & Sector: household work & 0.02 & 0.15 & 0.00 & 1.00 \\
\hline n_other & Sector: other activities & 0.02 & 0.13 & 0.00 & 1.00 \\
\hline onep_firm & Company size: 1 employee & 0.04 & 0.20 & 0.00 & 1.00 \\
\hline
\end{tabular}




\begin{tabular}{|c|c|c|c|c|c|}
\hline micro_firm & Company size: 2 to 10 & 0.12 & 0.33 & 0.00 & 1.00 \\
\hline small_firm & Company size: 11 to 100 & 0.27 & 0.44 & 0.00 & 1.00 \\
\hline med_firm & Company size: 101 to 500 & 0.21 & 0.41 & 0.00 & 1.00 \\
\hline large_firm & Company size: 501 to 1000 & 0.08 & 0.26 & 0.00 & 1.00 \\
\hline vlarge_firm* & Company size: 1001 or more & 0.28 & 0.45 & 0.00 & 1.00 \\
\hline CMEP & Occupational sickness fund & 0.41 & 0.49 & 0.00 & 1.00 \\
\hline CMFEP & Occupational sickness fund & 0.13 & 0.34 & 0.00 & 1.00 \\
\hline CMPI & Occupational sickness fund & 0.00 & 0.05 & 0.00 & 1.00 \\
\hline CMOA & Occupational sickness fund & 0.01 & 0.08 & 0.00 & 1.00 \\
\hline EMCFL & Occupational sickness fund & 0.02 & 0.13 & 0.00 & 1.00 \\
\hline CMFEC & Occupational sickness fund & 0.02 & 0.15 & 0.00 & 1.00 \\
\hline CMAGR & Occupational sickness fund & 0.00 & 0.03 & 0.00 & 1.00 \\
\hline CMEA & Occupational sickness fund & 0.01 & 0.10 & 0.00 & 1.00 \\
\hline $\mathrm{CMO}^{*}$ & Occupational sickness fund & 0.40 & 0.49 & 0.00 & 1.00 \\
\hline ln_eqdinc & $\begin{array}{l}\text { Logarithm of equivalised } \\
\text { household (hh) disposable }\end{array}$ & 10.17 & 0.63 & 0.00 & 12.00 \\
\hline poor & $\begin{array}{l}\text { Poor household: equivalised per } \\
\text { capita hh income }<60 \% \text { * }\end{array}$ & 0.10 & 0.30 & 0.00 & 1.00 \\
\hline deprived & $\begin{array}{l}\text { Economically deprived } \\
\text { communes }^{34}\end{array}$ & 0.21 & 0.40 & 0.00 & 1.00 \\
\hline high_unempl & $\begin{array}{l}\text { Communes with high } \\
\text { unemployment rate }{ }^{35}\end{array}$ & 0.15 & 0.36 & 0.00 & 1.00 \\
\hline \multicolumn{6}{|l|}{ Nationalities } \\
\hline Luxembourg* & Nationality & 0.53 & 0.50 & 0.00 & 1.00 \\
\hline Portugal & Nationality & 0.22 & 0.41 & 0.00 & 1.00 \\
\hline France & Nationality & 0.06 & 0.24 & 0.00 & 1.00 \\
\hline Italy & Nationality & 0.04 & 0.19 & 0.00 & 1.00 \\
\hline Belgium & Nationality & 0.04 & 0.19 & 0.00 & 1.00 \\
\hline Germany & Nationality & 0.02 & 0.15 & 0.00 & 1.00 \\
\hline f_Yugoslavia ${ }^{36}$ & $\begin{array}{l}\text { Nationality: of former } \\
\text { Yugoslavia countries }\end{array}$ & 0.02 & 0.15 & 0.00 & 1.00 \\
\hline UK & Nationality & 0.01 & 0.09 & 0.00 & 1.00 \\
\hline Netherlands & Nationality & 0.01 & 0.08 & 0.00 & 1.00 \\
\hline CapeVerde & Nationality: Cape Verde & 0.01 & 0.08 & 0.00 & 1.00 \\
\hline Spain & Nationality & 0.01 & 0.07 & 0.00 & 1.00 \\
\hline Denmark & Nationality & 0.00 & 0.06 & 0.00 & 1.00 \\
\hline Tajikistan & Nationality & 0.00 & 0.05 & 0.00 & 1.00 \\
\hline Poland & Nationality & 0.00 & 0.05 & 0.00 & 1.00 \\
\hline Sweden & Nationality & 0.00 & 0.05 & 0.00 & 1.00 \\
\hline other_nation & Other nationalities & 0.03 & 0.17 & 0.00 & 1.00 \\
\hline \multicolumn{6}{|l|}{ Control factors } \\
\hline Employment ar & 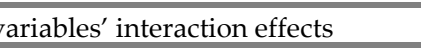 & & & & \\
\hline
\end{tabular}

\footnotetext{
${ }^{34}$ Based on regional aid provision to economically disadvantaged areas (EC, 2006).

${ }^{35}$ If commune unemployment rate, based on STATEC data (), is more than the country average $5.4 \% \mathrm{x}$ 1.5 .

36 This is a composite category of Yugoslavia, Bosnia and Herzegovina, Serbia and Montenegro nationalities.
} 


\begin{tabular}{|c|c|c|c|c|c|}
\hline pyear_agr1 & $\begin{array}{l}\text { Working less than } 12 \text { months \& } \\
\text { aged } 18 \text { to } 24\end{array}$ & 0.03 & 0.17 & 0.00 & 1.00 \\
\hline pyear_agr2 & $\begin{array}{l}\text { Working less than } 12 \text { months \& } \\
\text { aged } 25 \text { to } 29\end{array}$ & 0.02 & 0.14 & 0.00 & 1.00 \\
\hline fyear_unempl & $\begin{array}{l}\text { Working } 12 \text { months \& in receipt } \\
\text { of unemployment benefit }\end{array}$ & 0.02 & 0.16 & 0.00 & 1.00 \\
\hline overtime_mine & $\begin{array}{l}\text { Working overtime in mining, } \\
\text { manufacturing and utilities }\end{array}$ & 0.02 & 0.14 & 0.00 & 1.00 \\
\hline overtime_const & $\begin{array}{l}\text { Working overtime in } \\
\text { construction sector }\end{array}$ & 0.03 & 0.16 & 0.00 & 1.00 \\
\hline overtime_trade & $\begin{array}{l}\text { Working overtime in trade } \\
\text { sector }\end{array}$ & 0.01 & 0.12 & 0.00 & 1.00 \\
\hline overtime_trans & $\begin{array}{l}\text { Working overtime in transport } \\
\text { sector }\end{array}$ & 0.01 & 0.12 & 0.00 & 1.00 \\
\hline overtime_hot & $\begin{array}{l}\text { Working overtime in hotels \& } \\
\text { restaurants sector }\end{array}$ & 0.01 & 0.07 & 0.00 & 1.00 \\
\hline overtime_fin & $\begin{array}{l}\text { Working overtime in financial } \\
\text { sector }\end{array}$ & 0.01 & 0.09 & 0.00 & 1.00 \\
\hline overtime_pub & $\begin{array}{l}\text { Working overtime in public } \\
\text { services sector }\end{array}$ & 0.01 & 0.08 & 0.00 & 1.00 \\
\hline overtime_edu & $\begin{array}{l}\text { Working overtime in } \\
\text { educational sector }\end{array}$ & 0.00 & 0.03 & 0.00 & 1.00 \\
\hline overtime_he & $\begin{array}{l}\text { Working overtime in healthcare } \\
\text { sector }\end{array}$ & 0.00 & 0.04 & 0.00 & 1.00 \\
\hline overtime_com & $\begin{array}{l}\text { Working overtime in } \\
\text { community services sector }\end{array}$ & 0.00 & 0.05 & 0.00 & 1.00 \\
\hline overtime_hh & $\begin{array}{l}\text { Working overtime in household } \\
\text { sector }\end{array}$ & 0.00 & 0.04 & 0.00 & 1.00 \\
\hline overtime_oth & $\begin{array}{l}\text { Working overtime in other } \\
\text { activities' sector }\end{array}$ & 0.00 & 0.04 & 0.00 & 1.00 \\
\hline ptime_mine & $\begin{array}{l}\text { Working part time in mining } \\
\text { etc. sector }\end{array}$ & 0.00 & 0.05 & 0.00 & 1.00 \\
\hline ptime_const & $\begin{array}{l}\text { Working part time in } \\
\text { construction sector }\end{array}$ & 0.00 & 0.07 & 0.00 & 1.00 \\
\hline ptime_trade & $\begin{array}{l}\text { Working part time in trade } \\
\text { sector }\end{array}$ & 0.01 & 0.09 & 0.00 & 1.00 \\
\hline ptime_trans & $\begin{array}{l}\text { Working part time in transport } \\
\text { sector }\end{array}$ & 0.00 & 0.05 & 0.00 & 1.00 \\
\hline ptime_hot & $\begin{array}{l}\text { Working part time in hotels \& } \\
\text { restaurants sector }\end{array}$ & 0.01 & 0.08 & 0.00 & 1.00 \\
\hline ptime_fin & $\begin{array}{l}\text { Working part time in financial } \\
\text { sector }\end{array}$ & 0.00 & 0.07 & 0.00 & 1.00 \\
\hline ptime_pub & $\begin{array}{l}\text { Working part time in public } \\
\text { services sector }\end{array}$ & 0.02 & 0.12 & 0.00 & 1.00 \\
\hline ptime_he & $\begin{array}{l}\text { Working part time in healthcare } \\
\text { sector }\end{array}$ & 0.01 & 0.10 & 0.00 & 1.00 \\
\hline ptime_com & $\begin{array}{l}\text { Working part time in } \\
\text { community services' sector }\end{array}$ & 0.00 & 0.06 & 0.00 & 1.00 \\
\hline
\end{tabular}




\begin{tabular}{|c|c|c|c|c|c|}
\hline ptime_hh & $\begin{array}{l}\text { Working part time in household } \\
\text { sector }\end{array}$ & 0.01 & 0.10 & 0.00 & 1.00 \\
\hline ptime_oth & $\begin{array}{l}\text { Working part time in other } \\
\text { activities' sector }\end{array}$ & 0.00 & 0.05 & 0.00 & 1.00 \\
\hline \multicolumn{6}{|c|}{ Individual health needs } \\
\hline sick_days1* & No sickness days & 0.56 & 0.50 & 0.00 & 1.00 \\
\hline sick_days2 & 1 sickness day & 0.04 & 0.19 & 0.00 & 1.00 \\
\hline sick_days3 & 2-5 sickness days & 0.14 & 0.35 & 0.00 & 1.00 \\
\hline sick_days4 & 6-10 sickness days & 0.08 & 0.27 & 0.00 & 1.00 \\
\hline sick_days5 & $11-15$ sickness days & 0.04 & 0.20 & 0.00 & 1.00 \\
\hline sick_days6 & 16-30 sickness days & 0.06 & 0.24 & 0.00 & 1.00 \\
\hline sick_days7 & 31-60 sickness days & 0.04 & 0.20 & 0.00 & 1.00 \\
\hline sick_days8 & $61-90$ sickness days & 0.02 & 0.13 & 0.00 & 1.00 \\
\hline sick_days9 & 91-120 sickness days & 0.01 & 0.10 & 0.00 & 1.00 \\
\hline sick_days10 & 121-363 sickness days & 0.02 & 0.12 & 0.00 & 1.00 \\
\hline episode_nr1* & 1 sickness episode & 0.20 & 0.40 & 0.00 & 1.00 \\
\hline episode_nr2 & 2 sickness episodes & 0.11 & 0.31 & 0.00 & 1.00 \\
\hline episode_nr3 & 3 sickness episodes & 0.06 & 0.23 & 0.00 & 1.00 \\
\hline episode_nr4 & 4 sickness episodes & 0.03 & 0.18 & 0.00 & 1.00 \\
\hline episode_nr5 & 5 sickness episodes & 0.02 & 0.14 & 0.00 & 1.00 \\
\hline episode_nr6 & 6 to 122 episodes & 0.03 & 0.17 & 0.00 & 1.00 \\
\hline episode_nr7* & No sickness episode & 0.56 & 0.50 & 0.00 & 1.00 \\
\hline surgery & After surgery care ${ }^{37}$ & 0.03 & 0.18 & 0.00 & 1.00 \\
\hline cancer & Diverse cancers & 0.00 & 0.04 & 0.00 & 1.00 \\
\hline injury & Diverse injuries & 0.07 & 0.26 & 0.00 & 1.00 \\
\hline neuro & Nervous system diseases & 0.03 & 0.18 & 0.00 & 1.00 \\
\hline infectious & Infectious and parasitic diseases & 0.19 & 0.39 & 0.00 & 1.00 \\
\hline digestion & $\begin{array}{l}\text { Non-infectious diseases of the } \\
\text { digestive system }\end{array}$ & 0.03 & 0.16 & 0.00 & 1.00 \\
\hline skin & Skin diseases & 0.01 & 0.08 & 0.00 & 1.00 \\
\hline musculoskel & $\begin{array}{l}\text { Musculoskeletal system } \\
\text { diseases }\end{array}$ & 0.04 & 0.19 & 0.00 & 1.00 \\
\hline degenerative & $\begin{array}{l}\text { Osteoarticular system } \\
\text { degenerative diseases }\end{array}$ & 0.05 & 0.22 & 0.00 & 1.00 \\
\hline genito_urinary & $\begin{array}{l}\text { Diseases of the genitourinary } \\
\text { system }\end{array}$ & 0.01 & 0.10 & 0.00 & 1.00 \\
\hline dental & Dental diseases & 0.03 & 0.17 & 0.00 & 1.00 \\
\hline vision & Diseases of the eye and adnexa & 0.01 & 0.09 & 0.00 & 1.00 \\
\hline circulatory & Circulatory system diseases & 0.01 & 0.10 & 0.00 & 1.00 \\
\hline respiratory & Respiratory system diseases & 0.00 & 0.07 & 0.00 & 1.00 \\
\hline mental & $\begin{array}{l}\text { Mental and behavioural } \\
\text { diseases }\end{array}$ & 0.02 & 0.15 & 0.00 & 1.00 \\
\hline nutritional & $\begin{array}{l}\text { Endocrine, nutritional \& } \\
\text { metabolic diseases }\end{array}$ & 0.00 & 0.04 & 0.00 & 1.00 \\
\hline pregnancy_compl & Pregnancy complications & 0.01 & 0.09 & 0.00 & 1.00 \\
\hline
\end{tabular}

${ }^{3737}$ Rows from surgery to other_cond are defined in reference to International Codification of Diseases (ICD). 


\begin{tabular}{|c|c|c|c|c|c|}
\hline other_cond & Other health conditions & 0.08 & 0.27 & 0.00 & 1.00 \\
\hline gender & Gender: women $=1 ;$ men $=0$ & 0.43 & 0.50 & 0.00 & 1.00 \\
\hline age & Age: years & 37.64 & 9.37 & 18.00 & 55.00 \\
\hline age_sq & Age: years squared & 1504.29 & 708.16 & 324.00 & 3025.00 \\
\hline age_gr1 & aged 18 to 24 & 0.09 & 0.29 & 0.00 & 1.00 \\
\hline age_gr2 & aged 25 to 29 & 0.14 & 0.35 & 0.00 & 1.00 \\
\hline age_gr3 & aged 30 to 34 & 0.16 & 0.36 & 0.00 & 1.00 \\
\hline age_gr4* & aged 35 to 39 & 0.17 & 0.38 & 0.00 & 1.00 \\
\hline age_gr5 & aged 40 to 44 & 0.17 & 0.38 & 0.00 & 1.00 \\
\hline age_gr6 & aged 45 to 49 & 0.14 & 0.35 & 0.00 & 1.00 \\
\hline age_gr7 & aged 50 to 55 & 0.13 & 0.33 & 0.00 & 1.00 \\
\hline female_agr1 & female: aged 18 to 24 & 0.04 & 0.20 & 0.00 & 1.00 \\
\hline female_agr2 & female: aged 25 to 29 & 0.07 & 0.25 & 0.00 & 1.00 \\
\hline female_agr3 & female: aged 30 to 34 & 0.07 & 0.26 & 0.00 & 1.00 \\
\hline female_agr $4^{*}$ & female: aged 35 to 39 & 0.08 & 0.26 & 0.00 & 1.00 \\
\hline female_agr5 & female: aged 40 to 44 & 0.07 & 0.26 & 0.00 & 1.00 \\
\hline female_agr6 & female: aged 45 to 49 & 0.06 & 0.24 & 0.00 & 1.00 \\
\hline female_agr7 & female: aged 50 to 55 & 0.05 & 0.22 & 0.00 & 1.00 \\
\hline maternity & Pregnancy indication ${ }^{38}$ & 0.02 & 0.15 & 0.00 & 1.00 \\
\hline disability & Various disabilities & 0.00 & 0.02 & 0.00 & 1.00 \\
\hline \multicolumn{6}{|c|}{ Contextual- family } \\
\hline care & $\begin{array}{l}\text { A person taking care of a } \\
\text { dependent person }\end{array}$ & 0.00 & 0.06 & 0.00 & 1.00 \\
\hline hhsize & Household size & 2.50 & 1.43 & 1.00 & 14.00 \\
\hline n_dincome & $\begin{array}{l}\text { Indication of no record of } \\
\text { household disposable income }\end{array}$ & 0.00 & 0.03 & 0.00 & 1.00 \\
\hline single_hh & one adult + child(-ren) $<18$ (age) & 0.05 & 0.22 & 0.00 & 1.00 \\
\hline newborn_hh & $\#$ of children under age 1 & 0.04 & 0.20 & 0.00 & 3.00 \\
\hline married $^{*}$ & Marital status category & 0.56 & 0.50 & 0.00 & 1.00 \\
\hline single & Marital status category & 0.35 & 0.48 & 0.00 & 1.00 \\
\hline sep_widow & Marital status category: & 0.09 & 0.28 & 0.00 & 1.00 \\
\hline \multicolumn{6}{|c|}{ Contextual - public institutions } \\
\hline popdoc & Commune & 733.66 & 735.39 & 0.00 & 3462 \\
\hline nodoc & Commune: no GPs or specialists & 0.14 & 0.35 & 0.00 & 1.00 \\
\hline popdent & Commune: residents/dentists & 1294.85 & 1261.0 & 0.00 & 4558.0 \\
\hline nodent & Commune: no dentists & 0.25 & 0.43 & 0.00 & 1.00 \\
\hline \multicolumn{6}{|c|}{ External contextual factors } \\
\hline Lux_city* & Residence place: canton & 0.17 & 0.38 & 0.00 & 1.00 \\
\hline Lux_country & Residence place: canton & 0.10 & 0.30 & 0.00 & 1.00 \\
\hline Capellen & Residence place: canton & 0.08 & 0.27 & 0.00 & 1.00 \\
\hline Esch_Alzette & Residence place: canton & 0.31 & 0.46 & 0.00 & 1.00 \\
\hline Mersch & Residence place: canton & 0.06 & 0.23 & 0.00 & 1.00 \\
\hline Clervaux & Residence place: canton & 0.03 & 0.16 & 0.00 & 1.00 \\
\hline Diekirch & Residence place: canton & 0.06 & 0.24 & 0.00 & 1.00 \\
\hline Redange & Residence place: canton & 0.03 & 0.17 & 0.00 & 1.00 \\
\hline Vianden & Residence place: canton & 0.01 & 0.10 & 0.00 & 1.00 \\
\hline
\end{tabular}

\footnotetext{
${ }^{38}$ Indication of maternity and disability are based on respective benefit receipts.
} 
Chapter 3: Employment and healthcare use in Luxembourg

\begin{tabular}{|l|l|c|c|c|c|}
\hline Wiltz & Residence place: canton & 0.03 & 0.16 & 0.00 & 1.00 \\
\hline Echternach & Residence place: canton & 0.03 & 0.18 & 0.00 & 1.00 \\
\hline Grevenmacher & Residence place: canton & 0.05 & 0.22 & 0.00 & 1.00 \\
\hline Remich & Residence place: canton & 0.04 & 0.19 & 0.00 & 1.00 \\
\hline NA_canton & Residence place: unknown & 0.00 & 0.01 & 0.00 & 1.00 \\
\hline density & Population/commune area & 666.6 & 604.9 & 0.00 & 1951 \\
\hline high_foreign & $\begin{array}{l}\text { Commune with high \% of } \\
\text { foreigners }\end{array}$ & 0.20 & 0.40 & 0.00 & 1.00 \\
\hline low_foreign & $\begin{array}{l}\text { Commune with low \% of } \\
\text { foreigners }\end{array}$ & 0.02 & 0.15 & 0.00 & 1.00 \\
\hline
\end{tabular}

Notes: ${ }^{[1]}$ - all figures refer to annual observations; ${ }^{[2]}$ - $^{* \prime}$ indicates a reference category in the hurdle model.

\footnotetext{
${ }^{39}$ Foreigners - residents with other than Luxembourg nationality; selected communes: $>45 \%$ foreigners.

${ }^{40}$ Selected communes: $<15 \%$ of foreigners.
} 
Appendix 2. Hurdle model results - coefficients of control variables

\begin{tabular}{|c|c|c|c|c|c|c|c|c|}
\hline \multirow{3}{*}{$\begin{array}{l}\text { Coefficients in bold } \\
\text { font are significant } \\
\text { at } p=<0.05\end{array}$} & \multicolumn{4}{|c|}{ Consultations } & \multicolumn{4}{|c|}{ Dentist visits } \\
\hline & Estimate & S.E. & Estimate & S.E. & Estimate & S.E. & Estimate & S.E. \\
\hline & \multicolumn{2}{|c|}{$\begin{array}{c}\text { Part I } \\
N=167446\end{array}$} & \multicolumn{2}{|c|}{$\begin{array}{c}\text { Part II } \\
\mathrm{N}=139866\end{array}$} & \multicolumn{2}{|c|}{$\begin{array}{c}\text { Part I } \\
\mathrm{N}=167446\end{array}$} & \multicolumn{2}{|c|}{$\begin{array}{c}\text { Part II } \\
\mathrm{N}=94114\end{array}$} \\
\hline pyear_agr1 & 0.513 & 0.061 & 0.077 & 0.021 & 0.347 & 0.048 & -0.173 & 0.037 \\
\hline pyear_agr2 & 0.108 & 0.059 & -0.046 & 0.024 & 0.172 & 0.051 & -0.073 & 0.041 \\
\hline fyear_unempl & -0.400 & 0.112 & -0.087 & 0.036 & -0.314 & 0.084 & 0.100 & 0.067 \\
\hline overtime_mine & -0.166 & 0.093 & 0.021 & 0.027 & -0.029 & 0.063 & 0.006 & 0.046 \\
\hline overtime_const & -0.124 & 0.087 & -0.012 & 0.026 & -0.027 & 0.060 & 0.059 & 0.045 \\
\hline overtime_trade & -0.254 & 0.096 & -0.028 & 0.028 & 0.069 & 0.065 & 0.019 & 0.047 \\
\hline overtime_trans & -0.526 & 0.101 & -0.156 & 0.030 & -0.188 & 0.069 & -0.001 & 0.051 \\
\hline overtime_hot & -0.136 & 0.127 & 0.027 & 0.040 & 0.009 & 0.090 & -0.064 & 0.066 \\
\hline overtime_fin & -0.416 & 0.105 & -0.040 & 0.034 & -0.185 & 0.076 & 0.077 & 0.054 \\
\hline overtime_pub & -0.191 & 0.126 & -0.092 & 0.033 & 0.122 & 0.082 & -0.104 & 0.055 \\
\hline overtime_edu & 0.311 & 0.270 & 0.062 & 0.080 & 0.020 & 0.193 & 0.151 & 0.124 \\
\hline overtime_he & -0.083 & 0.212 & 0.066 & 0.050 & -0.221 & 0.125 & 0.068 & 0.086 \\
\hline overtime_com & -0.357 & 0.181 & 0.000 & 0.050 & -0.174 & 0.118 & 0.043 & 0.084 \\
\hline overtime_hh & -0.462 & 0.292 & 0.118 & 0.061 & -0.219 & 0.162 & 0.012 & 0.106 \\
\hline overtime_oth & 0.097 & 0.231 & -0.014 & 0.059 & -0.128 & 0.142 & -0.163 & 0.106 \\
\hline ptime_mine & 0.373 & 0.147 & 0.198 & 0.056 & 0.044 & 0.125 & 0.012 & 0.099 \\
\hline ptime_const & 0.237 & 0.113 & 0.084 & 0.050 & 0.074 & 0.107 & -0.043 & 0.091 \\
\hline ptime_trade & 0.588 & 0.100 & 0.194 & 0.034 & 0.309 & 0.078 & 0.033 & 0.059 \\
\hline ptime_trans & 0.314 & 0.154 & 0.187 & 0.053 & 0.080 & 0.124 & 0.140 & 0.095 \\
\hline ptime_hot & 0.130 & 0.100 & 0.092 & 0.042 & 0.139 & 0.089 & -0.002 & 0.072 \\
\hline ptime_fin & -0.339 & 0.108 & -0.053 & 0.053 & -0.341 & 0.102 & -0.144 & 0.087 \\
\hline ptime_pub & 0.520 & 0.089 & 0.092 & 0.029 & 0.410 & 0.067 & 0.004 & 0.050 \\
\hline ptime_he & 0.978 & 0.112 & 0.237 & 0.032 & 0.464 & 0.076 & 0.064 & 0.054 \\
\hline ptime_com & 0.439 & 0.138 & 0.193 & 0.045 & 0.402 & 0.105 & -0.058 & 0.074 \\
\hline ptime_hh & 0.270 & 0.139 & 0.095 & 0.037 & 0.103 & 0.087 & 0.121 & 0.063 \\
\hline ptime_oth & -0.092 & 0.142 & 0.046 & 0.059 & 0.068 & 0.123 & -0.078 & 0.099 \\
\hline sick_days2 & 0.787 & 0.045 & -0.022 & 0.013 & 0.275 & 0.030 & -0.002 & 0.019 \\
\hline sick_days3 & 0.900 & 0.039 & -0.017 & 0.008 & 0.154 & 0.020 & 0.029 & 0.014 \\
\hline sick_days4 & 1.116 & 0.068 & 0.140 & 0.011 & 0.070 & 0.027 & 0.014 & 0.019 \\
\hline sick_days5 & 1.220 & 0.092 & 0.250 & 0.013 & 0.034 & 0.033 & 0.053 & 0.023 \\
\hline sick_days6 & 1.484 & 0.096 & 0.404 & 0.012 & 0.073 & 0.031 & -0.003 & 0.022 \\
\hline sick_days7 & 1.611 & 0.126 & 0.584 & 0.013 & -0.010 & 0.036 & -0.028 & 0.025 \\
\hline sick_days8 & 1.593 & 0.187 & 0.748 & 0.017 & 0.024 & 0.049 & -0.058 & 0.034 \\
\hline sick_days9 & 1.539 & 0.207 & 0.786 & 0.020 & 0.034 & 0.058 & -0.061 & 0.039 \\
\hline sick_days10 & 1.303 & 0.173 & 0.972 & 0.018 & -0.012 & 0.052 & -0.070 & 0.036 \\
\hline episode_nr2 & -0.074 & 0.050 & 0.097 & 0.008 & 0.009 & 0.022 & 0.029 & 0.015 \\
\hline episode_nr3 & -0.180 & 0.073 & 0.156 & 0.011 & -0.029 & 0.028 & 0.070 & 0.019 \\
\hline episode_nr4 & -0.247 & 0.106 & 0.160 & 0.013 & 0.008 & 0.036 & 0.063 & 0.024 \\
\hline episode_nr5 & -0.281 & 0.145 & 0.188 & 0.016 & -0.022 & 0.045 & 0.030 & 0.030 \\
\hline episode_nr6 & -0.480 & 0.126 & 0.225 & 0.015 & -0.131 & 0.041 & 0.091 & 0.028 \\
\hline surgery & 1.830 & 0.153 & 0.222 & 0.011 & 0.296 & 0.033 & 0.062 & 0.021 \\
\hline cancer & 1.191 & 0.516 & 0.131 & 0.041 & 0.227 & 0.125 & 0.065 & 0.078 \\
\hline
\end{tabular}




\begin{tabular}{|c|c|c|c|c|c|c|c|c|}
\hline & \multicolumn{4}{|c|}{ Consultations } & \multicolumn{4}{|c|}{ Dentist visits } \\
\hline & Estimate & S.E. & Estimate & S.E. & Estimate & S.E. & Estimate & S.E. \\
\hline injury & 1.396 & 0.069 & 0.132 & 0.009 & 0.012 & 0.023 & -0.003 & 0.017 \\
\hline neuro & 1.468 & 0.123 & 0.145 & 0.011 & 0.023 & 0.030 & 0.000 & 0.021 \\
\hline infectious & 1.445 & 0.047 & 0.097 & 0.007 & 0.045 & 0.018 & -0.039 & 0.012 \\
\hline digestion & 1.283 & 0.119 & 0.162 & 0.012 & -0.003 & 0.033 & -0.017 & 0.023 \\
\hline skin & 1.761 & 0.277 & 0.204 & 0.024 & 0.064 & 0.066 & -0.057 & 0.046 \\
\hline musculoskel & 1.575 & 0.115 & 0.108 & 0.011 & -0.015 & 0.029 & -0.014 & 0.021 \\
\hline degenerative & 1.852 & 0.116 & 0.146 & 0.010 & 0.037 & 0.026 & -0.012 & 0.019 \\
\hline genito_urinary & 0.884 & 0.168 & 0.124 & 0.019 & 0.072 & 0.053 & -0.117 & 0.036 \\
\hline dental & 0.378 & 0.076 & 0.093 & 0.012 & 0.743 & 0.034 & 0.519 & 0.019 \\
\hline vision & 1.774 & 0.211 & 0.303 & 0.020 & 0.087 & 0.057 & -0.050 & 0.040 \\
\hline circulatory & 1.149 & 0.205 & 0.151 & 0.018 & 0.081 & 0.052 & 0.054 & 0.036 \\
\hline respiratory & 1.927 & 0.365 & 0.064 & 0.028 & -0.188 & 0.078 & 0.094 & 0.058 \\
\hline mental & 1.022 & 0.130 & 0.011 & 0.013 & -0.069 & 0.036 & 0.052 & 0.026 \\
\hline nutritional & 1.332 & 0.463 & 0.233 & 0.042 & -0.164 & 0.119 & 0.116 & 0.086 \\
\hline pregnancy_compl & 0.663 & 0.247 & -0.031 & 0.023 & 0.362 & 0.068 & -0.071 & 0.041 \\
\hline other_cond & 1.088 & 0.068 & 0.105 & 0.008 & 0.056 & 0.022 & -0.003 & 0.015 \\
\hline gender & 1.068 & 0.042 & 0.304 & 0.011 & 0.520 & 0.027 & -0.026 & 0.018 \\
\hline age & -0.051 & 0.020 & -0.002 & 0.006 & -0.004 & 0.014 & -0.002 & 0.010 \\
\hline age_sq & 0.001 & 0.000 & 0.000 & 0.000 & 0.000 & 0.000 & 0.000 & 0.000 \\
\hline age_gr1 & -0.234 & 0.102 & -0.153 & 0.032 & -0.074 & 0.074 & 0.137 & 0.053 \\
\hline age_gr2 & -0.070 & 0.065 & -0.100 & 0.021 & -0.093 & 0.047 & 0.110 & 0.034 \\
\hline age_gr3 & -0.005 & 0.041 & -0.028 & 0.013 & -0.040 & 0.030 & 0.041 & 0.022 \\
\hline age_gr5 & -0.001 & 0.040 & 0.020 & 0.013 & -0.019 & 0.029 & -0.017 & 0.020 \\
\hline age_gr6 & 0.094 & 0.065 & 0.030 & 0.018 & -0.097 & 0.045 & -0.041 & 0.030 \\
\hline age_gr7 & 0.205 & 0.104 & 0.053 & 0.028 & -0.197 & 0.070 & -0.023 & 0.047 \\
\hline female_agr1 & 0.013 & 0.066 & 0.153 & 0.019 & 0.031 & 0.044 & 0.001 & 0.031 \\
\hline female_agr2 & 0.067 & 0.058 & 0.153 & 0.016 & 0.057 & 0.038 & -0.058 & 0.026 \\
\hline female_agr3 & 0.076 & 0.058 & 0.076 & 0.015 & 0.001 & 0.037 & -0.007 & 0.025 \\
\hline female_agr5 & -0.060 & 0.057 & -0.053 & 0.015 & -0.031 & 0.036 & -0.028 & 0.024 \\
\hline female_agr6 & -0.162 & 0.061 & -0.058 & 0.015 & -0.084 & 0.038 & 0.025 & 0.025 \\
\hline female_agr7 & -0.235 & 0.066 & -0.082 & 0.016 & -0.101 & 0.040 & 0.002 & 0.026 \\
\hline maternity & 0.205 & 0.121 & -0.347 & 0.019 & 0.249 & 0.051 & -0.168 & 0.033 \\
\hline disability & 1.316 & 0.451 & 0.325 & 0.077 & 0.300 & 0.216 & -0.243 & 0.146 \\
\hline care & 0.189 & 0.161 & 0.227 & 0.037 & 0.041 & 0.097 & 0.051 & 0.062 \\
\hline hhsize & 0.181 & 0.008 & -0.008 & 0.002 & 0.088 & 0.005 & -0.011 & 0.004 \\
\hline ln_eqdinc & 0.324 & 0.023 & 0.037 & 0.008 & 0.328 & 0.018 & -0.061 & 0.013 \\
\hline n_dincome & 2.788 & 0.278 & 0.510 & 0.118 & 2.802 & 0.254 & -0.156 & 0.200 \\
\hline poor & -0.327 & 0.035 & -0.062 & 0.010 & -0.138 & 0.025 & 0.001 & 0.019 \\
\hline single_hh & 0.181 & 0.043 & -0.003 & 0.010 & 0.159 & 0.026 & 0.008 & 0.017 \\
\hline newborn_hh & -0.057 & 0.046 & 0.004 & 0.013 & -0.037 & 0.031 & -0.027 & 0.021 \\
\hline single & -0.163 & 0.025 & -0.014 & 0.008 & -0.066 & 0.018 & 0.023 & 0.013 \\
\hline sep_widow & 0.011 & 0.033 & -0.006 & 0.009 & -0.091 & 0.022 & 0.070 & 0.015 \\
\hline popdoc & 0.000 & 0.000 & 0.000 & 0.000 & 0.000 & 0.000 & 0.000 & 0.000 \\
\hline nodoc & -0.004 & 0.039 & -0.043 & 0.011 & -0.026 & 0.027 & -0.009 & 0.018 \\
\hline popdent & 0.000 & 0.000 & 0.000 & 0.000 & 0.000 & 0.000 & 0.000 & 0.000 \\
\hline nodent & -0.004 & 0.041 & 0.029 & 0.011 & 0.062 & 0.028 & 0.075 & 0.019 \\
\hline
\end{tabular}




\begin{tabular}{|l|c|c|c|c|c|c|r|c|}
\hline & \multicolumn{4}{|c|}{ Consultations } & \multicolumn{4}{c|}{ Dentist visits } \\
\cline { 2 - 10 } & Estimate & S.E. & Estimate & S.E. & Estimate & S.E. & Estimate & S.E. \\
\hline Lux_country & 0.051 & 0.056 & -0.006 & 0.016 & $\mathbf{0 . 1 0 0}$ & 0.040 & -0.021 & 0.027 \\
\hline Capellen & $\mathbf{0 . 1 4 0}$ & 0.063 & -0.020 & 0.018 & 0.008 & 0.044 & -0.001 & 0.030 \\
\hline Esch_Alzette & $\mathbf{0 . 1 0 5}$ & 0.054 & -0.008 & 0.016 & 0.028 & 0.038 & -0.019 & 0.026 \\
\hline Mersch & 0.119 & 0.067 & 0.016 & 0.019 & $\mathbf{0 . 0 9 9}$ & 0.046 & -0.004 & 0.031 \\
\hline Clervaux & 0.126 & 0.080 & -0.020 & 0.023 & -0.031 & 0.055 & $\mathbf{- 0 . 1 6 5}$ & 0.038 \\
\hline Diekirch & 0.090 & 0.069 & 0.020 & 0.020 & 0.009 & 0.048 & -0.059 & 0.032 \\
\hline Redange & 0.141 & 0.077 & 0.014 & 0.022 & -0.057 & 0.053 & -0.007 & 0.036 \\
\hline Vianden & -0.038 & 0.105 & -0.012 & 0.030 & -0.050 & 0.073 & -0.086 & 0.050 \\
\hline Wiltz & -0.064 & 0.083 & $\mathbf{- 0 . 1 1 0}$ & 0.024 & 0.027 & 0.058 & $\mathbf{- 0 . 1 9 9}$ & 0.040 \\
\hline Echternach & 0.043 & 0.084 & $\mathbf{- 0 . 0 6 1}$ & 0.024 & -0.063 & 0.058 & $\mathbf{- 0 . 1 0 1}$ & 0.039 \\
\hline Grevenmacher & $\mathbf{0 . 1 4 5}$ & 0.069 & -0.005 & 0.020 & $\mathbf{0 . 1 5 4}$ & 0.048 & $\mathbf{- 0 . 0 7 1}$ & 0.032 \\
\hline Remich & -0.046 & 0.071 & $\mathbf{- 0 . 0 6 2}$ & 0.020 & -0.054 & 0.049 & -0.030 & 0.034 \\
\hline density & 0.000 & 0.000 & 0.000 & 0.000 & $\mathbf{0 . 0 0 0}$ & 0.000 & $\mathbf{0 . 0 0 0}$ & 0.000 \\
\hline high_foreign & -0.023 & 0.044 & 0.007 & 0.013 & -0.003 & 0.031 & 0.036 & 0.021 \\
\hline low_foreign & 0.072 & 0.057 & $\mathbf{0 . 0 3 2}$ & 0.016 & 0.012 & 0.039 & 0.032 & 0.026 \\
\hline cons & $\mathbf{- 2 . 5 4 7}$ & 0.504 & $\mathbf{0 . 9 4 6}$ & 0.154 & $\mathbf{- 4 . 1 4 5}$ & 0.361 & $\mathbf{2 . 5 4 8}$ & 0.258 \\
\hline
\end{tabular}


Appendix 3. Hurdle model with nationality variables excluded

\begin{tabular}{|c|c|c|c|c|c|c|c|c|}
\hline \multirow{4}{*}{$\begin{array}{l}\text { Coefficients in } \\
\text { bold font are } \\
\text { significant at } \\
p=<0.05\end{array}$} & \multicolumn{4}{|c|}{ Consultations } & \multicolumn{4}{|c|}{ Dentist visits } \\
\hline & \multicolumn{2}{|c|}{ Part I } & \multicolumn{2}{|c|}{ Part II } & \multicolumn{2}{|c|}{ Part I } & \multicolumn{2}{|c|}{ Part II } \\
\hline & \multicolumn{2}{|c|}{ Estimate } & \multicolumn{2}{|c|}{ S.E. } & \multicolumn{2}{|c|}{ Estimate } & \multicolumn{2}{|c|}{ S.E. } \\
\hline & \multicolumn{2}{|c|}{$\log L=-57141.068$} & \multicolumn{2}{|c|}{$\log L=-350630.99$} & \multicolumn{2}{|c|}{$\log L=-107033.28$} & \multicolumn{2}{|c|}{$\log L=-264695.67$} \\
\hline fullyear & 0.703 & 0.039 & 0.102 & 0.014 & 0.633 & 0.032 & -0.100 & 0.025 \\
\hline unempl & 0.654 & 0.101 & 0.179 & 0.033 & 0.287 & 0.077 & -0.060 & 0.062 \\
\hline over_time & 0.209 & 0.069 & -0.021 & 0.021 & 0.074 & 0.048 & 0.017 & 0.035 \\
\hline part_time & -0.309 & 0.061 & -0.064 & 0.024 & -0.153 & 0.052 & -0.069 & 0.042 \\
\hline bluecollar & -0.475 & 0.170 & -0.393 & 0.040 & -0.116 & 0.100 & -0.162 & 0.070 \\
\hline civil & -0.819 & 0.193 & -0.314 & 0.043 & -0.039 & 0.117 & 0.173 & 0.076 \\
\hline othercategory & -0.751 & 0.128 & -0.445 & 0.029 & -0.381 & 0.073 & -0.169 & 0.048 \\
\hline quintile1 & 0.366 & 0.039 & 0.097 & 0.010 & 0.019 & 0.024 & 0.060 & 0.017 \\
\hline quintile2 & 0.055 & 0.026 & 0.019 & 0.007 & -0.069 & 0.017 & 0.051 & 0.012 \\
\hline quintile4 & 0.049 & 0.025 & -0.007 & 0.007 & 0.056 & 0.017 & -0.018 & 0.012 \\
\hline quintile5 & -0.205 & 0.030 & -0.077 & 0.009 & 0.048 & 0.021 & -0.062 & 0.014 \\
\hline bonus & 0.015 & 0.021 & -0.070 & 0.006 & 0.031 & 0.015 & 0.000 & 0.011 \\
\hline h_bonus & -0.288 & 0.080 & 0.052 & 0.034 & -0.446 & 0.069 & 0.068 & 0.050 \\
\hline m_bonus & -0.132 & 0.064 & 0.012 & 0.024 & -0.147 & 0.052 & 0.031 & 0.035 \\
\hline ln_eqdinc & 0.331 & 0.022 & 0.037 & 0.008 & 0.345 & 0.018 & -0.069 & 0.013 \\
\hline poor & -0.346 & 0.035 & -0.062 & 0.010 & -0.164 & 0.024 & 0.000 & 0.019 \\
\hline n_mine_man_ut & 0.124 & 0.041 & 0.001 & 0.013 & 0.244 & 0.029 & 0.001 & 0.021 \\
\hline n_construction & -0.054 & 0.041 & -0.025 & 0.013 & 0.005 & 0.029 & -0.002 & 0.022 \\
\hline n_trade & 0.142 & 0.036 & -0.003 & 0.011 & 0.192 & 0.025 & -0.042 & 0.018 \\
\hline n_hotels_rest & 0.044 & 0.048 & -0.066 & 0.015 & 0.158 & 0.034 & 0.100 & 0.025 \\
\hline n_transport & 0.352 & 0.046 & 0.126 & 0.014 & 0.257 & 0.032 & -0.043 & 0.022 \\
\hline n_financial & 0.213 & 0.035 & 0.107 & 0.011 & 0.217 & 0.025 & -0.033 & 0.018 \\
\hline n_public & 0.716 & 0.040 & 0.272 & 0.012 & 0.360 & 0.028 & -0.010 & 0.019 \\
\hline n_education & 0.065 & 0.086 & 0.071 & 0.029 & 0.214 & 0.066 & -0.128 & 0.045 \\
\hline n_health & 0.078 & 0.042 & 0.009 & 0.011 & 0.327 & 0.027 & -0.063 & 0.018 \\
\hline n_community & 0.342 & 0.057 & 0.026 & 0.016 & 0.368 & 0.039 & -0.064 & 0.026 \\
\hline n_household & 0.422 & 0.111 & -0.018 & 0.026 & 0.484 & 0.064 & -0.090 & 0.043 \\
\hline n_other & 0.152 & 0.073 & 0.028 & 0.022 & 0.237 & 0.051 & 0.023 & 0.037 \\
\hline onep_firm & -0.162 & 0.055 & -0.014 & 0.018 & -0.113 & 0.041 & -0.056 & 0.030 \\
\hline micro_firm & -0.042 & 0.034 & -0.026 & 0.010 & 0.011 & 0.024 & 0.020 & 0.016 \\
\hline small_firm & -0.050 & 0.028 & -0.031 & 0.008 & 0.006 & 0.019 & -0.021 & 0.013 \\
\hline med_firm & -0.045 & 0.027 & -0.017 & 0.008 & -0.056 & 0.018 & -0.046 & 0.012 \\
\hline large_firm & -0.038 & 0.034 & -0.009 & 0.010 & -0.101 & 0.024 & -0.008 & 0.016 \\
\hline CMEP & -0.479 & 0.169 & -0.403 & 0.039 & 0.111 & 0.100 & -0.298 & 0.069 \\
\hline CMFEP & 0.832 & 0.210 & 0.081 & 0.049 & 0.443 & 0.128 & -0.482 & 0.087 \\
\hline CMPI & 0.050 & 0.206 & -0.174 & 0.056 & 0.390 & 0.139 & -0.272 & 0.094 \\
\hline CMOA & 0.098 & 0.101 & -0.086 & 0.028 & -0.085 & 0.065 & -0.026 & 0.048 \\
\hline EMCFL & 1.368 & 0.219 & 0.301 & 0.052 & 0.461 & 0.136 & -0.387 & 0.091 \\
\hline CMFEC & 1.092 & 0.215 & 0.177 & 0.050 & 0.550 & 0.132 & -0.449 & 0.089 \\
\hline CMAGR & 0.203 & 0.262 & -0.146 & 0.077 & 0.705 & 0.194 & -0.076 & 0.119 \\
\hline CMEA & -0.437 & 0.185 & -0.381 & 0.047 & 0.300 & 0.115 & -0.328 & 0.079 \\
\hline deprived & 0.037 & 0.024 & 0.010 & 0.006 & -0.053 & 0.016 & 0.039 & 0.011 \\
\hline
\end{tabular}




\begin{tabular}{|c|c|c|c|c|c|c|c|}
\hline \multirow{4}{*}{$\begin{array}{lr}\text { Coefficients } & \text { in } \\
\text { bold font are } \\
\text { significant at } \\
p=<0.05\end{array}$} & \multicolumn{3}{|c|}{ Consultations } & \multicolumn{4}{|c|}{ Dentist visits } \\
\hline & Part I & \multicolumn{2}{|c|}{ Part II } & \multicolumn{2}{|c|}{ Part I } & \multicolumn{2}{|c|}{ Part II } \\
\hline & Estimate & \multicolumn{2}{|c|}{ S.E. } & \multicolumn{2}{|c|}{ Estimate } & \multicolumn{2}{|c|}{ S.E. } \\
\hline & $\log L=-57141.068$ & \multicolumn{2}{|c|}{$\log L=-350630.99$} & \multicolumn{2}{|c|}{$\log L=-107033.28$} & \multicolumn{2}{|c|}{$\log L=-264695.67$} \\
\hline high_unempl & 0.001 & 0.019 & 0.010 & -0.070 & 0.025 & 0.013 & 0.017 \\
\hline
\end{tabular}




\subsection{References}

Bago d'Uva, T. (2006). Latent Class Models for Utilisation of Health Care. Health Economics, 15(4), 329-343.

Bago d'Uva, T., Jones, A. M. \& van Doorslaer, E. (2009). Measurement of Horizontal Inequity in Health Care Utilisation Using European Panel Data. Journal of Health Economics, 28(2), 280-289.

De Broeck, V. (2008). More Women in Labour Market but Segregation Continues

(Publication no. LU0807029I). Retrieved 01.12.2011, from

EUROFOUND/PREVENT:

http://www.eurofound.europa.eu/ewco/2008/07/LU0807029I.htm

Deb, P. \& Trivedi, P. K. (2002). The Structure of Demand for Health Care: Latent

Class Versus Two-Part Models. Journal of Health Economics, 21(4), 601-625.

EC. (2006). State Aid: Commission Guidelines on National Regional Aid for 2007-2013,

Luxembourg and Malta - Frequently Asked Questions. (No. MEMO/06/376).

EPUNET. (2003, 2003). European Community Household Panel Study. Retrieved 10.02., 2010, from http://epunet.essex.ac.uk/index.php

Goerens, R. (2006). Occupational Health: Old Workers in Luxembourg (Power point presentation): Ministry of Health

Goyder, E. C., Blank, L., Ellis, E., Furber, A., Peters, J., Sartain, K., et al. (2005). Reducing Inequalities in Access to Health Care: Developing a Toolkit Through Action Research. Quality and Safety in Health Care 14(5), 336-339.

Greene, W. (2008). Functional Forms for the Negative Binomial Model for Count Data. Economics Letters, 99(3), 585-590.

Gurmu, S. (1998). Generalized Hurdle Count Data Regression Models. Economics Letters, 58(3), 263-268.

Hidayat, B. \& Pokhrel, S. (2010). The Selection of an Appropriate Count Data Model for Modelling Health Insurance and Health Care Demand: Case of Indonesia. International Journal of Environmental Research and Public Health(7), 9-27.

Hurst, J., Siciliani, L. \& OECD Secretariat. (2004). Tackling Excessive Waiting Times for Elective Surgery. In OECD Health Project (Ed.), Towards HighPerforming Health Systems: Policy Studies (pp. 207-263): OECD.

Jiménez-Martín, S., Labeaga, J. M. \& Martínez-Granado, M. (2004). An Empirical Analysis of the Demand for Physician Services across the European Union. The European Journal of Health Economics, 5(2), 150-165.

Jochmann, M. \& Leon-Gonzalez, R. (2004). Estimating the Demand for Health Care with Panel Data: a Semi-parametric Bayesian Approach. Health economics, 13(10), 1003-1014. 
Jones, A. M., Rice, N., Bago d'Uva, T. \& Balia, S. (2007). Applied Health Economics. New York: Routledge.

Kerr, E. (1999). Health Care Systems in Transition: Luxembourg. European Observatory on Health Care Systems.

Kirby, J. B. \& Kaneda, T. (2005). Neighborhood Socioeconomic Disadvantage and Access to Health Care. Journal of Health and Social Behavior, 46(1), 15-31.

Menendez, M., Benach, J., Muntaner, C., Amable, M. \& O'Campo, P. (2007). Is Precarious Employment More Damaging to Women's Health than Men's? Social Science \& Medicine, 64(4), 776-781.

Mossialos, E. \& Thomson, S. M. S. (2002). Voluntary Health Insurance in the European Union: a Critical Assessment. International Journal of Health Services, 32(1), 19-88.

Mullahy, J. (1986). Specification and Testing of Some Modified Count Data Models. Journal of Econometrics, 33(3), 341-365.

Muñoz de Bustillo, R. \& Antón, J. I. (2009). Health Care Utilization and Immigration in Spain. Munich Personal RePEc Archive.

Nguyen, L., Häkkinen, U. \& Rosenqvist, G. (2005). Determinants of Dental Service Utilization Among Adults - The Case of Finland. Health Care Management Science, 8(4), 335-345.

OECD. (2009). Health at a Glance 2009.

Pohlmeier, W. \& Ulrich, V. (1995). An Econometric Model of the Two-Part Decisionmaking Process in the Demand for Health Care. The Journal of Human Resources, 30(2), 339-361.

Schorr, A. L. (1990). Job Turnover - A Problem with Employer-Based Health Care. New England Journal of Medicine, 323(8), 543-545.

Schulz, E. (2004). Use Of Health And Nursing Care By The Elderly. ENEPRI Research Report No. 2, Berlin: DIW \& ENERPI.

Solé-Auró, A., Guillén, M. \& Crimmins, E. M. (2009). Health Care Utilization Among Immigrants and Native-born Populations in 11 European countries. Results from the Survey of Health, Ageing and Retirement in Europe.

STATEC. (2003). Economic and Social Portrait of Luxembourg. Retrieved 09022010 from http://www.portrait.public.lu/en/index.html

STATEC. (2004). Médecins et Pharmacies par Canton et Commune 1997 - 2004 (Publication. Retrieved 02.02.2010, from STATEC: http://www.statistiques.public.lu

STATEC. (2010). Population et Emploi (Publication. Retrieved 10022010 from STATEC: http://www.statistiques.public.lu/stat/ UN. (2006). Grand Duchy of Luxembourg: Public Administration Country Profile. 
van Doorslaer, E., Koolman, X. \& Jones, A. M. (2004). Explaining Income-related Inequalities in Doctor Utilisation in Europe. Health Economics, 13(7), 629647.

van Doorslaer, E., Koolman, X. \& Puffer, F. (2002). Equity in the Use of Physician Visits in OECD Countries: Has Equal Treatment for Equal Need Been Achieved? In OECD (Ed.), Measuring Up: Improving Health Systems Performance in OECD Countries (pp. 225-248).

van Doorslaer, E., Masseria, C. \& OECD Health Equity Research Group. (2004). Income-Related Inequality in the Use of Medical Care in 21 OECD Countries. In OECD Health Project (Ed.), Towards High-Performing Health Systems: Policy Studies (pp. 109-165): OECD.

van Ourti, T. (2004). Measuring Horizontal Inequity in Belgian Health Care Using a Gaussian Random Effects Two Part Count Data Model. Health Economics, 13(7), 705-724.

Whitehead, M., Evandrou, M., Haglund, B. \& Diderichsen, F. (1997). As the Health Divide Widens in Sweden and Britain, What's Happening to Access to Care? BMJ, 315(7114), 1006-1009.

WHO. (2006). The World Health Report 2006: Working Together for Health.

Wlodarski, O. (2006). Survey Reveals 'Moderate' Levels of Occupational Stress (Publication no. LU0607019I). Retrieved 01.12.2011, from EUROFOUND/PREVENT:

http://www.eurofound.europa.eu/ewco/2006/07/LU0607019I.htm

Wlodarski, O. (2010). Luxembourg : Flexible Forms of Work: 'Very Atypical' Contractual Arrangements (Publication no. LU0812019Q). Retrieved 12.01.2011, from EUROFOUND/PREVENT: http://www.eurofound.europa.eu/ewco/

Yuen, P. \& Balarajan, R. (1989). Unemployment and Patterns of Consultation with the General Practitioner. BMJ, 298(6682), 1212-1214. 



\section{Chapter 4: Tax-Benefit Microsimulation in European Transition Countries: A Review of Issues and Applications}

edition). 



\subsection{Introduction}

In the light of growing budgetary pressures, the motivation and effectiveness of public policies are increasingly subjected to rigorous scientific examination. At the same time more diverse data analysis techniques can be applied as the quality of data and computing abilities improves. Given ever more complex and multiobjective social protection systems, there is a rising demand both among academia and policy makers for comprehensive analysis tools that are able to highlight the costs and the diverse impacts of a given policy while simultaneously accounting for complex interactions with other transfers and taxes.

Microsimulation modelling (a.k.a. micro-analytic simulation) is a distributional analysis technique capable of tackling precisely this list of issues. With this method simulation is performed on a system of micro-units (i.e. persons, households, etc.). It enables the evaluation of diverse real or hypothetical events (i.e. tax-benefit system changes) in terms of their macro and micro impacts (e.g. Harding, Keegan, \& Kelly, 2010; Immervoll \& O'Donoghue, 2009).

In the social sciences microsimulation can be traced back to the 1950s (see Orcutt, 1957) as an attempt to move computational algorithms closer to an individual decision unit (Lewis \& Michel, 1990). However, the approach only started to develop more actively during the last two decades when both micro-databases and the computing power - two necessary prerequisites - have improved significantly (Bourguignon \& Spadaro, 2006). Lately microsimulation has been "experiencing a boom" (Spielauer, 2011). It is arguably driven by a couple of factors: an increased demand by policy makers and the emergence of new research areas focusing on complex individual contexts and technological advances. The perceived "boom" in microsimulation applications, however, mainly applies to (static) microsimulation models in the OECD countries. The technique is scarcely employed beyond the developed world (e.g. Davies, 2009; Lelkes, 2007).

This chapter focuses on the European transition countries. The region is particularly interesting because of its relatively high socio-economic and technological development, the considerable number of reforms of the economic and political systems and the generally insufficient analysis of the distributional impacts of all these changes. The main goal of this chapter is to document the existing microsimulation tools in the European transition countries and to discuss the structural reasons behind their limited use. As some of these reasons are necessarily specific to countries we use Lithuania as an illustrative case study. 
The chapter is organized as follows. Section 4.2 presents a quick review of the microsimulation modelling technique. The section 4.3 explores microsimulation applications in the European transition countries and discusses obstacles to MSM development. Finally, the last section presents the Lithuanian case in detail - the country with the highest MSM incidence. We review methodological specificities of the Lithuanian MSMs, discuss country specific development patterns and present a more detailed overview of EUROMOD LT - the most comprehensive Lithuanian tax-benefit model so far.

\subsection{Microsimulation modelling for public policy analysis}

In the public policy sphere microsimulation is mainly used for estimating ex-ante policy impacts. It provides valuable information to help policy makers make choices among the multi-objective public policy layers and thus significantly reduces the cost of designing more efficient and effective policies. The technique can also be used for ex-post analysis - a very convenient feature if actual data on causal relations of pre- and post-event conditions are not available. In the next sections we review the main technical features of microsimulation modelling.

\section{What is microsimulation?}

Microsimulation analysis is based on a sample or the entire population of individual units such as persons, households, vehicles or firms. Its purpose is to simulate micro-level effects of a certain event. Here, each outcome $y_{i}$ is obtained by transforming each (or a combination of) $x_{i}$ in line with given policy rules $p$ and/or behavioural parameters. Mathematically, this could be expressed as

$$
y_{i}=f\left(x_{i}, p, b\right) \text {, where: }
$$

- $y_{i}$ is a vector of simulated individual unit characteristics, and is the outcome of microsimulation modelling;

- $\quad x_{i}$ is a vector(s) of observed (baseline) individual unit characteristics;

- $\quad p$ is a vector of (actual or hypothetical) policy parameters, and

- $\quad b$ is a vector of behavioural parameters.

The transformation of $x_{i}$ can have any functional form $f$ (i.e. linear or non-linear) suitable for the description of policy rules or behavioural responses. This feature is particularly useful in policy simulations where tax and benefit rules are highly detailed and depend on individual/household characteristics in various non-linear ways. This also helps capturing heterogeneity of the population in a more flexible way. 
A tax-benefit microsimulation model (MSM) is a system in which a programming script interlinks two major components: a baseline dataset of micro-units (persons or households) and a set of accounting rules on benefit and tax provisions for these units. Programming software is an indispensable part of constructing a microsimulation model. Existing models use different types of multi-purpose programming software such as $\mathrm{C}++$, SAS, Microsoft Access and Excel for establishing simulation routines, communicating to micro-databases or storing diverse simulation parameters such as policy rules or simulation orders. Spielauer (2011) also reports a growing interest in using generic microsimulation languages like Modgen. The latter one has been specifically developed and maintained by Statistics Canada to facilitate the construction of microsimulation models.

\section{Diversity}

By now diverse types of microsimulation models have been developed. However, researchers often indicate that the taxonomy of the MSMs is not so straightforward as each MSM is shaped by specific objectives of the developing institution and the backgrounds of its developers (e.g. Mitton, Sutherland, \& Weeks, 2000).

Based on surveys on existing MSM types and features (e.g. Bourguignon \& Spadaro, 2006; Citro \& Hanushek, 1991; Gupta \& Kapur, 2000; Harding, 1996; O'Donoghue, 2001) we distinguish between methodological and policy features of MSMs (see Table 4-1). From a methodological point of view MSMs are first categorised by the time dimension criterion: static and dynamic models. Then, additional methodological features such as behavioural responses can be incorporated. From a policy point of view MSMs can be classified according to the coverage of specific sets of policies and by geographical coverage. These four categories can be cumulative.

Static models are based on snapshots of the current population characteristics and are used for the first-order distributional analysis of policy impacts. These models are sometimes called accounting or arithmetic models as their main goal is to unravel the complexity and inter-links of numerous public policies rather than to address behavioural changes of the population. Dynamic models "age" the characteristics of observed individual units using survival probabilities to build up a (partially) synthetic longitudinal database and, hence, enable long-term or lifecourse policy analysis. 
Table 4-1. Main MSM classification criteria

\begin{tabular}{|c|c|c|c|}
\hline \multirow{2}{*}{$\begin{array}{l}\text { के } \\
0 \\
0 \\
0 \\
0 \\
0 \\
0 \\
\sum_{1}^{0}\end{array}$} & $\begin{array}{l}\text { Time dimension: } \\
\text { Static or dynamic }\end{array}$ & $\begin{array}{l}\text { Policy coverage: } \\
\text { Comprehensive tax-benefit } \\
\text { system or selected policies }\end{array}$ & \multirow{2}{*}{ 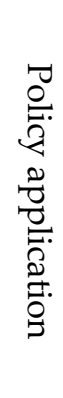 } \\
\hline & $\begin{array}{l}\text { Additional features/capacities: } \\
\text { Behavioural responses, spatial } \\
\text { features, linkage to macro } \\
\text { model, etc. }\end{array}$ & $\begin{array}{l}\text { Geographical coverage: } \\
\text { Regional, national, or cross- } \\
\text { country model }\end{array}$ & \\
\hline
\end{tabular}

Source: own presentation

Additional methodological features and capacities can diverge on the basis of the unit of analysis, the simulation of discrete or continuous time intervals, deterministic (i.e. a fixed response to the event) or stochastic (i.e. probabilistic response to the event) modelling, etc. Three major methodological capacities can be distinguished: inclusion of behavioural response relations such as changes in labour supply, savings or household composition; modelling spatial information; and combined micro- and macro modelling ${ }^{41}$.

For the purpose of evaluating policies usually a choice is made between comprehensive tax-benefit microsimulation models and models dedicated to the analysis of a specific policy. Decoster et al. (2008) for example, survey more than 30 diverse tax-benefit MSMs in Western Europe that cover both personal income taxes, social contributions and social benefits or focus specifically on the simulation of one sector only (i.e. pensions, taxes).

Regarding the geographical coverage, most of the developed MSMs represent national policy systems. Regional microsimulation analyses are much more widespread in the US than in Europe. According to Citro \& Hanushek (1991) half of the US states were using microsimulation modelling by the 1980s, whereas in Europe regional models were almost non-existent even in countries with federal political systems.

Cross-country microsimulation models are very rare, mainly because of the complexity (e.g. data comparability, varied policy systems) and resources needed to build a comparative simulation framework. The most noticeable cross-country

\footnotetext{
${ }^{41}$ Following Zaidi, Harding, \& Williamson (2009) linking micro- and macro modelling implies that "outputs from microsimulation models are inputs to macro-economic models and vice versa, in order to better capture the interplay between individual behaviours and the macro-economic environment within which they operate".
} 
MSM is EUROMOD - a static European tax-benefit model that currently expands its country coverage to all $27 \mathrm{EU}$ members ${ }^{42}$.

\section{Challenges}

We discuss some key challenges related to the accessibility of MSMs, their technical development and validation.

Microsimulation is quite often criticized as a "black-box" technique (Creedy, Duncan, Harris, \& Scutella, 2002; Spielauer, 2007). A few issues resonate behind the statement. First, access to MSMs is rarely (fully) feasible to external users often due to property rights but also due to data access issues, etc. This impedes a more detailed understanding of the MSM properties especially if external documentation on the MSM structure is limited or not available. Second, there is a large diversity of MSM construction approaches. This implies that substantial model specific knowledge is needed for its usage - a difficult barrier to overcome without the support of the developing institution. As such, comprehension of the final simulation outcomes or simulation capacities of different MSMs has usually been reserved to limited groups of specialists.

The shortage of proper MSM documentation relates to the other two MSM challenges, namely high costs and a lack of aesthetics, as labelled by Spielauer (2011). Building an MSM implies working with complexities such as integrating and parameterizing detailed policy rules into large-scale models as well as combining various data sources and types. The construction costs accrue due to various types of demands: people, hardware, software, data, etc. As a result, model setup, the development of its interface and the detailed and clear documentation of the MSM all contribute to making MSM's very costly (e.g. Anderson \& Hicks, 2011; Citro \& Hanushek, 1991; Spielauer, 2011). Moreover, the user-friendly presentation and aesthetics of many developed models is often sacrificed on grounds of efficiency (more discussion in e.g. Cassells, Harding, \& Kelly, 2006).

Though still an important "inhibitor", MSM development costs are expected to decrease with time as technological equipment becomes cheaper and economies of scale (in time spent for modelling) develop as more and more generic templates become available for MSM construction (see cases \& discussion in i.e. Spielauer, 2011; Wilkinson, 2011). On the other hand, MSM adaptation for specific research questions or national circumstances still requires a substantial time investment.

As is the case with many other complex modelling techniques MSM developers additionally face the challenge to produce trustworthy outcomes. Validation is

\footnotetext{
${ }^{42}$ For more details on EUROMOD see: http://www.iser.essex.ac.uk/research/euromod/
} 
crucial (e.g. Harding et al, 2010). In many cases the outputs of MSMs can diverge from reality because of data issues: underlying data quality, biases with survey weighting, use of imputed data, etc. Other issues such as the large number of interrelations, assumptions and conditions to account for, or even difficulties in acquiring external aggregates against which the MSM outputs could be compared to (i.e. Klevmarken, 2002) are of importance too. The latter point is particularly vital in dynamic simulations as in reality benchmark data often do not exist or are likewise based on projections.

\section{Development directions}

As a response to diverse challenges MSM development undergoes both "soft" and "hard" changes. With "soft" changes we refer to a widening public access to already developed MSM resources, programming languages and codes, training courses, etc. These overtures developed from both within and outside the MSM development community as a response to the "black box" critique, but also in order to increase MSM usability among researchers, policy makers and wider society.

"Hard" changes relate to at least three types of technical advancements. First, new MSMs are being developed. Some are static, such as new national tax-benefit models, others are methodologically different models (i.e. dynamic, spatial, etc.). This proliferation of new MSMs is the most widespread development. Second, existing MSMs are being enhanced as currently under-explored policies are being modelled (i.e. in-kind, contribution history related benefits or indirect taxes) and both technical capacities and the coherence of cross-national comparisons are being increased. Third, linkages between the existing MSMs (i.e. static and dynamic) or MSMs and other modelling resources (i.e. macro, computable general equilibrium, cell or agent based modelling) also increase.

\subsection{MSMs in European transition countries}

\section{What are European transition countries?}

The term transition usually refers to the transformation process of previously centrally planned economies into market economies. The transformation process covers a number of economic and political questions, such as political objectives, institutions, laws, tax and benefit systems (e.g. Newbery, 1997).

In this chapter we use the UN regional grouping of Eastern European countries (UN, 2009) to identify the European transition region (further on referred to as transition region). The region is then divided into $10 \mathrm{EU}$ and 13 non-EU members, 
reflecting the gap in the degree of macro-economic stabilization as well as structural and political transformation (e.g. Lavigne, 2000). Finally, we differentiate countries by the World Bank (WB) assigned country income scale ${ }^{43}$ (World Bank, 2009).

Table 4-2. Country grouping

\begin{tabular}{|c|c|c|}
\hline & 13 non-EU countries & 10 EU members \\
\hline \multicolumn{3}{|c|}{ 1. Developed transition countries } \\
\hline - high income & - & Slovenia \\
\hline $\begin{array}{l}\text { - upper middle } \\
\text { income }\end{array}$ & Croatia & $\begin{array}{l}\text { Czech Republic, Estonia, } \\
\text { Hungary, Latvia, Lithuania, } \\
\text { Poland, Slovakia }\end{array}$ \\
\hline \multicolumn{3}{|c|}{ 2. $\quad$ S.E.E. (South-Eastern Europe) } \\
\hline - lower middle & $\begin{array}{l}\text { Albania, Bosnia \& Herzegovina, } \\
\text { Serbia, Montenegro, F.Y.R. } \\
\text { Macedonia }\end{array}$ & Bulgaria, Romania \\
\hline \multicolumn{3}{|c|}{ 3. CIS (Commonwealth of Independent States) } \\
\hline - lower middle & Belarus, Russia & - \\
\hline - low & $\begin{array}{l}\text { Moldova, Ukraine, Armenia, } \\
\text { Azerbaijan, Georgia }\end{array}$ & - \\
\hline
\end{tabular}

Source: UN (2009), World Bank (2009).

As shown in Table 4-2 for the analysed sample of countries, average national income ranges from high to low income. Generally, the EU member countries have higher income levels compared to the non-EU countries - most of them are classified as upper middle income countries. Slovenia stands out as the only high income country among the entire transition group. Croatia has the highest income level among the non-EU transition countries whereas the rest within this group has lower-middle and low income levels.

\section{Identifying applications}

So far, no single registry of worldwide developed tax-benefit MSMs exists. Our own review of available resources in the transition region reveals the following.

First, we identified country specific MSMs reported in the following two chief information sources: the list of population-based microsimulation models reported to the International Microsimulation Organization (IMA) ${ }^{44}$ and a number of review

\footnotetext{
${ }^{43}$ This classification serves as a first hand description of the transition region rather than a comprehensive overview, which is outside the scope of this review.

${ }^{44}$ Www.microsimulation.org
} 
articles on MSMs (i.e. Ballas \& Clarke, 2000; Citro \& Hanushek, 1991; Decoster et al., 2008; Dekkers \& Belloni, 2009; Merz, 1991; Spielauer, 2007; Zaidi et al., 2009). Altogether, these sources describe 113 MSM applications that have been developed from the 1960s until recently and are often viewed as leading initiatives on methodological and policy analysis grounds. The obtained MSM references affirm the leading US position - 25 MSMs. Germany, the UK and Italy have at least ten applications. Many other countries, such as Australia, Belgium, Sweden or Canada have more than five MSMs. In contrast, these sources reveal only one MSM in the transition countries - the model developed by the Hungarian Statistical Office in the 1980s for the purpose of income tax and family allowance policies (i.e. Merz, 1991; Nelissen, 1993).

Because of such modest results we expanded our search scope by targeting information on microsimulation use in the European transition countries within larger electronic research databases. A systematic search of English language publications via Science Direct, SpringerLink and Sage Journals Online metadatabases yielded 850 publications for the keywords "microsimulation \& transition" and 730 publications for the keywords "microsimulation \& X country", where "X country" refers to each country of the transition region. We then further selected the relevant publications among the abstracts and/or the full contents, including reference lists. Publications with the word "transition" used in the context other than "transition" region (i.e. transition rules, probabilities, etc.) and publications with the word "Georgia" referring to the US state or replicate publications have been dropped. As a result, the final list of relevant publications radically reduced to 7 articles.

Finally, we also manually searched for relevant information using the World Wide Web (in English and Russian). We identified region-specific publications on MSM development, such as publications by Lelkes (2007), Davies (2009) and Lelkes \& Sutherland (2009). Additionally, we also scanned the activity reports of a number of international institutions that support and/or develop MSM models (i.e. USAID, UNU-WIDER ${ }^{45}$ ) . Other reviewed material consists of conference publications (e.g. O'Donoghue, 2005), references to project outcomes (i.e. CORDIS listed projects by National University of Ireland ${ }^{46}$ ), journal articles and studies (e.g. Cornelius, 1995) or institutional websites dedicated to specific models (e.g. Essex University; Centre for Economic Analysis, CenEA; etc.) and various combined information sources.

\footnotetext{
${ }^{45}$ The U.S. Agency for International Development (USAID); World Institute for Development Economics Research of the United Nations University (UNU-WIDER).

${ }^{46}$ CORDIS $=$ Community Research and Development Information Service.
} 
Our search efforts resulted in references to 36 MSMs in the 23 European transition countries. They include country specific models as well as national systems modelled within the EU-wide model EUROMOD (for 10 transition EU member states). The policy scopes stretch from entire tax-benefit systems to specific policies. For example, five models focus solely on modelling income taxation; three models are developed to simulate specific benefits; and three models cover both indirect and direct taxation systems. Generally, models are static except for three MSMs that include behavioural responses and one model that includes dynamic elements. Few MSMs have been constructed in the 1990s or before. The major wave started from 2000 onwards and this predominantly in the EU countries. Only seven recent resources are identified in the lower middle and low income countries. The remaining 29 MSMs are found in the developed European transition countries. Overall, the description of the models in the obtained references varies substantially from case to case. Some models have a detailed technical description available, while information on the other ones is scant and mainly refers to the developing institution/persons and the primary model use. A general scarcity of information also exists on the MSMs' wider use either in research or policy debates.

On the other hand, the obtained information provides a useful overview of the prevalence of MSMs in the transition region. Figure 4-1 presents the distribution of MSMs by country and country groups. The range of identified resources per country spans from 1 (in six countries) to 6 (in Lithuania). We found references to MSMs in 17 out of 23 European transition countries. A few patterns of MSM development emerge.

Figure 4-1. MSMs in transition countries

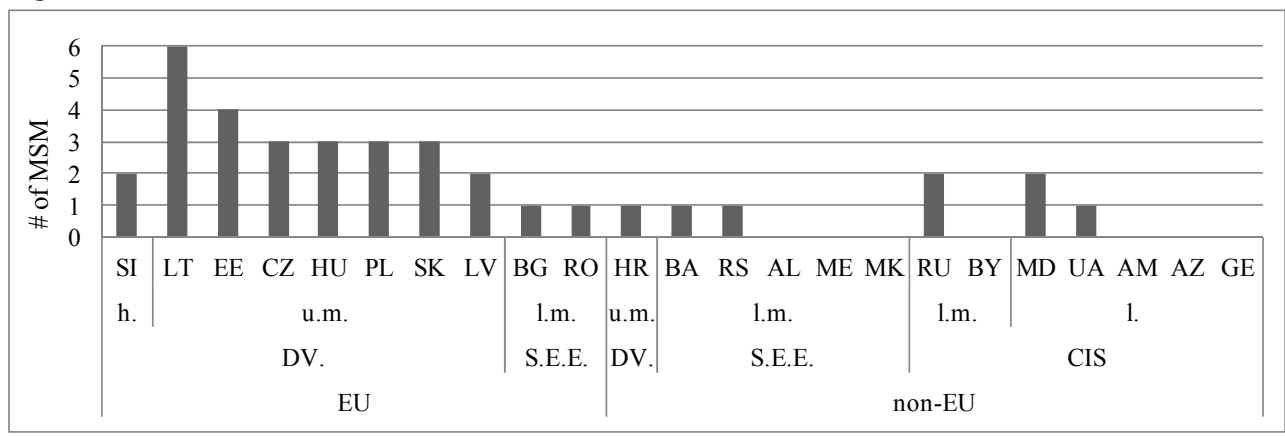

Note: h.= high; u.m. = upper middle; l.m. =lower middle; l. =low; DV. - developed transition countries.

Source: own survey

Higher income countries tend to have more MSM development. Income, though, is not the only determining factor. For example, we observe that all upper middle 
and high income EU countries have at least two MSM applications. But we also note two MSMs in Russia and Moldova - CIS countries in the lower middle and low income group. However, for Russia and Moldova this is a maximum MSM count per country, while for the higher income countries the count is a minimum count. Among the higher income countries, one would expect to find more MSMs in Slovenia. For the lower middle and low income group fewer countries have MSM development. In contrast, EU members and countries in the upper income group such as Croatia produced at least one MSM initiative.

Table 4-3. MSM developers

\begin{tabular}{|c|c|c|c|c|c|c|c|}
\hline & MSMs\# & EUROMOD[1] & XLMSM[2] & USAID[3] & Interntl.[4] & Nat. Res.[5] & Nat. Gov.[6] \\
\hline LT & 6 & $x$ & $x$ & $x$ & $X X X$ & & \\
\hline $\mathrm{EE}$ & 4 & $x$ & $X$ & & & $x$ & $x$ \\
\hline SK & 3 & $x$ & & & $X X$ & & \\
\hline PL & 3 & $x$ & $x$ & & & $x$ & \\
\hline $\mathrm{HU}$ & 3 & $x$ & & & & $X$ & $x$ \\
\hline $\mathrm{CZ}$ & 3 & $x$ & & & $\mathrm{X}$ & & $x$ \\
\hline RU & 2 & & & & $x$ & $x$ & \\
\hline SI & 2 & $x$ & & & & $\mathrm{X}$ & \\
\hline MD & 2 & & $x$ & $x$ & & & \\
\hline $\mathrm{LV}$ & 2 & $x$ & $x$ & & & & \\
\hline UA & 1 & & $\mathrm{X}$ & & & & \\
\hline RO & 1 & $x$ & & & & & \\
\hline BG & 1 & $x$ & & & & & \\
\hline RS & 1 & & & & & $x$ & \\
\hline BA & 1 & & & $X$ & & & \\
\hline HR & 1 & & & $x$ & & & \\
\hline
\end{tabular}

Notes: [1] - more details on the "EUROMODupdate" project website http://www.iser.essex.ac.uk/euromod/developing-euromod/euromodupdate); ${ }^{22]}$ - XLMSM (A Generic Microsimulation Tax-Benefit Model), more details in O'Donoghue (2005); [3] - Various publications prepared for or by the U.S. Agency for International Development (USAID); [4] - Interntl. (other international initiatives): RU - more details on the UNU-WIDER website www.wider.unu.edu; CZ in Coulter, Heady, Lawson, \& Smith (1997); SK (1) in Coulter et al. (1995) \& (2) in Trautman (1999); LT (1) via CORDIS \& personal communications with developer; (2) in Salanauskaite \& Verbist (2009); (3) in Cornelius (1995); [5] - Nat. Res. (national projects, initiated by non-governmental institutions): SI in Čok (2002), RU in Volchkova et al. (2006), HU in Benedek, Scharle, \& Szabó (2007); PL in Bargain, Morawski, Myck, \& Socha (2007); EE in Lelkes (2007); RS (SRMOD project) more details at http://www.fren.org.rs; ${ }^{[6]}$ - Nat. Gov. (national governmental institutions): CZ in Lelkes (2007); HU in Merz (1991); EE in Lelkes (2007).

Source: own survey

In Table 4-3 we report information on MSM resources by country and by project sponsor ${ }^{47}$. Overall, three cross-national initiatives represent the majority of

\footnotetext{
${ }^{47}$ Offspring initiatives, such as the Serbian model SRMOD that is developed using the EUROMOD technical platform but outside the EUROMOD project, are counted separately. Russia also expressed an interest in adapting the EUROMOD framework as its own national model (Sutherland, 2009). As no further information on model development is available yet, we did not include it in this overview.
} 
identified resources: the EUROMOD project (all 10 transition EU member states), the XLMSM project (6 countries) and various USAID projects (4 countries). Seven MSMs have been developed by researchers at international institutions such as the UNU-WIDER institution, the Harvard Institute for International Development, the Institute of Fiscal Studies, National Galway University, etc. Altogether international initiatives account for $75 \%$ of all identified resources.

National projects refer to activities by national researchers or research institutes as well as government institutions (or a cooperation of both as is the case in Hungary). Such national projects have been developed in Slovenia, Hungary, Poland, Estonia, the Czech Republic, Russia and Serbia. Serbia is the only country where the national initiative is not complemented by international projects, though a link with the EUROMOD platform exists. Estonia and Hungary have the highest count of nationally developed MSMs (two models). The four EU members (i.e. Lithuania, Latvia, Romania and Bulgaria) do not have national constructions yet. They also have among the lowest GDP levels within the EU.

\subsection{Issues behind MSM construction and use}

As noted by Murthi \& Tiongson (2008) it is often assumed that people of the transition region attach greater value to income equality owing to their socialist past. If so, one could expect an extensive use of microsimulation models in the region as they are one of the most comprehensive techniques to analyse distributional changes as a result of policy shifts. Our review has already shown that this is not particularly the case especially when we focus on the national initiatives. In this section we explore potential explanations and distinguish two major groups of (inter-related) issues: political factors on the one hand and the research environment on the other hand.

\section{Political factors}

A number of studies (e.g. Roberts \& Zolkiewski, 1996; Simai, 2006) suggest that the transformation of the post-Soviet systems has led to higher inequality and poverty, though the figures vary substantially from country to country. As portrayed by Figure 4-2 income inequality is particularly high in some CIS countries, whereas the Czech Republic, Hungary, Croatia and Slovenia are among the most equal countries worldwide. The GINI coefficients indicate that the region as a whole has experienced an overall rise in income inequality since the break-up of the Soviet Union. More recently, this trend has been (partially) reversed especially in the transition EU member states. 
Figure 4-2. GINI in transition countries, 1989-2006

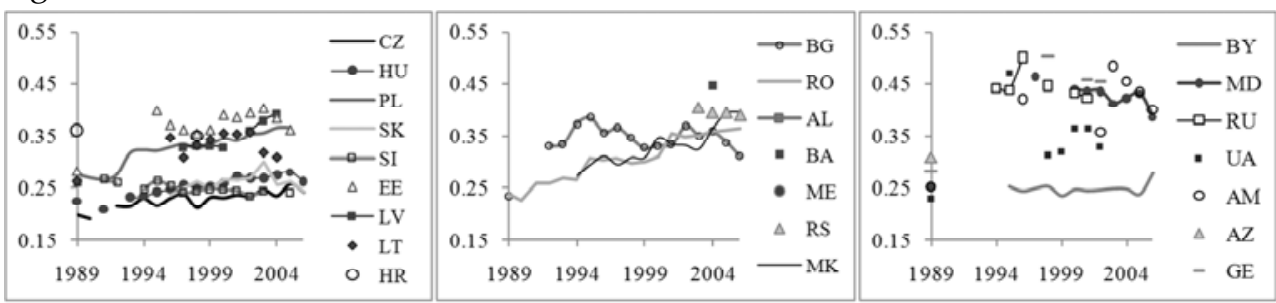

Note: point observations or breaks in trends are due to missing data

Source: the TransMONEE database, http://www.transmonee.org

Observed inequality levels are closely related to national preferences on equality or inequality which are then translated into political agendas. For example, Murthi \& Tiongson (2008) find that the former Soviet EU members prefer greater equality as compared to the CIS countries, with the Baltic states (i.e. Estonia, Latvia, Lithuania) have somewhat intermediary preferences ${ }^{48}$. Countries with the highest preferences for equality also possess the most and oldest MSM resources - particularly the national ones.

Microsimulation development is also affected by a country's political culture that can hinder or encourage research initiatives. For example, distributional analysis has been restricted in the Soviet Union due to fears of breaking the "equality myth" (Davies, 2009). This generally explains the late interest, knowledge and development of MSMs in the entire transition region, and particularly in the countries with the strongest historical Soviet grip.

The effect of political structures is not limited to the use of analytical tools but also extends to the ease of scientific exchange and knowledge transfers. With the collapse of the Soviet Union regular communication ways (e.g. language, networks) and knowledge channels closed or became irrelevant. On the other hand, the enlargement of the EU has offered new opportunities for some transition countries to facilitate access to the Western European pool of knowledge. This is for example reflected in the expansion of EUROMOD to all new EU member states, whereas the CIS and S.E.E. countries are somewhat lagging behind.

The transition process in itself entails major modelling difficulties and can be seen as another key MSM development related factor. Highly diverse, quickly changing and complex national policy agendas are more cumbersome to model. For example, Coulter et al. (1995) note that in 1989 microsimulation of indirect taxes in the Czech Republic was unfeasible as at that time there were 1506 turnover tax rates varying from $-291 \%$ to $+88 \%$. This made the system hard to grasp, document

\footnotetext{
${ }^{48}$ No information of the national preferences in the S.E.E countries is provided in this study.
} 
and model in a robust way and partially explains the prevailing construction of static MSM models. Roberts \& Zolkiewski (1996) and Davies (2009) also find that the transition countries' governments are often preoccupied with impact analyses of globalization and adjustment policies and hence pay less attention to micro-level policy questions (and associated analytical tools).

\section{Research environment}

Though early MSM development required "years of effort by large teams of researchers" (Spielauer, 2011), nowadays the direct cost of hardware and software needed for the development of MSMs is no longer a prohibitive factor, especially given the availability of open source/free software programs as well as significantly reduced computer costs. Some gaps in the use of information and communication technology (ICT) between the transition and developed countries as well as within the transition region still exist. For example, Spremić et al. (2009) observe that among the new EU member states Estonia is a frontrunner with a remarkable increase of personal computers (PC) reaching the Euro area level of 60 PCs per 100 people by 2008. On the other hand, in 2008 Bulgaria was found to have the lowest number of personal computers - around 10 PCs per 100 people.

Figure 4-3. Democracy and knowledge ranking in transition countries

2002-2003

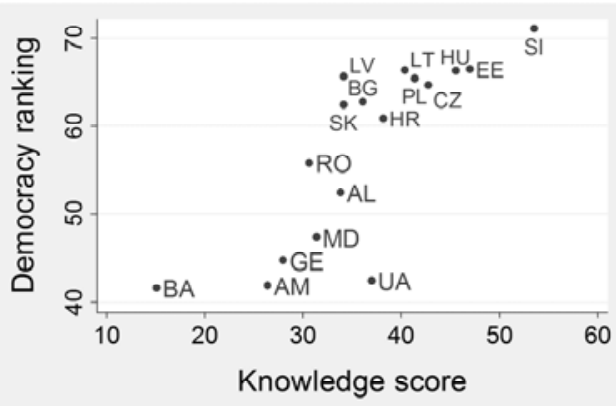

2005-2006

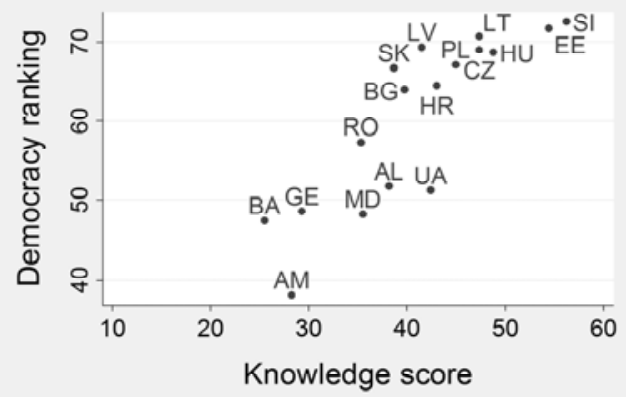

Notes: No data is available on Montenegro, Serbia, F.Y.R. Macedonia, Russia, Belarus and Azerbaijan; the democracy ranking is a composite indicator of political, economic and knowledge based information systems, socioeconomic gender equality, environmental sustainability, health status and health system. The knowledge score covers information on school enrolment, ownership of personal computers, internet use, ICT as \% of GDP. Source: www.democracyranking.org

Figure 4-3 reveals a few related regional trends. First, access to information technology, expressed as a knowledge score is highly heterogeneous across the region. Second, most countries experience a fast ICT development. Third, a high correlation between the countries' democracy ranking and knowledge 
environment exists: a higher democracy ranking is associated with a higher knowledge score.

As compared to developed countries, the lack of data that could be used for MSM development is still a more acute issue in the transition countries. For example, Figure 4-2 uses the best available data on the economic and social indicators in countries of Central Eastern Europe and CIS - TransMONEE49. Though it is a remarkable achievement in its own right it still suffers from information gaps especially in the CIS and S.E.E countries.

If data are available the transition region faces specific challenges regarding data access and use. For example, UNECE (2003) points out that in some countries micro-data are still considered a privileged information source for administering and controlling state activities. Therefore, restricted access applies to any "outsider". Filer and Hanousek (2002) also report the existence of a "business" attitude by government statistical institutions especially when granting micro-data access to "presumably rich western academics": unnecessary difficulties are often created in order to collect higher fees. On the other hand, data sometimes can be more accessible to foreign researchers particularly when their collection is sponsored and administered by international data/project funding organizations. Additionally, UNECE (2003) notes that national researchers hardly submit any data requests. This reflects the limited capacity for empirical research in the transition region. Consequently, as Trautman (1999) observes, the "existence of a staff which can run, maintain, and improve the models" is directly linked to (national) MSM development. In a circular way, local expertise is not built if MSMs are developed entirely by outside modellers.

\subsection{MSMs in Lithuania}

To illustrate the general challenges we previously discussed we now focus on Lithuania - statistically the forerunner in terms of MSM development within the European transition region. As information obtained in our own MSM review is not sufficient to provide more extensive technical details on all six Lithuanian models, we have contacted each of the identified model constructors to gain additional information.

\footnotetext{
${ }^{49}$ More information could be found at http://www.transmonee.org
} 


\section{Review of applications}

In Table 4-4 we show that the first two MSM applications in Lithuania emerged in the 1990s. The first initiative performed a static microsimulation analysis on the poverty effectiveness of social assistance policies. The research was carried out by the IMF representative in Lithuania based on Household Budget Survey data (Cornelius, 1995). A few years later a static tax MSM was developed by the Harvard Institute for International Development (HIID) with USAID funding. The project aimed at helping the Ministry of Finance to conduct basic tax policy analyses using micro data from tax returns ${ }^{50}$. The model has included some behavioural responses and had a broader capacity to tackle diverse policy issues compared to the first MSM application. Regrettably, no further methodological/use details of both models are available today.

Lithuania has also benefited from two cross-national MSM initiatives: the adaptation of the XLMSM model and the integration of Lithuania into EUROMOD.

XLMSM is a general Excel software based microsimulation framework developed at the National University of Ireland. It enables the modelling of diverse policy research questions in both developed and developing countries. Based on the information by the model's developer ${ }^{51}$, the XLMSM based Lithuanian MSM has been mainly employed for research on the distributional impact of taxation.

EUROMOD is an EU-wide static tax-benefit microsimulation model developed and maintained at the University of Essex. The model is used on the national (e.g. academia, state institutions) and European level (e.g. the EU Commission) to determine distributional effects of major policy changes, assess revenue constraints, etc. The Lithuanian part has been developed from 2010 onwards in cooperation with several Lithuanian researchers. Among all Lithuanian MSMs this model has the widest coverage of policies (direct taxes, social contributions and benefits) and years (2005-2009). The model has been used for the analysis of the impact of family transfers on child poverty (e.g. see Chapter 5 of this thesis), as well as in wider cross-country research (e.g. Figari, Salvatori, \& Sutherland, 2010). EUROMOD is currently being updated to cover the policy years 2010-2011.

The last two MSM initiatives in Lithuania consist of two PhD research projects initiated by developers of Lithuanian origin. LitFAMOD was developed in 2008 at Maastricht University within the context of the PhD thesis of this author (see Chapter 5 of this thesis). It is designed to statically simulate family benefits in Lithuania, and particularly to evaluate its 2004 family benefit system reform. The

\footnotetext{
${ }^{50}$ Personal communication with William Trautman, one of the model constructors.

${ }^{51}$ I.e. Cathal O’Donoghue.
} 
model allows interactions with the social assistance system, while links with contributory benefits or taxes are excluded. LitFAMOD can be seen as a reducedscope predecessor of EUROMOD - and thus its reason of existence ceases with EUROMOD reaching its operational stage. The LITSIM model is currently being developed at the National University of Ireland based on the HBS and FFS data ${ }^{52}$.

Table 4-4. MSMs in Lithuania

\begin{tabular}{|c|c|c|c|c|c|c|}
\hline $\begin{array}{l}\text { Model } \\
\text { name }\end{array}$ & $\begin{array}{l}\text { Model } \\
\text { type }\end{array}$ & $\begin{array}{c}\text { Policy } \\
\text { coverageE }\end{array}$ & $\begin{array}{l}\text { Input } \\
\text { data } \mathcal{E}\end{array}$ & $\begin{array}{l}\text { Developing } \\
\text { institution }\end{array}$ & Main users & Information source \\
\hline LITSIM & $\begin{array}{l}\text { Static + } \\
\text { dynamic } \\
\text { elements }\end{array}$ & $\begin{array}{c}\text { Benefits } \\
\text { (excl.pensions) } \\
\text { / n.a. }\end{array}$ & $\begin{array}{l}\text { HBS, } \\
\text { FFS / } \\
\text { n.a. }\end{array}$ & $\begin{array}{l}\text { National } \\
\text { University } \\
\text { of Ireland } \\
\text { (PhD thesis) }\end{array}$ & Academia & $\begin{array}{c}\text { CORDIS; personal } \\
\text { communication }\end{array}$ \\
\hline $\begin{array}{l}\text { EURO- } \\
\text { MOD LT } \\
\text { module }\end{array}$ & Static & $\begin{array}{c}\text { Taxes } \\
\text { \&benefits } \\
\text { (excl. pen- } \\
\text { sions, indirect } \\
\text { taxation) } \\
\text { / 2005-2009 }\end{array}$ & $\begin{array}{c}\text { EU- } \\
\text { SILC \& } \\
\text { LT SILC } \\
\text { / } 2006\end{array}$ & $\begin{array}{c}\text { EURO- } \\
\text { MODUpdate } \\
\text { project* }^{*}\end{array}$ & $\begin{array}{c}\text { Academia } \\
\text { \& not-for } \\
\text { profit } \\
\text { organi- } \\
\text { zations }\end{array}$ & $\begin{array}{c}\text { Ivaškaitè- } \\
\text { Tamošiūnè et al. } \\
\text { (2010); Ivaškaitè- } \\
\text { Tamošiūnė et al. } \\
\text { (2011) }\end{array}$ \\
\hline $\begin{array}{l}\text { LitFA- } \\
\text { MOD }\end{array}$ & Static & $\begin{array}{c}\text { Family } \\
\text { benefits } \\
\text { / 2004; } 2008\end{array}$ & $\begin{array}{l}\text { EU- } \\
\text { SILC } \\
\text { / } 2005\end{array}$ & $\begin{array}{l}\text { Maastricht } \\
\text { University } \\
\text { (PhD thesis) }\end{array}$ & Academia & Own information \\
\hline $\begin{array}{l}\text { XLMSM } \\
\text { Lithuania }\end{array}$ & Static & n.a. & n.a. & $\begin{array}{l}\text { National } \\
\text { University } \\
\text { of Ireland }\end{array}$ & Academia & $\begin{array}{l}\text { http://www.pep- } \\
\text { net.org \& personal } \\
\text { communication }\end{array}$ \\
\hline No name & $\begin{array}{l}\text { Static + } \\
\text { beha- } \\
\text { vioural } \\
\text { res- } \\
\text { ponses }\end{array}$ & $\begin{array}{l}\text { Taxes only } \\
\text { / ( 1999) }\end{array}$ & $\begin{array}{l}\text { Admi- } \\
\text { nistra- } \\
\text { tive tax } \\
\text { return } \\
\text { data / } \\
\text { n.a. }\end{array}$ & $\begin{array}{l}\text { HIID \& the } \\
\text { USAID }\end{array}$ & $\begin{array}{c}\text { LT } \\
\text { Ministry } \\
\text { of Finance }\end{array}$ & $\begin{array}{c}\text { http://www.usaid.g } \\
\text { ov \& personal } \\
\text { communication }\end{array}$ \\
\hline No name & Static & $\begin{array}{l}\text { Benefits only } \\
\text { / (1994) }\end{array}$ & $\begin{array}{l}\text { HBS } \\
\text { / } 1994\end{array}$ & IMF & IMF & Cornelius (1995) \\
\hline
\end{tabular}

Notes: HBS = Household Budget Survey; FFS = Family Fertility Survey; EU-SILC = Community Statistics on Income and Living Conditions; LT SILC = the National Lithuanian SILC survey - the source of information for the EU-SILC; IMF - International Monetary Fund.

* - EUROMODUpdate project is carried out by ISER institute, Essex University; EUROMOD LT module is implemented in collaboration with a Lithuanian national team, which comprises Lina Salanauskaite (Maastricht/Antwerp Universities) \& Romas Lazutka, Jekaterina Navickè and Viginta Ivaškaitė-Tamošiūne (Institute for Social Research, Lithuania).

Source: own presentation

52 Personal communication with Tatjana Stirling, the model constructor. 
Summarising, all Lithuanian MSMs perform static analyses and are mainly based on survey data. No public administration has yet developed a full-fledged national tax-benefit model that could be routinely used for policy analysis. Out of the six recorded MSM applications three are not used outside the scope of the initial research questions, one is more used as a generic rather than Lithuanian specific model and one is still under construction. Consequently, the EUROMOD LT module provides the widest and most recent coverage of the Lithuanian policy system, and has the most promising potential for current and future research applications.

\section{EUROMOD's Lithuanian module: capacities \& limitations}

An extensive technical description of the EUROMOD Lithuanian tax-benefit policies and their validation is provided in Ivaškaitè-Tamošiūnè et al. (2010; 2011). Here we briefly discuss the model's structure, capacities and limitations.

The primary aim of EUROMOD simulations is to derive net income from gross components: labour earnings; (taxable) benefits; taxes; social contributions; etc. As some incomes are observed rather than simulated using policy rules, the disposable income is acquired by adding and subtracting various simulated and observed components. Due to assumptions of $100 \%$ take-up rates and no tax evasion final simulation outcomes reflect what disposable income would be within a framework of perfect compliance ${ }^{53}$. Changes in policy rules lead to changes in disposable incomes and thus enable the comparison of distributional outcomes after the introduction of reforms.

In terms of the technical structure EUROMOD mainly operates in the following software framework. National policy parameters are collected in Excel, data files are stored in .txt environment, and $\mathrm{C}++$ programming language is used for "communications" between the data files and policy parameters. While constructing EUROMOD, STATA statistical software is used to transform original national micro-data into the EUROMOD underlying dataset.

Such a structure has advantages and disadvantages. Excel is a relatively known program and permits the integration of a number of user friendly "buttons". On the other hand, the Excel operational mode could create some usage deficiencies. Furthermore, the EUROMOD specific programming language (see Appendix for an example) should be learnt in order to transcribe policy rules as entered parameters must be recognized by the underlying $\mathrm{C}++$ code. The advantage of the structure is that the knowledge of $\mathrm{C}++$ language is not required and that the

\footnotetext{
${ }^{53}$ Other behavioural assumptions are feasible to integrate.
} 
"EUROMOD" language has been specifically adapted to tax-benefit microsimulation.

The currently available (November, 2011) EUROMOD version covers Lithuanian policies from 2005 to 2009. The model enables the simulation of the following benefits: unemployment social insurance; maternity and paternity leaves; social (assistance) allowances; birth grants; child benefits; and pregnancy grants. The simulated taxes and social contributions cover personal income tax, credited social contributions (partially), employers, employees and self-employed social insurance contributions. The EUROMOD underlying micro-dataset for these policy years is derived from the 2006 EU-SILC survey with imputed variables based on information from the Lithuanian SILC survey. The latter survey is used as a complementary information source, as the EU-SILC does not provide information on specific national transfers (i.e. only aggregate information on family transfers is available) or other national circumstances (i.e. holding a business certificate information needed to simulate Lithuanian personal income tax policies more accurately).

As EUROMOD is a static model all policy rules are simulated as of June 30 each year. Simulating rules on June 30 (the choice made by the EUROMOD developers) allows more coherent comparisons across countries and time. However, it also means that intermediate system changes are not captured within the year. This could cause deviations between EUROMOD simulated and observed incomes. EUROMOD offers two robustness checks to deal with this issue: the most significant changes are reported in the country reports and if feasible, are implemented as alternative policies.

Differences between observed and simulated incomes could also occur due to survey data deficiencies. A potential reason could be a low representativeness of survey data for certain population groups and/or the used weights structure. For example, this is observed for social assistance benefits where values reported in the Lithuanian SILC lead to a vast overestimation of aggregate expenditures.

Given these limitations of the EU-SILC (e.g. it is less specific in the description of national circumstances, such as national transfers) one could wonder why it was selected as the main EUROMOD underlying micro-dataset. The key advantage of the EU-SILC turns out to be its cross-national availability and comparability. Access issues to other data (i.e. administrative records, household budget survey) and the quality and type of other datasets are of importance too. For example, as a result of budgetary restrictions due to the ongoing financial crisis (as of 2008) the Lithuanian HBS data were not collected in 2009 \& 2010. Owing to different financial arrangements, the data for the EU-SILC continued to be collected. 


\section{From international to national initiatives?}

Lithuanian MSM resources are mainly developed by or in collaboration with foreign institutions either in the EU or the US. In the early 1990s MSM development in Lithuania was not so much hindered by a lack of political support but rather by a lack of research funding or low(er) ICT access. Since then some country specific developments explain both a higher incidence of MSM developments as well as the dominance of international initiatives.

Though very limited in the early 1990s, the use of ICT expanded dramatically in Lithuania (see Graph 4) and does not represent a hindering factor anymore. In addition, micro-data have become accessible soon after the collapse of the Soviet Union. According to Cornelius (1995) "Lithuania has been one of the few transition economies for which relatively detailed household surveys were available" by the mid-1990s. The methodology for these surveys has been developed with support from the World Bank and EUROSTAT around 1995. By 2005 Stirling and Lazutka (2006) list at least three Lithuanian household surveys suitable for MSM development: the Labour Force Survey (LFS), the Family Fertility Survey (FFS) and the Household Budget Survey (HBS). The latter one was identified as the most suitable one for tax-benefit simulations. The release of the EU-SILC data (in 2007) has enabled their adaptation to EUROMOD. Administrative micro-data on the other hand, is still not widely accessible to academia (i.e. Stirling \& Lazutka, 2006).

The dominance of international initiatives is related to Lithuania specific sociodemographic patterns. It is barely an accident that some Lithuanian MSMs are developed by Lithuanian expatriates. Lithuania is the largest emigration country in the EU. About 5\% of Lithuanian scientists who hold at least one national academic degree have emigrated abroad since the beginning of the transition period (Užsienio Lietuvių Rėmimo Centras, 2009). According to International Migration Outlook (OECD, 2008) net migration since 1990 amounts to an estimated $10 \%$ loss of the population and has strongly affected the Lithuanian labour market. While usually linked to a potential "brain drain" phenomenon, Lithuanian international migration has actually facilitated access to the EU MSM knowledge and resources.

Overall, the recognition and national awareness of MSM increased especially in the last few years. For example, according to information by the Labour and Social Protection Ministry ${ }^{54}$ and the Statistics Department of Lithuania (Statistics Lithuania, 2008) the idea of technically preparing and pooling administrative records with survey data for MSM analysis is gaining ground. This would help develop a more detailed national MSM. In parallel, discussions on the usage of the

\footnotetext{
54 Personal communication with the Labour and Social Protection Ministry, 09 June 2009.
} 
microsimulation technique are increasingly present on the national research agenda: the microsimulation technique is referred to as a suitable tool for profit tax modelling and forecasting in Mačiulaityte (2006) and a national MSM is also noted as one of the national social policy priorities by the Research Council of Lithuania (2008).

\subsection{Conclusions}

Developed countries extensively use tax-benefit MSMs in evaluating ex-ante, expost and hypothetical social policy impacts. The countries of the European transition region, though going through numerous structural reforms, make limited use of distributional analysis techniques such as MSMs. This chapter is the first attempt to systematically record the heterogeneity of MSM development in the region and to provide the profile of major development initiatives, model types and obstacles behind MSM construction and usage. The Lithuanian case adds insights into the country-specific MSM development pattern.

Overall, information on MSMs within the transition region is scarce with most resources being described on project specific websites rather than within the social science publications/periodicals. Our survey identifies 36 (past, present or underconstruction) MSMs though available technical descriptions are highly varied. To illustrate the Lithuanian case, we have pursued additional personal communications with the model developers.

The emerging "typical" portrait of MSM development in the European transition countries could be described as a scarcity of MSMs within a much more active environment in the recent past, the dominance of internationally initiated and static models, and a higher prevalence of models in more affluent countries. Among the international initiatives, which cover $75 \%$ of resources, the EUROMOD project is particularly interesting because of its scope (all $10 \mathrm{EU}$ member states, a full-fledged tax-benefit model, numerous policy years, detailed technical information, etc.) and because of its link to the political context (based on EU membership).

Changing national preferences and access to micro-data explain the lack of MSM initiatives before the 1990s and the expansion afterwards. Restrictions in conducting distributional analyses within the Soviet Union prohibited earlier MSM development. Nowadays, high income inequality and low national preferences towards a more equal society correlate to low or no use of MSMs, especially in the CIS countries. 
The transition process brings about its own modelling challenges too due to highly diverse, quickly changing and complex national policy agendas. This is reflected in the taxonomy of the identified models: all identified models are static MSMs with three models including some behavioural responses and one model including dynamic elements. The covered policy scopes stretch from specific policies (e.g. 5 MSMs models on income taxation, 3 MSMs on benefits, etc.) to entire tax-benefit systems. These are the most common MSM types in the developed countries too. The lag of MSM development in the transition region is also reflected by the fact that no initiatives in modelling under-explored policies (e.g. in-kind benefits) or linking micro and macro models is recorded yet.

The case study of Lithuania, the country with currently the highest recorded number of MSM applications within the transition region, reveals how important diverse contextual national and cross-national factors for stimulating MSM development are. All 6 recorded MSMs proved to be international initiatives, leading to a low continuation of developed resources by national researchers: most of Lithuanian MSMs cannot be accessed anymore or have little capacity to adapt to policies outside the initial research scope.

Of the 6 MSMs in Lithuania the EUROMOD LT module is the most accessible, technically best described and most user-friendly model to analyse diverse national and cross-national policy questions. Furthermore, the model already includes a number of policy years (2005-2009) and is being continuously updated to allow more recent research. Its major advantage is its embedding in a crosscountry modelling framework. Its major disadvantages relates to the limited scope of simulated national policies (due to the underlying data choice) and a few other technical features (i.e. "pure" static modelling, an aged underlying data-set, assumptions of $100 \%$ tax collection and benefit take-up, etc.).

The listed EUROMOD LT disadvantages would be easiest to address within the framework of a new and more comprehensive national model. More dynamic and behavioural modelling would be most welcome for testing second-order policy effects and datasets with richer national characteristics could be used (for example, by pooling survey and administrative records). 


\subsection{Appendix: EUROMOD Excel Interface}

Version F3.0+

Child benefit rules (years 2005-2007) transcribed in EUROMOD language

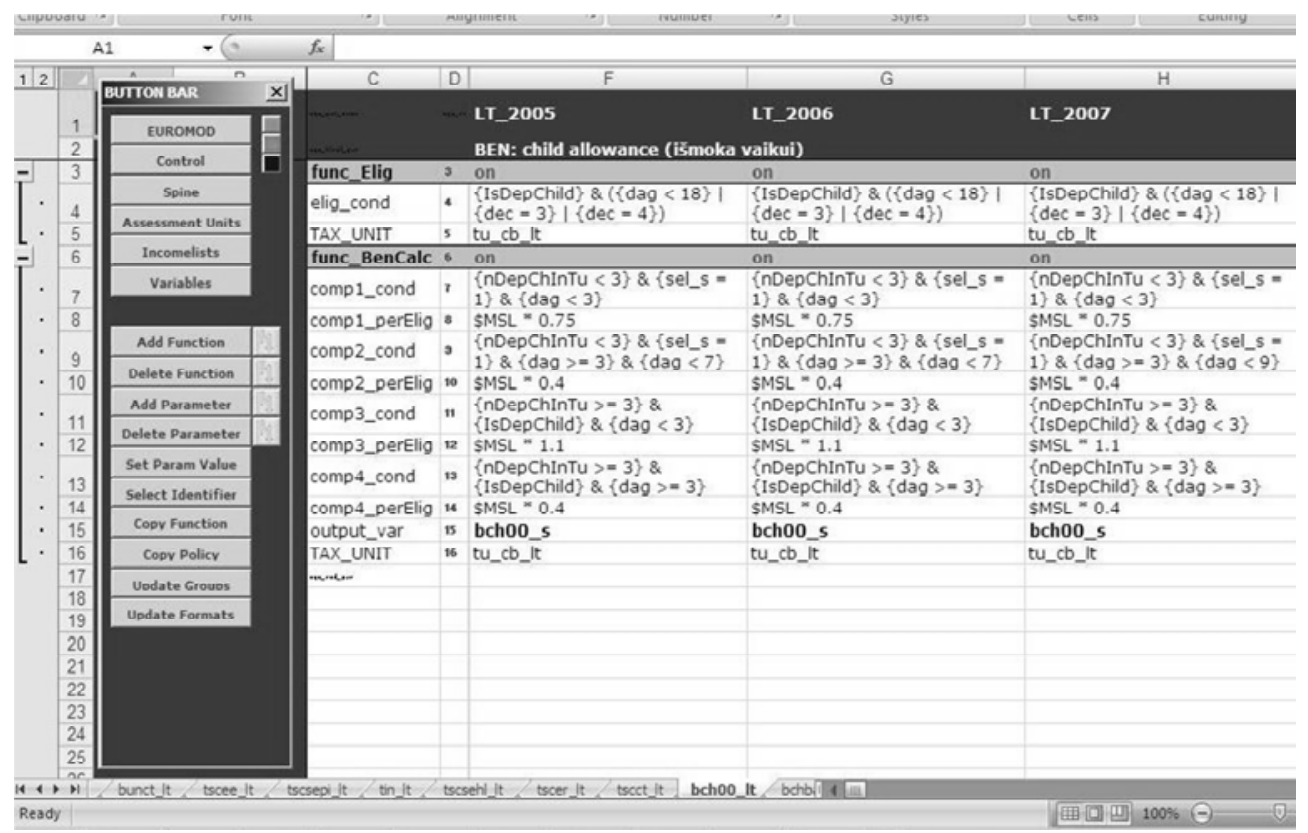




\subsection{References}

Anderson, R. E., \& Hicks, C. (2011). Highlights of Contemporary Microsimulation. Social Science Computer Review, 29(1), 3-8.

Ballas, D., \& Clarke, G. (2000). GIS and Microsimulation for Local Labour Market Analysis. Computers, Environment and Urban Systems, 24(4), 305-330.

Bargain, O., Morawski, L., Myck, M., \& Socha, M. (2007). As SIMPL as That: Introducing a Tax-Benefit Microsimulation Model for Poland. IZA Discussion Papers, No. 2988.

Benedek, D., Scharle, Á., \& Szabó, P. A. (2007). Microsimulation in Government Decision Making in Hungary. Paper presented at the 1st General Conference of International Microsimulation Association. Vienna, 20-22 August, 2007.

Bourguignon, F., \& Spadaro, A. (2006). Microsimulation as a Tool for Evaluating Redistribution Policies. Journal of Economic Inequality, 4(1), 77-106.

Cassells, R., Harding, A., \& Kelly, S. (2006). Problems and Prospects for Dynamic Microsimulation: A Review and Lessons for APPSIM (No. 63): NATSEM Discussion Paper. NATSEM, University of Canberra.

Citro, C. F., \& Hanushek, E. A. (Eds.). (1991). Improving Information for Social Policy Decisions: the Uses of Microsimulation Modelling (Vol. 1). Washington, D.C. : National Academy Press.

Čok, M. (2002). A Microsimulation Model for Slovenia's Personal Tax System. Economic and Business Review, 4(1), 75-92.

Cornelius, P. K. (1995). Cash Benefits and Poverty Alleviation in an Economy in Transition: the Case of Lithuania. Comparative Economic Studies, 37, 49-70.

Coulter, F., Heady, C., Lawson, C., \& Smith, S. (1995). Fiscal Systems in Transition: The Case of the Czech Income Tax. Europe-Asia Studies, 47(6), 1007-1023.

Coulter, F., Heady, C., Lawson, C., \& Smith, S. (1997). Social Security Reform for Economic Transition: the Case of the Czech Republic. Journal of Public Economics, 66(2), 313-326.

Creedy, J., Duncan, A. S., Harris, M., \& Scutella, R. (2002). Microsimulation Modelling of Taxation and the Labour Market: the Melbourne Institute Tax and Transfer Simulator: Cheltenham, Edward Elgar Publishing Limited.

Davies, J. B. (2009). Combining Microsimulation with CGE and Macro Modelling for Distributional Analysis in Developing and Transition Countries. International Journal of Microsimulation, 2(1), 49-65.

Decoster, A., De Swerdt, K., Orsini, K., Lefèbvre, M., Maréchal, C., Paszukiewicz, A., et al. (2008). Final Report Project Ag/01/116 Valorisation of the Microsimulation Model for Social Security Mimosis. Part 2.

Dekkers, G., \& Belloni, M. (2009). Microsimulation, Pension Adequacy and the Dynamic Model MIDAS: an Introduction (Project AIM - Deliverable 4.10). 
Figari, F., Salvatori, A., \& Sutherland, H. (2010). Economic Downturn and Stress

Testing European Welfare Systems. EUROMOD Working Paper No. EM4/10.

Gupta, A., \& Kapur, V. (Eds.) (2000). Microsimulation in Government Policy and Forecasting. New York: Elsevier Science Inc.

Harding, A. (Ed.) (1996). Microsimulation and Public policy. Amsterdam: NorthHolland, Elsevier.

Harding, A., Keegan, M., \& Kelly, S. (2010). Validating a Dynamic Population

Microsimulation Model: Recent Experience in Australia. International Journal of Microsimulation, 3(2), 46-64.

Immervoll, H., \& O'Donoghue, C. (2009). Towards A Multi-Purpose Framework For Tax-Benefit Microsimulation: Lessons From EUROMOD. International Journal Of Microsimulation, 2(2), 43-54.

Ivaškaitè-Tamošiūnè, V., Kazakevičiūtè, J., Lazutka, R., Navickè, J., \&

Salanauskaitè, L. (2011). EUROMOD Country Report: Lithuania (2005-2009).

Ivaškaitè-Tamošiūnè, V., Lazutka, R., \& Salanauskaitè, L. (2010). EUROMOD Country Report: Lithuania (2005-2008).

Lavigne, M. (2000). Ten Years of Transition: a Review Article. Communist and PostCommunist Studies, 33(4), 475-483.

Lelkes, O. (2007). Tax-benefit microsimulation models in Eastern Europe. International Journal of Microsimulation, 1(1), 54-56.

Lelkes, O., \& Sutherland, H. (2009). Tax and Benefit Policies in the Enlarged Europe: Assessing the Impact with Microsimulation Models. In O. Lelkes \& H. Sutherland (Eds.), Public Policy and Social Welfare (Vol. 35). European Centre Vienna: Ashgate.

Lewis, G. H., \& Michel, R. C. (1990). Microsimulation techniques for tax and transfer analysis. Washington, DC: The Urban Institute Press.

Mačiulaityte, E. (2006). The Ways of Modelling and Forecasting Profit Tax Revenue in Lithuania. Ekonomika, 76, 57-67.

Merz, J. (1991). Microsimulation - a Survey of Principles, Developments and Applications. International Journal of Forecasting, 7(1), 77-104.

Mitton, L., Sutherland, H., \& Weeks, M. J. (2000). Introduction. In L. Mitton, H. Sutherland \& M. J. Weeks (Eds.), Microsimulation Modelling for Policy Analysis: Challenges and Innovations: Cambridge, Cambridge University Press.

Murthi, M., \& Tiongson, E. R. (2008). Attitudes to Equality: the "Socialist Legacy" Revisited. The World Bank Policy Research Working Paper Series, No. 4529.

Nelissen, J. H. M. (1993). Labour Market, Income Formation and Social Security in the Microsimulation Model NEDYMAS. Economic Modelling, 10(3), 225-272.

Newbery, D. M. (1997). Optimal Tax Rates and Tax Design During Systemic Reform. Journal of Public Economics, 63(2), 177-206. 
O'Donoghue, C. (2001). Dynamic Microsimulation: A Methodological Survey. Brazilian Electronic Journal of Economics, 4(2).

O’Donoghue, C. (2005). XLMSM: A Generic Microsimulation Tax-Benefit Model. Paper presented at the Poverty and Economic Policy General Meeting: Colombo, Sri Lanka.

OECD. (2008). International Migration Outlook 2008. Paris: OECD.

Orcutt, G. H. (1957). A New Type of Socio-Economic System. The Review of Economics and Statistics, 39(2), 116-123.

Research Council of Lithuania. (2008). Nacionalinè Mokslo Programa: Socialiniai Iššūkiai Nacionaliniam Saugumui. Vilnius, Lithuania. [Electronic Version] from http://www.ulrc.lt

Roberts, B. M., \& Zolkiewski, Z. (1996). Modelling Income Distribution in

Countries in Transition: A Computable General Equilibrium Analysis for Poland. Economic Modelling, 13(1), 67-90.

Salanauskaite, L., \& Verbist, G. (2009). Reforming Child Allowances in Lithuania: What Does Microsimulation Tell Us? In O. Lelkes \& H. Sutherland (Eds.), Tax and Benefit Policies in the Enlarged Europe: Assessing the Impact with Microsimulation Models. European Centre Vienna: Ashgate.

Simai, M. (2006). Poverty and Inequality in Eastern Europe and the CIS Transition Economies. UN/DESA Working Paper, No. 17.

Spielauer, M. (2007). Dynamic Microsimulation of Health Care Demand, Health Care Finance and the Economic Impact of Health Behaviours: Survey and Review. International Journal of Microsimulation, 1(1), 35-53.

Spielauer, M. (2011). What is Social Science Microsimulation? Social Science Computer Review, 29(1), 9-20.

Spremić, M., Šimurina, J., Jaković, B., \& Ivanov, M. (2009). E-Government in Transition Economies. World Academy of Science, Engineering and Technology, 53(84).

Stirling, T., \& Lazutka, R. (2006). I-CUE Feasibility Study: Lithuania (2005 TaxBenefit System). I-CUE Project: Improving the Capacity and Usability of EUROMOD, Deliverable D3.8.

Sutherland, H. (2009). Chapter 3 - EUROMOD: Past, Present and Future. In O. Lelkes \& H. Sutherland (Eds.), Tax and Benefit Policies in the Enlarged Europe: Assessing the Impact with Microsimulation Models. European Centre Vienna: Ashgate.

Trautman, W. B. (1999). A Microsimulation Model of the Slovak Individual Income Tax.

Development Discussion Paper No. 716: Harvard Institute for International Development.

UN. (2009). Millennium Development Indicators: World and Regional Groupings [Electronic Version]. Retrieved 2010.02.15 from 
http://mdgs.un.org/unsd/mdg/Host.aspx?Content=Data/RegionalGrouping $\mathrm{s}$.

Užsienio Lietuvių Rèmimo Centras. (2009). Socialinis Tyrimas: Kodèl Jauni

Perspektyvūs Mokslininkai Palieka Lietuvą ir Kas Paskatintų Grįžti?

[Electronic Version]. Report to Media from http://www.ulrc.lt/.

Volchkova, N., Gorshkova, E., Lobanov, S., Turdyeva, N., Khaleeva, J., \& Yudaeva,

K. (2006). Microsimulation Analysis of the Consequencies of Monetization of Social Benefits in Russia. New Economic School Working Paper, No. 63.

Wilkinson, K. (2011). Modelling the Impact of Taxes and Transfers on Child Poverty in South Africa. Social Science Computer Review, 29(1), 127-144.

World Bank. (2009). Country Groups. [Electronic Version]. Retrieved 2010.02.15 from http://go.worldbank.org/D7SN0B8YU0.

Zaidi, A., Harding, A., \& Williamson, P. (Eds.). (2009). New Frontiers in Microsimulation Modelling. European Centre Vienna: Ashgate. 


\section{Chapter 5: Family Allowances' Reform in Lithuania: Microsimulation of its Distributional Impacts}

\section{This chapter is published as:}

Salanauskaite, L., E Verbist, G. (2009). Reforming Child Allowances in Lithuania: What Does Microsimulation Tell Us? In O. Lelkes \& H. Sutherland (Eds.), Tax and Benefit Policies in the Enlarged Europe: Assessing the Impact with Microsimulation Models. European Centre Vienna: Ashgate. 



\subsection{Background}

Children in Lithuania live in poverty conditions much more often compared to other population groups. Lithuanian family benefit system ability to improve income situation of families with children is, though, often considered to be limited (TÁRKI, 2010). The latter report also points out that family benefits could have a much bigger role in combating child poverty, as is in such European countries France, the Netherlands, Austria or Slovenia.

The situation in Lithuania might have also changed with the recent major reform of the family benefit system: in July 2004 the new Law on Allowances to Children came into force (Republic of Lithuania, 2004a). This reform aimed at improving material conditions of families with children, and especially if living in poverty. Furthermore, the new benefits' design is said 1) to overcome the drawbacks of the previous system, 2) is drawn based on the other countries' experiences, but 3) keeping to the national budgetary capacities (The Ministry of Social Security and Labour, 2005). Overall, this reform entails a shift from means-tested benefits to a more universal system. Due to budget constraints, however, the full reform design has been fully implemented in 2008 only. Consequently, the state increased spending on benefits to families with children by 23\% (20 million Euros) in 2005 already. By 2008, the state transfers to families with children have doubled compared to the levels of 2005. No distributional impact analysis of this reform has yet been implemented.

This chapter aims to fill in the knowledge gap on the distributional impacts of this reform and on the poverty/inequality effectiveness of Lithuanian family benefits' system. Both issues are highly under-explored given the national context. Our analysis concerns all state cash financial support for raising children, which we further on refer to as family benefits. Various other family policy instruments, such as childcare services, tax allowances or social insurance benefits, are important family policy instruments too. Nevertheless, these measures are left outside the scope of this analysis due to the chapter's focus on highlighting monetary weights of the cash support instruments. The same is true for cash social assistance though it also plays an important role in the real world. Due to changes in household income following the reform, actual entitlements to social assistance benefits might have changed too. We do observe that while spending on family benefits increased by $23 \%$ (from 2004 to 2005), spending on cash social assistance to low-income families dropped by $24 \%$ (or 14 million Euros). This might indicate an increase in household income because of new family benefits, which simultaneously moved some households out of social assistance dependence. On the other hand, many 
other reasons than the family benefit reform could be responsible (e.g. improving overall population wages and pensions). Nevertheless, analysis linking expenses on social assistance and family benefits is not yet conducted.

This chapter, therefore, systematically evaluates linkages and monetary impacts of both family and social assistance benefits - the main cash support instruments to families with children in Lithuania. It assesses direct (reform affected family benefits) and indirect (reform affected family benefits plus social assistance) monetary impacts. Furthermore, as the reform was introduced gradually, we look at poverty and inequality effects of the initial (July 1, 2004) and final reform implementation (January 1, 2008) designs.

The chapter begins with a brief review of studies on family benefits, as a determinant of child poverty, in the EU and Lithuania. Then, we explore legislative regulations of the Lithuanian family benefits' and social assistance system before and after July 1, 2004. Here, we determine what benefits are relevant for this study and what inter-connections between them exist. Next, we assess the EU-SILC (2005) micro-dataset in terms of its simulation potential of Lithuanian family policy measures. This study uses a static microsimulation approach in order to determine each household's entitlement to family and social assistance benefits before and after the reform. As no other microsimulation model is accessible for this type of analysis, own static benefits' microsimulation model LitFAMOD is developed to carry out the study. The last section of this chapter analyses and discusses direct and indirect, initial and final distributional impacts of the reform using a range of standard inequality and poverty measures.

\subsection{Combating Child Poverty: a European and a Lithuanian concern}

A recent synthesis report on child poverty in the EU member states notes that overall children are at greater risk of poverty than the rest of the population, with the difference between overall and child poverty largest in most of the new member states, such as Poland, Bulgaria, Hungary, Romania or Lithuania (Frazer \& Marlier, 2007). The report also highlights that poverty severity is most acute in the three Baltic States, Poland and Southern EU member states, such as Italy, Spain and Portugal. Generally, child poverty rates in the EU are getting to such 
disturbing heights, that the EU identifies the situation as "calling for urgent integrated actions across a wide range of social, economic and cultural policies 55 ".

Despite growing concerns over long-term implications of an increasing number of children being raised in extreme poverty conditions, public policy responses to tackle the situation are rather limited and lagged. Heikillä et al (2006), for example, show that the EU countries (before 2004) with above average post-transfer national and child poverty rates, particularly Mediterranean countries, have less efficient poverty reduction measures. A study by Matsaganis et al (2007) on child poverty in Southern Europe identifies that observed inefficiency in poverty reduction is highly due to eligibility restrictions for income support (as is the case in Greece and in Italy) and low benefit levels of existing transfer schemes (as in Spain and to some extent in Portugal). The latter finding is confirmed by a number of other studies which indicate that lower child poverty rates are attributed to more generous child benefit programmes (i.e. Bradshaw and Finch, 2003; Notten and Gassman, 2008). Links between Lithuanian child poverty levels and the design of its (family) benefit system are not yet explored. Overall, few empirical studies carry analysis on the poverty effectiveness of family benefit systems in the new EU member states (after 2004 enlargement).

Impact of transfers on the poverty rates is also known to be highly dependent on initial inequality of market incomes, as well the overall tax-benefit structure in the country. Thereby, Atkinson et al. (1995) find that for example Norway has both a low poverty rate and a low level of transfers, whereas the UK and Ireland have the opposite.

The debate on the effective design of anti-poverty programmes also relates to the issue of universal versus selective policy measures. Cross-national empirical evidence suggests a more mixed pattern of the redistributive effects of meanstested benefits compared to non-means-tested entitlements (Nelson, 2007). These findings vary based on the levels and design of the benefits offered (Notten and Gassman, 2008; Hölsch, \& Kraus, 2002). The results are also highly dependent on the institutional settings of selected countries, the initial distribution of market income, and the balance of means versus non-means tested benefits. Nelson (2007) finds for instance that the high degree of poverty reduction in Sweden and Germany is achieved by non-means tested benefits, while means-tested benefits achieve a greater alleviation of poverty in the United Kingdom.

Despite lack of national empirical studies, poverty concern is highly present in Lithuanian policy discussions. The Lithuanian Poverty Reduction Strategy, approved

\footnotetext{
${ }^{55}$ http://ec.europa.eu/employment_social/spsi/child_poverty_en.htm (accessed on 01.10.2008)
} 
in 2000, highlighted that one of the major national goals is to reduce the poverty level for large and single parent families. At that time, policies to combat poverty among Lithuanian families with children were specifically designed along selective lines by using means-tested family benefits (Aidukaite, 2006). Since 2004, the Lithuanian family benefit system has shifted towards a more universal provision. The Law on Allowances to Children (Republic of Lithuania, 2004a), which became effective as of July 1, 2004, is the main trigger of these systematic changes (further on referred to as the "reform"). This law aimed to redesign existing family benefits and to ensure their compatibility with the rest of the social security system, which was reformed intensely during the last decade. The introduction of the universal child benefit system also explicitly aimed at combating child poverty, especially for large families (Republic of Lithuania, 2004b; National Report on Strategies of Lithuania for Social Protection and Social Inclusion 2006-2008, 2006).

The new law abolished four existing family benefits, introduced two new benefits and redefined amounts and eligibility conditions of some other transfers to families with children. Corresponding to the reform induced changes, the total state spending on family benefits increased from 253 million LTL ${ }^{56}$ in 2003 to 363 million LTL in 2005. This was mainly due to the introduction of a universal child benefit, commonly known as "child money". As the law established a gradual implementation of this child benefit (due to budgetary restrictions), full reform implications were delayed until 2008.

Despite embedded anti-poverty objectives of the new family benefit system, its actual distributional effects are not straightforward and not yet empirically tested. As the National Report on Strategies of Lithuania for Social Protection and Social Inclusion 2006-2008 (2006) indicates, the largest number of children in poverty is found among children from three to five years old. In $2005^{57}$, these families were mainly entitled to the universal child benefit (and social assistance benefits). Families with children under three years old experienced a comparatively lower impoverishment. This was partially explained by a larger (in terms of benefit size and types) state support available to this age group. The current at-risk-of-poverty rate for single parents and for couples with three or more children remains more than $40 \%$ - before and after the reform. This is twice the total poverty rate. ${ }^{58}$ Furthermore, the recent study on child poverty in the EU links such high latter child poverty rates to the less-effective income support system to families with children if compared to the other EU member states (TÁRKI, 2010). The report,

\footnotetext{
$563.4528 \mathrm{LT}=1$ EUR

57 The reference year of the conducted analysis

${ }^{58}$ EUROSTAT (At-risk-of-poverty rate after social transfers, by household type: accessed on 10.07.2008) and Statistics Lithuania data (http://www.stat.gov.lt/en/pages/view/?id=2246) for 2005 and 2006.
} 
however, does not provide with a more detailed evaluation of the poverty effectiveness of the newly designed family benefit system due to the lack of Lithuanian tax-benefit microsimulation model (in 2009) to conduct this type of analysis.

\subsection{The Lithuanian family policy reform of 2004: main strands}

Family policy in this chapter includes non-contributory cash measures that are specifically targeted at families with children. Table 5-1 gives an overview of all such measures in Lithuania around the reform year 2004. In addition to this, it traces changes in Lithuanian social assistance system during the same time period.

As Table 5-1 shows, the total budget of family benefits increased considerably from 2003 (253 million LTL) to 2005 (363 million LTL) - mainly due to the reform. The amount is expected to increase further on, as the reform comes into full swing from 2008 onwards. This is already indicated by 2007 data: the closest available administrative data before the final implementation of the reform. We briefly discuss the specific pre- and post-reform measures here ${ }^{59}$. But before we do this, we must mention two important parameters of Lithuanian social policy: the "minimum standard of living" (MSL) and the "state supported income" level $(\mathrm{SSI})^{60}$. MSL was equal to 125 LTL (36.2 EUR) per person per month in 2004, and SSI to 135 LTL (39.10 EUR) (Statistics Lithuania, 2008).

\section{Direct effects}

Direct reform effects measure cumulative change in household disposable income due to change in eligibility and (or) size of benefits, which were defined by the new Law on Allowances to Children ${ }^{61}$.

\footnotetext{
${ }^{59}$ More specific details on this in and other benefits, discussed in this Chapter, can be found in Appendix 1.

${ }^{60}$ The MSL refers to a specified income level aimed at the satisfaction of basic needs. The SSI is the Government approved personal income level after taxes and contributions, but before transfers of cash social assistance. Both measures are used as administrative tools for benefit calculation rather than tools for poverty monitoring,

${ }^{61}$ Apart from the hereby described family benefits, two more measures belong to the family policy domain: baby diapers and municipal support. These benefits are defined outside the scope of the Law on Allowances to Children, and were not affected by the reform.
} 
The concerned changes we brought by the abolishment of the four following monthly benefits:

1. The family allowance - a categorical benefit, i.e. non-means-tested and noncontributory cash benefit (for a detailed description of this benefit and the following ones, see Appendix 1).

2. The benefit for families raising three or more children - a (partially) means tested benefit.

3. The orphan's stipend - a categorical benefit.

4. The maternity benefit for studying women - a categorical benefit.

In 2003, these four measures accounted for around $70 \%$ of the total budget of family benefits (see Table 5-1).

As of July 1, 2004, two benefits, which were partial adaptations of some of the abolished benefits, were introduced:

1. The child benefit - a monthly categorical benefit.

2. The pregnancy grant - a lump-sum benefit.

In 2005 these two measures took up around $72 \%$ of the total budget, which corresponds approximately to the share of the abolished benefits in the pre-reform period.

We expect this share to increase, though, when the reform comes into the full effect in $2008^{62}$. This is mainly related to gradual eligibility extension of child benefit rules, as summarized below:

- As of July 1, 2004 (further on referred to as the "initial implementation of the reform") child benefit is granted to all children up to age 3. If raised in families with three or more dependent children (commonly called "large families"), the child benefit is also granted to dependent children up to age 24 if in full time secondary or higher education. The latter entitlement to large families remained unchanged during the entire reform period.

- $\quad$ Since September 1, 2006, the child benefit is paid to all children up to age 9.

- Since September 1, 2007 the child benefit is also paid to all children up to age 12.

- Since January 1, 2008 the child benefit is paid to all children up to age 18 or older if in full time secondary education. We further on refer to this stage as the "full implementation of the reform".

\footnotetext{
${ }^{62}$ The reform has been fully implemented in 2008; however aggregate date on beneficiaries is not yet available at the time of this analysis.
} 
Table 5-1. State spending on non-contributory family policy measures

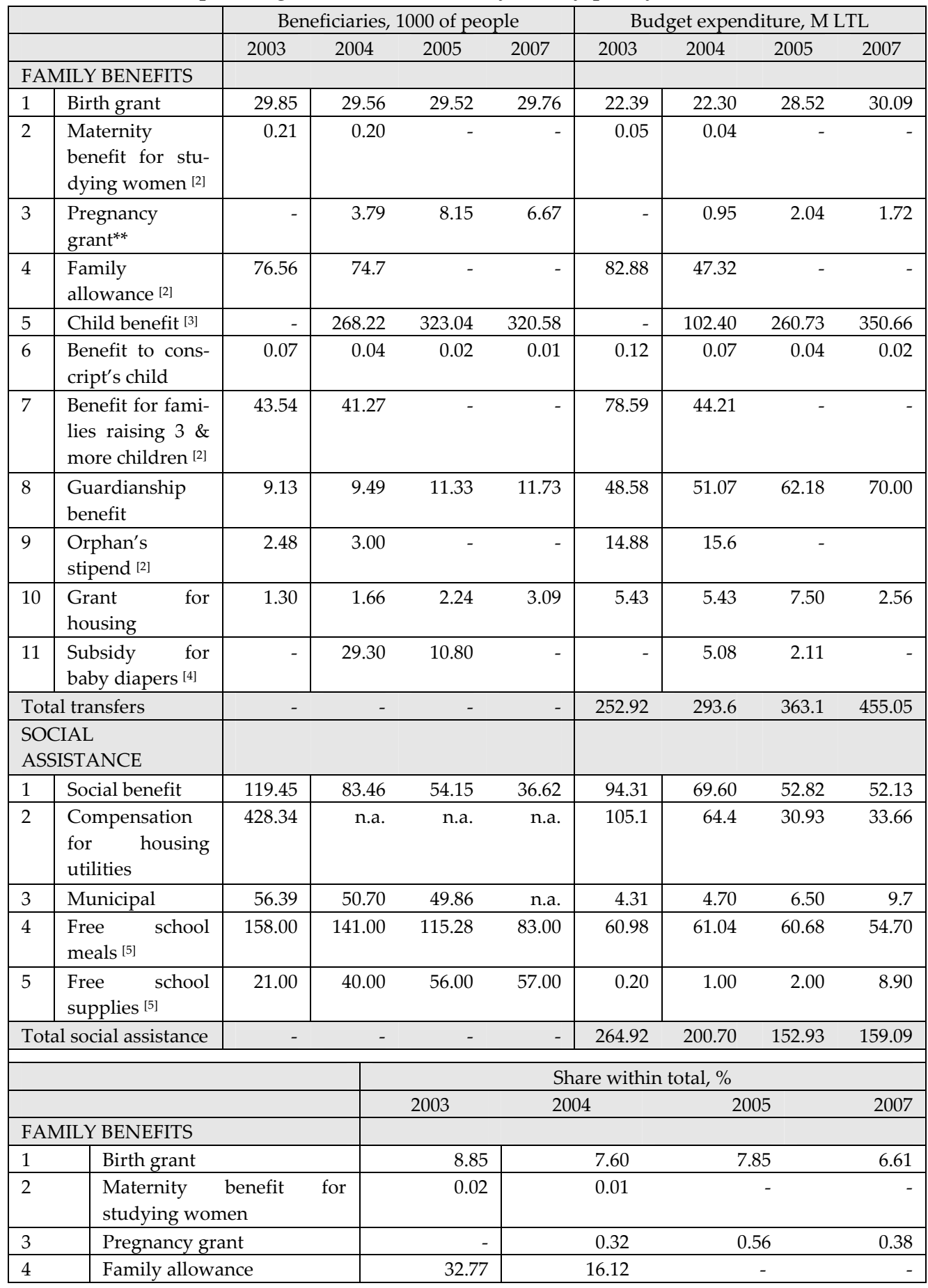




\begin{tabular}{|c|c|c|c|c|c|}
\hline 5 & Child benefit & - & 34.88 & 71.81 & 77.06 \\
\hline 6 & Benefit to conscript's child & 0.05 & 0.02 & 0.01 & - \\
\hline 7 & $\begin{array}{l}\text { Benefit for families raising } 3 \\
\& \text { more children }\end{array}$ & 31.07 & 15.06 & - & 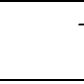 \\
\hline 8 & Guardianship benefit & 19.21 & 17.39 & 17.12 & 15.38 \\
\hline 9 & Orphan's stipend & 5.88 & 5.31 & - & - \\
\hline 10 & Grant for housing & 2.15 & 1.85 & 2.07 & 0.56 \\
\hline 11 & Subsidy for baby diapers & - & 1.73 & 0.58 & 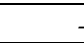 \\
\hline \multicolumn{2}{|c|}{ Total transfers } & 100.00 & 100.00 & 100.00 & 100.00 \\
\hline \multicolumn{6}{|c|}{ SOCIAL ASSISTANCE } \\
\hline 1 & Social benefit & 49.45 & 41.78 & 33.93 & 32.77 \\
\hline 2 & Compensation for housing & 16.22 & 18.16 & 21.62 & 21.16 \\
\hline 3 & Municipal support & 2.26 & 2.82 & 4.18 & 6.10 \\
\hline 4 & Free school meals & 31.97 & 36.64 & 38.98 & 34.38 \\
\hline 5 & Free school supplies & 0.10 & 0.60 & 1.28 & 5.59 \\
\hline \multicolumn{2}{|c|}{ Total social assistance } & 100.00 & 100.00 & 100.00 & 100.00 \\
\hline
\end{tabular}

Notes: [1] - Within this table, beneficiaries are families. The exception is free meals to pupils and free school supplies, where beneficiaries are children receiving these entitlements. One should also note that the term "family" is used in the administrative context and means spouses or persons living together, or one of the parents, as well as their own and adopted children under 18 years of age (see Republic of Lithuania, 2004a). This family concept also includes persons between the ages 18 and 24 who are unmarried and not cohabitating: full-time pupils and students of general education schools or other institutions of formal education. ${ }^{[2]}$ - Benefit erased since July 1 , 2004; ${ }^{[3]}$ - Benefit introduced on July 1, 2004; ${ }^{[4]}$-Temporary benefit. ${ }^{[5]}$ - - non-cash benefits directed at children (for information purposes only, more details in the following laws: Republic of Lithuania, 1999; Republic of Lithuania, 2006).

Source: the primary source of data is Statistics Lithuania www.stat.gov.lt [accessed on April 30, 2008]; the secondary source of data is the Ministry of Social Security and Labour http://www.socmin.lt [accessed on November 15, 2008]

Some benefits were not or only minimally affected by the 2004 reform. These are:

1. The birth grant - a lump-sum benefit.

2. The benefit to a conscript's child - a monthly categorical benefit.

3. The guardianship benefit - a monthly categorical benefit.

4. The grant for housing - a lump sum benefit.

\section{Indirect effects}

Change in household income due to direct reform effects may alter eligibility and size of other income maintenance transfers, most notably social assistance. Thereby, we define indirect reform effects as changes in household disposable income because of recalculation of social assistance benefits. This is mainly due to the fact that family benefits are included in the calculation and testing of family income for the purpose of granting social assistance. Modelling indirect effects shows to what extent a change in family benefits is counteracted by a likewise loss (or gain) in social assistance. 
Lithuanian social assistance system provides two major monthly cash transfers to low-income families and single persons (Republic of Lithuania, 2003):

1. Social benefit - a means-tested income support benefit.

2. Compensation for heating, hot and cold water costs - a means-tested reimbursement of utility, such as gas, heating and water, costs.

Neither social assistance nor family benefits are taxable in Lithuania.

\subsection{Methodology}

This chapter uses a static microsimulation approach in order to determine each household's entitlement to family policy measures before and after the reform. A static microsimulation enables evaluating distributional impacts of a certain taxbenefit policy system on a selected point in time (e.g. Spadaro, 2007). The static approach implies analysis of short-term effects for a given population. Due to data shortage, as well as numerous and rapid reforms in Lithuania, behavioural responses are not estimated in this study ${ }^{63}$.

At the time of the analysis (i.e. 2008-2009) no national tax-benefit microsimulation model (MSM) is available to test distributional impacts of this family benefits' reform (Immervoll et al, 1999; Lelkes, 2007). Hence, for the purpose of this study, we develop our own MSM. The model, named LitFAMOD, is a static STATA software based partial (concerned benefits only) microsimulation model. It consists of two major components. First, the EU-SILC (Survey on Income and Living Conditions) 2005 survey data for Lithuania is used as the underlying microdatabase. Second, a set of rules on benefit provisions for the individuals and households, as well as calculation of their disposable incomes before and after the reform, are programmed in STATA language.

\section{EU-SILC capacity to simulate non-contributory family policy measures}

EU-SILC collects comparable cross-sectional and longitudinal multidimensional micro data on income poverty and social exclusion in European countries (EUROSTAT, 2007b). It provides information on a number of household attributes, such as income, social exclusion, housing, health, education and participation in the labour market.

\footnotetext{
63 A more detailed discussion of static microsimulation methodology as well as microsimulation resource availability in Lithuania is provided in Chapter 1 of this thesis.
} 
Since 2005, the dataset contains information on income and living conditions of Lithuanian people. The Lithuanian part of the database is collected via a survey of 12,117 individuals, coming from 4,441 households. The average household size is 2.5 people. EU-SILC 2005 information on Lithuania refers to demographic information for 2005, but to income information of 2004. For the purpose of this analysis, we use EU-SILC demographic variables at the end of income reference period (2004) in order to better align with income information.

The EU-SILC does not distinguish among different national transfer types, as indicated in Table 5-1. Instead, it provides with the aggregate categories, such as all family or social exclusion benefits. Thereby, evaluation of national benefits should be based on the simulated, rather than observed values. For simulation purposes, other EU-SILC variables, such as age, family composition or incomes, are used. The detailed overview of EU-SILC contained variables and their potential to carry simulation of Lithuanian family benefits is presented in Appendix 164. Out of Table 5-1 indicated 14 cash benefits, 6 benefits could be simulated using EU-SILC data: 5 family benefits and a social (assistance) benefit. A benefit to conscript's child is further excluded due to lack of children among the identifiable conscripts.

The relative weight of the four family benefits, which are simulated, constitutes around $73 \%$ of the state budget for all family benefits in 2003 and 2004 . This share increased to $80 \%$ and $83 \%$ in 2005 and 2007 respectively. In 2004, social benefit consumed around $35 \%$ of the state budget on means of social assistance.

\section{Simulated policies}

Due to family benefits' interaction via income testing, the sequence of benefit simulation is conducted in a predefined order, which is indicated by numbers in parentheses (see Figure 5-1).

\footnotetext{
${ }^{64}$ This study is the first one evaluating EU-SILC capacity to simulate Lithuanian non-contributory benefits. Previously, Stirling \& Lazutka (2006) assessed the Household Budget Survey, the Labour Force Survey (LFS), and the Family Fertility Survey (FFS) as potential MSM input datasets for Lithuanian policies' inclusion into EUROMOD - the EU-wide tax benefit microsimulation model. At the moment of this study, Lithuanian policies are still on the way to be implemented in EUROMOD, but using the EU-SILC data.
} 
Figure 5-1. The simulation framework

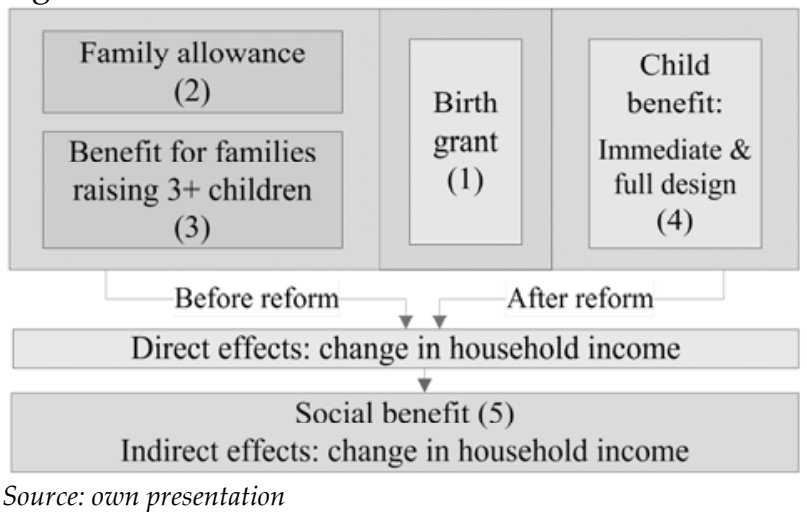

Because of gradual implementation of the child benefit, this study simulates two reform scenarios: the initial schedule, effective as of July 1, 2004, and the final schedule, which became effective as of January 1, 2008. Other policies, as well as socioeconomic and demographic structure of the population are held constant. We use Lithuanian policies (on family benefits and social assistance) specific rather than EU-SILC database definition of a child for the purpose of simulations ${ }^{65}$. Appendix 2 provides further details on the overall structure and selected technical parameters of the constructed LitFAMOD MSM.

\section{Measuring distributional impacts}

There are a number of ways to measure distributional impacts; this chapter focuses on a selection of commonly accepted inequality and poverty indices ${ }^{66}$ :

- The Laeken indicators: the Gini coefficient, S80/S20 income quintile share ratio, and at-risk-of-poverty rate (or also noted as $\mathrm{P0}$ );

- Foster-Greer-Thorbecke (FGT) indicators (Foster et al., 1984): poverty gap index (or also noted as P1) and poverty severity (or also noted as P2);

- $\quad$ GE class measures for inequality aversion parameter $a$ of values [-1; 2];

Indicators are calculated before and after (immediate and full design scenarios of) the reform; both direct and indirect reform effects are taken into account. Poverty line is fixed to the pre-reform settings. Welfare measures are based on household

\footnotetext{
${ }^{65}$ More details on EU-SILC used child definition could be found in EUROSTAT (2007a).

${ }^{66} \mathrm{GE}$ indexes and Gini coefficient are obtained through the application of the STATA module "ineqdeco" (Jenkins, 1999)66. The FGT family of poverty measures are estimated using STATA module "sepov" (Jollife and Semykina, 1999). We use a bootstrap simulation method in order to estimate standard errors for both poverty and inequality indexes.
} 
disposable income, equivalised with the modified OECD scale ${ }^{67}$. A change in income due to the reform is estimated by adding the difference between simulated transfers after the reform (child benefit and birth grant) and simulated benefits before the reform (birth grant, family benefit and benefit to families raising three or more children). Results are calculated, as well as broken down for household types depending on household configuration, age of the children and place of residence. EU-SILC definition of household types is used for presentation of simulation results $^{68}$. In order to better capture reform effects for, this chapter also presents between- and within-group inequality measures. All associated formulas are presented in Appendix 3 of this Chapter.

\subsection{Distributional impacts of family and child benefits reform}

\section{Benefit simulation results}

The simulated number of beneficiaries for most of the benefits, as well as their intermediate estimation values, match administrative data within the interval of $( \pm) 10 \%$ (see Table 5-2). In-between simulation results are presented in order to identify potential sources of observed differences. As Table 5-2 indicates, the largest deviations from external estimates are found in a benefit for families raising three or more children, child benefit and social assistance, while birth grant and family benefit reveal a rather precise estimation. Generally, differences in simulations are larger if more diverse causes of possible deviations accrue:

\footnotetext{
${ }^{67}$ Household disposable income is: the sum of all monetary income received from any source by each member of the household (including income from work, investment and social benefits) net of taxes and social contributions paid and certain unavoidable expenditures (EUROSTAT, 2008). The modified OECD equivalence scale assigns a weight of 1.0 to the first household member aged 14 or over; 0.5 to each additional member aged 14 or more and 0.3 to each member aged less than 14 years old.

${ }^{68}$ Lithuanian administrative and EU-SILC definition of a child are close matches, though small inconsistencies regarding children aged 18 to 23 exists. Under the Lithuanian rules, a child above the age of 17 should not be working or a full-time student and not married. In EU-SILC, children are those who are economically inactive and living with at least one parent. This implies that some persons identified as children under the Lithuanian law, would be classified as adults within the EU-SILC, and vice versus. The divergence in a number of children due to the differences in definitions is expected to be small. The EU-SILC defined household types are: one person household; 2 adults, no dependent children, both adults under 65 years; 2 adults, no dependent children, at least one adult 65 years or more; other households without dependent children; single parent household, one or more dependent children; 2 adults, one dependent child; 2 adults, two dependent children; 2 adults, three or more dependent children; other households with dependent children; other households.
} 
- Influences of underlying demographic differences (i.e. over-representation of new-born children, as in birth grant, or under-representation of children, aged 17 to 23 , as in child benefit);

- Identification of eligible population requires use of more socio-economic proxy variables to recreate "nuclear" family category, defined as parents or guardians and children only (i.e. EU-SILC contains no information on foster care and contains limited information to identify the full-time studying status of potentially eligible children).

- Simulation of social benefit requires means-testing. This might be affected by systematic income underreporting due to long recollection period, high nonresponse rates among top-income households or other survey related income reporting issues ${ }^{69}$, which could inflate a number of simulated social assistance beneficiaries.

In addition to simulation deficiencies due to household survey design, differences in estimated and reported number of beneficiaries could occur because of actual benefit take-up or targeting performance being lower than $100 \%$ (i.e. stigma, administrative complexity or targeting leakage related reasons $)^{70}$. Comparison of simulated and actual number of beneficiaries is also rather cumbersome due to shortage of administrative data. For example, we use the latest available 2001 Population census data to verify distribution of benefits for large families, even though the representation of this data for population in 2004 is weakened by relatively rapid changes in fertility rates and migration processes ${ }^{71}$. Also, administrative information might contain possible erroneous accounting of beneficiaries due to complexities of family identification, when merging quarterly collected regional data into the pooled annual central administrative social security database $\mathrm{T}^{72}$.

\footnotetext{
${ }^{69}$ For example, see Milanovic (1999) for more details on income underreporting in transition countries.

${ }^{70}$ More details on targeting and take up rates of social benefit in Lithuania, could be found at: http://siteresources.worldbank.org/SAFETYNETSANDTRANSFERS/Resources/2819451131468287118/1876750-1138736077420/Lithuania_Brief.pdf

${ }^{71}$ More details on fertility rates and international migration in Lithuania could be found at: http://www.stat.gov.lt/en/pages/view/?id=1383

${ }^{72}$ Based on personal communication with Social Security and Labour Ministry, 21 May, 2008
} 
Table 5-2. Family benefits: simulation versus administrative data

\begin{tabular}{|c|c|c|c|c|}
\hline & $\begin{array}{l}\text { Av. yearly } \\
\text { benefit per } \\
\text { beneficiary, } \\
\text { LTL[1] }^{[1]}\end{array}$ & $\begin{array}{l}\text { Beneficiaries, } \\
\text { EU-SILC } \\
\text { data }\end{array}$ & $\begin{array}{l}\text { Beneficiaries, } \\
\text { external data }\end{array}$ & $\Delta, \%$ \\
\hline Total population, beginning of 2005 & - & 3391098 & 3425324 & 1 \\
\hline Average family size & & 2.65 & 3.18 & -17 \\
\hline \multicolumn{5}{|l|}{ Transfers to families with children before reform: } \\
\hline Birth grant & $770(122)$ & 30729 & 29600 & 4 \\
\hline - children born in 2004 & $750(0)$ & 31560 & 30419 & 4 \\
\hline Family benefit & $1217(309)$ & 73409 & 74703 & -2 \\
\hline - eligible children & $1125(0)$ & 79403 & n.a. & n.a. \\
\hline - children aged 0 to 2 , beginning of 2005 & - & 89816 & 90302 & -1 \\
\hline Benefit for families raising 3 or more children & $1668(351)$ & 54332 & 41274 & 32 \\
\hline - eligible children & $330(36)$ & 183263 & n.a. & n.a. \\
\hline - children aged 0 to 15 , beginning of 2005 & - & 629125 & 637431 & -1 \\
\hline - children aged 16 to 23 , beginning of 2005 & - & 419068 & 426712 & -2 \\
\hline - families with 3 or more children until age 18 & - & 46855 & $49613[2]$ & -6 \\
\hline - persons in families with 3 or more children & - & 300969 & $278487[2]$ & 8 \\
\hline \multicolumn{5}{|l|}{ Transfers to families with children after reform: } \\
\hline Child benefit (immediate implementation) & $1341(832)$ & 206320 & 266000 & -22 \\
\hline - children aged 0 to 2 , beginning of 2005 & $1777(1114)$ & 89816 & 90302 & -1 \\
\hline - children aged 3 to 6 , beginning of 2005 & $600(0)$ & 130042 & 135762 & -4 \\
\hline - eligible children aged 7 to 23 , raised in 3 or & $600(0)$ & 148585 & n.a. & n.a. \\
\hline - all eligible children & $751(284)$ & 368443 & n.a. & n.a. \\
\hline - eligible children receiving $0.4 \mathrm{MSL}$ & $600(0)$ & 278627 & 320000 & -13 \\
\hline Child benefit (full design) & $1069(633)$ & 499714 & n.a. & n.a. \\
\hline - children aged 0 to 17 , beginning of 2005 & - & 743684 & 746274 & 0 \\
\hline - children ages 18 to 23 , beginning of 2005 & - & 304507 & 317869 & -4 \\
\hline - families with children under 18 & - & 473404 & $509973[2]$ & -7 \\
\hline - eligible children & - & 802954 & $700000^{[3]}$ & 15 \\
\hline \multicolumn{5}{|l|}{ Social assistance before reform (2004 for external data) } \\
\hline Social benefit & $1629(1167)$ & 97403 & 83463 & 17 \\
\hline \multicolumn{5}{|c|}{ Social assistance after reform (2005 for external data) } \\
\hline Social benefit, immediately after reform & $1601(1112)$ & 95001 & $54100^{[4]}$ & 76 \\
\hline Social benefit, given full design of reform & $1519(1035)$ & 89933 & n.a. & n.a. \\
\hline
\end{tabular}

Notes: [1] - Positive values only; [2] - Information from http://www.stat.gov.lt/ (2001 Population census) ; [3]

- Figure is based on an estimate by Social Security and Labour Ministry $=$ an average expected number of eligible children per month $\mathrm{x}$ 12: http://www.vtv.lt/naujienos/socialiniai-reikalai/vaiko-pinigaiskiriami-visiems-vaikams.html ${ }^{[4]}$ - The large difference in simulated and external data is largely due to different reference dates and our simulation of social benefit, mainly based on income rather than wealth testing. Simulated social benefit is primarily based on 2004 incomes, whereas external data reports distribution of social benefit given 2005 incomes. As no administrative records are available for social benefit expenses for the first and the second halves of 2004, the provided external indicator is the best estimation on the upcoming dynamics of social benefit.

Source: own calculation and other reported sources (standard errors presented in parentheses)

A note should be also made, that selected external data in Table 5-2. Family benefits: simulation versus administrative data also refer to expected rather than 
observed number of beneficiaries (i.e. eligible children receiving 0.4 MSL, children receiving child benefit after the full implementation of reform). These data helps to assess potential accuracy of ex-ante simulations.

\section{Disposable household income before and after the reform}

\section{Direct effects}

According to the EU-SILC data allowances to families and children constituted around $4 \%$ of average household income in $2004.16 \%$ of Lithuanian households received transfers to families, which on average amounted to $14 \%$ of their equivalised disposable income. Allowances to families play an especially significant role among poor households: more than $25 \%$ of the first income decile households receive these transfers. Their average weight within the household budget reaches $34 \%$.

The average simulated weight of transfers to families within household income before the reform constituted $16 \%$ of recipient households' income. Around $10 \%$ of all Lithuanian households receive these types of state transfers.

With the initial implementation of the reform, annual transfers to families raising children increased by around 78 LTL per household (see Figure 5-2). Full implementation of the reform would have raised household income by an additional 221 LTL per year, revealing a large impact of the reform still to be realised. Reform induced income gains are highly diverse for different types of households. Households raising three or more children gain mostly from the initial part of the reform. On the other hand, full implementation of the reform brings relatively higher gains to single parent families and families, raising one or two children, as before the reform most of these households were not eligible for existing benefits.

The performed simulation also suggests that despite significantly lower income levels, rural households have on average gained less than urban households during the initial reform implementation stage. This is largely due to the fact that rural households are larger, but poorer than urban households, and therefore had a higher incidence of family benefit receipt before the reform implementation. 
Figure 5-2. Average yearly equivalised household income by household types (direct effects), LTL
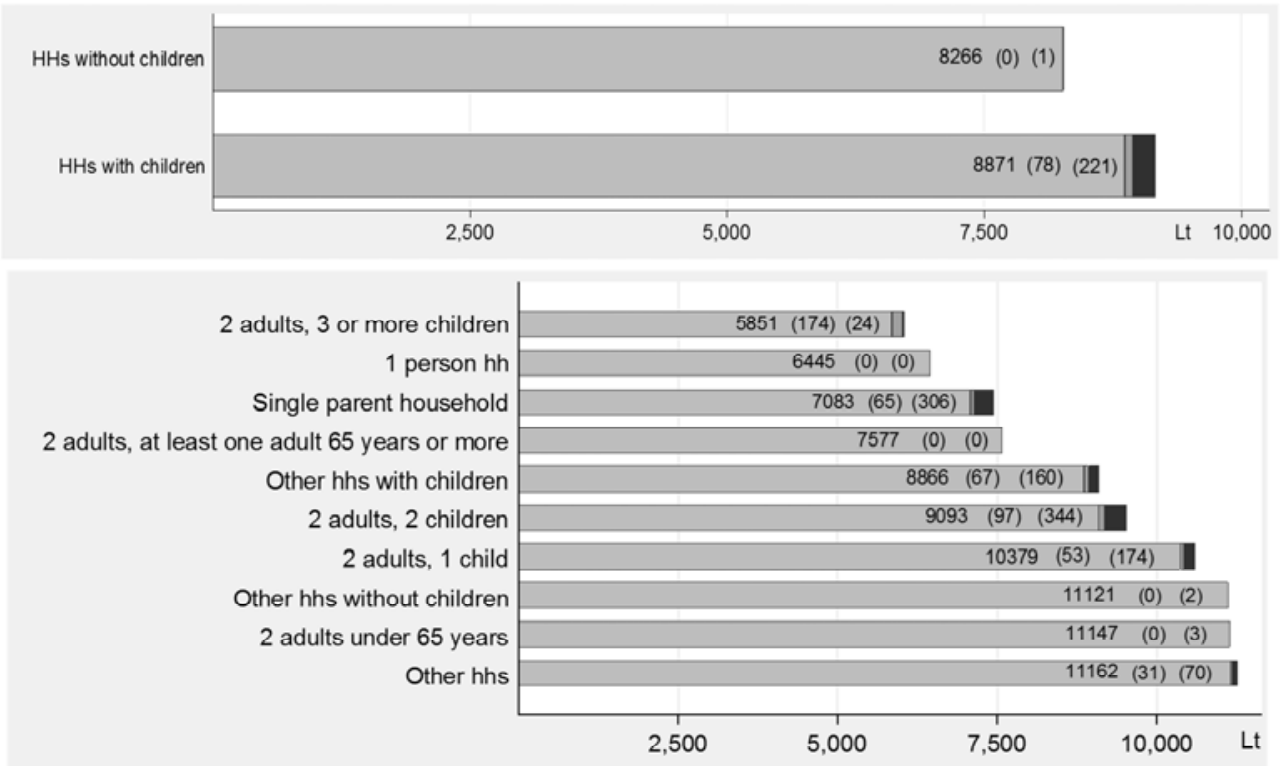

$\mathrm{HH}$ inc. before ref. Change in $\mathrm{HH}$ inc. due to immediate ref.

Additional change in $\mathrm{HH}$ inc. due to full design ref.
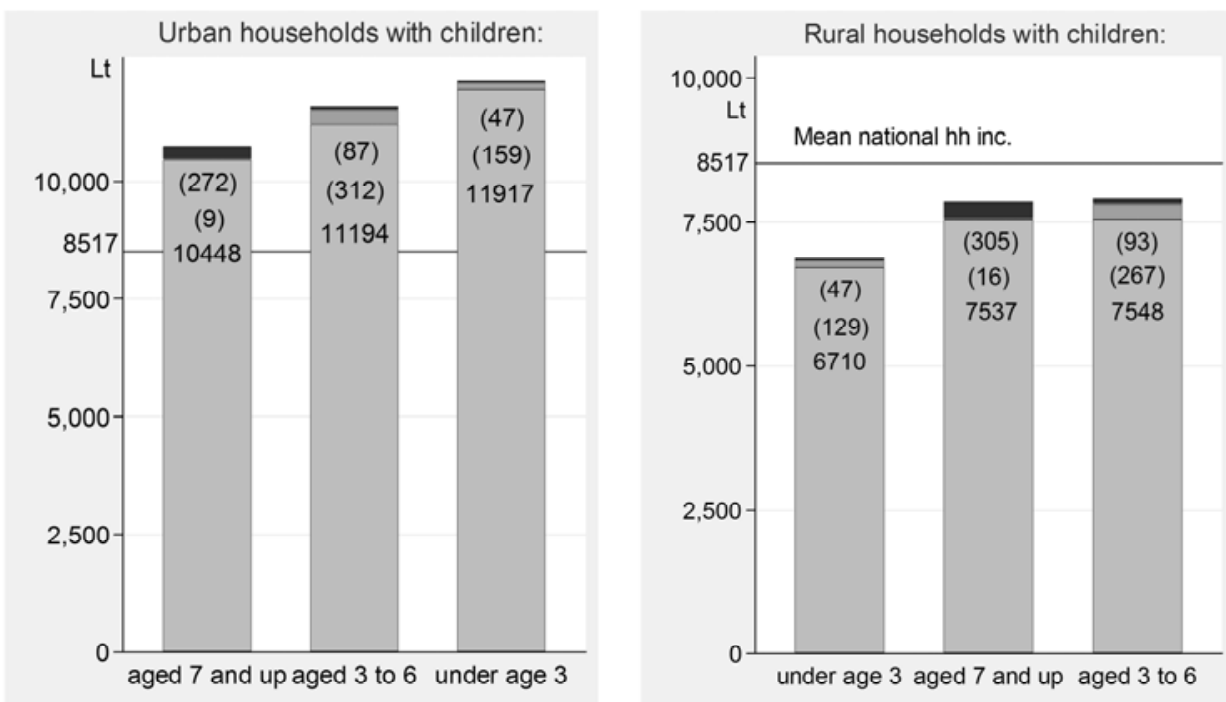

Notes: Values inside the bars show income before reform and income changes (in parentheses) due to the immediate or full design of the reform; Household types are ranked based on the group's average pre-reform equivalised household disposable income (ascending); Households with children in several age categories are assigned to a group based on the age of the youngest child.

Source: own calculations 
Furthermore, a breakdown of household by children's age indicates that households with at least one child under age three are found at completely opposite sides of the distribution if residence is taken into account: rural households annual income is more than 5000 LTL lower compared to their urban counterparts. In contrast, urban households with children aged seven or more are the poorest household type within this group. All rural households with children above age 3 have comparably similar mean income, which is significantly higher than income of households with very small children.

Additionally, Figure 5-2 demonstrates that on average income ranking of the analysed household types with or without children did not change due to the direct budgetary impacts of the reform. This finding particularly implies that direct income gains are not sufficiently large to significantly raise well-being of the most vulnerable household types: large families with children, single parent households or certain rural households with children. Thereby, poverty and particularly inequality implications of the reform are expected to be limited.

\section{Indirect effects}

As mentioned before, indirect effects measure change in household disposable income if change in eligibility and size of the cash social assistance benefit is considered. Adding the simulated value of this benefit increases the average weight of before reform transfers to families from $16 \%$ to $45 \%$ of recipient households' income. This corresponds to an increase in simulated yearly equivalised transfers from 684 LTL to 859 LTL.

Though no absolute loss in households' income is observed, Figure 5-3 reveals that gain in income of households' with children shrinks slightly from 78 LTL to 72 LTL when recalculation of social benefit is considered. The drop is even larger if the full design of the reform is considered: then income gains on average reduce from 221 LTL to 206 LTL. This finding proves that analysis of indirect effects is vital in order to comprehend the full reform effect on household income.

A significant loss in reform-related gains is especially observed for households that are eligible for social assistance, but with income close to the set threshold. Larger drops in income gains due to recalculation of social benefit amount are observed for e.g. rural families with children aged seven or more or with children aged three to six. Alternatively, the poorest rural households, which tend to raise children under three, are less affected by the change in eligibility for social benefit. As their income falls greatly below the given social assistance threshold compared to the other two household types, the probability of moving out of social assistance due to family benefits is much lower. Other relative losers of the reform are found to be single parent households. 
Figure 5-3. Average yearly equivalised household income change due to direct and indirect effects (by household types), LTL
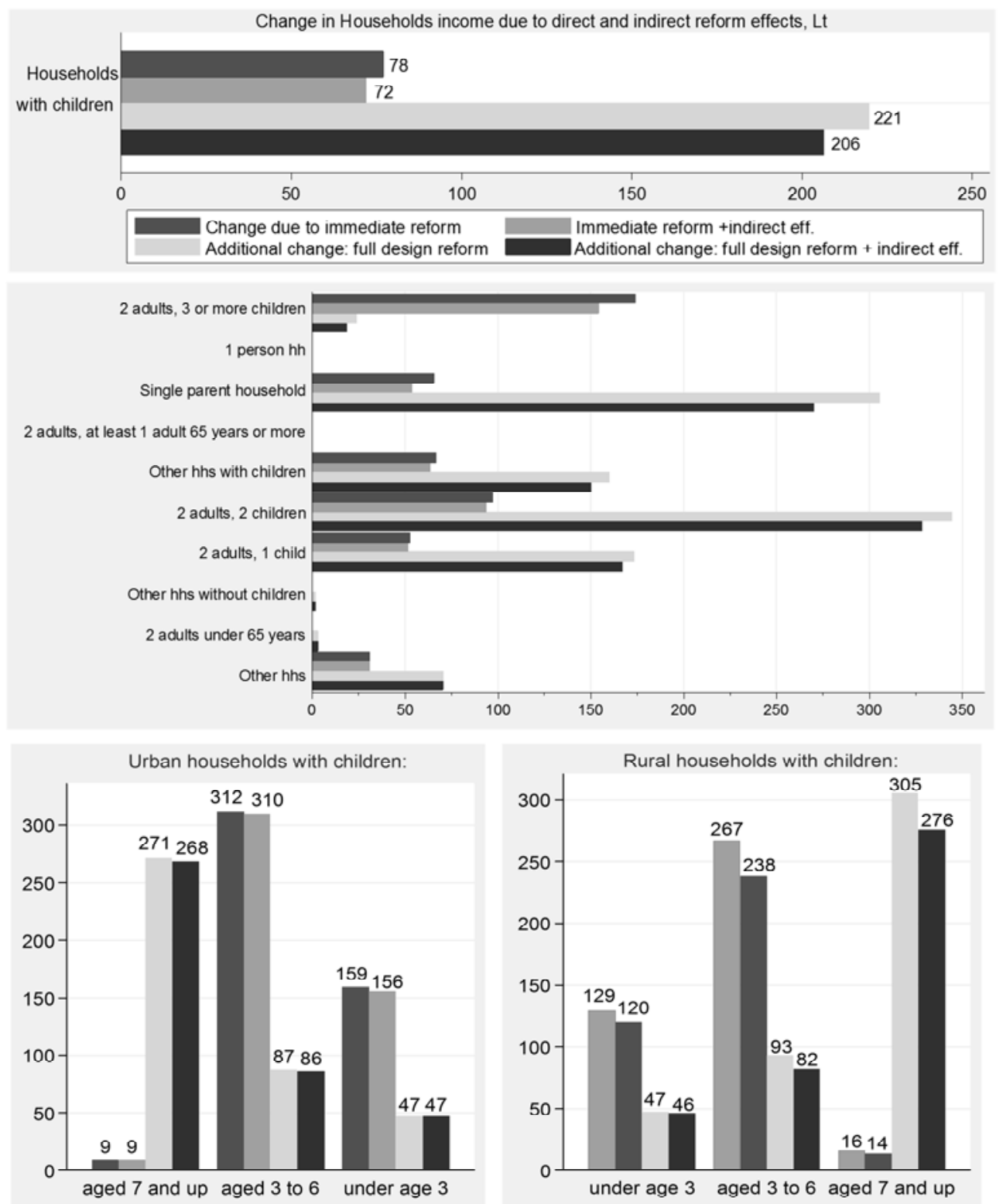

Notes: Household types are ranked based on the group's average pre-reform equivalised household disposable income (ascending); Households with children in several age categories are assigned to a group based on the age of the youngest child. Other households refer to such households, where e.g. conventional definition of a dependent child/adult cannot be directly applied (i.e. a teenager living without any other adult).

Source: own calculation 
Generally, Figure 5-3 confirms that more affluent households are less or not affected by reform associated influences on social assistance. Therefore, their income change is mainly driven by direct rather than indirect reform effects. For example, urban households, which tend to have higher than average national income, are less influenced by indirect reform effects. This is demonstrated by a negligible reduction or no change in income due to both immediate and full reform implementation scenarios.

\subsection{Poverty and inequality before and after the reform}

\section{Direct and indirect effects: total population}

Before the reform, $20.25 \%$ of Lithuanian population were poor ${ }^{73}$. Due to the initial part of the reform quite a few poor households in Lithuania would be lifted just above the poverty threshold (see Figure 5-4). Given relatively small child benefit amounts and rather minor changes in the amounts of other family benefits, a 0.5 percentage point decrease in poverty rate and a simultaneous relief in poverty gap and poverty severity could be considered as a positive poverty reduction action. If the full design of the reform would be implemented, the poverty alleviation would become even more significant: at risk of poverty rate would drop by approximately 1.5 percentage points.

Evaluation of direct and indirect reform effects confirm the observation that in reality the overall positive effect of the reform is lessened for households receiving social assistance. We observe a slight increase in poverty measures displaying direct versus total reform effects. Remarkably, this difference is not that significant as shown by the $95 \%$ confidence interval.

Inequality measures provide a similar picture of income mobility before and after the reform: overall inequality slightly reduces during both initial and final phases of the reform. It is worth pointing that these changes are only significant if the full reform design is taken into account. Full reform implementation would lead to greater equality, especially when comparing bottom and top income quintiles. For example, with full reform design s80/s20 income quintile ratio would reduce by more than 0.3 percentage points.

\footnotetext{
${ }^{73}$ EUROSTAT (http://epp.eurostat.ec.europa.eu) estimate for total Lithuanian at-risk-of-poverty rate after social transfers in 2005 is $21 \%$ (Date of extraction: October 15, 2008)
} 
Figure 5-4. Poverty changes: implications for total population

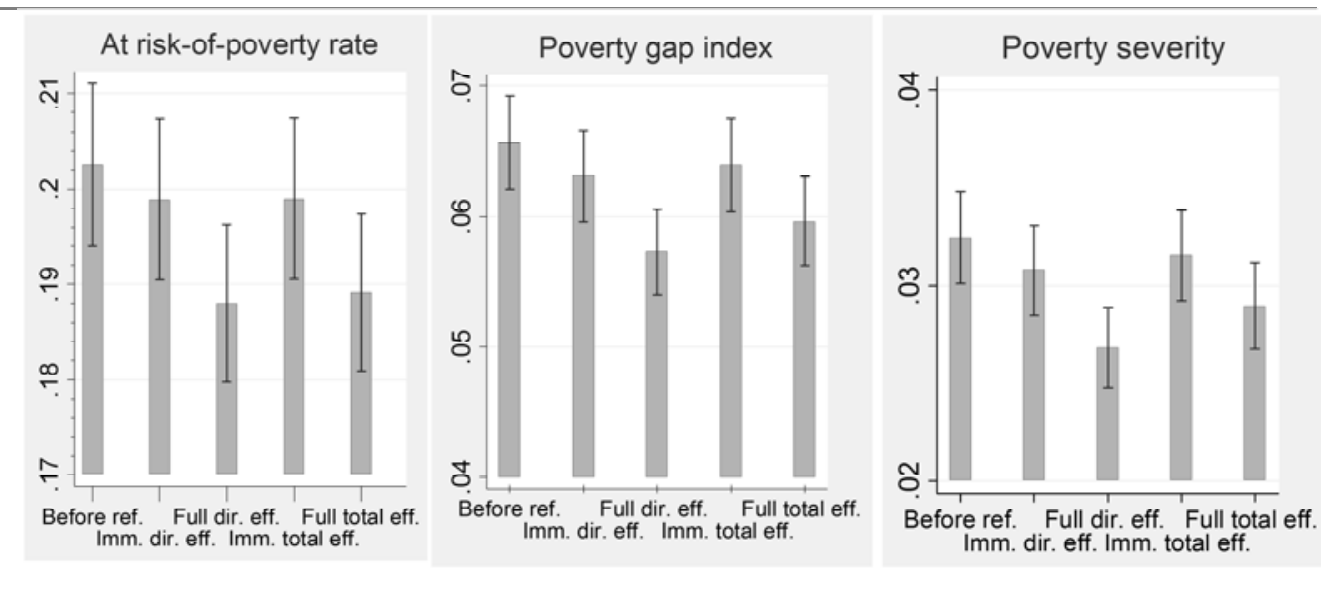

Note: Income ranking for poverty measures is based on the pre-reform income distribution, while income ranking for inequality measures reflects income distribution in pre-and post-reform environments.

Source: own calculation ('error bars' represent a 95\% confidence interval)

Figure 5-5 also depicts that the overall magnitude of inequality reduction is mitigated by relatively lower income gains for households at the threshold of receiving social assistance. This is captured by a slight increase in inequality measures if in addition to direct effects, indirect effects are also considered.

Figure 5-5. Inequality changes: implications for total population
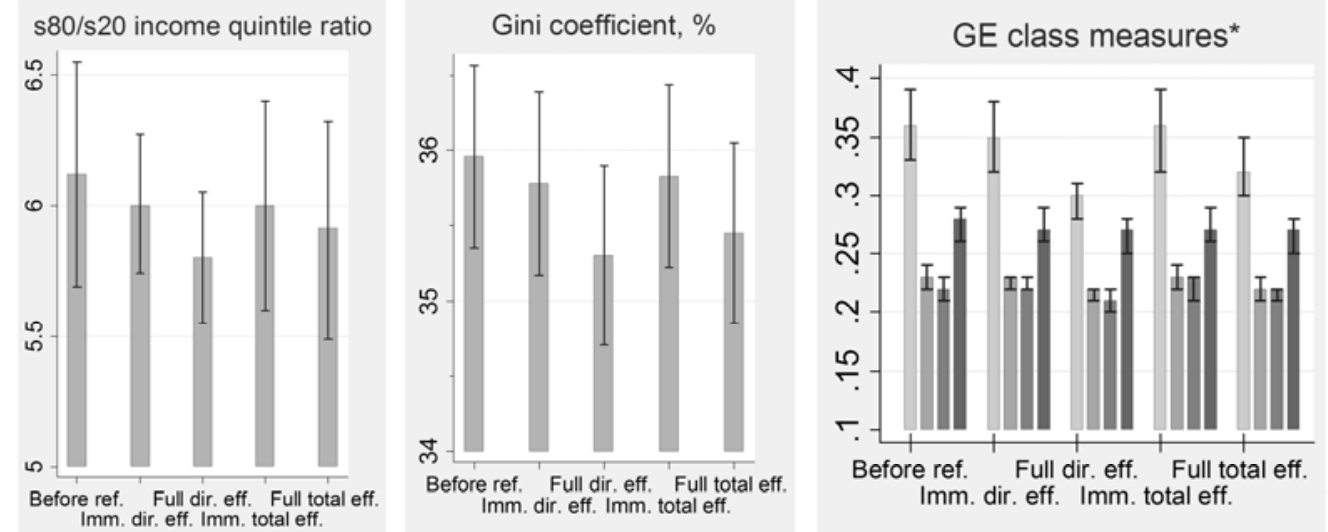

Note: * ${ }^{*} E(\alpha)$; for $\alpha[-1 ; 0,1,2]$ measures are ranked in $\alpha$ ascending order. Source: own calculation ('error bars' represent a 95\% confidence interval)

On the other hand, inequality measures, portraying changes in the upper part of income distribution (i.e. GE (2)), point out to almost no significant changes in 
inequality. This finding goes in line with previous observations that higher income households are relatively less affected by the monetary impacts of the reform.

\section{Direct and indirect effects: decomposition by household groups}

Figure 5-6 displays initial poverty indices before the reform, as well as their respective changes due to initial reform set-up and additional change if the full design reform is carried out. ${ }^{74}$ It reveals that all households raising children, except urban households with children, are more likely to be poor compared to the average poverty rate in the country. All households with children also experience poverty alleviation either in one or the other stage of the reform.

Yet, single parent households, the most deprived population group, gain most from the full reform scenario. The reverse observation holds for large households: they gain most from the initial reform scenario. The graph also displays that poverty intensity would be first and foremost addressed among single parent households. Actually, poverty gap and poverty severity indices reveal that this group is the most disadvantaged on all poverty dimensions, and that the full reform scenario brings largest gains to it.

Figure 5-6. Poverty changes (\%): implications for selected household groups

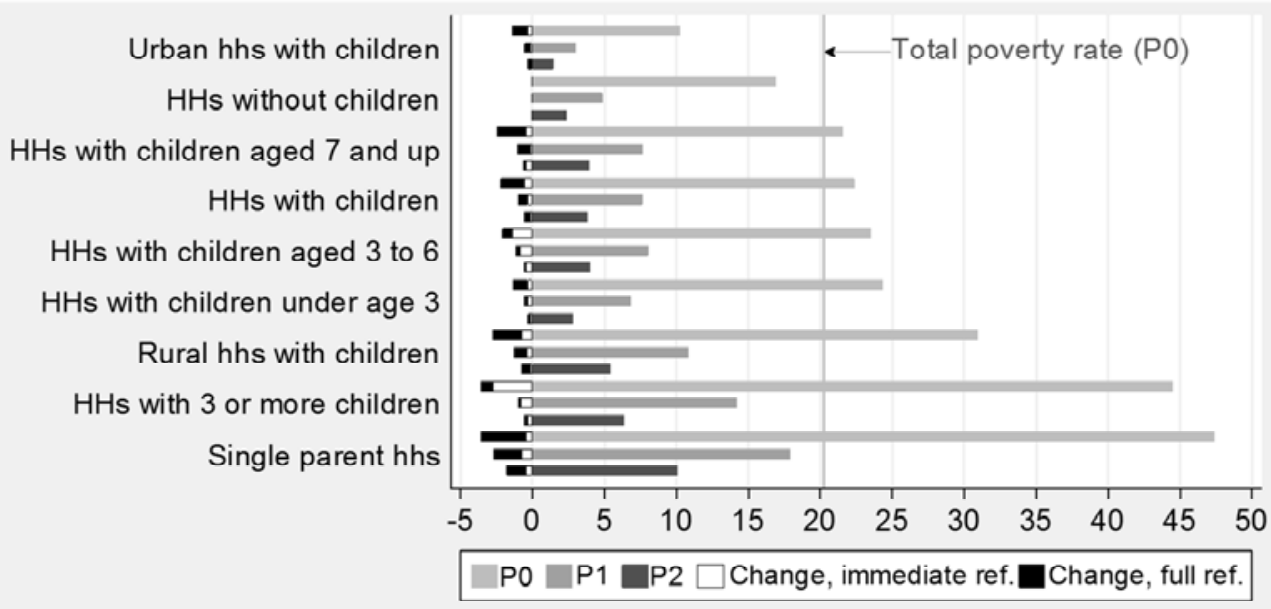

Note: household types are not exclusive and ranked based on the group's poverty rate before the reform Source: own calculation

Rural households with children are among primary gainers, mainly due to the initial reform implementation. The rules of gradual extension of eligibility to child benefit, based on number of children and their ages, are reflected in moderate

\footnotetext{
${ }^{74}$ Precise indices and associated standard errors are presented in Appendix 3.
} 
immediate poverty alleviation among households with children aged seven and up.

In addition to poverty decomposition, we analyse changes in inequality. For this purpose we form four broad household groups among dimensions of: living in a household with children, children's age, rural or urban residence place and income vulnerability.

Figure 5-7. Inequality changes (\%): implications for selected household groups

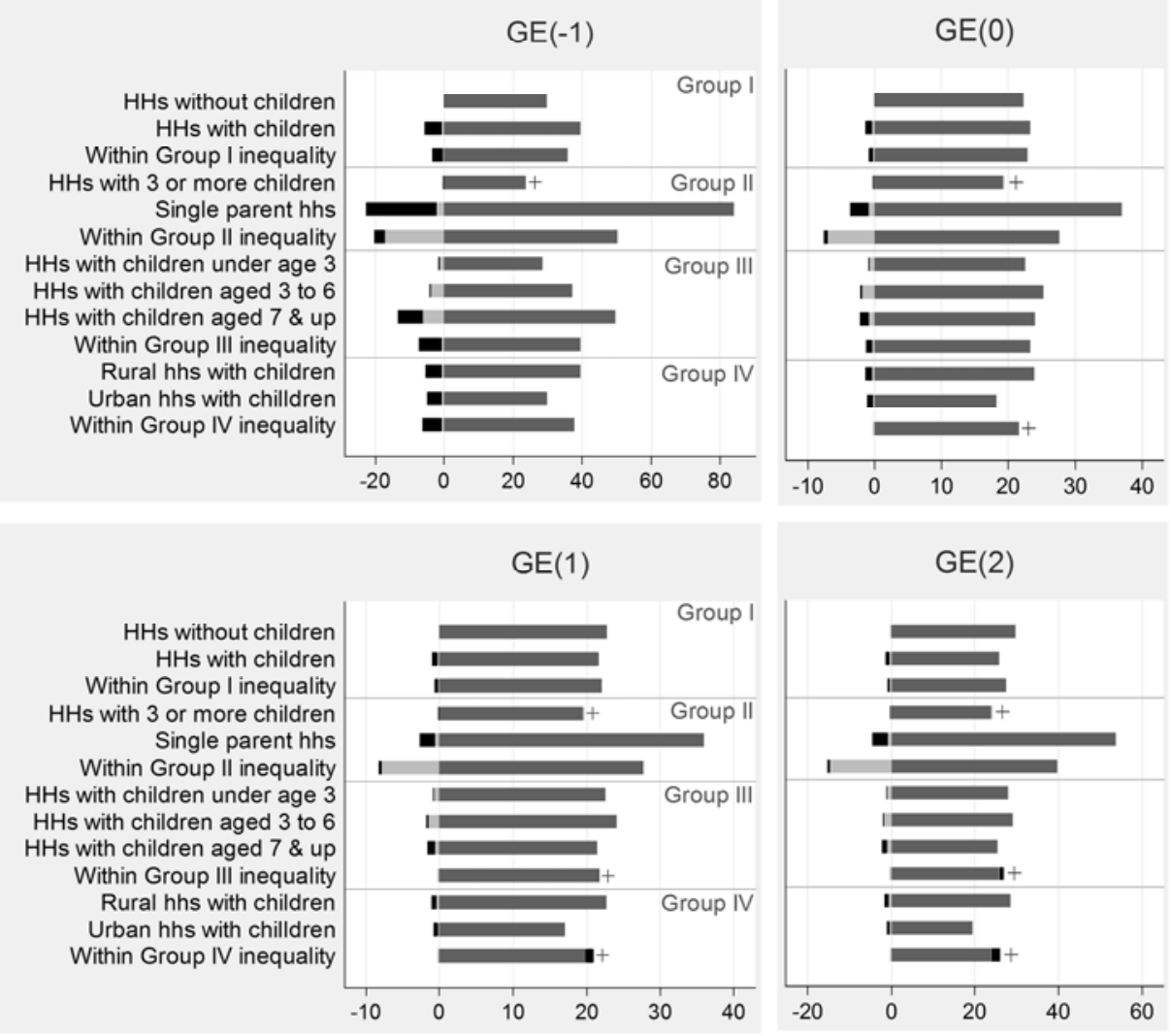

Before ref. Imm ref. $\mathbf{D}$ Full ref.

Notes: Groups [I-IV] are composed of mutually exclusive household types, as indicated on y axis; "+" indicates observation of an increase in inequality measure

Source: own calculations

Figure 5-775 reveals that the most widespread income inequality is observed among single parent households. This group is much more heterogeneous compared to

\footnotetext{
${ }^{75}$ Precise indices and associated standard errors are presented in Appendix 3 of this Chapter. Inequality between different household types is negligible; therefore, this data is not included here. Within group
} 
the next most vulnerable household group: large families with three or more children. If pooling these two household types into group II, as displayed in Figure 5-7, we identify diverse inequality changes during different reform stages. All $\mathrm{GE}(\alpha)$ measures, and particularly the ones focused on lower incomes, point to a sharp decrease in inequality among single parent households due to full reform implementation.

On the other hand, inequality among households with three or more children does not display any significant reduction, but rather point to a marginal rise of inequality among these families. If taken into account within group II inequality reduction, we note that opposing inequality movements led to narrowing income dispersion immediately after the reform. This indicates that broadening income dispersion among large families significantly reduced overall dispersion within the group II after the initial reform.

Overall, GE $(\alpha)$ measures focusing on higher incomes point to a marginal increase in inequality within group III (composed of all households raising children). As this group includes households with children, separated by different age categories, we conclude that despite slight inequality reduction among specific age groups, full reform implementation brings a small inequality increase within households with children.

The breakdown by residence place displays the largest within group inequality increase after the full reform implementation. As already observed in Figure 5-2, these two household groups have contrasting income profiles. Therefore, aggregate effect of tightening income dispersion among both rural and urban households, indicates an increasing income gap among households with children, if residence place is considered.

In sum, the reform has contributed towards narrowing income dispersion for all selected household groups (Figure 5-7). This principally holds for the lower part of income distribution. However, significant inequality reduction is also expected for overall income distribution, especially if looking at income movements among the poorest household types: large and single parent families. This analysis shows that single parent households are primary beneficiaries of the full design of the reform, while large families have received relatively more income gains with initial implementation of the reform.

inequality measure is sensitive to group's composition. As presented in Appendix 3, total inequality index $\mathrm{GE}(\alpha)$ is composed of each group's within and between inequality indexes: GE_within $(\alpha)+$ GE_between $(\alpha)$, Jenkins (2006). 


\subsection{Conclusions}

This chapter is one of the first attempts to use a microsimulation method for the evaluation of public policy effectiveness in Lithuania. We actually develop and utilise the first static microsimulation benefit model based on the EU-SILC household survey data for the analysis of distributional impacts of Lithuanian family benefit system's reform - LitFAMOD. EU-SILC data enables simulation of four family benefits, which together constitute around $73 \%$ of the state budget for all family benefits in 2004 . The simulated social benefit accounts for around $35 \%$ of the state budget on social assistance in 2004.

We find that the shift from means tested to universal family benefit system raised average population income without causing income losses for eligible households. Analysis of direct (only reformed family benefits) and indirect (with changes in social assistance) reform effects also suggests that total poverty and inequality declined in the country. From this point of view, the reform could be seen as effective in terms of reaching its overall anti-poverty goals, even though its capacity to alleviate poverty is very limited: we estimate 0.5 poverty headcount reduction due to initial and 1.5 percentage points' reduction due to full design reform implementation. This would bring Lithuanian total poverty rate to around 19\%: a level that is around three percentage points above the overall EU at-risk-ofpoverty rate $^{76}$.

The magnitude of income changes associated with the reform is small, which is also reflected in a small decrease in the number of social assistance recipients. We estimate that around $2 \%$ and $7 \%$ of Lithuanian families would be lifted out of dependence on social assistance respectively due to initial and full reform implementation. If take-up problems associated with pre-reform means tested family benefits are taken into account, actual gains are expected to be higher.

There are two main types of social implications of our results: one is related to the gradual implementation of the reform, which means temporary poverty or income loss to certain groups, the other highlights a change in the situation of groups after the full implementation of the reform. From a policy point of view, the latter is perhaps of greater relevance.

Due to gradual implementation of this reform, eligibility to universal child benefit was initially restricted to families raising less than three children if children were

\footnotetext{
${ }^{76}$ In 2005 , total EU at-risk-of-poverty rate after social transfers was at $16 \%$ (http://epp.eurostat.ec.europa.eu)
} 
above age of six. Because of that, we find that poverty reduction among these households is much larger in the case of the full reform implementation.

Our analysis also points to delayed income gains for one of the poorest population groups: single parent households. Actually, there are almost twice as many single parent households (5.8\% of all households) compared to households raising three or more children (3.3\% of all households), and both of these groups are recognised as primary anti-poverty targets. Nevertheless, our research reveals that single parent households would obtain income gains comparable to those of large families only when the full design reform scenario is implemented. If considering indirect effects, their relative gains become even smaller.

The full implementation of the reform would reduce poverty among rural households with children: a more vulnerable population group, especially if not only residence place, but also household composition and age of children is considered. Actually, our analysis points out that high poverty prevalence among households with children under age three is mainly due to extreme impoverishment of rural households. Taken into account a potential increase in inequality between rural and urban households with children after the full reform implementation, additional policy measures targeted at improving income situation of rural households seem appropriate.

This chapter also shows the importance of distributional analysis, given a rapidly changing policy context. We hope to have highlighted that this kind of evaluation research by using a microsimulation model can be a feasible and useful exercise for a country in transition such as Lithuania, both for ex ante and ex post monitoring of policy reforms. There is wide scope of potential research in this area. An important issue to tackle is of how to handle the rapidly changing demographic and socio-economic environment in a transition country. Another route for future research is to integrate the simulation framework presented here in a tool like the EU-wide tax-benefit microsimulation model EUROMOD (Immervoll, et al., 1999); this would open up the perspective of comparing Lithuanian tax-benefit policies more easily with those used in other countries. 


\subsection{Appendixes}

\section{Appendix 1: Rules of family benefits and EU-SILC capacity to simulate them}

\begin{tabular}{|c|c|c|c|c|c|c|c|c|}
\hline & $\begin{array}{l}\text { Benefit } \\
\text { type }\end{array}$ & \multicolumn{5}{|l|}{ Benefit rules } & $\begin{array}{l}\text { Limitations in } \\
\text { EU-SILC }\end{array}$ & $\begin{array}{l}\text { Simu- } \\
\text { lation }\end{array}$ \\
\hline 1 & $\begin{array}{l}\text { Birth } \\
\text { grant }\end{array}$ & \multicolumn{5}{|c|}{$\begin{array}{l}\text { The birth grant is a universal lump-sum benefit paid } \\
\text { upon the birth of a child to one of the parents or a } \\
\text { guardian. During the course of } 2004 \text { this benefit was } \\
\text { equal to } 6 \text { MSL. As of January 1, 2005, the size of this } \\
\text { benefit was increased to } 8 \text { MSL. }\end{array}$} & $\begin{array}{l}\text { Birth data: EU- } \\
\text { SILC indicates } \\
\text { the quarter of a } \\
\text { birth }\end{array}$ & Yes \\
\hline 2 & $\begin{array}{l}\text { Mater- } \\
\text { nity } \\
\text { benefit } \\
\text { for stu- } \\
\text { dying } \\
\text { women }\end{array}$ & \multicolumn{5}{|c|}{$\begin{array}{l}\text { A monthly benefit, given to pregnant women in } \\
\text { full time education who have no right to receive a } \\
\text { maternity benefit under the Law on Sickness and } \\
\text { Maternity Social Insurance. The benefit level } \\
\text { equalled to } 0.75 \text { MSL per month and was paid for } \\
\text { the } 70 \text { days preceding delivery. Since July } 1,2004 \text {, } \\
\text { this benefit was replaced by a pregnancy grant. }\end{array}$} & $\begin{array}{l}\text { Lack of } \\
\text { information on } \\
\text { receipt of } \\
\text { benefit; too few } \\
\text { observations }\end{array}$ & No \\
\hline 3 & $\begin{array}{l}\text { Preg- } \\
\text { nancy } \\
\text { grant }\end{array}$ & \multicolumn{5}{|c|}{$\begin{array}{l}\text { A lump-sum benefit to a pregnant unemployed } \\
\text { woman who, is not eligible to receive a maternity } \\
\text { leave benefit. The grant totals to } 2 \text { MSL and is } \\
\text { given upon the } 28^{\text {th }} \text { week of pregnancy ( } 70 \\
\text { calendar days before a baby is due). }\end{array}$} & $\begin{array}{l}\text { No information } \\
\text { on entitlement } \\
\text { to maternity } \\
\text { (paternity) } \\
\text { social insu- } \\
\text { rance; too few } \\
\text { observations }\end{array}$ & No \\
\hline 4 & $\begin{array}{l}\text { Family } \\
\text { allowan- } \\
\text { ce }\end{array}$ & \multicolumn{5}{|c|}{$\begin{array}{l}\text { A monthly benefit for families raising a child up } \\
\text { to the age of three. Its monthly amount equalled } \\
0.75 \text { MSL per eligible child. The benefit was paid } \\
\text { only if a family did not receive a corresponding } \\
\text { maternity (paternity) social insurance. The reform } \\
\text { integrated this allowance into the child benefit. }\end{array}$} & $\begin{array}{l}\text { No information } \\
\text { on maternity } \\
\text { (paternity) } \\
\text { social insurance }\end{array}$ & Yes \\
\hline \multirow[t]{5}{*}{5} & $\begin{array}{l}\text { Child } \\
\text { benefit }\end{array}$ & \multicolumn{5}{|c|}{$\begin{array}{l}\text { A monthly benefit for children up to the majority } \\
\text { age of } 18 \text { or older, if they continue in full time } \\
\text { secondary education. Full-time students from } \\
\text { families with } 3 \text { children or more, who continue in } \\
\text { secondary or higher education, are eligible for the } \\
\text { benefit until age } 24 \text {. The benefit size is determined } \\
\text { by the child's age and the size of the family: }\end{array}$} & $\begin{array}{l}\text { Birth data: EU- } \\
\text { SILC indicates } \\
\text { the quarter of a } \\
\text { birth }\end{array}$ & \multirow[t]{5}{*}{ Yes } \\
\hline & & & & $\begin{array}{l}\text { Child } \\
\text { aged } \\
3 \text { to } 6\end{array}$ & $\begin{array}{l}\text { Child } \\
\text { aged } 7 \\
\text { to } 18\end{array}$ & $\begin{array}{l}\text { Child aged } \\
19 \text { to } 24, \text { if in } \\
\text { full time } \\
\text { education }\end{array}$ & & \\
\hline & & $\begin{array}{l}1 \text { or } 2 \\
\text { children }\end{array}$ & $\begin{array}{l}0.75 \\
\text { MSL }\end{array}$ & $\begin{array}{l}0.4 \\
\text { MSL }\end{array}$ & $\begin{array}{l}0.4 \\
\text { MSL* }\end{array}$ & $0.4 \mathrm{MSL}^{77 *}$ & & \\
\hline & & $\begin{array}{l}3 \text { or more } \\
\text { children }\end{array}$ & $\begin{array}{l}1.1 \\
\text { MSL }\end{array}$ & $\begin{array}{l}0.4 \\
\text { MSL }\end{array}$ & $\begin{array}{l}0.4 \\
\text { MSL }\end{array}$ & $0.4 \mathrm{MSL}$ & & \\
\hline & & \multicolumn{5}{|c|}{${ }^{*}$ Entitlement available only since January, 2008} & & \\
\hline 6 & Benefit & \multicolumn{5}{|c|}{ A monthly benefit paid for each child during the } & Approx. & Yes \\
\hline
\end{tabular}

77 Only if in secondary education 


\begin{tabular}{|c|c|c|c|c|}
\hline & $\begin{array}{l}\text { Benefit } \\
\text { type }\end{array}$ & Benefit rules & $\begin{array}{l}\text { Limitations in } \\
\text { EU-SILC }\end{array}$ & $\begin{array}{l}\text { Simu- } \\
\text { lation }\end{array}$ \\
\hline & $\begin{array}{l}\text { to } \\
\text { conscrip } \\
\text { t's child }\end{array}$ & $\begin{array}{l}\text { military service of the father. The level of the } \\
\text { benefit is equal to } 1.5 \mathrm{MSL} \text {. The recipient of this } \\
\text { benefit also has the right to receive a monthly } \\
\text { child benefit as described above. }\end{array}$ & $\begin{array}{l}\text { information on } \\
\text { the duration of } \\
\text { compulsory } \\
\text { military service; }\end{array}$ & \\
\hline 7 & $\begin{array}{l}\text { Benefit } \\
\text { for } \\
\text { families } \\
\text { raising } \\
3+ \\
\text { children }\end{array}$ & $\begin{array}{l}\text { A monthly } 1.0 \text { MSL benefit for the } 3^{\text {rd }} \text { child; the } \\
\text { amount for the } 4^{\text {th }} \text { and each additional child was } \\
\text { increased by } 0.3 \text { MSL. Income testing }{ }^{78} \text { was not } \\
\text { applied for families raising more than } 3 \text { children. } \\
\text { From July } 1,2004 \text {, this benefit was integrated into } \\
\text { the child benefit. The reform also provided an } \\
\text { income security measure for large families: if the } \\
\text { calculated child benefit would be lower than the } \\
\text { previously received benefit for families raising three } \\
\text { or more children, a family should continue } \\
\text { receiving the latter benefit until a change in } \\
\text { entitlement rights occurs. }\end{array}$ & $\begin{array}{l}\text { Approximate } \\
\text { reconstruction } \\
\text { of income list, } \\
\text { as indicated by } \\
\text { the law. }\end{array}$ & Yes \\
\hline 8 & $\begin{array}{l}\text { Guar- } \\
\text { dianship } \\
\text { benefit }\end{array}$ & $\begin{array}{l}\text { A monthly benefit for a child placed in a family } \\
\text { or non-governmental institution during the } \\
\text { period of the guardianship. Its amount equals to } \\
4 \mathrm{MSL} \text { per month. In some cases the benefit can } \\
\text { be paid until the child reaches the age of } 24 \text {. }\end{array}$ & $\begin{array}{ll}\text { Lack } & \text { of } \\
\text { information } & \text { to } \\
\text { determine } & \\
\text { adoptive } & \\
\text { parents } & \end{array}$ & No \\
\hline 9 & $\begin{array}{l}\text { Or- } \\
\text { phan's } \\
\text { stipend }\end{array}$ & $\begin{array}{l}\text { A monthly benefit paid to unemployed full-time } \\
\text { students until the age of } 24 \text { if both parents have } \\
\text { passed away. The amount of the benefit was } \\
\text { equal to } 4 \text { MSL. The reform has transformed it } \\
\text { into the guardianship benefit }\end{array}$ & $\begin{array}{lr}\text { Lack } & \text { of } \\
\text { information on } \\
\text { the loss of } \\
\text { parents }\end{array}$ & $\mathrm{No}$ \\
\hline 10 & $\begin{array}{l}\text { Grant } \\
\text { for } \\
\text { housing }\end{array}$ & $\begin{array}{l}\text { A lump sum benefit, given to a child upon the } \\
\text { expiration of guardianship. The benefit is given } \\
\text { to purchase a dwelling or to cover } \\
\text { accommodation related expenses. The entitled } \\
\text { benefit amounts to } 50 \mathrm{MSL} \text {. It cannot be paid in } \\
\text { cash, unless the unused part of the grant is less } \\
\text { than } 1 \mathrm{MSL} \text {. }\end{array}$ & $\begin{array}{ll}\text { Lack } & \text { of } \\
\text { information } & \text { to } \\
\text { determine } & \\
\text { adoptive } & \\
\text { parents } & \end{array}$ & $\mathrm{No}$ \\
\hline 11 & $\begin{array}{l}\text { Social } \\
\text { benefit }\end{array}$ & $\begin{array}{l}\text { A means tested benefit, which depends on the one } \\
\text { hand on the value of the family or person's assets, } \\
\text { and on the other on the level of per capita family } \\
\text { income. The size of the social benefit is equal to } 90 \% \\
\text { of the difference between the amount of SSI per } \\
\text { family (single resident) and the average monthly } \\
\text { income per family (single resident). }\end{array}$ & $\begin{array}{l}\text { Lack of } \\
\text { information on } \\
\text { the household } \\
\text { assets }\end{array}$ & $\begin{array}{l}\text { Yes/ } \\
\text { partial }\end{array}$ \\
\hline 12 & $\begin{array}{l}\text { Com- } \\
\text { pen- } \\
\text { sation }\end{array}$ & $\begin{array}{l}\text { A means tested benefit, which depend on the actual } \\
\text { cost of heating, sewage and hot and cold water used. } \\
\text { The granted compensation is equal to the part of }\end{array}$ & $\begin{array}{l}\text { Lack of } \\
\text { information on } \\
\text { the household }\end{array}$ & No \\
\hline
\end{tabular}

\footnotetext{
${ }^{78}$ The income test condition is to have per capita family income less than 3 SSI levels. Income list includes income from work, agricultural and commercial activities, property rent, dividends, aliments, pensions, scholarship, social support and incomes of other types of activities.
} 


\begin{tabular}{|c|c|c|c|c|}
\hline & $\begin{array}{l}\text { Benefit } \\
\text { type }\end{array}$ & Benefit rules & $\begin{array}{l}\text { Limitations in } \\
\text { EU-SILC }\end{array}$ & $\begin{array}{l}\text { Simu- } \\
\text { lation }\end{array}$ \\
\hline & $\begin{array}{l}\text { for } \\
\text { housing } \\
\text { utilities }\end{array}$ & $\begin{array}{l}\text { expenses that exceed the thresholds set under the } \\
\text { benefit means conditions. }\end{array}$ & $\begin{array}{l}\text { assets and } \\
\text { actual expenses } \\
\text { on utilities }\end{array}$ & \\
\hline 13 & $\begin{array}{l}\text { Free } \\
\text { school } \\
\text { meals }\end{array}$ & $\begin{array}{l}\text { Free provision of school meals at the primary, basic, } \\
\text { secondary or special education institutions during the } \\
\text { academic year. It consists of lunch and breakfast for } \\
\text { pupils from extremely low-income families and free } \\
\text { meals during summer holidays at summer day } \\
\text { camps. The benefit is granted if the monthly per } \\
\text { capita family income is lower than } 1.5 \text { of SSI or if the } \\
\text { family receives a social benefit. }\end{array}$ & $\begin{array}{l}\text { Lack of } \\
\text { information on } \\
\text { the attendance } \\
\text { of summer } \\
\text { camps/ lack of } \\
\text { monetary value } \\
\text { of the provision }\end{array}$ & No \\
\hline 14 & $\begin{array}{l}\text { Free } \\
\text { school } \\
\text { supplies }\end{array}$ & $\begin{array}{l}\text { During the course of } 2004 \text {, the provision of school } \\
\text { supplies was not defined by any particular law, but } \\
\text { based on the availability of the state assigned budget. }\end{array}$ & $\begin{array}{l}\text { Lack of policy } \\
\text { rules }\end{array}$ & No \\
\hline 15 & $\begin{array}{l}\text { A } \\
\text { subsidy } \\
\text { for baby } \\
\text { diapers }\end{array}$ & \multicolumn{2}{|c|}{$\begin{array}{l}\text { Only a temporary measure: (introduced in September, } 2004 \text { and } \\
\text { abolished in 2005) }\end{array}$} & No \\
\hline 16 & $\begin{array}{l}\text { Muni- } \\
\text { cipal } \\
\text { support }\end{array}$ & \multicolumn{2}{|l|}{ Lack of information on benefit eligibility rules } & No \\
\hline
\end{tabular}

Additional explanations: (1) Beneficiaries of specific family and child benefits are not identified in EU-SILC. The database only contains an aggregate on family/children related allowances, which is defined as financial support to households raising children or taking care of relatives other than children (EUROSTAT, 2007a). Due to the aggregate nature of this variable, it cannot be used for the identification of receipt of specific transfers. The same is true for social assistance benefits. (2) EU-SILC does contain individual demographic information, as well as descriptions of personal socio-economic characteristics, which enable full or partial simulation of 9 out of 15 family policy measures. (3) Due to the lack of EU-SILC information (i.e. foster care, loss of parent, actual expenses on utilities, socio-economic status in the previous year) orphan's stipend, guardianship benefit, grant for housing, compensation for housing utilities, the maternity benefit for studying women and the pregnancy grant could not be simulated. (4) The benefit to conscript's child could not be simulated as EU-SILC identifies only 9 persons in compulsory military service - none of them have children. (5) Other benefits are excluded from simulation due to ambiguous rules or timing of implementation. For example, municipal support is not simulated due to lack of clear eligibility rules. A subsidy for baby diapers is excluded from the further analysis, as it was only a temporary policy measure (not applicable at the timing of our simulation). Eligibility to free school meals could not be simulated, unless by establishing the monetary value of this benefit. (6) The meaning of the "extremely lowincome" families was not explicitly defined until 2006, when the Law on Social Assistance to Pupils came into force. Since then, children growing in the families, which have per capita household income lower than 1 SSI, were given a right to both free lunch and breakfast. (7)Free school meals could also be granted if special circumstances, such as parents becoming severely sick or unemployed due to disability, occur. 


\section{Appendix 2: Overview of LitFAMOD}

\section{Rationale}

As no microsimulation model yet exists in Lithuania (as of 2008), which could enable analysis of the family benefits' reform, own LitFAMOD partial static microsimulation model is developed. This means, that for the first time this chapter analysed benefits are parameterized (using STATA programming language) within the simulation structure.

\section{LitFAMOD and other MSMs}

A number of technical parameters of this model could be aligned to the EUROMOD - the EU wide tax-benefit microsimulation model. For example, both EUROMOD and LitFAMOD use STATA programming language to adjust EUSILC data for simulation purposes (adequate data preparation is a major task for any MSM construction). Also, LitFAMOD policy rules before the reform are taken as of June 30. The same reference date choice is made by the EUROMOD developers for simulating each calendar year. As LitFAMOD is tailored for this specific analysis, policy rules are transcribed not only on June 30, 2004, but also on July 1, 2004 and June 30, 2008.

Policy years: 2004 and 2008.

\section{Simulated policies}

Birth grant; child benefit; family allowance; benefit for families raising 3+ children; social (assistance) benefit. Other benefits, taxes and social contributions are not simulated, but observed from the EU-SILC data (in the aggregate form or as final disposable income).

\section{Software use}

LitFAMOD is entirely written in STATA script, with both policy parameters and EU-SILC data treated via the number of subsequent " $\mathrm{do}^{\prime}$ f files. The data is stored in .txt files. While such a structure is convenient for the purpose of its construction aim (i.e. analysis of the family benefit reform in 2004), adjustment of the LitFAMOD files for the other types of policy analyses requires significant additions and changes into the STATA files' contents and sequence. The decision to implement such a structure is related to a few factors: 1) in case of external model's use, the user has a full control on adjusting the entire model's parameters; 2) the structure is technically feasible, as the model operates within a relatively limited number of parameters (i.e. selected benefits only and one country). 


\section{Simulation routine}

As LitFAMOD is the first Lithuanian MSM, a special attention has been paid in establishing simulation order. The selected benefits' inter-relations have to be assessed before establishing the simulation order. Social assistance benefit is simulated as the last one, as it requires means-testing inclusive of (simulated) transfers to families.

\section{Assumption on take-up}

an assumption of $100 \%$ take-up rates for all transfers to families is assumed.

\section{Simulation of social (assistance) benefit}

First, income as defined by the law on social assistance is approximated using EUSILC available incomes; second, income test is applied and potential beneficiaries are identified; third, as no wealth data is available in EU-SILC, diverse assumptions of housing characteristics are used to identify potential beneficiaries (i.e. households entitled to social housing, households with lower imputed rent values are included); fourth, data from administrative records is used to calibrate the cut-off value for the wealth test; fifth, combined wealth and income test identifies final beneficiaries; sixth, wealth test is not changed for the reform scenarios, while income test is applied on the new set of corresponding (simulated) incomes.

\section{Sequence of STATA programming files}

1) merging EU-SILC individual and household level files, identifying Lithuanian data; 2) EU-SILC adaptation for MSM purposes (see more detailed explanation below); 3) Programming policy rules; 4) Identifying direct effects; 5) Identifying indirect effects; 6) Absolute income changes; 7) Poverty and inequality analysis; 8) Decomposition by household groups.

\section{EU-SILC adaptation for MSM}

First, 15 households with non-response inflation factor are dropped; second, babies born in 2005 and until the survey data is collected (May-June) are dropped from the analysis - this ensures coherence between reference times for demographic and income variable; third, demographic data is available for all included individuals; fourth, missing income values are imputed using linear regression method; fifth, weighted estimates of demographic variables are checked against the administrative records (while number of children under 5 years old has a very close match to administrative data, a small under-estimation is observed for the weighted number of children/persons between 6 and 24 years old); sixth, EU-SILC inconsistencies on partner/parent identifications links are identified and fixed; seventh, family units, as defined by Lithuanian laws, are established (moving away 
from household definition used in EU-SILC); eight, inconsistencies related to children "living alone" fixed. 


\section{Appendix 3: Index calculations}

\section{Common notations}

- y - equivalised disposable income;

- w - personal cross-sectional weight;

- $\mathrm{i}$ - person $\mathrm{i}$.

- $\quad w^{\prime} i$ - the weight for person $i$;

- $\quad \mathrm{z}$ - at risk-of-poverty threshold;

- $\alpha$-sensitivity parameter.

\section{Gini coefficient}

It is defined as the relationship of cumulative shares of the population arranged according to the level of income, to the cumulative share of the total income received by them (EUROSTAT, 2005):

$$
G I N I=100 *\left[\frac{2 * \sum_{i=1^{s t} \text { person }}^{\text {last person }}\left(w^{\prime} i^{*} y_{i} * \sum_{1^{s t}}^{\text {person }} w^{\prime} i\right)-\sum_{i=1^{s t} \text { person }}^{\text {person } i}\left(w^{\prime} i\right)^{2} * y_{i}}{\left(\sum_{i=1^{s t} \text { person }}^{\text {last person }}\left(w^{\prime} i\right)\right) * \sum_{i=1^{\text {st }} \text { person }}^{\text {last person }}\left(w^{\prime} i^{*} y_{i}\right)}-1\right]
$$

S80/S20 income quintile $(Q)$ share ratio

The ratio of the sum of income received by the $20 \%$ of the country's population with the highest income to that received by the $20 \%$ of the country's population with the lowest income (EUROSTAT, 2005):

$S 80 / S 20=\frac{\sum_{5^{\text {th }} \text { Qpersons }} w^{\prime} i^{*} y_{i} / \sum_{5^{\text {th }} \text { Qpersons }} w^{\prime} i}{\sum_{1^{\text {st }} \text { Qpersons }} w^{\prime} i_{i} / \sum_{1^{\text {st }} \text { Qpersons }} w^{\prime} i}$

\section{At-risk-of-poverty rate}

The percentage of persons, over the total population, with an income below the 'atrisk-of-poverty threshold (poverty line)', set at $60 \%$ of the national median income(EUROSTAT, 2005):

$$
P_{0}=\frac{\sum_{\text {persons with }} w^{\prime} i}{\sum_{\text {Total population }} w^{\prime} i} * 100
$$




\section{Poverty gap}

It measures the average difference between the income of poor people (people with income below the at-risk-of poverty threshold) and poverty line.

Poverty severity

This index is defined as the squared poverty gap index.

$$
P_{\alpha}=\frac{1}{\sum_{\text {Total population }} w^{\prime} i} * \sum_{\text {persons with } y<z} w^{\prime} i\left(\frac{z-y_{i}}{z}\right)^{\alpha}
$$

where $\alpha=1$ indicates poverty gap index; $\alpha=2$ indicates poverty severity index.

General Entropy (GE) inequality measures

The general formula is the following:

$G E(\alpha)=\frac{1}{\alpha^{2}-\alpha}\left[\frac{1}{\sum_{\text {Total population }} w^{\prime} i} * \sum_{i=1}^{\text {Total population }} w^{\prime} i\left(\frac{y_{i}}{\bar{y}}\right)^{\alpha}-1\right]$,

where $\bar{y}$ is the mean national income and $\alpha$ is an income difference sensitivity parameter.

The parameter $\alpha$ in the GE class represents the weight given to different incomes of the income distribution. It can take any real value. GE is more sensitive to changes in the lower tail of the income distribution at the lower $\alpha$ values, and vice versus. 
Appendix 4: Decomposition of poverty and inequality measures by household groups

\begin{tabular}{|c|c|c|c|c|c|c|c|c|c|c|}
\hline \multirow[b]{2}{*}{ POVERTY } & \multirow[t]{2}{*}{$\begin{array}{l}\% \text {, of all } \\
\text { households }\end{array}$} & \multicolumn{3}{|c|}{ Before reform } & \multicolumn{3}{|c|}{$\begin{array}{l}\text { After immediate reform, } \\
\text { direct + indirect effects }\end{array}$} & \multicolumn{3}{|c|}{$\begin{array}{l}\text { After full reform, direct + } \\
\text { indirect effects }\end{array}$} \\
\hline & & P0, \% & $\mathrm{P} 1, \%$ & $\mathrm{P} 2, \%$ & P0, \% & $\mathrm{P} 1, \%$ & $\mathrm{P} 2, \%$ & $\mathrm{P} 0, \%$ & $\mathrm{P} 1, \%$ & $\mathrm{P} 2, \%$ \\
\hline Total & 100.00 & 20.25 & 6.57 & 3.24 & 19.90 & 6.96 & 3.15 & 18.92 & 5.96 & 2.90 \\
\hline $\begin{array}{l}\text { Households, } \\
\text { without } \\
\text { children }\end{array}$ & 57.47 & $\begin{array}{l}16.91 \\
(0.66)\end{array}$ & $\begin{array}{l}4.91 \\
(0.26)\end{array}$ & $\begin{array}{l}2.36 \\
(0.17)\end{array}$ & $\begin{array}{l}16.91 \\
(0.66)\end{array}$ & $\begin{array}{l}4.91 \\
(0.26)\end{array}$ & $\begin{array}{l}2.36 \\
(0.17)\end{array}$ & $\begin{array}{l}16.90 \\
(0.66)\end{array}$ & $\begin{array}{l}4.90 \\
(0.26)\end{array}$ & $\begin{array}{l}2.36 \\
(0.17)\end{array}$ \\
\hline $\begin{array}{l}\text { Households } \\
\text { with children }\end{array}$ & 42.53 & $\begin{array}{l}22.40 \\
(0.57)\end{array}$ & $\begin{array}{l}7.63 \\
(0.25)\end{array}$ & $\begin{array}{l}3.81 \\
(0.16)\end{array}$ & $\begin{array}{l}21.81 \\
(0.57)\end{array}$ & $\begin{array}{l}7.35 \\
(0.24)\end{array}$ & $\begin{array}{l}3.66 \\
(0.16)\end{array}$ & $\begin{array}{l}20.21 \\
(0.55)\end{array}$ & $\begin{array}{l}6.65 \\
(0.23)\end{array}$ & $\begin{array}{l}3.24 \\
(0.15)\end{array}$ \\
\hline $\begin{array}{l}\text { Households } \\
\text { with } 3 \text { or } \\
\text { more children }\end{array}$ & 3.33 & $\begin{array}{l}44.47 \\
(1.99)\end{array}$ & $\begin{array}{l}14.24 \\
(0.82)\end{array}$ & $\begin{array}{l}6.38 \\
(0.47)\end{array}$ & $\begin{array}{l}41.77 \\
(1.97)\end{array}$ & $\begin{array}{l}13.47 \\
(0.81)\end{array}$ & $\begin{array}{l}6.04 \\
(0.46)\end{array}$ & $\begin{array}{l}40.92 \\
(1.97)\end{array}$ & $\begin{array}{l}13.24 \\
(0.79)\end{array}$ & $\begin{array}{l}5.85 \\
(0.44)\end{array}$ \\
\hline $\begin{array}{l}\text { Single parent } \\
\text { households }\end{array}$ & 5.82 & $\begin{array}{l}47.40 \\
(2.15)\end{array}$ & $\begin{array}{l}17.92 \\
(1.14)\end{array}$ & $\begin{array}{l}10.07 \\
(0.87)\end{array}$ & $\begin{array}{l}46.99 \\
(2.15)\end{array}$ & $\begin{array}{l}17.17 \\
(1.12)\end{array}$ & $\begin{array}{l}9.62 \\
(0.84)\end{array}$ & $\begin{array}{l}43.87 \\
(2.13)\end{array}$ & $\begin{array}{l}15.24 \\
(1.07)\end{array}$ & $\begin{array}{l}8.28 \\
(0.78)\end{array}$ \\
\hline $\begin{array}{l}\text { Households } \\
\text { with children } \\
\text { under age } 3\end{array}$ & 6.25 & $\begin{array}{l}24.36 \\
(1.51)\end{array}$ & $\begin{array}{l}6.85 \\
(0.50)\end{array}$ & $\begin{array}{l}2.83 \\
(0.26)\end{array}$ & $\begin{array}{l}24.05 \\
(1.51)\end{array}$ & $\begin{array}{l}6.55 \\
(0.48)\end{array}$ & $\begin{array}{l}2.66 \\
(0.25)\end{array}$ & $\begin{array}{l}23.03 \\
(1.48)\end{array}$ & $\begin{array}{l}6.29 \\
(0.47)\end{array}$ & $\begin{array}{l}2.53 \\
(0.24)\end{array}$ \\
\hline $\begin{array}{l}\text { Households } \\
\text { with children } \\
\text { aged } 3 \text { to } 6\end{array}$ & 6.99 & $\begin{array}{l}23.53 \\
(1.45)\end{array}$ & $\begin{array}{l}8.08 \\
(0.63)\end{array}$ & $\begin{array}{l}4.05 \\
(0.42)\end{array}$ & $\begin{array}{l}22.11 \\
(1.42)\end{array}$ & $\begin{array}{l}7.23 \\
(0.60)\end{array}$ & $\begin{array}{l}3.58 \\
(0.38)\end{array}$ & $\begin{array}{l}21.48 \\
(1.41)\end{array}$ & $\begin{array}{l}6.94 \\
(0.60)\end{array}$ & $\begin{array}{l}3.46 \\
(0.38)\end{array}$ \\
\hline $\begin{array}{l}\text { Households } \\
\text { with children } \\
\text { aged } 7 \text { and up }\end{array}$ & 29.28 & $\begin{array}{l}21.59 \\
(0.68)\end{array}$ & $\begin{array}{l}7.70 \\
(0.31)\end{array}$ & $\begin{array}{l}3.99 \\
(0.21)\end{array}$ & $\begin{array}{l}21.16 \\
(0.67)\end{array}$ & $\begin{array}{l}7.58 \\
(0.31)\end{array}$ & $\begin{array}{l}3.58 \\
(0.38)\end{array}$ & $\begin{array}{l}19.14 \\
(0.65)\end{array}$ & $\begin{array}{l}6.65 \\
(0.29)\end{array}$ & $\begin{array}{l}3.36 \\
(0.19)\end{array}$ \\
\hline $\begin{array}{l}\text { Rural } \\
\text { households } \\
\text { with children }\end{array}$ & 24.13 & $\begin{array}{l}30.93 \\
(0.83)\end{array}$ & $\begin{array}{l}10.86 \\
(0.38)\end{array}$ & $\begin{array}{l}5.44 \\
(0.25)\end{array}$ & $\begin{array}{l}30.17 \\
(0.82)\end{array}$ & $\begin{array}{l}10.50 \\
(0.37)\end{array}$ & $\begin{array}{l}5.25 \\
(0.25)\end{array}$ & $\begin{array}{l}28.18 \\
(0.81)\end{array}$ & $\begin{array}{l}9.57 \\
(0.35)\end{array}$ & $\begin{array}{l}4.68 \\
(0.23)\end{array}$ \\
\hline $\begin{array}{l}\text { Urban } \\
\text { households } \\
\text { with children }\end{array}$ & 18.39 & $\begin{array}{l}10.29 \\
(0.62)\end{array}$ & $\begin{array}{l}3.04 \\
(0.23)\end{array}$ & $\begin{array}{l}1.49 \\
(0.15)\end{array}$ & $\begin{array}{l}9.95 \\
(0.61)\end{array}$ & $\begin{array}{l}2.88 \\
(0.22)\end{array}$ & $\begin{array}{l}1.41 \\
(0.15)\end{array}$ & $\begin{array}{l}8.90 \\
(0.56)\end{array}$ & $\begin{array}{l}2.50 \\
(0.21)\end{array}$ & $\begin{array}{l}1.20 \\
(0.14)\end{array}$ \\
\hline
\end{tabular}

\begin{tabular}{|c|c|c|c|c|c|c|c|c|c|c|c|c|}
\hline \multirow[t]{2}{*}{$\begin{array}{l}\text { INE- } \\
\text { QUALITY }\end{array}$} & \multicolumn{4}{|c|}{ Before reform } & \multicolumn{4}{|c|}{$\begin{array}{l}\text { After immediate reform, direct + } \\
\text { indirect effects }\end{array}$} & \multicolumn{4}{|c|}{$\begin{array}{l}\text { After full reform, direct + indirect } \\
\text { effects }\end{array}$} \\
\hline & $\begin{array}{l}\text { GE } \\
(-1)\end{array}$ & $\begin{array}{l}\text { GE } \\
(0)\end{array}$ & $\begin{array}{l}\text { GE } \\
(1)\end{array}$ & $\begin{array}{l}\text { GE } \\
(2)\end{array}$ & $\begin{array}{l}\text { GE } \\
(-1)\end{array}$ & $\begin{array}{l}\text { GE } \\
(0)\end{array}$ & $\begin{array}{l}\text { GE } \\
(1)\end{array}$ & $\begin{array}{l}\text { GE } \\
(2)\end{array}$ & $\begin{array}{l}\text { GE } \\
(-1)\end{array}$ & $\begin{array}{l}\text { GE } \\
(0)\end{array}$ & $\begin{array}{l}\text { GE } \\
(1)\end{array}$ & $\begin{array}{l}\text { GE } \\
(2)\end{array}$ \\
\hline Total & $\begin{array}{l}0.36 \\
(0.01)\end{array}$ & $\begin{array}{l}0.23 \\
(0.00)\end{array}$ & $\begin{array}{l}0.22 \\
(0.00)\end{array}$ & $\begin{array}{l}0.28 \\
(0.01)\end{array}$ & $\begin{array}{l}0.36 \\
(0.01)\end{array}$ & $\begin{array}{l}0.23 \\
(0.00)\end{array}$ & $\begin{array}{l}0.22 \\
(0.00)\end{array}$ & $\begin{array}{l}0.27 \\
(0.01)\end{array}$ & $\begin{array}{l}0.32 \\
(0.01)\end{array}$ & $\begin{array}{l}0.22 \\
(0.00)\end{array}$ & $\begin{array}{l}0.21 \\
(0.00)\end{array}$ & $\begin{array}{l}0.27 \\
(0.01)\end{array}$ \\
\hline $\begin{array}{l}\text { House- } \\
\text { holds } \\
\text { without } \\
\text { children }\end{array}$ & $(0.01)$ & $(0.00)$ & $(0.01)$ & $(0.01)$ & $(0.01)$ & $(0.00)$ & $(0.01)$ & $(0.01)$ & $(0.01)$ & $(0.00)$ & $(0.01)$ & 0.30 \\
\hline $\begin{array}{l}\text { House- } \\
\text { holds with } \\
\text { children }\end{array}$ & $\begin{array}{l}0.40 \\
(0.02)\end{array}$ & $(0.00)$ & $(0.00)$ & $(0.01)$ & $(0.02)$ & $(0.00)$ & $(0.00)$ & $(0.01)$ & $(0.02)$ & $(0.00)$ & $(0.00)$ & $(0.01)$ \\
\hline $\begin{array}{l}\text { - within } \\
\text { group } \\
\text { inequality }\end{array}$ & 0.36 & $\begin{array}{l}0.23 \\
(0.00)\end{array}$ & $\begin{array}{l}0.22 \\
(0.00)\end{array}$ & $\begin{array}{l}0.28 \\
(0.01)\end{array}$ & $\begin{array}{l}0.35 \\
(0.01)\end{array}$ & $\begin{array}{l}0.23 \\
(0.00)\end{array}$ & $\begin{array}{l}0.22 \\
(0.00)\end{array}$ & $\begin{array}{l}0.27 \\
(0.01)\end{array}$ & $\begin{array}{l}0.32 \\
(0.01)\end{array}$ & $\begin{array}{l}0.22 \\
(0.00)\end{array}$ & $\begin{array}{l}0.21 \\
(0.00)\end{array}$ & $\begin{array}{l}0.27 \\
(0.01)\end{array}$ \\
\hline
\end{tabular}




\begin{tabular}{|c|c|c|c|c|c|c|c|c|c|c|c|c|}
\hline \multirow[t]{2}{*}{$\begin{array}{l}\text { INE- } \\
\text { QUALITY }\end{array}$} & \multicolumn{4}{|c|}{ Before reform } & \multicolumn{4}{|c|}{$\begin{array}{l}\text { After immediate reform, direct + } \\
\text { indirect effects }\end{array}$} & \multicolumn{4}{|c|}{$\begin{array}{l}\text { After full reform, direct + indirect } \\
\text { effects }\end{array}$} \\
\hline & $\begin{array}{l}\text { GE } \\
(-1)\end{array}$ & $\begin{array}{l}\text { GE } \\
(0)\end{array}$ & $\begin{array}{l}\text { GE } \\
(1)\end{array}$ & $\begin{array}{l}\text { GE } \\
(2)\end{array}$ & $\begin{array}{l}\text { GE } \\
(-1)\end{array}$ & $\begin{array}{l}\text { GE } \\
(0)\end{array}$ & $\begin{array}{l}\text { GE } \\
(1)\end{array}$ & $\begin{array}{l}\text { GE } \\
(2)\end{array}$ & $\begin{array}{l}\text { GE } \\
(-1)\end{array}$ & $\begin{array}{l}\text { GE } \\
(0)\end{array}$ & $\begin{array}{l}\text { GE } \\
(1)\end{array}$ & $\begin{array}{l}\text { GE } \\
(2)\end{array}$ \\
\hline $\begin{array}{l}\text { - between } \\
\text { group } \\
\text { inequality }\end{array}$ & $\begin{array}{l}0.00 \\
(0.00)\end{array}$ & $\begin{array}{l}0.00 \\
(0.00)\end{array}$ & $\begin{array}{l}0.00 \\
(0.00)\end{array}$ & $\begin{array}{l}0.00 \\
(0.00)\end{array}$ & $\begin{array}{l}0.00 \\
(0.00)\end{array}$ & $\begin{array}{l}0.00 \\
(0.00)\end{array}$ & $\begin{array}{l}0.00 \\
(0.00)\end{array}$ & $\begin{array}{l}0.00 \\
(0.00)\end{array}$ & $\begin{array}{l}0.00 \\
(0.00)\end{array}$ & $\begin{array}{l}0.00 \\
(0.00)\end{array}$ & $\begin{array}{l}0.00 \\
(0.00)\end{array}$ & $\begin{array}{l}0.00 \\
(0.00)\end{array}$ \\
\hline $\begin{array}{l}\text { Households } \\
\text { with } 3 \text { or } \\
\text { more } \\
\text { children }\end{array}$ & $\begin{array}{l}0.24 \\
(0.02)\end{array}$ & $\begin{array}{l}0.19 \\
(0.01)\end{array}$ & $\begin{array}{l}0.20 \\
(0.01)\end{array}$ & $\begin{array}{l}0.24 \\
(0.02)\end{array}$ & $\begin{array}{l}0.24 \\
(0.02)\end{array}$ & $\begin{array}{l}0.19 \\
(0.01)\end{array}$ & $\begin{array}{l}0.20 \\
(0.01)\end{array}$ & $\begin{array}{l}0.24 \\
(0.02)\end{array}$ & $\begin{array}{l}0.23 \\
(0.02)\end{array}$ & $\begin{array}{l}0.19 \\
(0.01)\end{array}$ & $\begin{array}{l}0.20 \\
(0.01)\end{array}$ & $\begin{array}{l}0.24 \\
(0.02)\end{array}$ \\
\hline $\begin{array}{l}\text { Single } \\
\text { parent } \\
\text { households }\end{array}$ & $\begin{array}{l}0.84 \\
(0.12)\end{array}$ & $\begin{array}{l}0.37 \\
(0.02)\end{array}$ & $\begin{array}{l}0.36 \\
(0.03)\end{array}$ & $\begin{array}{l}0.54 \\
(0.08)\end{array}$ & $\begin{array}{l}0.82 \\
(0.12)\end{array}$ & $\begin{array}{l}0.36 \\
(0.02)\end{array}$ & $\begin{array}{l}0.35 \\
(0.03)\end{array}$ & $\begin{array}{l}0.53 \\
(0.07)\end{array}$ & $\begin{array}{l}0.61 \\
(0.07)\end{array}$ & $\begin{array}{l}0.33 \\
(0.02)\end{array}$ & $\begin{array}{l}0.33 \\
(0.03)\end{array}$ & $\begin{array}{l}0.49 \\
(0.07)\end{array}$ \\
\hline $\begin{array}{l}\text { - within } \\
\text { group } \\
\text { inequality }\end{array}$ & $\begin{array}{l}0.50 \\
(0.05)\end{array}$ & $\begin{array}{l}0.28 \\
(0.01)\end{array}$ & $\begin{array}{l}0.28 \\
(0.02)\end{array}$ & $\begin{array}{l}0.40 \\
(0.04)\end{array}$ & $\begin{array}{l}0.33 \\
(0.05)\end{array}$ & $\begin{array}{l}0.21 \\
(0.01)\end{array}$ & $\begin{array}{l}0.20 \\
(0.02)\end{array}$ & $\begin{array}{l}0.25 \\
(0.04)\end{array}$ & $\begin{array}{l}0.30 \\
(0.03)\end{array}$ & $\begin{array}{l}0.20 \\
(0.01)\end{array}$ & $\begin{array}{l}0.19 \\
(0.01)\end{array}$ & $\begin{array}{l}0.25 \\
(0.04)\end{array}$ \\
\hline $\begin{array}{l}\text { - between } \\
\text { group } \\
\text { inequality }\end{array}$ & $\begin{array}{l}0.00 \\
(0.00)\end{array}$ & $\begin{array}{l}0.00 \\
(0.00)\end{array}$ & $\begin{array}{l}0.00 \\
(0.00)\end{array}$ & $\begin{array}{l}0.00 \\
(0.00)\end{array}$ & $\begin{array}{l}0.02 \\
(0.00)\end{array}$ & $\begin{array}{l}0.02 \\
(0.00)\end{array}$ & $\begin{array}{l}0.02 \\
(0.00)\end{array}$ & $\begin{array}{l}0.02 \\
(0.00)\end{array}$ & $\begin{array}{l}0.02 \\
(0.00)\end{array}$ & $\begin{array}{l}0.02 \\
(0.00)\end{array}$ & $\begin{array}{l}0.02 \\
(0.00)\end{array}$ & $\begin{array}{l}0.02 \\
(0.00)\end{array}$ \\
\hline $\begin{array}{l}\text { Households } \\
\text { with } \\
\text { children } \\
\text { under age } 3\end{array}$ & $\begin{array}{l}0.29 \\
(0.01)\end{array}$ & $\begin{array}{l}0.23 \\
(0.01)\end{array}$ & $\begin{array}{l}0.23 \\
(0.01)\end{array}$ & $\begin{array}{l}0.28 \\
(0.02)\end{array}$ & $\begin{array}{l}0.27 \\
(0.01)\end{array}$ & $\begin{array}{l}0.22 \\
(0.01)\end{array}$ & $\begin{array}{l}0.22 \\
(0.01)\end{array}$ & $\begin{array}{l}0.27 \\
(0.01)\end{array}$ & $\begin{array}{l}0.27 \\
(0.01)\end{array}$ & $\begin{array}{l}0.22 \\
(0.01)\end{array}$ & $\begin{array}{l}0.22 \\
(0.01)\end{array}$ & $\begin{array}{l}0.27 \\
(0.01)\end{array}$ \\
\hline $\begin{array}{l}\text { Households } \\
\text { with } \\
\text { children } \\
\text { aged } 3 \text { to } 6\end{array}$ & $\begin{array}{l}0.37 \\
(0.02)\end{array}$ & $\begin{array}{l}0.25 \\
(0.01)\end{array}$ & $\begin{array}{l}0.24 \\
(0.01)\end{array}$ & $\begin{array}{l}0.29 \\
(0.02)\end{array}$ & $\begin{array}{l}0.33 \\
(0.01)\end{array}$ & $\begin{array}{l}0.24 \\
(0.01)\end{array}$ & $\begin{array}{l}0.23 \\
(0.01)\end{array}$ & $\begin{array}{l}0.28 \\
(0.01)\end{array}$ & $\begin{array}{l}0.33 \\
(0.02)\end{array}$ & $\begin{array}{l}0.23 \\
(0.01)\end{array}$ & $\begin{array}{l}0.22 \\
(0.01)\end{array}$ & $\begin{array}{l}0.27 \\
(0.01)\end{array}$ \\
\hline $\begin{array}{l}\text { Households } \\
\text { with } \\
\text { children } \\
\text { aged } 7 \text { and } \\
\text { up }\end{array}$ & $(0.03)$ & $(0.01)$ & $(0.01)$ & $(0.01)$ & $(0.03)$ & $(0.01)$ & $(0.01)$ & $(0.01)$ & $(0.02)$ & $(0.01)$ & $(0.01)$ & $(0.01)$ \\
\hline $\begin{array}{l}\text { - within } \\
\text { group } \\
\text { inequality }\end{array}$ & $\begin{array}{l}0.40 \\
(0.02)\end{array}$ & $\begin{array}{l}0.23 \\
(0.00)\end{array}$ & $\begin{array}{l}0.22 \\
(0.00)\end{array}$ & $\begin{array}{l}0.26 \\
(0.01)\end{array}$ & $\begin{array}{l}0.39 \\
(0.02)\end{array}$ & $\begin{array}{l}0.23 \\
(0.00)\end{array}$ & $\begin{array}{l}0.21 \\
(0.00)\end{array}$ & $\begin{array}{l}0.26 \\
(0.01)\end{array}$ & $\begin{array}{l}0.32 \\
(0.01)\end{array}$ & $\begin{array}{l}0.22 \\
(0.00)\end{array}$ & $\begin{array}{l}0.21 \\
(0.00)\end{array}$ & $\begin{array}{l}0.27 \\
(0.01)\end{array}$ \\
\hline $\begin{array}{l}\text { - between } \\
\text { group } \\
\text { inequality }\end{array}$ & $\begin{array}{l}0.00 \\
(0.00)\end{array}$ & $\begin{array}{l}0.00 \\
(0.00)\end{array}$ & $\begin{array}{l}0.00 \\
(0.00)\end{array}$ & $\begin{array}{l}0.00 \\
(0.00)\end{array}$ & $\begin{array}{l}0.00 \\
(0.00)\end{array}$ & $\begin{array}{l}0.00 \\
(0.00)\end{array}$ & $\begin{array}{l}0.00 \\
(0.00)\end{array}$ & $\begin{array}{l}0.00 \\
(0.00)\end{array}$ & $\begin{array}{l}0.00 \\
(0.00)\end{array}$ & $\begin{array}{l}0.00 \\
(0.00)\end{array}$ & $\begin{array}{l}0.00 \\
(0.00)\end{array}$ & $\begin{array}{l}0.00 \\
(0.00)\end{array}$ \\
\hline $\begin{array}{l}\text { Rural } \\
\text { households } \\
\text { with } \\
\text { children }\end{array}$ & $\begin{array}{l}0.40 \\
(0.03)\end{array}$ & $\begin{array}{l}0.24 \\
(0.01)\end{array}$ & $\begin{array}{l}0.23 \\
(0.01)\end{array}$ & $\begin{array}{l}0.29 \\
(0.01)\end{array}$ & $\begin{array}{l}0.39 \\
(0.03)\end{array}$ & $\begin{array}{l}0.24 \\
(0.01)\end{array}$ & $\begin{array}{l}0.22 \\
(0.01)\end{array}$ & $\begin{array}{l}0.28 \\
(0.01)\end{array}$ & $\begin{array}{l}0.34 \\
(0.02)\end{array}$ & $\begin{array}{l}0.23 \\
(0.01)\end{array}$ & $\begin{array}{l}0.22 \\
(0.01)\end{array}$ & $\begin{array}{l}0.27 \\
(0.01)\end{array}$ \\
\hline $\begin{array}{l}\text { Urban } \\
\text { households } \\
\text { with } \\
\text { children }\end{array}$ & $\begin{array}{l}0.30 \\
(0.03)\end{array}$ & $\begin{array}{l}0.18 \\
(0.01)\end{array}$ & $\begin{array}{l}0.17 \\
(0.00)\end{array}$ & $\begin{array}{l}0.20 \\
(0.01)\end{array}$ & $\begin{array}{l}0.29 \\
(0.03)\end{array}$ & $\begin{array}{l}0.18 \\
(0.01)\end{array}$ & $\begin{array}{l}0.17 \\
(0.00)\end{array}$ & $\begin{array}{l}0.19 \\
(0.01)\end{array}$ & $\begin{array}{l}0.25 \\
(0.01)\end{array}$ & $\begin{array}{l}0.17 \\
(0.00)\end{array}$ & $\begin{array}{l}0.16 \\
(0.00)\end{array}$ & $\begin{array}{l}0.19 \\
(0.01)\end{array}$ \\
\hline $\begin{array}{l}\text { - within } \\
\text { group } \\
\text { inequality }\end{array}$ & $\begin{array}{l}0.38 \\
(0.02)\end{array}$ & $\begin{array}{l}0.22 \\
(0.00)\end{array}$ & $\begin{array}{l}0.20 \\
(0.00)\end{array}$ & $\begin{array}{l}0.24 \\
(0.01)\end{array}$ & $\begin{array}{l}0.37 \\
(0.01)\end{array}$ & $\begin{array}{l}0.21 \\
(0.02)\end{array}$ & $\begin{array}{l}0.20 \\
(0.00)\end{array}$ & $\begin{array}{l}0.24 \\
(0.00)\end{array}$ & $\begin{array}{l}0.32 \\
(0.01)\end{array}$ & $\begin{array}{l}0.21 \\
(0.00)\end{array}$ & $\begin{array}{l}0.21 \\
(0.00)\end{array}$ & $\begin{array}{l}0.26 \\
(0.01)\end{array}$ \\
\hline $\begin{array}{l}\text { - between } \\
\text { group } \\
\text { inequality }\end{array}$ & $\begin{array}{l}0.02 \\
(0.00)\end{array}$ & $\begin{array}{l}0.02 \\
(0.00)\end{array}$ & $\begin{array}{l}0.02 \\
(0.00)\end{array}$ & $\begin{array}{l}0.02 \\
(0.00)\end{array}$ & $\begin{array}{l}0.02 \\
(0.00)\end{array}$ & $\begin{array}{l}0.02 \\
(0.00)\end{array}$ & $\begin{array}{l}0.02 \\
(0.00)\end{array}$ & $\begin{array}{l}0.02 \\
(0.00)\end{array}$ & $\begin{array}{l}0.01 \\
(0.00)\end{array}$ & $\begin{array}{l}0.01 \\
(0.00)\end{array}$ & $\begin{array}{l}0.01 \\
(0.00)\end{array}$ & $\begin{array}{l}0.01 \\
(0.00)\end{array}$ \\
\hline
\end{tabular}




\subsection{References}

Aidukaite, J. (2006) 'Reforming family policy in the Baltic States: The views of the elites', Communist and Post-Communist Studies 39 (2006): 1-23.

Atkinson, A. B., Rainwater, L., and Smeeding, T. M. (1995) 'Income Distribution in OECD Countries: Evidence from the Luxembourg Income Study (LIS)', Social Policy Studies 18, Organization for Economic Cooperation and Development, Paris.

Bradshaw, J., \& Finch, N. (2003) 'Child Benefit Packages in 22 Countries', 4th International Research Conference on Social Security, Antwerp, Belgium, May 5-7, 2003.

Davidson, R., Flachaire, R. (2007) 'Asymptotic and Bootstrap Inference for Inequality and Poverty Measures', Journal of Econometrics 141 (1): 141166.

EUROSTAT (2005) Continuity of indicators between end-ECHP and start-SILC: algorithms to compute cross-sectional indicators of poverty and social inclusion adopted under the open method of coordination. Retrieved March 302008 from the World Wide Web:http://www.insee.fr/en/inseestatistiquepublique/colloques/pauvrete/pdf/Eurostat_social_indicators_EN.pdf

EUROSTAT (2007a) Description of SILC User database variables: Cross-sectional and Longitudinal (Version 2005.1 from 01-06-07).

EUROSTAT (2007b) EU-SILC User database description (Version 2005-2 from 2706-07).

EUROSTAT (2008) Social Cohesion: Living conditions structural indicators; EUROSTAT Metadata in SDDS format: Base Page. Retrieved October 15 2008 from the World Wide Web: http://ec.europa.eu/eurostat

Foster, J., Greer, J. and Thorbecke, E. (1984) 'A Class of Decomposable Poverty Measures', Econometrica, 52: 761-766.

Frazer, H. \& Marlier, E. (2007). Tackling child poverty and promoting the social inclusion of children in the EU: Key lessons, European Commission 2007, available at http://www.peer-review-social-inclusion.net/policyassessment-activities/reports/first-semester-2007/synthesis-report-2007-1/.

Heikillä, M., Moisio, P., Ritakallio, V.M., Bradshaw, J., Kuivalainen, S., Hellsten, K., and Kajanoja, J. (2006) Poverty Policies, Structures and Outcomes in the EU-25. Report for the Fifth European Round Table on Poverty and Social Exclusion, 16-17, October, 2006, Finland.

Hölsch, K. and Kraus, M. (2002) 'European Schemes of Social Assistance: An Empirical Analysis of Set-Ups and Distributive Impacts', Luxembourg Income Study Working Paper Series 312. 
Immervoll, H., O'Donoghue, C., and Sutherland, H. (1999) An Introduction to EUROMOD. Microsimulation Unit, Department of Applied Economics, Cambridge University.

Jenkins, S. P. (1999) 'Analysis of income distributions', STATA Technical Bulletin 48: 4-18.

Jenkins, S.P. (2006) Estimation and interpretation of measures of inequality, poverty, and social welfare using STATA. Presentation at North American STATA Users' Group Meetings 2006, Boston MA. Retrieved 15 October 2008 from the World Wide web:

http://econpapers.repec.org/paper/bocasug06/16.htm

Jolliffe, D. and Semykina, A. (1999) 'Robust Standard Errors for the Foster-GreerThorbecke Class of Poverty Indices: SEPOV', STATA Technical Bulletin 51: 34-36.

Lelkes, O. (2007) ‘Tax-Benefit Microsimulation Models In Eastern Europe', International Journal of Microsimulation 1 (1): 54-56.

Matsaganis, M., Levy, H., Mercader-Prats, M., Toso, S., O’Donoghue, C., Coromaldi, M., Rodrigues, C. F., and Tsakloglou, P. (2007) 'Child Poverty and Family Transfers in Southern Europe', , pp 293-321 in Spadaro, A. (ed.), Microsimulation as a Tool for the Evaluation of Public Policies: Methods and Applications. Fundación BBVA, Bilbao.

Milanovic, B. (1999) 'Explaining the Increase in Inequality during Transition', the Economics of Transition 7 (2): 299-341.

National Report on Strategies of Lithuania for Social Protection and Social Inclusion 2006-2008 (2006). Retrieved 15 October 2008 from the World Wide Web:

http://ec.europa.eu/health/ph_determinants/socio_economics/documents/li thuania_rd05_en.pdf

Nelson, K. (2007) 'Universalism versus targeting: the vulnerability of social insurance and means-tested minimum income protection in 18 countries, 1990-2002' International Social Security Review 60 (1): 33-58.

Notten, G., and Gassmann, F. (2008) 'Size matters: targeting efficiency and poverty reduction effects of means-tested and universal child benefits in Russia', Journal of European Social Policy, 18 (3): 260-274.

Republic of Lithuania (1999) The Order on Provision of Free Meals in General Education Institutions for Pupils in Low-Income Families, August 16, 1999. Republic of Lithuania (2003) The Law on Cash Social Assistance for Low-Income Families (Single Residents), July 1, 2003.

Republic of Lithuania (2006) The Law on Social Assistance for Pupils, 13 June 2006, No. X-686, Vilnius.

Republic of Lithuania, (2004a) The Law Amending The Law On State Benefits To Families Raising Children, May 18, 2004, Vilnius. 
Republic of Lithuania (2004b) National Action Plan (NAP) Against Poverty And Social Exclusion in 2004-2006. Retrieved 15 October 2008 from the World Wide web:

http://ec.europa.eu/employment_social/social_inclusion/docs/nap_incl_200 4_lt_en_version.pdf

Spadaro, A. (eds.) (2007) Microsimulation as a Tool for the Evaluation of Public Policies: Methods and Applications. Madrid: FBBVA.

Statistics Lithuania (2008). Statistika (teminès lentelès), Gyventojai ir socialinė statistika, Darbo užmokestis, Minimalieji dydžiai 1995-2007 m. Retrieved 20 January 2008 from the World Wide Web: http://www.stat.gov.lt

Stirling, T. and Lazutka, R. (2006). 'I-CUE Feasibility Study: Lithuania (2005 TaxBenefit System)', I-CUE Project: Improving the Capacity and Usability of EUROMOD, Deliverable D3.8.

TÁRKI. (2010). 'Child poverty and child well-being in the European Union', report prepared for the DG Employment, Social Affairs and Equal Opportunities (Unite E.2) of the European Commission, Budapest.

The Ministry of Social Security and Labour (2005). The Social Report 2004.

Retrieved 23 October 2007 from the World Wide web: www.socmin.lt 


\section{Chapter 6: Is the Neighbour's Grass Greener? Comparing Family Support in Lithuania and Four Other New Member States}

This chapter is published as:

Salanauskaite, L., \& Verbist, G. (2012). Is the Neighbour's Grass Greener? Comparing Family Support in Lithuania and Four Other New Member States. Journal of European Social Policy (forthcoming).

The paper is a part of the GINI project, which studies the economic and educational drivers and the social, cultural and political impacts of increasing inequality with novel contributions on the measurement of income, wealth and education inequality. More information could be found at http://www.gini-research.org

The results presented here are primarily based on EUROMOD versions F2.38 and F3.0. EUROMOD is maintained, developed and managed by the Institute for Social and Economic Research (ISER) at the University of Essex in collaboration with national teams from the EU member states. We are indebted to the many people who have contributed to the development of EUROMOD and to the European Commission for providing financial support for it. The results and their interpretation are the authors' responsibility. 



\subsection{Introduction}

Child poverty remains a serious problem across the EU, and especially in the new EU member states (NMS), be it with significant variations in extent and intensity. Especially children in single parent and large families are the subject of policy concern, given that about half of the poor children in the EU live in these two types of households(Commission of the European Communities, 2008) (Commission of the European Communities, 2008). Compared to other EU countries, Lithuania has "below- (EU) average performance in all dimensions of child poverty and wellbeing, and particularly in terms of risk of poverty" (TÁRKI, 2011). Poverty in Lithuania is especially concentrated among single parent households and households raising three or more children. The Lithuanian family system design is criticised on poverty effectiveness grounds despite numerous past and recent reforms of state provided income support to families with children (Cornelius, 1995; Kabašinskaitè and Bak, 2006; Salanauskaite and Verbist, 2009). Apparently, the implemented policy reforms are not so poverty reduction effective, especially when compared to the achievements of other new EU member states (NMS), such as Estonia, Hungary, the Czech Republic or Slovenia (TÁRKI, 2011).

Most research on the poverty effectiveness of family support tools has concentrated on Anglo-Saxon countries and 'old' EU member states (Kamerman et al., 2003; Levy et al., 2007; Matsaganis et al., 2007). Research within the NMS region is still quite scarce, Förster and Tóth (2001) being one of the few examples. The region, though, is very interesting not only because of the fast changing socioeconomic environment and demographic conditions, but also because of recent reforms in family policy. Actually, (relative) child poverty rates in some of the NMS are lower than in a number of richer EU member states.

In this chapter, we study the poverty effectiveness of family transfers, more specifically child benefits and child-related tax advantages. Existing studies often point to the size of family transfers as the key factor to reduce child poverty. We hypothesize that also the interaction with the design of policies is a crucial factor. Our focus is on the Lithuanian system. We compare its effectiveness in combating child poverty to that of Estonia, Hungary, the Czech Republic and Slovenia. These four countries resemble Lithuanian political and socio-economic circumstances in many ways (e.g. Soviet heritage, relatively similar pathways in reforming/introducing tax-benefit policies, etc.), though there are also important differences (e.g. in terms of share of single parents and large families, work intensity in households with children, etc.). The four countries are also selected as they all have better child poverty outcomes, which are attributed to arguably more 
effective family policy measures (TÁRKI, 2011). Our interest is to examine to what extent one country's success story in achieving low(-er) child poverty rates, especially among the most vulnerable household types, can be attributed to the size and the design of the selected transfers. The study is anchored in 2008 - the year when a major family benefit reform has been fully implemented in Lithuania (for more details see Salanauskaite and Verbist, 2009).

The chapter starts with background information on child poverty in the five NMS. We also review evidence on the poverty effectiveness of family tax-benefit mechanisms. Next, we describe the methodology of policy swapping scenarios within the microsimulation framework of EUROMOD. We then present and analyse the microsimulation results. Finally, we conclude and suggest some policy lessons.

\subsection{Child poverty and family support systems: existing evidence}

In 2008 the at-risk of child poverty rate (or child poverty) in Lithuania is above the EU and just below the NMS average. However, the at-risk-of-poverty rates (or poverty) of large households and single parent households are with over $45 \%$ extremely high (Figure 6-1), despite the state's recognition of these household categories as major poverty reduction targets (e.g. National Report of Lithuania on Social Protection and Social Inclusion Strategies 2008-2010, 2008). This contrasts with most other EU countries, where at least one of these categories has a better income position. Among our five countries, Slovenia performs best for these two most vulnerable household types. In Hungary, similarly to Lithuania, both household types have increased poverty risks, though at much lower absolute levels. Given these outcomes we pay particular attention in our analysis to the poverty outcomes of these two groups.

Along with socio-demographic characteristics of the child's family, the parents' labour market positions as well as overall tax-benefit policies are seen as major child poverty determinants (Commission of the European Communities, 2008; TÁRKI, 2011). Even though cash family policies in itself are often insufficient and are actually not meant to fully eliminate child poverty (Bradbury and Jäntti, 2001; Cantillon and Van den Bosch, 2003), their role is of high importance, with size and design as major parameters. 
Figure 6-1. Poverty among different households with children in the selected countries (2008)

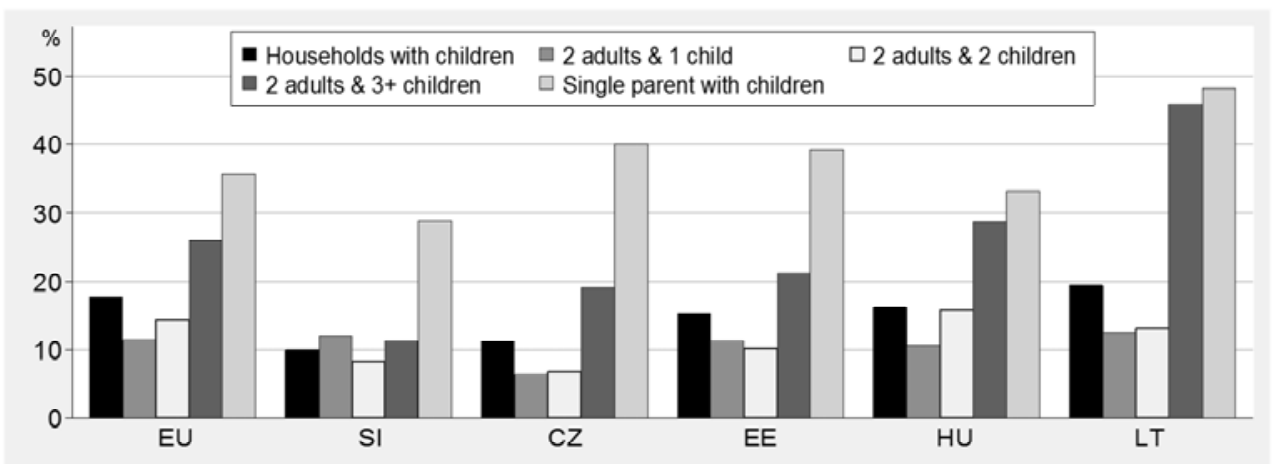

Notes: Countries ranked by poverty rates (defined as $60 \%$ of the median equivalised household disposable income) for households with children; Children: persons under the age of 18 or under 24 if economically inactive.

Source: EUROSTAT

The size of social spending dedicated to families with children is often considered to be the key factor influencing child poverty (e.g. Bradshaw and Finch, 2003; Notten and Gassmann, 2008). Figure confirms that a higher share of GDP spent on tax breaks and transfers to families with children is associated with lower child poverty rates. Among the five selected countries, Hungary spends the largest share of GDP on families, and Lithuania the least. Child poverty levels in both countries, though, are somewhat higher in comparison to other countries with similar spending levels. The best performance is noted in Slovenia: a relatively low share of GDP spent on transfers corresponds to a very low child poverty risk.

The size and the design of the systems are arguably interlinked, with universal rather than targeted systems having both higher budgets available and larger poverty reduction effectiveness (e.g. Korpi and Palme, 1998; Nelson, 2004). The most recent empirical evidence, though, seems to suggest that this observation might not be valid anymore (e.g. Kenworthy, 2011). Furthermore, the final poverty outcomes are highly country specific due to other complexities of national policy systems, socio-demographic environments, original income distributions, etc. The benefits' design is also very diverse. Countries use universal, categorical or income selective family benefits. Tax advantages are also increasingly used as an important family policy tool (e.g. Figari et al., 2011). The poverty impact of these diverse benefits' designs is often not well assessed, especially for the NMS. Three studies on NMS are particularly interesting in this respect. 
Figure 6-2. Generosity of family transfers and (child) poverty in the EU, 2007

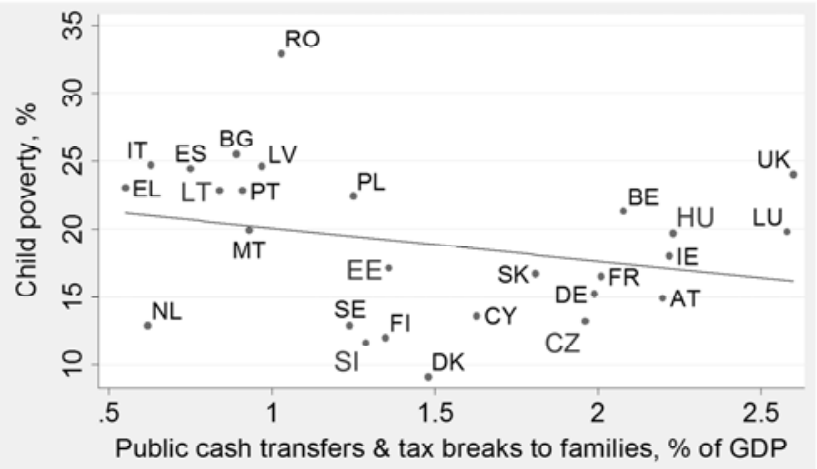

Notes: Tax breaks primarily refer to tax credits; tax allowances are excluded (data not available for Greece, Italy, Estonia, Slovenia, Finland, Luxembourg, Hungary, Denmark \& Iceland); child poverty calculated on EU-SILC 2008.

Source: EUROSTAT, OECD Family Database \& Social Observatory data

Förster and Tóth (2001) study the evolution of benefit types and their effectiveness in Poland, Hungary and the Czech Republic in the mid-1990s. They find that large and single parent families became particularly income vulnerable during the economic transition years, with the most dramatic changes for the latter household type. Most of the reforms at that time introduced means-testing, which consequently increased poverty reduction effectiveness of the programmes. Nonetheless, the political will for the reintroduction of universal benefits remained and crystallised in the numerous reforms in times of economic upturn (e.g. as of 2004 in Lithuania). Levy, Morawski, and Myck (2009) evaluate the poverty effectiveness of Polish state support to families by comparing it to systems in France, the United Kingdom and Austria using EUROMOD. They find that single parents in Poland would benefit most if the French system (using both universal and means-tested benefits) were adopted, whereas two parent families would similarly benefit either from the universal Austrian or from the means-tested British systems. TÁRKI (2011) provides the most extensive evaluation of the EU countries' performances in reducing child poverty. It finds low effectiveness of income support to families with children in Lithuania. The means-tested benefits in the Czech Republic and the universal benefits of Hungary are observed to produce similar child poverty outcomes. Social transfers in Slovenia are often seen as not specifically targeted at children, however, their effectiveness in reducing poverty is noted to be high. As such, the latter two studies do not single out any particular benefit type as having higher poverty effectiveness, but rather highlight their greatly varied impacts under particular national designs and different sociodemographic circumstances. 


\subsection{Methodology}

\section{EUROMOD}

Building further on the insights of the studies discussed in Section 6.2, we want to use EUROMO, the European static tax-benefit microsimulation model, to assess impacts of family policy changes. Using microsimulation models can help to highlight the role of certain family support instruments, be it taxes or benefits, while at the same time allowing for interactions with the remaining tax-benefit structures. This method also enables testing hypothetical public policy designs - a usually complex task due to the effects of various counterfactuals. Similar approaches, as used here, include Matsaganis et al. (2007) for Southern Europe or Immervoll et al. (2001) for a comparison between the UK and the Netherlands.

We use the tax-benefit microsimulation EUROMOD model (versions F3.0 and F2.38), which is a static model. Static means that no behavioural reactions are taken into account. Currently (i.e. 2011), EUROMOD embeds policy designs of $21 \mathrm{EU}$ countries, among them Lithuania, Estonia, Hungary, the Czech Republic and Slovenia ${ }^{79}$. The model was initially designed to cover the 15 "old" EU member states, with the NMS being added progressively. For four countries the policy system of 2008 is included in EUROMOD and used here ${ }^{80}$. As for Slovenia, 2005 is the policy year yet available - we use the annual consumer price index to uprate Slovenian benefits to 2008 .

Table 6-1. EUROMOD included policies \& datasets of the selected countries

\begin{tabular}{l|c|c|c|c|c}
\hline & Lithuania & Estonia & Hungary & $\begin{array}{c}\text { Czech } \\
\text { Rep. }\end{array}$ & Slovenia \\
\hline $\begin{array}{l}\text { Source } \\
\text { database(s) }\end{array}$ & $\begin{array}{c}\text { EU-SILC+ } \\
\text { nat. SILC }\end{array}$ & EU-SILC & EU-SILC & $\begin{array}{c}\text { EU-SILC+ } \\
\text { nat. SILC }\end{array}$ & $\begin{array}{c}\text { SURS : sample of } \\
\text { administrative } \\
\text { records }\end{array}$ \\
\hline $\begin{array}{l}\text { Income reference } \\
\text { year }\end{array}$ & 2005 & 2005 & 2006 & 2005 & $2004 / 2002$ \\
\hline \# of households & 4660 & 5623 & 8737 & 7483 & 4777 \\
\hline \# of individuals & 12098 & 15755 & 22271 & 17793 & 13798 \\
\hline
\end{tabular}

Source: EUROMOD country reports

In Table 6-1, we describe EUROMOD input data. Due to earlier implementation, Slovenian policies are simulated on a sample of administrative records (Čok et al., 2008). Other countries use the EU-SILC as basic input dataset. Lithuanian micro-

\footnotetext{
79 More info is available in Sutherland (2001), Lietz and Mantovani (2007) and at http://www.iser.essex.ac.uk/research/euromod/developing-euromod/euromodupdate

${ }^{80}$ June 30 is the reference date for all policy descriptions.
} 
database for EUROMOD is derived from the EU-SILC data with a few imputations on the basis of the national SILC survey (Ivaškaite-Tamošiūnè et al., 2010). In the Czech Republic, the national SILC additional variables are merged with the EUSILC data (Münich and Pavel, 2010). "Pure" EU-SILC is used for Estonia and Hungary (Hegedüs and Szivós, 2010; Võrk et al., 2010). As income reference dates are "older" than analysed policies, all countries use adjustment factors to update income levels to a respective policy year. This implies that the policy year of 2008 is set on the socio-demographic structure of 2005, but with income levels uprated to 2008. Furthermore, EUROMOD assumes full take-up of benefits and full compliance with taxes and social contributions ${ }^{81}$.

\section{Family cash policies in EUROMOD}

We identify four major types of non-contributory 'transfers to children' in the five selected NMS: birth grants, universal child benefits, large family allowances (which can be labelled as categorically selective) and means tested family allowances (income selective) ${ }^{82}$. This covers 17 different national benefits ${ }^{83}$. Among them, only one benefit type is not simulated in EUROMOD: an Estonian child benefit supplement for single parents ${ }^{84}$. All benefits are not subject to income taxation. In Hungary, however, the benefit to large families increases the taxable income base. This affects the calculation of personal income taxes due (i.e. the rate, tax advantage amount) and consequently the disposable income. All countries also use either tax credits or tax allowances to support families with children. These measures are simulated in all countries.

The principal design features and state expenses of both benefit and tax support measures are reviewed in Table 6-2Error! Reference source not found. In the latter table, countries are ranked from left to the right based on the extent to which they rely on means-testing. Lithuania has the most universalistic package, closely followed by Estonia. Hungary uses the most complete package of the transfers, with larger expenditure share going to universal/categorical benefits. Slovenia has

\footnotetext{
${ }^{81}$ Based on the EUROMOD country reports, full-take up is a plausible assumption for all noncontributory family benefits in the selected countries. Tax revenues are overall well simulated, with the largest deviation $(-17 \%)$ reported in Hungary and the smallest deviation $(+1 \%)$ noted in Estonian baseline policies.

${ }^{82}$ Contributory benefits or benefits with eligibility conditional on parents' labour market status are excluded.

${ }^{83}$ The validation parameters of simulated benefits (i.e. ratios indicating how well simulated benefits match other sources of information) are provided in Appendix 2 of this Chapter along with their original names in national languages.

${ }^{84}$ This benefit is not simulated due to lack of information to be defined as a 'single parent': this means strictly no parenthood information on the second parent (e.g. a father is unknown) or assimilated situations (e.g. a fugitive parent).
} 
a dominant means-tested child benefit, but universal/categorical transfers are also employed, especially when tax advantages for families are taken into account. The Czech Republic exclusively relies on means-tested transfers.

Birth grants are found in all countries, with quite similar benefit rules. The benefit is proportional to the number of newborns in all countries, except in Hungary. The benefit is particularly high in the Czech Republic.

Universal child benefits are provided in Lithuania, Estonia and Hungary, though the rules are quite different both in terms of eligibility and calculation. In Lithuania child benefit is provided to all children up to age 18, and up to age 24 , if a child is still in education and belongs to a large family. The benefit is increased for children up to age 3 if raised in a large family. As such, these two components of the child benefit could be considered as a large family allowance. Lithuania does not provide these benefits separately, indicating that the demarcation between benefit types is not always straightforward. Estonia applies a lower age threshold for children who are still in (higher) education (i.e. under 20). It also provides a benefit supplement for children younger than 8, with higher rates applicable to those below age 3. In Hungary, child benefit is not directly linked to a specific age threshold, but depends on the child's enrolment in education. The benefit size does not depend on the child's age and has a regressive schedule for numerous children. Overall, Hungary offers the most generous child benefit provision.

Categorical selectivity is most explicit in the form of specific allowances for large families in three countries: Estonia, Hungary and Slovenia. The Estonian benefit is targeted towards families raising seven or more children. In Hungary, families with three children or more are entitled, but only if the youngest child is between three and seven years old. In Slovenia all families with three or more children are eligible. In all three countries, the allowance's size is uniform per eligible family. Hungary offers the most generous support.

Income selectivity is applied in Hungary, Slovenia and the Czech Republic through means-tested child allowances. In the Czech Republic this is the only benefit type available, aside the birth grant. Here, the means-tested income threshold is family specific and is set in relation to the state determined minimum living standard (MLS, a parameter that depends on the age and the number of family members ${ }^{85}$ ). The benefit size is set per child and increases with age. Hungary applies the simplest benefit calculation rules: any family with per capita incomes lower than

\footnotetext{
${ }^{85}$ For example, (monthly) MLS for a child under the age of six is $\approx 70$ EUR, for a child aged 6 to 9 years $\approx$ 80 EUR, for the first adult $\approx 120$ EUR.
} 
$125 \%$ of the minimum old-age pension (OAP ${ }^{86}$ ) is entitled to a uniform benefit amount. The Slovenian means-tested threshold is much higher than in Hungary. The benefit size depends on per capita family income and is gradually reduced to 0 , when reaching $99 \%$ of the average gross wage ${ }^{87}$. Due to the use of per capita incomes in benefit calculations, larger families receive proportionally bigger benefits.

Lithuania, Estonia and Slovenia have personal income taxation systems, which use tax allowances (i.e. income-independent amounts deductible from taxable income). Allowances are increased for families with children. The rules of family tax allowances are relatively similar, though levels differ. Lithuanian tax allowances differ by family type: the most generous support goes to large families, followed by the support to single parent families and, finally, families with up to two children. Estonian family tax allowance assigns an identical amount per each child. Slovenian family tax allowance increases with each subsequent child. Using EUROMOD to calculate the value of these measures, the Slovenian system appears to be the most generous. Here, the tax support amount is actually the second largest state support to families (after the means tested allowance). The Lithuanian tax allowance is relatively small compared to the state expenses on benefits. In Estonia, expenses on family tax allowance almost reach the level of the state's spending on the family benefits.

Hungary and the Czech Republic have tax credits for families with children (i.e. deductions from tax liabilities). In Hungary, only families with three or more children are entitled to receive a lump-sum family tax credit: around $2 \%$ of total population. The amount is income dependent. If tax liability is smaller than the tax credit, nothing is paid (i.e. it is non-refundable). Both small and large families are entitled to an income-dependent tax credit in the Czech Republic. The credit amount is proportional to the number of children and is subject to a maximum yearly amount. If the tax liability is lower than the tax credit, the difference is paid to the taxpayer (i.e. it is refundable).

\footnotetext{
${ }^{86} \mathrm{OAP}(\approx 120$ EUR per month) is around $15 \%$ of gross average wage (in 2008).
}

${ }^{87}$ About 1160 EUR per month. 
Table 6-2. State annual expenses \& beneficiaries of 'transfers to children', in EUR (2008) [1]

\begin{tabular}{|c|c|c|c|c|c|c|}
\hline & & LT & EE & $\mathrm{HU}$ & SI & $\mathrm{CZ}$ \\
\hline Birth grant & Benefit per recipient, EUR & 301.1 & 317.4 & 270.4 & 212.0 & $544.1^{[2]}$ \\
\hline \multirow{7}{*}{$\begin{array}{l}\text { Child } \\
\text { benefit }\end{array}$} & Age thresholds & $18(24)$ & 17 & $\sim 17(\sim 20)$ & & \\
\hline & Size: $\Delta^{[3]}$ with child age & $\downarrow$ & No & No & & \\
\hline & Size: $\Delta$ with \# of children & $\uparrow$ & $\uparrow$ & $\downarrow$ & & \\
\hline & Extra1: for single parents & No & Yes & Yes & & \\
\hline & Extra2: for young children & Yes & Yes & No & & \\
\hline & Extra2: age thresholds & 3 & $3(8)$ & No & & \\
\hline & Benefit per recipient $t^{[4]}$ & 388.1 & 332.1 & 1117.6 & & \\
\hline \multirow{3}{*}{$\begin{array}{l}\text { Allowance } \\
\text { to large } \\
\text { families }\end{array}$} & Age thresholds & & 17 & $17(25)$ & $18(26)$ & \\
\hline & Eligibility: \# of children & & $>=7$ & $>=3$ & $>=3$ & \\
\hline & Benefit per recipient & & 277.6 & 1426.0 & 334.2 & \\
\hline \multirow{5}{*}{$\begin{array}{l}\text { Means } \\
\text { tested } \\
\text { allowance }\end{array}$} & Age thresholds & & & $17(25)$ & $18(26)$ & $18(26)^{[8]}$ \\
\hline & Income threshold & & & $1.25^{*} \mathrm{OAP}$ & Avg. wage & $2.4^{*} \mathrm{MLS}$ \\
\hline & Size1: $\Delta \#$ of children & & & No & Yes & Yes \\
\hline & Size2: $\Delta$ other factors & & & No & $\downarrow$ income & $\uparrow$ age \\
\hline & Benefit per recipient & & & $756.4^{[5]}$ & 1031.9 & 353.6 \\
\hline \multirow{7}{*}{$\begin{array}{l}\text { Tax relief: } \\
\text { allowances } \\
\text { or } \\
\text { credits }\end{array}$} & Allowance (A)/credit (C) & A & A & $\mathrm{C}$ & A & C \\
\hline & Age thresholds & 18 & 18 & $17(25)$ & $18(26)$ & $18(26)$ \\
\hline & Eligibility: \# of children & $>=1$ & $>=1$ & $>=3$ & $>=1$ & $>=1$ \\
\hline & Size: $\Delta$ with $\#$ of children & Yes & Yes & No & Yes & Yes \\
\hline & Extra: for single parents & Yes & No & No & No & No \\
\hline & Means tested & No & No & Yes & No & Yes \\
\hline & Support per recipient & 48.1 & 459.0 & 307.6 & 738.1 & 421.1 \\
\hline \multicolumn{2}{|c|}{ Country population, mln. people } & 3.3 & 1.4 & 10.1 & 2.0 & 10.2 \\
\hline \multicolumn{2}{|c|}{ Expenses on benefits, mln. EUR (B) } & 150.0 & 94.0 & 1866.9 & 282.7 & 369.5 \\
\hline \multicolumn{2}{|c|}{ Per capita benefits, EUR } & 45.5 & 69.6 & 185.8 & 124.2 & 36.2 \\
\hline \multicolumn{2}{|c|}{ Expenses on tax relief, mln. EUR (T) } & 25.2 & 79.2 & 52.9 & 237.8 & 594.1 \\
\hline \multicolumn{2}{|c|}{ Per capita tax support, EUR } & 7.6 & 58.7 & 5.3 & 118.9 & 58.2 \\
\hline \multicolumn{2}{|c|}{ Total "transfers to children": $\mathrm{B}+\mathrm{T}^{[6]}$} & 175.2 & 173.2 & 1919.8 & 486.1 & 963.6 \\
\hline \multicolumn{2}{|c|}{ Per capita "transfers to children", EUR } & 53.1 & 128.3 & 191.1 & 243.1 & 94.5 \\
\hline \multicolumn{2}{|c|}{ Per capita "transfers to children", PPS[7] } & 88.5 & 175.8 & 285.2 & 319.8 & 152.4 \\
\hline
\end{tabular}

Notes: [1] Information refers to actual state expenses, unless otherwise stated; SI data refers to 2005; national currency rates have reference date of June 30, 2008; local currency amounts converted using the June 30 exchange rate; [2] No data available, estimation based on [benefit amount, 2008] $x$ [\# of beneficiaries, 2005]; [3] $\Delta$ denotes 'change(-s)'; ${ }^{[4]}$ EE supplement to the single parents excluded ( 15\% of the child benefit expenses). ${ }^{[5]}$ No administrative data available; EUROMOD simulated expenses used instead. ${ }^{[6]}$ Administrative costs excluded (differences by transfer/country could exist). [7] PPS (=purchasing power standard) is a common currency that eliminates differences in price levels between countries allowing more meaningful international volume comparisons. The used PPS and currency rates for selected countries are provided in Appendix 1 of this Chapter. ${ }^{[8]}$ The category pools two means-tested benefits: child allowance (prídavek na dite) and social allowance (socialni priplatek). Both are given only to families with children. The rules in this table refer to the larger benefit - child allowance. Stricter means testing threshold (i.e. $1.6^{*}$ MLS) is used for social allowance. Benefit per recipient is estimated as total expenses of both benefits divided by recipients of child allowance (five time numerous compared to social allowance).

Source: EUROMOD Country reports and MISSOC 
Overall, Hungary has the most extensive support using benefits (see Table 6-2): about 186 EUR per capita. However, when tax concessions are also taken into account, Slovenia is taking the lead in generosity with 243 EUR per capita. Lithuania has with 53 EUR the lowest spending on transfers to children. Taking into account differences in purchasing power standards (PPS), the per capita transfer to children slightly reduces from 1:4.6 (in EUR) to 1:3.6 (in PPS) across the selected countries. Still, this indicates high disparities in the generosity levels of the identified family benefit systems. Furthermore, Section 6.2 presented observation that systems with the most universal design of benefits tend to have the largest budgets does not hold across the selected countries. Here, countries with at least some means-tested benefits also have the highest budgets available.

\section{Microsimulation scenarios}

Microsimulation models allow testing distributional impacts of both existing and "what-if" policies. In this chapter, we exploit both options.

In order to check how effective selected transfers to children are in reducing child poverty within the national circumstances, we "eliminate" them within the country's tax-benefit system. For this, we use EUROMOD, which means that the other tax-benefit rules still play a role in further increasing or decreasing household income (e.g. the social assistance safety net may compensate part of abolishing family transfers). Other national parameters, such as original income distribution or socio-demographic structure, are of high importance too. By comparing poverty outcomes with and without transfers to children we evaluate the first-order poverty effects of existing arrangements ${ }^{88}$.

Swapping policies means that family benefits of a 'donor' country are integrated into the tax-benefit system of a 'recipient' country instead of the existing family benefit system. Such swapping allows testing the effectiveness of a specific 'donor' policy given interactions with the remaining tax-benefit structure and sociodemographic features of the 'recipient' country ${ }^{89}$. We model the impact of transfers, assuming a $100 \%$ take-up. We think this is a reasobale assumption for at

\footnotetext{
${ }^{88}$ Though outside the scope of this study, behavioural effects would be expected to occur if benefit entitlements were to be considerably increased (e.g. larger uncondintional benefits could imply lower work incentives). This is one of the reasons for considering budget neutral (swapping) simulation. One of the limitations of the latter approach is that we control for the total expenditure level and not of the individual entitlements.

${ }^{89}$ For example, based on EUROSTAT and OECD Family Database: largest share of both parents working is noted in SI (76\%) and LT $(61 \%)$, the lowest - in HU (39\%); largest share of children with single parents is in EE (24\%), the lowest - in HU (14\%); large families are prevalent in HU (34\%); lowest mean equivalised net annual income is in HU (4827 EUR), the highest - in SI (11709 EUR). More details are provided in Appendix 1 of this Chapter.
} 
least two reasons. First, this allows comparing the intended systems' designs. Second, take-up is not always well documented, but for the countries where the information is available, actual take-up of the family transfers is very high or not well researched (e.g. see the corresponding EUROMOD Country reports). Simulation biases also occur due to imperfections of the underlying survey microdata, inability to fully "parameterize" policy rules, etc., though overall EUROMOD simulations provide "reasonably consistent" poverty results in comparison to survey data (e.g. see Figari, Iacovou, Skew and Sutherland 2012).

We analyse three major policy swapping scenarios (see Figure 6-3) ${ }^{90}$, distinguishing between the actual (full) and budget neutral implementation.

Figure 6-3. Simulation scenarios
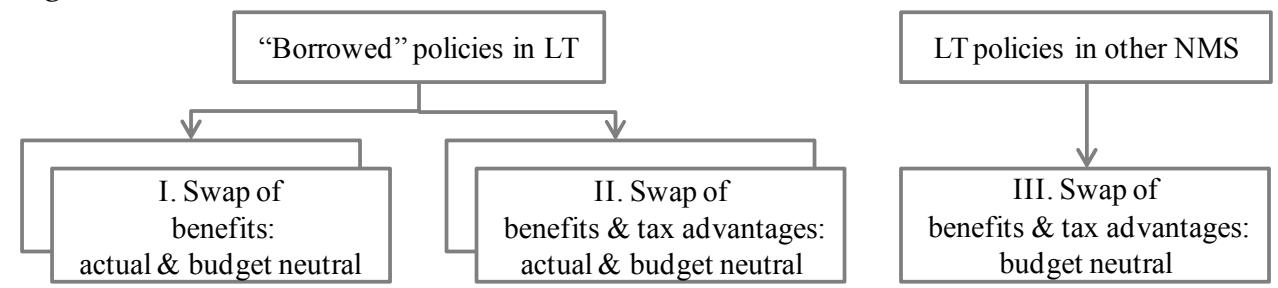

Source: own presentation

In all three swapping scenarios we rely on national monetary references (i.e. average gross wage), when converting intermediary monetary parameters (i.e. income brackets, eligibility thresholds, etc.). This allows (at least partial) policy "adaptation" to national circumstances. The sizes of entitlements depend on the scenario. We also employ the annual consumer price index (CPI) to update Slovenian transfers (of 2005) to account for changes in purchasing power by 2008. This allows a more coherent swap of Slovenian 2005 policies into the Lithuanian tax-benefit environment of 2008.

In Scenario I, we implement the benefits of the four other countries in Lithuania ${ }^{91}$. Swapping of tax support measures is excluded here. In the actual (full) swap of

\footnotetext{
${ }^{90}$ Other scenarios have been considered too. For example, small poverty reduction effects are recorded by swapping definitions (i.e. a child, a family, etc.). The size effect of Lithuanian baseline policies has been tested by assigning budget levels of the other countries (increasing by approximately 1.8 times for a spending level of Estonia, 7 times - for Slovenia, even higher levels - for Hungary and the Czech Republic). Small poverty reduction effects (mainly for large families) were noted under the Estonian level of spending; poverty in large families was halved (with barely any effects for single parent families) under Slovenian spending. Further increases in spending are found to be highly counterproductive as Lithuanian incomes are unable to absorb ever increasing tax advantages (aside any other behavioural effects). We have also estimated that an increase of a Lithuanian budget by 3 to 4 times would produce comparable poverty outcomes as under Scenario II presented budget neutral implementation of Slovenian policies.
} 
policies, the benefit amounts are introduced at the original levels, except of the adjustment for PPS and currency rates (as of June 30) among the analysed countries. This actually implies an increase in total benefits' expenses compared to original Lithuanian settings from 1.7 times under Estonian policies to 3.7 times under Hungarian policies. In the budget neutral scenario the simulated state expenses (as in the actual implementation scenario) are adjusted to the baseline Lithuanian spending by scaling each benefit's size by the country specific budgetary adjustment factor $\left(F_{j l}\right)^{92}$ :

$$
F_{j l}=\sum_{i}^{n} y_{j k} / \sum_{i}^{n} y_{l k}
$$

where: $j$ - is a country, from which policies are borrowed; $l$-Lithuania; $n$ - number of simulated recipients given Lithuanian population qualities; $k$ - number of transfer types $(\mathrm{k}) ; y$ - total simulated state expenditures.

Potential changes in taxes or other transfers (e.g. social assistance) are allowed (due to benefits' influence). Appendix 4 illustrates a stylized simulation procedure of both budget neutral and actual implementations. In the Czech Republic and Hungary the above presented formula serves as the first step in making budget neutral calculations. Due to non-linear interactions among benefits (some of the benefits are on the list of means-testing for the other benefits), empirical calibration is also used in finding the final adjustment factor (see Appendix 5 on intermediary parameters of Scenario I).

In Scenario II, we replace both Lithuanian benefits and tax advantages to children with the respective policies of the other countries (see Table 6-2) ${ }^{93}$. A comparison between Scenarios I \& II highlights additional influence of the tax support instruments. Overall, Scenario II measures the effect of benefits and tax measures together. Under budget neutrality both state expenses on benefits (i.e. using scalars of Scenario I) and income taxation revenue are calibrated separately to the baseline

\footnotetext{
${ }^{91}$ Swapping benefits' packages is feasible, as selected transfers represent comparable structures: all countries have general provision to children (i.e. birth grants, child benefits); they also give an additional support to vulnerable groups, though designs of these transfers are different. For example, though Lithuania does not have an explicit benefit to large families, its child benefit includes special treatment for large families. The same logic applies when swapping benefits and tax support measures. 92 The factor could only be applied if there are no interactions between benefits. For example, a different factor should be considered as a child benefit is included into the income list of means tested allowances in the Czech Republic. In this case, we take the estimated scaling factor as a starting point, with the final factor found during the calibration procedure.

${ }^{93}$ Other parameters (tax rate, basic allowance, etc.) of the Lithuanian income taxation system remain unchanged.
} 
Lithuanian levels (i.e. imposing changes on spending proportions between benefits and tax advantages). This means that proportional spending between tax advantages and benefits, as observed in Lithuania, is imposed on the foreign policies too. The scaling factors for tax support instruments are estimated using empirical calibration due to non-linearity in income tax calculation: first, the same budgetary adjustment factors are used to scale benefits as in Scenario I; then, scaling factors for tax support instruments are estimated using empirical calibration due to non-linearity in income tax calculation (see Appendix 6 for this Scenario related parameters).

In Scenario III, we shift Lithuanian transfers and tax instruments for children to the other four countries, while keeping the remaining tax-benefit structure of those countries unchanged (see Appendix 7 for this Scenario related intermediary parameters). We focus on the budget neutral swapping impacts, using analogous assumptions as already described in the Scenarios I and II. This scenario shows the extent of Lithuanian policies' effectiveness given different socio-economic and demographic settings, as well as interactions with the remaining tax-benefit system. Due to budget neutral condition, the composition of spending on benefits and tax advantages is matched to the proportions observed in the recipient country. This scenario allows testing if Lithuanian policies are indeed less poverty reduction effective Lithuanian policies or whether un-favourable sociodemographic settings drive the observed poverty rates in Lithuania. By adopting Lithuanian policies into different and arguably more advantageous (if considering lower poverty rates) socio-demographic settings we obtain additional evidence on the policies' effectiveness.

\section{Policy effectiveness indicators}

We evaluate swapped programmes' effectiveness by their impact on the two measures of poverty (i.e. poverty headcount and gap) before and after implementation of a certain scenario (see formulas in Appendix 3). Poverty headcount measures the prevalence of poverty and is expressed as a percentage of the (total) population with incomes below the certain poverty line. Poverty gap points to the shortfall from the poverty line for those people identified as poor. Thereby, poverty gap measures both the depth and the prevalence of poverty.

We present these two poverty indicators for the entire population, all children and children in large and single parent families. We use the relative poverty concept with the poverty line ( $60 \%$ of the median equivalised income) being recalculated for each scenario (see thresholds in Appendix 3). In comparison to the poverty line in original Lithuanian settings (about 216 EUR), it decreases by maximum $2 \%$ (Scenario III, Estonia) or increases by maximum 5\% (Scenario II - actual 
implementation, the Czech Republic) for different scenarios. Using a recalculated poverty line means that we maintain the relative character of the poverty line, thus allowing for the potential shift in median income following from changes in the income distribution (see e.g. Marx et al., 2012). Disposable income is the annual sum of total gross household income from labour earnings, plus income from investment and savings, plus all types of simulated or observed contributory and non-contributory benefits, minus simulated social contributions, minus simulated final personal income taxes and observed other taces (i.e. property, wealth taxes). Income is equivalised with the EU scale, also called the modified OECD equivalence scale. Standard errors (with a 95\% confidence level) of poverty indicators are computed using Taylor first order linearization with the STATA DASP programme ${ }^{94}$.

A comparison of the poverty outcomes in the baseline and swap scenarios gives the effect of implementing the foreign system. By simulating the budget neutral implementation, we can distinguish between the design (the baseline in comparison to the budget neutral implementation) and the size (the budget neutral in comparison to the full implementation) effects. Statistically significant changes between the point (poverty) estimates of a baseline and and a swap scenario are determined at the micro-level (i.e. comparing poverty status of each person in the two scenarios) with a $95 \%$ confidence level. More information on this estimation could be found in Appendix 8.

\subsection{Simulation results}

\section{Poverty impacts of baseline policies}

If not for transfers to children (i.e. both benefits and tax concesscions) all countries would have higher poverty levels for all groups of interest (see Table 6-3).The smallest effect of the transfers is observed in Lithuania (a 7\% reduction in child poverty rate). The largest role is played by the Hungarian system, with a child poverty reduction of around $40 \%$. The analysed systems have varied poverty gap and headcount effects for vulnerable household types.

The Slovenian system is particularly effective for large families, reducing the pretransfer poverty rate from $45 \%$ to $16 \%$ (a reduction of more than $60 \%$ ). Overall, all countries but Lithuania seem to be able to manage poverty risk of this household type with transfers to children: a reduction of around 50\% in Estonia and Hungary, and $36 \%$ in the Czech Republic. The poverty reduction rate of large families in

\footnotetext{
${ }_{94}^{94}$ More details in Araar and Duclos, 2007.
} 
Lithuania is only $8 \%$ The same holds for single parent families. Generally, the latter group has lower income protection in comparison to large families in all countries. The largest reduction is achieved by Slovenian $(36 \%)$ and Hungarian systems (32\%). The Estonian (18\%) and the Czech systems (15\%) have a smaller effect.

Slovenia also shows a large capacity of cutting poverty depth for large families (by $85 \%$ ), and for single parent families (by 73\%). These achievements bring the poverty gap indicators for these two family types to the lowest levels among our countries. The Hungarian transfers to children are important not only in combating child, but also for overall poverty. The poverty gap among large families is also reduced drastically here (by 75\%). In the Czech Republic the pre-transfer poverty gap is already small. Its means-tested system, though, achieves less for large and single parent families compared to the Slovenian system. The Estonian system halves the poverty gap among children in large families. A smaller effect is achieved among the other groups. Results on Lithuania reveal the lowest poverty gap reducing capacities.

Overall, simulation on the poverty effectiveness of these countries' existing transfers does not support above-mentioned literature (e.g. Korpi and Palme, 1998; Nelson, 2004) observations that a greater targeting achieving less poverty alleviation. 
Table 6-3. Poverty headcount and gap in pre- and post- transfer systems

\begin{tabular}{|c|c|c|c|c|c|c|c|c|c|c|}
\hline & $\begin{array}{l}\text { LT- } \\
\text { pre }\end{array}$ & $\begin{array}{l}\text { LT- } \\
\text { post }\end{array}$ & $\begin{array}{l}\text { EE- } \\
\text { pre }\end{array}$ & $\begin{array}{l}E E- \\
\text { post }\end{array}$ & $\begin{array}{l}\text { HU- } \\
\text { pre }\end{array}$ & $\begin{array}{l}\mathrm{HU}- \\
\text { post }\end{array}$ & $\begin{array}{l}\text { SI- } \\
\text { pre }\end{array}$ & $\begin{array}{l}\text { SI- } \\
\text { post }\end{array}$ & $\begin{array}{l}\text { CZ- } \\
\text { pre }\end{array}$ & $\begin{array}{l}\text { CZ- } \\
\text { post }\end{array}$ \\
\hline \multicolumn{11}{|l|}{$\begin{array}{l}\text { Poverty } \\
\text { headcount, \% }\end{array}$} \\
\hline \multirow[t]{2}{*}{ Total } & 20.8 & 20.3 & 18.5 & 17.5 & 17.8 & 13.3 & 18.3 & 15.7 & 9.8 & 8.5 \\
\hline & $(0.78)$ & $(0.78)$ & $(0.59)$ & (0.59) & $(0.52)$ & (0.47) & $(0.57)$ & (0.54) & $(0.50)$ & (0.47) \\
\hline \multirow{2}{*}{ Children } & 28.2 & 26.2 & 26.5 & 20.1 & 32.6 & 19.6 & 23.6 & 15.0 & 15.3 & 10.8 \\
\hline & (1.63) & (1.61) & $(1.22)$ & (1.13) & (1.18) & (1.02) & (1.18) & $(0.98)$ & (1.07) & (0.97) \\
\hline \multirow{2}{*}{$\begin{array}{l}\text { - in large }(3+) \\
\text { families }\end{array}$} & 48.0 & 44.3 & 40.1 & 20.2 & 60.2 & 30.6 & 44.9 & 16.2 & 31.8 & 20.5 \\
\hline & (6.22) & (6.27) & (4.59) & (3.41) & (3.48) & (3.39) & (5.57) & (4.17) & $(4.78)$ & (4.55) \\
\hline \multirow[t]{2}{*}{$\begin{array}{l}\text { - in single parent } \\
\text { families }\end{array}$} & 49.3 & 45.1 & 55.7 & 45.6 & 44.5 & 30.2 & 39.8 & 25.6 & 32.9 & 27.9 \\
\hline & (6.29) & (6.40) & $(4.48)$ & $(4.62)$ & (3.93) & (3.54) & (5.01) & (4.79) & (3.50) & (3.41) \\
\hline \multicolumn{11}{|l|}{ Poverty gap, \% } \\
\hline \multirow[t]{2}{*}{ Total } & 6.3 & 5.9 & 5.3 & 4.9 & 6.0 & 3.2 & 4.7 & 3.4 & 1.7 & 1.5 \\
\hline & (0.41) & (0.39) & $(0.28)$ & $(0.26)$ & (0.29) & (0.16) & $(0.22)$ & (0.15) & $(0.14)$ & (0.13) \\
\hline \multirow[t]{2}{*}{ Children } & 8.7 & 7.5 & 8.3 & 6.2 & 12.0 & 4.5 & 6.5 & 2.5 & 2.7 & 1.9 \\
\hline & $(0.76)$ & $(0.68)$ & $(0.57)$ & $(0.50)$ & $(0.67)$ & $(0.30)$ & (0.45) & (0.19) & $(0.28)$ & $(0.26)$ \\
\hline \multirow{2}{*}{$\begin{array}{l}\text { - in large }(3+) \\
\text { families }\end{array}$} & 14.8 & 12.0 & 10.9 & 5.2 & 26.1 & 6.3 & 12.3 & 1.9 & 6.0 & 4.3 \\
\hline & (2.49) & (2.19) & (1.54) & (0.99) & (2.17) & (0.83) & (2.03) & $(0.55)$ & (1.26) & (1.24) \\
\hline \multirow[t]{2}{*}{$\begin{array}{l}\text { - in single parent } \\
\text { families }\end{array}$} & 13.9 & 13.1 & 18.0 & 14.1 & 18.2 & 6.7 & 11.3 & 3.1 & 5.3 & 3.7 \\
\hline & (2.07) & (2.01) & (1.89) & (1.85) & (2.33) & (1.14) & (2.18) & $(0.61)$ & (0.73) & $(0.62)$ \\
\hline
\end{tabular}

Notes: Here and further on: standard errors in parentheses; children defined as persons under the age of 18. Shaded cells indicate significant changes between pre-and post- scenarios.

Source: own calculations using EUROMOD

\section{Are "borrowed" policies more poverty reduction effective?}

Table 6-4 displays the poverty outcomes of swapping foreign policies - both benefits and tax advantages - into Lithuania. Our findings show that the relative importance of the size and the design effects of the simulated changes depends on the system the household type and the poverty index.

The full implementation indicates that three systems lead to significantly better poverty outcomes than the existing Lithuanian system: the Hungarian, Slovenian and Czech systems. This is the case for the swap of benefits, as well as for the combined swap of benefits and tax advantages. These three countries include means-tested transfers in the child transfer package. An introduction of the Slovenian system (both for the benefits-only and for the combined benefit-tax advantage scenarios) leads to the best results for large families: poverty is halved. Much smaller poverty changes are noted for single parent families and across all three swapped systems. The poverty effects of the Estonian system, that resembles the Lithuanian design most closely, are highly heterogeneous: no significant 
changes are noted for population and child poverty with a swap of benefits; small but significant poverty reduction is noted for children in large families when adding tax advantages; overall small but significant increase in poverty is recorded for children in single parents' families. The latter result is the only negative effect across all swaps. The overall results indicate that the effect of the benefit swapping tends to be stronger than the effect of swapping tax advantages. Exceptions are the Hungarian and the Czech systems, where adding tax advantages leads to a significant reduction in poverty risk for single parents. Remember that Hungary and the Czech Republic have a tax credit rather than a tax allowance.

A quick glance at Table 6-4 would tempt the reader to think that the transfer size is the major determinant for the reduction of the poverty risk, as budget-neutrality leads to fewer significant changes. Having said that, we want to make some qualifications regarding the perceived dominance of size effects. First, the results are dependent on the system's design. For example, overall child poverty reduction is comparable across all borrowed systems (except of Estonia), however the Slovenian benefits' (only) system leads to the largest reduction in poverty risk of large families. The latter system does not offer the most generous benefits' package though. Second, when tax advantages are included, all systems achieve significant changes in child poverty. The direction of the changes is varied. For example, adding Slovenian tax advantages slightly increases poverty estimates for single parent families, while the Czech tax measures achieve coherent and large poverty drop for all concerned groups. Third, the use of the indicator matters too: with the poverty gap we measure significant reductions for all three 'successful' systems (HU, SI, CZ), both under budget neutral and full implementation scenarios.

While overall design effect tends to be smaller than the size effect, the final comparison is highly dependent on the population group and the system. For example, under the Slovenian regime, both the design and the size effects are of equal importance for large families (each effect achieves around a 12 percentage points reduction from the baseline poverty rate). The design effect is even stronger for the poverty gap. As discussed before, Slovenia pays considerable attention to large families. It offers an allowance to large families as well as a means-tested child benefit, which is advantageous to large families due the benefit's size being linked to per capita income. Hungarian tax and benefit measures reveal equally important size and design effects (about 10 percentage points each) for the large families too. Overall, the design effect seems to be considerably interlinked with the size effect of the policies: the systems with the strongest design effects (i.e. Slovenia and Hungary) for large families are also able to achieve the strongest size effects. 
Table 6-4. Poverty headcount and gap under the "borrowed" policies

\begin{tabular}{|c|c|c|c|c|c|c|c|c|c|}
\hline & \multirow{3}{*}{$\begin{array}{l}\text { LT } \\
\text { base- } \\
\text { line }\end{array}$} & \multicolumn{8}{|c|}{ Scenario I: Swap of Benefits } \\
\hline & & \multicolumn{4}{|c|}{ Budget neutral } & \multicolumn{4}{|c|}{ Actual } \\
\hline & & $\mathrm{EE}$ & HU & SI & $\mathrm{CZ}$ & EE & $\mathrm{HU}$ & SI & $\mathrm{CZ}$ \\
\hline \multicolumn{10}{|c|}{ Poverty headcount, \% } \\
\hline \multirow[t]{2}{*}{ Total } & 20.3 & 20.3 & 19.9 & 18.9 & 19.4 & 20.1 & 18.5 & 17.6 & 17.1 \\
\hline & $(0.78)$ & $(0.78)$ & $(0.78)$ & $(0.78)$ & $(0.78)$ & $(0.78)$ & $(0.78)$ & $(0.78)$ & $(0.78)$ \\
\hline \multirow{2}{*}{ Children } & 26.2 & 26.8 & 25.6 & 23.1 & 24.7 & 25.9 & 20.4 & 18.6 & 18.9 \\
\hline & (1.61) & (1.62) & (1.60) & $(1.57)$ & (1.62) & (1.61) & (1.52) & (1.49) & (1.53) \\
\hline \multirow{2}{*}{$\begin{array}{l}- \text { in large } \\
(3+) \text { fam. }\end{array}$} & 44.3 & 42.6 & 40.3 & 32.6 & 42.9 & 41.2 & 24.9 & 20.4 & 27.2 \\
\hline & $(6.27)$ & $(6.29)$ & $(6.27)$ & $(6.08)$ & $(6.29)$ & (6.29) & $(5.82)$ & $(5.60)$ & $(5.88)$ \\
\hline \multirow{2}{*}{$\begin{array}{l}\text { - in single } \\
\text { parent fam. }\end{array}$} & 45.1 & 49.3 & 45.9 & 45.0 & 43.6 & 48.1 & 39.5 & 38.1 & 40.2 \\
\hline & $(6.40)$ & (6.29) & $(6.38)$ & $(6.40)$ & (6.44) & (6.33) & (6.29) & (6.50) & (6.53) \\
\hline \multicolumn{10}{|c|}{ Poverty gap, \% } \\
\hline \multirow[t]{2}{*}{ Total } & 5.9 & 6.0 & 5.7 & 5.4 & 5.4 & 5.9 & 4.9 & 4.8 & 4.4 \\
\hline & $(0.39)$ & $(0.39)$ & $(0.37)$ & $(0.35)$ & $(0.35)$ & $(0.38)$ & $(0.32)$ & $(0.31)$ & $(0.29)$ \\
\hline \multirow[t]{2}{*}{ Children } & 7.5 & 7.7 & 7.1 & 6.2 & 6.7 & 7.5 & 4.9 & 4.3 & 4.3 \\
\hline & $(0.68)$ & $(0.69)$ & $(0.65)$ & $(0.56)$ & $(0.62)$ & $(0.67)$ & $(0.48)$ & $(0.43)$ & $(0.46)$ \\
\hline \multirow{2}{*}{$\begin{array}{l}- \text { in large } \\
(3+) \text { fam. }\end{array}$} & 12.1 & 12.1 & 10.7 & 7.5 & 10.6 & 11.1 & 5.9 & 3.1 & 5.7 \\
\hline & $(2.19)$ & $(2.20)$ & $(2.16)$ & $(1.63)$ & $(2.02)$ & $(2.10)$ & $(1.45)$ & $(0.99)$ & $(1.38)$ \\
\hline \multirow{5}{*}{$\begin{array}{l}\text { - in single } \\
\text { parent fam. }\end{array}$} & 13.1 & 14.3 & 12.1 & 12.0 & 11.9 & 14.7 & 8.8 & 9.5 & 9.0 \\
\hline & $(2.01)$ & (2.10) & (1.82) & $(1.83)$ & (1.92) & (2.16) & (1.50) & (1.58) & (1.77) \\
\hline & \multirow{3}{*}{$\begin{array}{l}\text { LT } \\
\text { base- } \\
\text { line }\end{array}$} & \multicolumn{8}{|c|}{ "Scenario II: Swap of Benefits \& Tax Advantages } \\
\hline & & \multicolumn{4}{|c|}{ Budget neutral } & \multicolumn{4}{|c|}{ Actual } \\
\hline & & EE & $\mathrm{HU}$ & SI & $\mathrm{CZ}$ & EE & $\mathrm{HU}$ & SI & $\mathrm{CZ}$ \\
\hline \multicolumn{10}{|c|}{ Poverty headcount, $\%$} \\
\hline \multirow[t]{2}{*}{ Total } & 20.3 & 20.3 & 19.6 & 18.9 & 19.6 & 20.0 & 18.4 & 18.5 & 16.9 \\
\hline & $(0.78)$ & $(0.78)$ & $(0.79)$ & $(0.79)$ & $(0.78)$ & $(0.78)$ & $(0.78)$ & $(0.78)$ & $(0.78)$ \\
\hline \multirow[t]{2}{*}{ Children } & 26.2 & 26.8 & 24.4 & 23.0 & 25.4 & 25.5 & 19.7 & 18.6 & 16.6 \\
\hline & $(1.61)$ & $(1.62)$ & $(1.57)$ & $(1.56)$ & $(1.62)$ & $(1.60)$ & (1.46) & $(1.47)$ & $(1.50)$ \\
\hline \multirow{2}{*}{$\begin{array}{l}\text { - in large } \\
(3+) \text { families }\end{array}$} & 44.3 & 42.6 & 34.4 & 31.1 & 45.0 & 41.2 & 24.1 & 19.8 & 25.3 \\
\hline & $(6.27)$ & (6.29) & (6.11) & $(6.07)$ & $(6.27)$ & (6.29) & $(5.80)$ & (5.55) & (5.85) \\
\hline \multirow{2}{*}{$\begin{array}{l}\text { - in single } \\
\text { parent }\end{array}$} & 45.1 & 49.8 & 45.3 & 45.2 & 44.7 & 47.8 & 33.2 & 39.8 & 29.2 \\
\hline & $(6.40)$ & $(6.28)$ & (6.39) & $(6.40)$ & (6.41) & (6.34) & $(5.78)$ & (6.46) & $(6.66)$ \\
\hline Poverty gap, & & & & & & & & & \\
\hline Total & 5.9 & 6.0 & 5.6 & 5.4 & 5.4 & 5.9 & 4.8 & 5.0 & 3.9 \\
\hline & $(0.39)$ & $(0.39)$ & $(0.36)$ & $(0.35)$ & $(0.35)$ & $(0.38)$ & $(0.31)$ & $(0.32)$ & $(0.26)$ \\
\hline Children & 7.5 & 7.9 & 6.6 & 6.1 & 6.6 & 7.4 & 4.3 & 4.4 & 2.9 \\
\hline & $(0.68)$ & $(0.69)$ & $(0.59)$ & $(0.56)$ & $(0.61)$ & $(0.67)$ & $(0.42)$ & $(0.45)$ & $(0.32)$ \\
\hline - in large & 12.1 & 12.4 & 8.5 & 7.2 & 10.5 & 10.9 & 3.8 & 3.3 & 3.4 \\
\hline$(3+)$ fam. & $(2.19)$ & (2.23) & $(1.82)$ & $(1.61)$ & (1.98) & $(2.08)$ & $(0.97)$ & (1.09) & $(0.84)$ \\
\hline - in single & 13.1 & 14.6 & 11.0 & 12.1 & 11.5 & 14.8 & 7.8 & 10.1 & 4.8 \\
\hline parent fam. & $(2.01)$ & (2.11) & (1.73) & $(1.85)$ & $(1.82)$ & (2.18) & $(1.56)$ & $(1.68)$ & $(1.02)$ \\
\hline
\end{tabular}

Note: Abbrevatiation 'fam.' refers to 'families'; shaded cells indicate significant changes between baseline and swap scenarios (Appendix 8 provides more details on calculation of significantly different poverty changes across the scenarios).

Source: own calculations using EUROMOD 
The fact that the budget-neutral swap of the Czech system does not introduce significant poverty changes for both vulnerable groups may come as a surprise, given the fact that it only has means-tested transfers. The difference from the better scoring Slovenian system relates to benefit's size determination: it is not differentiated according to income under the Czech system. Also, the income threshold is family type specific (uniform thresholds are applied in Slovenia and Hungary). Czech tax measures under the full implementation (hence the size effect is dominant), though, achieve the best poverty headcount score for single parent households. This is partly due to the fact that the tax credit is non-wastable, i.e. when the tax credit exceeds tax liabilities the difference is paid to families.

In general, the situation of children living in single parent households is least or even negatively (i.e. under the Estonian system) affected by the policy swaps. This is in line with the designs of the systems, which hardly have advantageous provisions for single parent families (especially in comparison to large families). Furthermore, original Lithuanian measures include preferential tax rather than benefit regimes for single parents. In parallel, the largest relative income improvement for this family type is noted under Hungarian and Czech tax measures, but only with a considerable increase in the tax relief size if compared to the Lithuanian baseline.

\section{Poverty reduction effectiveness of Lithuanian policies in other countries}

Across all countries, the budget neutral implementation of Lithuanian policies worsens child poverty, though to different degrees.

We observe the largest deterioration in poverty rates and for all concerned groups in the Czech Republic, even though the budget neutral Czech policies did not achieve significant poverty changes for vulnerable groups in Lithuania. Poverty rates in Hungary and Slovenia would also increase under Lithuanian policies. In both countries, however, the relative position of the single parent families does not change, indicating that neither of these countries has a more effective state support package for this group. Estonian budget neutral policies had mixed results in Lithuania. The reverse swap worsens poverty situation slightly, except of the insignificant change for single parent families. Note, that Estonian policies implied a worsening poverty situation for Lithuanian single parent families too.

The trends in poverty gaps point to larger and negative changes for children, particularly if raised in large families, for all systems. The worst performance would occur in Slovenia. The poverty gap would also widen for single parent households (though to a lesser degree than for large families), especially in 
Hungary and Slovenia. This is also a somewhat surprising effect, as a much smaller effect was detected when swapping foreign policies into Lithuania.

Table 6-5. Poverty headcount \& gap, swapping Lithuanian policies into four NMS

\begin{tabular}{|c|c|c|c|c|c|c|c|c|}
\hline & \multicolumn{2}{|c|}{ EE } & \multicolumn{2}{|c|}{$\mathrm{HU}$} & \multicolumn{2}{|c|}{ SI } & \multicolumn{2}{|c|}{$\mathrm{CZ}$} \\
\hline & post & $L T$ & post & $L T$ & post & $L T$ & post & $L T$ \\
\hline \multicolumn{9}{|l|}{ Poverty headcount, \% } \\
\hline \multirow[t]{2}{*}{ Total } & \multirow{2}{*}{$\begin{array}{c}17.5 \\
(0.59)\end{array}$} & 17.9 & \multirow{2}{*}{$\begin{array}{c}13.3 \\
(0.47)\end{array}$} & 13.8 & \multirow{2}{*}{$\begin{array}{c}15.7 \\
(0.54)\end{array}$} & 17.5 & \multirow{2}{*}{$\begin{array}{c}8.5 \\
(0.47)\end{array}$} & 10.6 \\
\hline & & $(0.58)$ & & $(0.50)$ & & $(0.55)$ & & $(0.50)$ \\
\hline \multirow[t]{2}{*}{ Children } & 20.1 & 21.0 & \multirow{2}{*}{$\begin{array}{c}19.6 \\
(1.02)\end{array}$} & 21.3 & \multirow{2}{*}{$\begin{array}{c}15.0 \\
(0.98)\end{array}$} & 17.8 & \multirow{2}{*}{$\begin{array}{c}10.8 \\
(0.97)\end{array}$} & 15.9 \\
\hline & $(1.13)$ & (1.15) & & $(1.06)$ & & (1.05) & & (1.07) \\
\hline \multirow[t]{2}{*}{ - in large (3+) families } & 20.2 & 21.4 & \multirow{2}{*}{$\begin{array}{c}30.6 \\
(3.39)\end{array}$} & 36.8 & \multirow{2}{*}{$\begin{array}{c}16.2 \\
(4.17)\end{array}$} & 23.8 & \multirow{2}{*}{$\begin{array}{c}20.5 \\
(4.55)\end{array}$} & 31.9 \\
\hline & $(3.41)$ & $(3.47)$ & & $(3.51)$ & & $(4.94)$ & & $(4.74)$ \\
\hline \multirow[t]{2}{*}{ - in single parent families } & 45.6 & 47.1 & 30.2 & 32.2 & 25.6 & 26.7 & 27.9 & 35.8 \\
\hline & $(4.62)$ & $(4.60)$ & (3.54) & $(3.68)$ & $(4.79)$ & $(4.80)$ & $(3.41)$ & (3.55) \\
\hline \multicolumn{9}{|l|}{ Poverty gap, \% } \\
\hline \multirow[t]{2}{*}{ Total } & \multirow{2}{*}{$\begin{array}{c}4.9 \\
(0.26)\end{array}$} & 5.1 & \multirow{2}{*}{$\begin{array}{c}3.2 \\
(0.16)\end{array}$} & 3.7 & \multirow{2}{*}{$\begin{array}{c}3.4 \\
(0.15)\end{array}$} & 4.1 & \multirow{2}{*}{$\begin{array}{c}1.5 \\
(0.13)\end{array}$} & 1.9 \\
\hline & & $(0.26)$ & & $(0.18)$ & & $(0.18)$ & & $(0.14)$ \\
\hline \multirow[t]{2}{*}{ Children } & \multirow{2}{*}{$\begin{array}{c}6.2 \\
(0.50)\end{array}$} & 6.7 & \multirow{2}{*}{$\begin{array}{c}4.5 \\
(0.30)\end{array}$} & 5.6 & \multirow{2}{*}{$\begin{array}{c}2.5 \\
(0.19)\end{array}$} & 4.0 & \multirow{2}{*}{$\begin{array}{c}1.9 \\
(0.26)\end{array}$} & 2.8 \\
\hline & & $(0.52)$ & & $(0.38)$ & & $(0.29)$ & & $(0.29)$ \\
\hline \multirow[t]{2}{*}{ - in large (3+) families } & 5.2 & 6.6 & \multirow{2}{*}{$\begin{array}{c}6.3 \\
(0.83)\end{array}$} & 10.0 & \multirow{2}{*}{$\begin{array}{c}1.9 \\
(0.55)\end{array}$} & 5.2 & \multirow{2}{*}{$\begin{array}{c}4.3 \\
(1.24)\end{array}$} & 5.7 \\
\hline & $(0.99)$ & (1.21) & & $(1.24)$ & & (1.15) & & (1.29) \\
\hline \multirow[t]{2}{*}{ - in single parent families } & 14.1 & 14.8 & 6.7 & 9.4 & 3.1 & 6.1 & 3.7 & 5.8 \\
\hline & $(1.85)$ & (1.86) & (1.14) & $(1.51)$ & $(0.61)$ & (1.29) & $(0.62)$ & $(0.78)$ \\
\hline
\end{tabular}

Source: own calculations using EUROMOD

\subsection{Conclusions and policy recommendations}

This study is the first application of a full tax-benefit microsimulation model for testing family transfers' effectiveness within a comparative setting of five NMS. EUROMOD, the European static tax-benefit model, allows swapping policies from one country to another. Though a number of limitations are associated with using such a model, the advantage is its comprehensive structure in handling crossnational analysis on distributional policy impacts. The policy systems differ across five countries in terms of size and design of their non-contributory transfers to children: birth grants, universal child benefits, large family allowances (categorical benefit), means tested child allowances and tax advantages to families. An advantage of using EUROMOD is that also the distribution of tax measures can be captured - an often neglected factor which can significantly impact poverty, as was illustrated by our results from the Czech and Hungarian systems.

Literature usually points to the size of the transfers as the major determinant of child poverty. Our results confirm it is of high importance. Nevertheless, we find 
the design effect could be of equal significance and is noted to have a size reinforcing effect. The strength of the size and the design effects are also highly dependent on the composition of the selected policy measures (universal, categorical, income selective) and the parametric choices of the policies' inner design (i.e. thresholds, benefit size determination, etc.).

Our study confirms that the best poverty score is not necessarily achieved by the most extensive means-tested systems - systems - in line with Korpi and Palme (1998) observations. On the other hand, "pure" universal systems are found to be the least poverty effective. A mix of means-tested and categorical benefits, sensitive to characteristics of the poor families, can act as highly poverty effective tools. This is the case with the large family allowance in Slovenia or the tax credit to large families in Hungary. The common features of these two transfers are a high reach of large families and a non-age dependent benefit's size calculation. As families with older kids could be as prone to poverty as those with younger kids, the policy design sensitive to the age rather than the number of children seems to be countereffective. A higher threshold for means-tested benefits also ensures a higher reach of the most vulnerable families. The combination of a generous means-testing threshold with benefit's size dependence on per capita family income seems to be the key behind the Slovenian child benefit's design. This is a major difference with the other means-tested benefits, found in the Czech Republic or Hungary where the benefit size respectively depends on the child's age or is uniform for all eligible families.

Our simulations do not reveal any significant design features that would reduce child poverty among single parent families in Lithuania. We would have expected more positive outcomes given expectations by the analysis of baseline policies (e.g. Slovenia's system reduces the poverty gap for single parents with $73 \%$ ). Apparently, only an increase in size is able to reduce prevalence of poverty among single parent families in Lithuania. Poverty gap analysis reveals small positive changes, except under the Estonian system. The latter design worsens both poverty score and depth among single parent families be it under budget neutral and full implementation settings.

It is essential to stress that aside benefit design and size criteria, policy alignment to national characteristics is of high importance. Although Lithuania and Estonia have the most similar non-contributory family benefit and tax measures, Estonia achieves a much better poverty reduction for both large and single parent families within own socio-demographic settings. As such, the observed size and design effects interact with a number of country-specific characteristics: sociodemographic settings, tax and benefit policies, etc. 
Summarising, we argue that Lithuanian policy makers can indeed learn from foreign experiences, if they want to improve poverty outcomes for Lithuanian children. It is important to keep in mind though that these lessons need to consider the specific socio-demographic characteristics and the wider tax-benefit system of Lithuania. 


\subsection{Appendixes}

\section{Appendix 1: Socio-demographic profiles of the selected countries}

Annual gross earnings and purchasing power standards, 2008 (2005 in SI)

\begin{tabular}{|c|c|c|c|c|c|c|c|}
\hline & $E U$ & NMS & LT & EE & $\mathrm{HU}$ & $\mathrm{CZ}$ & SI \\
\hline EUR exchange rate, June 30 & n.a. & n.a. & 3.4528 & 15.647 & 242.963 & 23.893 & 239.57 \\
\hline National currency unit & n.a. & n.a. & LTL & EEK & HUF & $C Z K$ & SIT \\
\hline PPS & 1.00 & n.a. & 0.60 & 0.73 & 0.67 & 0.62 & 0.79 \\
\hline Mean equivalised net annual & 16,756 & 4,713 & 4,932 & 6,331 & 4,827 & 6,810 & 11,709 \\
\hline Mean equivalised net annual & 16,756 & n.a. & 8,221 & 8,665 & 7,235 & 10,910 & 14,817 \\
\hline
\end{tabular}

Note: Exchange rate between Euro and EEK and between Euro and LLT is fixed.

so that $P P S_{L T}$ multiplier $* Y_{[\text {EUR amount in EU country }]}=X_{[\text {in EUR \& PPS adjusted amount in LT }]} P P S_{L T}$ multiplier

$$
=P P S_{[o f L T]} / P P S_{[o f \text { EU country] }},
$$

Source: EUROSTAT and European Central Bank

\section{Labour market situation of parents, 2007}

\begin{tabular}{|l|c|c|c|c|c|c|c|}
\hline \multirow{2}{*}{} & \multicolumn{3}{|c|}{ Children in couple households, \% } & \multicolumn{3}{c|}{ Children in sole parent households, \% } \\
\cline { 2 - 8 } & Both & One & Neither & & Parent & Parent & Parent not \\
\hline EU & 43.6 & 31.7 & 4.4 & 20.3 & 52.1 & 14.4 & 34.1 \\
\hline Lithuania & 61.0 & 22.0 & 4.8 & 12.2 & 65.2 & 8.3 & 26.5 \\
\hline Estonia & 49.0 & 38.4 & 2.8 & 9.8 & 67.9 & 5.7 & 26.4 \\
\hline Hungary & 39.4 & 44.7 & 10.4 & 5.5 & 52.2 & 3.7 & 44.2 \\
\hline Slovenia & 76.2 & 14.9 & 1.3 & 7.6 & 84.3 & 3.1 & 12.6 \\
\hline Czech & 46.6 & 41.6 & 3.7 & 8.1 & 54.3 & 6.5 & 39.2 \\
\hline
\end{tabular}

Note: children defined as household members aged 0-14; "Other" category includes households with 1 parent working full-time $\mathcal{E} 1$ parent working part-time, plus other working or not-working arrangements.

Source: OECD Family Database

\section{Full-time work}

The highest rate of children (76\%) living with both working parents is noted in Slovenia; the respective rate is also high Lithuania; full-time work of single parents is most common in Slovenia, followed by Estonia and Lithuania.

\section{Part-time work}

Part-time work by one of the two partners is of high importance in the Czech Republic and Hungary; part-time work by single parents is highest in Lithuania, followed by the Czech Republic.

\section{Jobless households}

Hungary has the highest rate of children living in jobless households (with both or one parent); this ratio for single parent households is very high in the Czech Republic too. 
Selected demographic figures, 2007

\begin{tabular}{|c|c|c|c|c|c|c|c|c|}
\hline & \multicolumn{3}{|c|}{ Share of children living in: } & \multicolumn{3}{|c|}{ Share of families raising: } & \multirow{2}{*}{$\begin{array}{c}\text { Share of } \\
\text { families } \\
\text { with } \\
\text { children }\end{array}$} & \multirow{2}{*}{$\begin{array}{l}\text { Mean age of } \\
\text { women at } \\
\text { birth of the } \\
1^{\text {st }} \text { child }\end{array}$} \\
\hline & $\begin{array}{c}\text { Sole } \\
\text { parent } \\
\text { families }\end{array}$ & $\begin{array}{l}\text { Couple } \\
\text { families }\end{array}$ & $\begin{array}{l}\text { Other } \\
\text { fami- } \\
\text { lies }\end{array}$ & $\begin{array}{c}1 \text { or } 2 \\
\text { child- } \\
\text { ren }\end{array}$ & $\begin{array}{c}3+ \\
\text { children }\end{array}$ & $\begin{array}{l}\text { Child } \\
\text { under } \\
\text { age } 6\end{array}$ & & \\
\hline Lithuania & 18.3 & 79.0 & 2.6 & 74.2 & 25.9 & 49.6 & 54 & 25.0 \\
\hline Estonia & 24.0 & 71.9 & 3.8 & 73.9 & 26.1 & 57.5 & 43 & 25.1 \\
\hline Hungary & 14.4 & 83.0 & 2.5 & 66.5 & 33.5 & 51.8 & 48 & 27.2 \\
\hline Slovenia & 15.5 & 83.3 & 0.7 & 78.2 & 21.9 & 54.5 & 50 & 28.2 \\
\hline Czech & 20.8 & 78.3 & 0.9 & 80.1 & 19.9 & 52.4 & 47 & 27.3 \\
\hline
\end{tabular}

Source: OECD Family Database

In all countries, except of Estonia, around $80 \%$ of children live with both parents. In Estonia, around a quarter of all children live in sole parent families - the highest share across our countries. Families with three children are dominant in Hungary approximately one third of all families. Living in small families is the most prevalent arrangement in Slovenia and the Czech Republic. Lithuania has the smallest share of families with children under the age of 6 . The largest share of families with children is also observed in Lithuania: $54 \%$ of all Lithuanian households. On average women have the first child at the age of 25 in both Lithuania and Estonia. The first child is usually born around 2 to 3 years later in Hungary, Slovenia and the Czech Republic. 


\section{Appendix 2. EUROMOD: validation parameters \& original names of "transfers to children"}

\section{Abbreviations:}

Simulation ratios: Ratio 'recipients'=simulated recipients/actual recipients (i.e. administrative data information); Ratio 'expenses' = simulated expenses/actual recipients; Ratio 'sim./input' = simulated expenses/expenses estimated from(survey) input data.

\begin{tabular}{|c|c|c|c|c|c|c|c|c|c|}
\hline \multirow{2}{*}{$\begin{array}{c}\text { Simulation } \\
\text { ratios / } \\
\text { original } \\
\text { name }\end{array}$} & \multicolumn{3}{|c|}{ Hungary* } & \multicolumn{3}{|c|}{ Czech Rep.** } & \multicolumn{3}{|c|}{ Slovenia $^{* * *}$} \\
\hline & $\begin{array}{l}\text { Reci- } \\
\text { pients }\end{array}$ & $\begin{array}{c}\text { Ex- } \\
\text { penses }\end{array}$ & $\begin{array}{l}\text { Sim./ } \\
\text { Input }\end{array}$ & $\begin{array}{l}\text { Reci- } \\
\text { pients }\end{array}$ & $\begin{array}{c}\text { Ex- } \\
\text { penses }\end{array}$ & $\begin{array}{l}\text { Sim./ } \\
\text { Input }\end{array}$ & $\begin{array}{l}\text { Reci- } \\
\text { pients }\end{array}$ & $\begin{array}{c}\text { Ex- } \\
\text { penses }\end{array}$ & $\begin{array}{l}\text { Sim./ } \\
\text { Input }\end{array}$ \\
\hline \multirow[t]{2}{*}{ Birth grant } & 0.95 & 0.93 & n.a. & $0.81^{* *}$ & $1.02^{* *}$ & 0.82 & 1.11 & 1.26 & n.a. \\
\hline & \multicolumn{3}{|c|}{ Anyasági támogatás } & \multicolumn{3}{|c|}{ Sünnitoetus } & \multicolumn{3}{|c|}{ Pomoč ob rojstou } \\
\hline \multirow{2}{*}{$\begin{array}{l}\text { Child } \\
\text { benefit }\end{array}$} & 1.03 & 1.07 & n.a. & & & & & & \\
\hline & \multicolumn{3}{|c|}{ Családi pótlék } & & & & & & \\
\hline \multicolumn{10}{|l|}{$\begin{array}{l}\text { Child } \\
\text { benefit } \\
\text { supplement }\end{array}$} \\
\hline \multirow{2}{*}{$\begin{array}{l}\text { Large family } \\
\text { allowance }\end{array}$} & 1.08 & 1.07 & n.a. & & & & 1.07 & 1.07 & n.a. \\
\hline & \multicolumn{3}{|c|}{ Gyermeknevelési támogatás } & & & & \multicolumn{3}{|c|}{ Dodatek za veliko družino } \\
\hline \multirow{4}{*}{$\begin{array}{l}\text { Means } \\
\text { tested } \\
\text { allowance }\end{array}$} & n.a. & n.a. & n.a. & 0.76 & 1.26 & 1.00 & 1.20 & 17 & 1.a. \\
\hline & \multicolumn{3}{|c|}{ Rendszeres gyermekvé-delmi } & \multicolumn{3}{|c|}{ Prídavek na díte } & \multicolumn{3}{|c|}{ Ootroški dodatek } \\
\hline & & & & 2.02 & 1.35 & 1.72 & & & \\
\hline & & & & \multicolumn{3}{|c|}{ Socialni priplatek } & & & \\
\hline $\begin{array}{l}\text { Single } \\
\text { parent } \\
\text { allowance }\end{array}$ & & & & & & & & & \\
\hline
\end{tabular}

Notes: ${ }^{*}$ - Observations on Hungary $\rightarrow$ Official social statistics is not collected for the Hungarian means tested allowance; **- Observations on the Czech Republic $\rightarrow$ Birth grant: under-estimation is mainly due to underestimated number of new-borns in the input data; Child and social allowances (means tested): EUROMOD simulation is not able to capture the drop in a number of actual recipients in 2008. ${ }^{* * *}$ - Observations on Slovenia $\rightarrow$ Birth grant: over-estimation is largely due to the assumption that the newly born babies are all children born from 2001 to March 2002; Child benefit: over-estimation is mainly due to differences in observed family structures and family units which apply for child benefits.

Source: EUROMOD country reports and MISSOC database 


\begin{tabular}{|c|c|c|c|c|c|c|}
\hline \multirow[b]{2}{*}{$\begin{array}{l}\text { Simulation ratios / } \\
\text { original name }\end{array}$} & \multicolumn{3}{|c|}{ Lithuania* } & \multicolumn{3}{|c|}{ Estonia $^{* *}$} \\
\hline & $\begin{array}{l}\text { Reci- } \\
\text { pients }\end{array}$ & Expenses & $\begin{array}{l}\text { Sim./ } \\
\text { Input }\end{array}$ & $\begin{array}{l}\text { Reci- } \\
\text { pients }\end{array}$ & Ex-penses & $\begin{array}{l}\text { Sim./ } \\
\text { Input }\end{array}$ \\
\hline \multirow[t]{2}{*}{ Birth grant } & 0.87 & 0.89 & 1.00 & 0.78 & 0.78 & n.a. \\
\hline & \multicolumn{3}{|c|}{ Vienkartine išmoka } & \multicolumn{3}{|c|}{ Sünnitoetus } \\
\hline \multirow{2}{*}{ Child benefit } & 1.33 & 1.12 & 1.12 & 1.06 & 1.04 & n.a. \\
\hline & \multicolumn{3}{|c|}{ Išmoka vaikui } & \multicolumn{3}{|c|}{ Lapsetoetus } \\
\hline \multirow{2}{*}{$\begin{array}{l}\text { Child benefit } \\
\text { supplement }\end{array}$} & & & & 0.98 & 1.04 & n.a. \\
\hline & & & & \multicolumn{3}{|c|}{ Lapsehooldustasu } \\
\hline \multirow{2}{*}{$\begin{array}{l}\text { Large family } \\
\text { allowance }\end{array}$} & & & & 1.12 & 1.05 & n.a. \\
\hline & & & & \multicolumn{3}{|c|}{ Seitsme-ja enamalapselise pere vanema } \\
\hline \multicolumn{7}{|l|}{$\begin{array}{l}\text { Means tested } \\
\text { allowance }\end{array}$} \\
\hline \multirow{2}{*}{$\begin{array}{l}\text { Single parent } \\
\text { allowance }\end{array}$} & & & & \multicolumn{3}{|c|}{ Not simulated } \\
\hline & & & & \multicolumn{3}{|c|}{ Üksikvanema lapse toetus } \\
\hline
\end{tabular}

Notes: *- Observations on Lithuania $\rightarrow$ Birth grant: under-estimation occurs as the actual number of children has increased from 2005 to 2008; child benefit: over-estimation in the number of recipients could occur due to inability distinguishing between full-time and part-time studying status. The assumption is made that all students study full time, which is also an eligibility condition. ${ }^{* *}$ - Observations on Estonia $\rightarrow$ Child birth allowance: Small benefit groups, such as childbirth allowance, have some problems with precision but their impact on overall expenditures is relatively small.

Source: EUROMOD country reports and MISSOC database 


\section{Appendix 3: Poverty measures}

\section{At-risk-of-poverty rate}

The percentage of persons, over the total population, with an income below the 'atrisk-of-poverty threshold (poverty line)', set at $60 \%$ of the median disposable income (EUROSTAT, 2005):

$$
P_{0}=\frac{\sum_{\text {persons with }} w^{\prime} i}{\sum_{\text {Total population }} w^{\prime} i} * 100
$$

\section{Poverty gap}

It measures the average difference between the income of poor people (people with income below the at-risk-of poverty threshold) and poverty line.

$$
P_{\alpha}=\frac{1}{\sum_{\text {Total population }} w^{\prime} i} * \sum_{\text {persons with }} w_{<<z} i\left(\frac{z-y_{i}}{z}\right)^{\alpha} \text {, where } \alpha=1 \text { indicates poverty gap index }
$$

\section{Poverty line of each scenario}

\begin{tabular}{c|cc|cccc|ccc}
\hline & \multicolumn{5}{|c|}{ Lithuania + Country X aspects (in LTL) } & \multicolumn{3}{c}{ Country X+LT policies } \\
\hline & pre & post & $1 A$ & $1 B$ & $2 A$ & $2 B$ & pre & post \\
\hline LT & $98.04 \%$ & 215.7 & & & & & & 3 \\
EE & & & $100.1 \%$ & $99.4 \%$ & $100.5 \%$ & $99.4 \%$ & $95.4 \%$ & 298.5 & $99.7 \%$ \\
SI & & & $101.5 \%$ & $99.3 \%$ & $104.5 \%$ & $99.4 \%$ & $94.4 \%$ & 400.9 & $99.9 \%$ \\
HU & & & $103.0 \%$ & $99.7 \%$ & $103.1 \%$ & $99.9 \%$ & $94.6 \%$ & 228.1 & $100.4 \%$ \\
CZ & & & $102.8 \%$ & $99.9 \%$ & $104.8 \%$ & $99.9 \%$ & $95.9 \%$ & 348.7 & $99.2 \%$ \\
\hline
\end{tabular}

Note: "post" - refers to the original country settings (with original benefit-tax policies). These poverty thresholds are presented in EUR. "Pre" - refers to the original country settings without (original) benefits and tax advantages to families. The poverty threshold for "pre" \& 1, 2, 3 Scenarios are expressed as a share of a relevant "post" poverty threshold. 


\section{Appendix 4: Main simulation steps}

Example using Scenario I assumptions; Slovenian benefits in Lithuania: main simulation steps

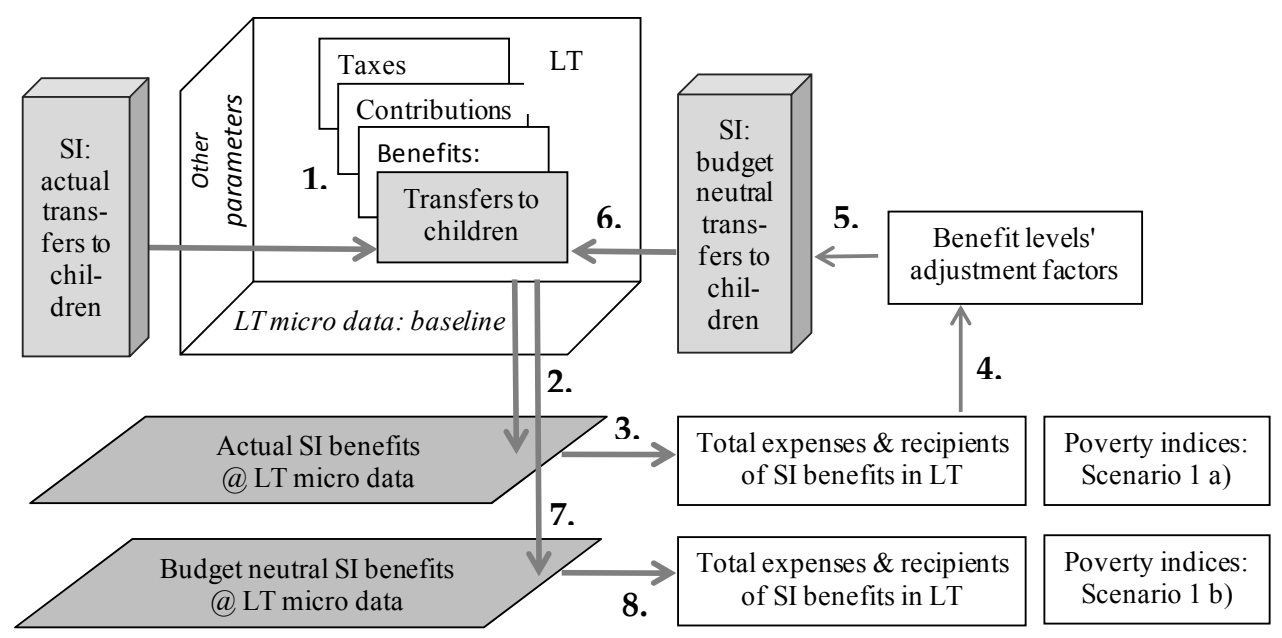

This figure illustrates a stylized simulation procedure of swapping Slovenian benefits to Lithuanian settings, with both actual and budget neutral scenarios sequencing indicated. Figure numbering " 1 to 8 " refers to the order of simulation steps. 


\section{Appendix 5: Intermediary parameters - Scenario I}

Scenario $1 A$ - actual implementation of benefits (3.4528 LTL=1 EUR)

\begin{tabular}{l|c|c|c|c|c}
\hline & LT "post" & EE & HU & SI & CZ \\
\hline Birth grant: & & & & & \\
Annual expenses, mln. LTL & 32.2 & 41.5 & 30.5 & 28.3 & 57.0 \\
Mean annual grant, LTL & 1040.0 & 1377.6 & 711.0 & 937.4 & 1941.2 \\
\# of beneficiary families[1] & 30147 & 30147 & 30147 & 30147 & 29348 \\
\hline Child benefit: & & & & & \\
Annual expenses, mln. LTL & 538.0 & 866.4 & 2004.0 & & \\
Mean annual benefit, LTL & 94.0 & $149.4 / 172.7^{[2]}$ & 344.1 & & \\
\# of beneficiary families & 477450 & $483431 / 109777^{[3]}$ & 486362 & & \\
\hline Allowance to large & & & & & \\
Annual expenses, mln. LTL & & 2.7 & $42.2^{[4]}$ & 76.4 & \\
Mean annual benefit, LTL & & 708.8 & 3792.0 & 106.5 & \\
\# of beneficiary families & & 316 & 7822 & 59762 & \\
\hline Means tested allowance: & & & & & \\
Annual expenses, mln. LTL & & & 38.5 & 1043.1 & $1321.5^{[5]}$ \\
Mean annual benefit, LTL & & & 14.5 & 353.5 & $156.1 / 171.7^{[6]}$ \\
\# of beneficiary families & & 910.6 & 2115.2 & 1147.8 & 1378.5 \\
\hline Total expenses, mln. LTL & 570.2 & & & \\
\hline
\end{tabular}

Notes: [1] - Definition of "family" (or benefit incidence assessment unit) is country and policy specific. [2]- 149.4 LTL is the mean benefit of child benefit; 172.7 LTL is the mean benefit of child benefit supplement. ${ }^{[3]}$ - the first number refers to the recipients of the child supplement; the second number refers to the recipients of the child benefit supplement. ${ }^{[4]}$ - This benefit is included into the taxable income list, but not taxed (i.e. treated as tax credit). Hence, it has an impact on tax revenues too. In Scenario $1 A$ changes in tax revenues are not taken into account. ${ }^{[5]}$ - The means tested allowance includes expenses on two benefits $(759.0 \mathrm{mln}$. LTL on child allowance + $562.5 \mathrm{mln}$. LTL on social allowance). ${ }^{[6]}-156.1 \mathrm{LTL}$ is the mean benefit of child allowance; 171.7 LTL is the mean benefit of social allowance. ${ }^{[7]}$ - the first number refers to the recipients of the child allowance; the second number refers to the recipients of the social allowance.

Scenario 1B - budget neutral implementation of benefits

\begin{tabular}{lccccc}
\hline & LT (base) & EE & HU & SI & CZ \\
\hline Applied budgetary adjustment factor $\left(\mathrm{F}_{\mathrm{jl}}\right)$ & 1.0 & 0.7418 & $0.3330^{*}$ & 0.4968 & $0.4054^{*}$ \\
\hline$*$ - Additional calibration of the $F_{j l}$ factor was needed due to interactions among benefits: e.g. child benefit is included in the income \\
list when calculating eligibility to a means tested allowance in $\mathrm{CZ}$; allowance to large families is a taxable benefit in HU; allowance \\
to large families, child benefit and birth grant are counted as income sources for the means tested benefit in HU.
\end{tabular}




\section{Appendix 6: Intermediary parameters - Scenario II}

Scenario II - actual implementation of taxes and benefits (3.4528 LTL=1 EUR)

\begin{tabular}{l|c|c|c|c|c}
\hline & LT "post" & EE & HU & SI & CZ \\
\hline State income tax revenue, mln. & 7549.2 & 7372.0 & 7491.6 & 7012.5 & 6730.6 \\
Mean monthly tax paid*, LTL & 443.0 & 435.9 & 445.6 & 425.3 & 420.7 \\
\hline
\end{tabular}

* Only positive amounts in income tax paid are taken into account.

Scenario II - budget neutral implementation of taxes and benefits*

\begin{tabular}{|c|c|c|c|c|c|}
\hline & LT & EE & $\mathrm{HU}$ & SI & $\mathrm{CZ}$ \\
\hline Budgetary adjustment factor for & 1.0 & 0.3569 & 0.7009 & 0.3927 & 0.1091 \\
\hline
\end{tabular}




\section{Appendix 7: Intermediary parameters - Scenario III}

Lithuanian tax-benefit measures to families in Estonia

\begin{tabular}{l|l|l}
\hline & EE post & EE+LT (budget neutral) \\
\hline Annual (simulated) total expenses on benefits, mln. EUR & 96.3 & 96.3 \\
\hline - Birth grant & 4.0 & 5.9 \\
\hline - Child benefit & 75.0 & 90.4 \\
\hline - Child benefit supplement & 16.9 & \\
\hline - Large family allowance & 0.4 & \\
\hline Budgetary adjustment factor for benefits (Fjl) & - & 1.2805 \\
\hline \hline Annual state income tax revenue, mln. EUR & 921.8 & 921.8 \\
\hline Mean monthly tax paid, EUR & 111.5 & 115.6 \\
\hline Budgetary adjustment factor for family tax advantages & - & 2.8793 \\
\hline
\end{tabular}

Lithuanian tax-benefit measures to families in Hungary

\begin{tabular}{l|l|l}
\hline & HU post & HU+LT (budget neutral) \\
\hline Annual (simulated) total expenses on benefits, mln. EUR & 1613.6 & 1613.6 \\
\hline - Birth grant & 23.8 & 92.8 \\
\hline - Child benefit & 1488.0 & 1520.8 \\
\hline - Large family allowance & 63.5 & \\
\hline - Means tested allowance & 38.3 & \\
\hline Budgetary adjustment factor for benefits $\left(\mathrm{F}_{j 1}\right)$ & - & 3.0392 \\
\hline \hline Annual state income tax revenue, mln. EUR & 4941.8 & 4941.8 \\
\hline Mean monthly tax paid, EUR & 170.1 & 169.2 \\
\hline Budgetary adjustment factor for family tax advantages & - & 0.7170 \\
\hline
\end{tabular}

Lithuanian tax-benefit measures to families in Slovenia

\begin{tabular}{l|l|l}
\hline & SI post & SI+LT (budget neutral) \\
\hline Annual (simulated) total expenses on benefits, mln. EUR & 288.6 & 288.6 \\
\hline - Birth grant & 4.8 & 9.4 \\
\hline - Large family allowance & 9.0 & 279.2 \\
\hline - Means tested allowance & 274.8 & \\
\hline Budgetary adjustment factor for benefits $\left(\mathrm{F}_{\mathrm{jl}}\right)$ & - & 1.2783 \\
\hline \hline Annual state income tax revenue, mln. EUR & 1607.5 & 1607.5 \\
\hline Mean monthly tax paid, EUR & 163.5 & 172.15 \\
\hline Budgetary adjustment factor for family tax advantages & - & 8.0528 \\
\hline
\end{tabular}

Lithuanian tax-benefit measures to families in the Czech Republic

\begin{tabular}{l|l|l}
\hline & CZ post & CZ+LT (budget neutral) \\
\hline Annual (simulated) total expenses on benefits, mln. EUR & 552.3 & 552.3 \\
\hline - Birth grant & 44.7 & 30.9 \\
\hline - Means tested allowance (child allowance) & 328.8 & 521.4 \\
\hline - Means tested allowance (social allowance) & 178.8 & \\
\hline Budgetary adjustment factor for benefits $\left(\mathrm{F}_{\mathrm{jl}}\right)$ & - & 1.2076 \\
\hline \hline Annual state income tax revenue, mln. EUR & 3596.6 & 3596.6 \\
\hline Mean monthly tax paid, EUR & 79.8 & 81.8 \\
\hline $\begin{array}{l}\text { Budgetary adjustment factor for family tax advantages } \\
\text { (Fij) }\end{array}$ & - & 31.8468 \\
\hline
\end{tabular}




\section{Appendix 8: What are statistically different poverty rates across simulation scenarios?}

Tax-benefit microsimulation models are often used to evaluate (child) poverty effectiveness of hypothetical public policies (e.g. Immervoll et al., 2001; Corak, Lietz and Sutherland, 2005; Levy et al., 2009; Figari et al., 2011; etc.). The usual way of evaluating different simulation scenarios is by directly comparing obtained point estimates (i.e. poverty headcount, poverty gap, mean income, etc.) rather than by evaluating standard errors (confidence intervals) of the difference between the results. The same practice is observed not only in (child) poverty simulations, but also in the broader simulation field.

In this analysis, we improve the existing practice of comparing point estimates only: we do take into account the co-variation between the baseline and the simulations results, when establishing if the difference between the two selected poverty estimates is statistically significant. As both baseline and simulation results are estimated on the same sample (plus, simulation is a static one, without any random draws), the standard error of the difference between the two point estimates of different scenarios is smaller than the one reported for a single point estimate (when comparing across different population groups within the same scenario).

In the two tables below, we present an example of calculations for establishing a statistically significant difference between the poverty scores of different simulation scenarios. We evaluate the difference between the observed (baseline) and the simulated variable (i.e. poor people/poverty depth under EE, $\mathrm{HU}$, SI or CZ policies). The evaluation is conducted on the individual level. We report the average difference from the baseline scenario (in percentage points) and the confidence interval (in parentheses below) of this difference. Statistically significant (average) poverty changes are shaded. Under the LT baseline, we also report the point estimates and associated standard errors (in parentheses below, at the $95 \%$ significance level).

Swap of benefits, budget neutral implementation: poverty headcount, $\%$

\begin{tabular}{l|l|l|l|l|l}
\hline & LT baseline & EE & HU & SI & $C Z$ \\
\hline Total & 20.3 & -0.0 & 0.3 & 1.4 & 0.9 \\
& $(0.78)$ & $(-0.28 ; 0.10)$ & $(0.15 ; 0.49)$ & $(1.07 ; 1.67)$ & $(0.71 ; 1.09)$ \\
\hline Children & 26.2 & -0.5 & 0.7 & 3.1 & 1.5 \\
& $(1.61)$ & $(-1.14 ; 0.07)$ & $(0.11 ; 1.21)$ & $(2.13 ; 4.11)$ & $(0.95 ; 2.04)$ \\
\hline - in large (3+) families & 44.3 & 1.7 & 4.0 & 11.7 & 1.4 \\
& $(6.27)$ & $(-0.22 ; 3.63)$ & $(0.82 ; 7.08)$ & $(6.52 ; 16.8)$ & $(-0.18 ; 2.99)$ \\
\hline - in single parent & 45.1 & -4.2 & -0.8 & 0.0 & 1.4 \\
& $(6.40)$ & $(-6.79 ;-1.69)$ & $(-1.9 ; 0.32)$ & $(-0.64 ; 0.68)$ & $(-0.26 ; 3.16)$ \\
\hline
\end{tabular}

Swap of benefits, budget neutral implementation: poverty gap, \%

\begin{tabular}{l|l|l|l|l|l}
\hline & LT baseline & $E E$ & $H U$ & $S I$ & $C Z$ \\
\hline \multirow{2}{*}{ Total } & 5.9 & -0.1 & 0.2 & 0.5 & 0.5 \\
& $(0.39)$ & $(-0.08 ;-0.02)$ & $(0.15 ; 0.22)$ & $(0.47 ; 0.60)$ & $(0.45 ; 0.53)$ \\
\hline Children & 7.5 & -0.2 & 0.4 & 1.4 & 0.8 \\
& $(0.68)$ & $(-0.32 ;-0.10)$ & $(0.29 ; 0.53)$ & $(1.14 ; 1.57)$ & $(0.74 ; 0.94)$ \\
\hline - in large (3+) families & 12.1 & 0.0 & 1.3 & 4.5 & 1.4 \\
& $(2.19)$ & $(-0.47 ; 0.43)$ & $(0.70 ; 1.93)$ & $(3.61 ; 5.38)$ & $(1.06 ; 1.76)$ \\
\hline - in single parent & 13.1 & -1.2 & 1.0 & 1.0 & 1.1 \\
& $(2.01)$ & $(-1.85 ;-0.64)$ & $(0.58 ; 1.44)$ & $(0.57 ; 1.49)$ & $(0.79 ; 1.47)$ \\
\hline
\end{tabular}




\subsection{References}

Araar, A. \& Duclos, J. Y. (2007). DASP: Distributive Analysis Stata Package: Université Laval, PEP, CIRPEE and World Bank.

Bradbury, B. \& Jäntii, M. (2001). Child Poverty Across the Industrialized World: Evidence from the Luxembourg Income Study. In K. Vleminckx \& T. M. Smeeding (Eds.), Child Poverty, Child Well-being and Child Policy in Modern Nations: What Do We Know? (pp. 11-32): Bristol Policy Press.

Bradshaw, J. \& Finch, N. (2003). Child Benefit Packages in 22 countries. Paper prepared for the 4th International Research Conference on Social Security, Antwerp, Belgium, May 5-7.

Cantillon, B. \& Van den Bosch, K. (2003). Social Policy Strategies to Combat Income Poverty of Children and Families in Europe. In P. Krause, G. Bäcker \& W. Hanesch (Eds.), Combating Poverty in Europe: The German Welfare Regime in Practice. Aldershot: Ashgate.

Čok, M., Kump, N. \& Majcen, B. (2008). EUROMOD Country Report: Slovenia (2005). Commission of the European Communities (Ed.). (2008). The EU Social Protection and Social Inclusion Process. Thematic study on policy measures concerning child poverty, Vol. 10.

Corak, M., Lietz, C. \& Sutherland, H. (2005). The Impact of Tax and Transfer Systems on Children in the European Union. Innocenti Working Paper No. 2005-04, Florence, UNICEF Innocenti Research Centre.

Cornelius, P. K. (1995). Cash Benefits and Poverty Alleviation in an Economy in Transition: the Case of Lithuania. Comparative Economic Studies, 37, 49-70.

EUROSTAT (2005). Continuity of Indicators Between end-ECHP and start-SILC: Algorithms to Compute Cross-Sectional Indicators of Poverty and Social Inclusion Adopted under the Open Method of Coordination. Accessed March, 2008 at: [http://www.insee.fr/en/insee-statistiquepublique/colloques/pauvrete/pdf/Eurostat_social_indicators_EN.pdf].

Figari, F., Iacovou, M., Skew, A. and Sutherland, H. (2012) Approximations to the Truth: Comparing Survey and Microsimulation Approaches to Measuring Income for Social Indicators', Social Indicators Research, 105(3), 387-407.

Figari, F., Paulus, A. \& Sutherland, H. (2011). Measuring the Size and Impact of Public Cash Support for Children in Cross-national Perspective. Social Science Computer Review, 29(1), 85-102.

Förster, M. F. \& Tóth, I. G. (2001). Child Poverty and Family Transfers in the Czech Republic, Hungary and Poland. Journal of European Social Policy, 11(4), 324341. 
Foster, J., Greer, J. \& Thorbecke, E. (1984). A Class of Decomposable Poverty Measures. Econometrica: Journal of the Econometric Society, 761-766.

Hegedüs, P. \& Szivós, P. (2010). EUROMOD Country Report: Hungary (2005-2008). Immervoll, H., Sutherland, H. \& de Vos, K. (2001). Reducing Child Poverty in the European Union: the Role of Child Benefits. In K. Vleminckx \& T. M. Smeeding (Eds.), Child Poverty, Child Well-being and Child Policy in Modern Nations: What Do We Know? Bristol: The Policy Press.

Ivaškaite-Tamošiūnè, V., Lazutka, R. \& Salanauskaitė, L. (2010). EUROMOD Country Report: Lithuania (2005-2008).

Kabašinskaitè, D. \& Bak, M. (2006). Lithuania's Children's Policy in the Period of Transition. International Journal of Social Welfare, 15(3), 247-256.

Kamerman, S. B., Neuman, M., Waldfogel, J. \& Brooks-Gunn, J. (2003). Social Policies, Family Types and Child Outcomes in Selected OECD Countries. OECD Social, Employment and Migration Working Papers, No.6.: Organisation for Economic Co-operation and Development, Employment, Labour and Social Affairs Committee.

Kenworthy, L. (2011) Progress for the Poor. Oxford: Oxford University Press. Korpi, W. \& Palme, J. (1998). The Paradox of Redistribution and Strategies of Equality: Welfare State Institutions, Inequality, and Poverty in the Western Countries, American Sociological Review, 63(5): 661-687.

Levy, H., Lietz, C. \& Sutherland, H. (2007). Swapping Policies: Alternative TaxBenefit Strategies to Support Children in Austria, Spain and the UK. Journal of Social Policy, 36(04), 625-647.

Levy, H., Morawski, L. \& Myck, M. (2009). Alternative Tax-Benefit Strategies to Support Children in Poland. In O. Lelkes \& H. Sutherland (Eds.), Tax and Benefit Policies in the Enlarged Europe: Assessing the Impact with Microsimulation Models. Vienna: Ashgate.

Lietz, C. \& Mantovani, D. (2007). A Short Introduction to EUROMOD: An integrated European tax-benefit model. In O. Bargain (Ed.), Microsimulation in Action: Policy Analysis in Europe using EUROMOD (pp. 1-26): Elsevier Ltd.

Marx, I., Vandenbroucke, P. , Verbist G. (2012), “Can higher employment levels bring down poverty in the EU? Regression-based simulations of the Europe 2020 target", Journal of European Social Policy (forthcoming).

Matsaganis, M., O’Donoghue, C., Levy, H., Coromaldi, M., Mercader-Prats, M., Rodrigues, C. F., et al. (2007). Child Poverty and Family Transfers in Southern Europe. In A. Spadaro (Ed.), Microsimulation as a Tool for the Evaluation of Public Policies: Methods and Applications. Bilbao.

Münich, D. \& Pavel, J. (2010). EUROMOD Country Report: Czech Republic (20052008). 
Chapter 6: Comparing family support in Lithuania and other NMS P a g e | 191

National Report of Lithuania on Social protection and Social Inclusion Strategies 20082010 (NR - SPSIS). (2008). Retrieved. from http://www.socmin.lt/index.php?-311688494

Nelson, K. (2004). Mechanisms of Poverty Alleviation: Anti-Poverty Effects of NonMeans-Tested and Means-Tested Benefits in Five Welfare States. Journal of European Social Policy,14(4): 371-390.

Nelson, K. (2007) ‘Universalism versus Targeting: the Vulnerability of Social Insurance and Means-Tested Minimum Income Protection in 18 Countries, 1990-2002', International Social Security Review 60: 33-58.

Notten, G. and Gassmann, F. (2008). Size Matters: Targeting Efficiency and Poverty Reduction Effects of Means-tested and Universal Child Benefits in Russia. Journal of European Social Policy, 18(3): 260-274.

Salanauskaite, L. \& Verbist, G. (2009). Reforming Child Allowances in Lithuania: What Does Microsimulation Tell Us? In O. Lelkes \& H. Sutherland (Eds.), Tax and Benefit Policies in the Enlarged Europe: Assessing the Impact with Microsimulation Models. European Centre Vienna: Ashgate.

Sutherland, H. (Ed.). (2001). Final Report EUROMOD: An Integrated European Benefit-Tax Model, EUROMOD Working paper EM9/01, ISER, University of Essex.

TÁRKI (2011). Child Well-Being in the European Union - Better Monitoring Instruments for Better Policies. Report prepared for the State Secretariat for Social Inclusion of the Ministry of Public Administration and Justice, Budapest.

Võrk, A., Paulus, A. \& Lüpsik, S. (2010). EUROMOD Country Report: Estonia (2005-2008). 

Chapter 7: Conclusions 



\subsection{Main outputs}

This dissertation offers five major outputs that contribute to diverse aspects of public policy analysis. Two major outputs develop and discuss methodological concepts and approaches valuable for evidence-based distributional policy analysis. Three of the major outputs present new empirical evidence on the selected policies' performances. Specifically, we provide new evidence on the distributional impacts of one monetary and one in-kind public policy instrument. For the former, we refer to family cash support systems in Lithuania and four selected new EU member states (i.e. the Czech Republic, Estonia, Hungary and Slovenia). For the latter we refer to the utilisation of the national healthcare system in Luxembourg. We provide analysis of the distributional consequences of these two public policies across population sub-groups in terms of the utilisation of services and in terms of the monetary effects on poverty and inequality.

Theme I of our thesis ("Disparities in Healthcare use - accounting for employment influences") corresponds to two major outputs:

- Output 1: We propose a structure of healthcare use determinants, which explicitly accounts for diverse institutional influences. It then suggests a conceptual framework, which enhances understanding of the diverse pathways, through which both individual and contextual employment factors explain differences in healthcare use;

- Output 2: We present empirical evidence on how occupational and ethnic heterogeneity explains utilisation of national healthcare services in Luxembourg, based on the analysis of administrative social security records;

Theme II (i.e. Distributional impacts of family cash support measures: a microsimulation approach) has three major outputs.:

- Output 3: We survey the major development initiatives, the incidence and the reasons for the limited use of microsimulation tax-benefit models in European transition economies. We also include a case study of Lithuania as the most active country in the field;

- Output 4: develops and utilises the partial static microsimulation benefit model (LitFAMOD) based on household survey data for the analysis of distributional impacts of Lithuanian family benefit reform;

- Output 5: provides cross-country and microsimulation based policy evidence on the child poverty effectiveness of the Lithuanian family cash support system and offers the first-hand insights on the effectiveness and efficiency (i.e. 
under budget neutral conditions) of the "neighbouring" countries policies if they were implemented in Lithuania and vice versus.

In the next three sub-sections, we discuss in more detail the evidence we derive on the distributional impacts of selected public policies, conclusions regarding methodological approaches, conclusions regarding the corresponding data needs and the overall policy lessons.

\subsection{Evidence on distributional impacts of public policies}

The design of social policies in the EU is a matter of national competencies. Evidence on the effectiveness of national public policies is, however, shared on the wider EU or international level and creates a "pool" of policy design knowledge and associated challenges. In parallel, empirical evidence provided in this thesis provides both country specific and wider policy knowledge.

\section{National healthcare utilisation}

This dissertation studies the pattern of healthcare utilisation by diverse workers' groups in Luxembourg.

First, our research reveals that Luxembourg is a particularly interesting case for exploring occupational impacts on healthcare utilisation, given the country's highly mobile, as well as socially and culturally diverse labour market. One of our major findings actually shows that employment, as an array of diverse attributes, is highly interlinked with the impact of other contextual surroundings and other socio-economic factors, such as nationality. The latter observation is particularly interesting given high ethnical disparities of the Luxembourg labour market. We observe that foreign nationals have a lower probability of contacting healthcare, be it ambulatory or dental care, compared to Luxembourg nationals. The same observation holds for the frequency of ambulatory care. However, a few foreign nationalities are also noted to have a higher utilisation of dental services in comparison to the Luxembourgish. Our sensitivity analysis also reveals that omitting nationality variable leads to an overestimated role of income parameters and an under-estimation of non-monetary employment influences - a notable finding, given that many survey based studies do not have sufficient information for tracing the influences of ethnic backgrounds.

Second, the study points to a major influence of employment-related use of healthcare. Our findings reveal that employment characteristics are more powerful in explaining contact to healthcare services as compared to the frequency 
of use. This particularly holds true for the explanation of the dental care use. The explicit distinguishing between individual and contextual level employment characteristics allows noting diversified impacts: individual level employment attributes are found to be more influential in explaining the use of ambulatory care, whereas contextual level characteristics have a stronger role for dental care. Employment characteristics also have heterogeneous and sometimes oppositesigned effects on ambulatory and dental care utilisation. Overall, this finding is particularly true in explaining the frequency rather than the probability of a healthcare use. This result also shows that the role of employment characteristics should be carefully explained in relation to the specific healthcare service type analysed. Furthermore, this finding indicates that the way healthcare services are defined and aggregated could highlight different utilisation patterns among diverse socio-economic groups.

Our study also reveals a number of specific employment influences. We confirm wider literature observations that full-year and overtime work increase ambulatory care use, whereas being a blue-collar worker is associated with a lower use of dental services. Healthcare utilisation pattern, in relation to a specific occupational sector, company type or occupational sickness funds, presents more of unexpected results. Given that related initial expectations have been based on very limited and the country non-specific indications, the latter findings point to the need of further analysis. Overall, the study revealed that differentiated use of healthcare services by occupational group requires policy makers' attention if higher standards in population health are to be achieved.

\section{Family cash support system}

Our findings show that the move from the means tested to a universal family benefit system (from 2004 to 2008) has had a small beneficial effect on poverty and inequality in Lithuania. More specifically, using a partial tax-benefit microsimulation model, we estimate a 1.5 percentage point reduction in poverty headcount when the reform is fully implemented. The relatively small poverty effect is mainly attributed to the very modest child benefit levels: from 15 EUR per month to children above the age 3 up to 40 EUR per month to children under age 3, if raised in large families.

An indirect effect of the above reform is shown to lead to an immediate decrease of $2 \%$ of the number of families receiving social assistance benefits in 2005 and of $7 \%$ in 2008. This indicates how interactive the family benefit system and the meanstested social assistance system are. The interaction of a higher family benefit with the social assistance system implies that some household types are relatively "bigger" winners compared to others. For example, our simulations show that 
single parent households benefit the least from the reforms as a result of this interaction. Actually, our study points out that there are almost twice as many single parent households (5.8\% of all households) compared to households raising three or more children (3.3\% of all households). According to various government documents, both of these groups are recognised as primary anti-poverty targets. Nevertheless, our research reveals that single parent households would obtain income gains comparable to those of large families only when the full reform scenario is implemented. If considering indirect effects (i.e. loss of social assistance benefits), their relative gains become even smaller.

Despite small income improvements brought by the newly designed Lithuanian family allowances' system (in 2008), its overall child poverty reduction effectiveness is highly limited. Our study shows that two factors are responsible: both the system design and the available transfers' size. This finding relies on international comparisons of how effective differently designed family transfers could be, given Lithuanian socio-demographic settings and vice versus. Specifically, we evaluate the design of non-contributory cash support measured to families, be it transfers or tax advantages, as observed in the four other new EU member states that are noted to have more poverty reduction effective policies.

Our findings show that the Lithuanian cash support system to families would be more child poverty effective if some means-testing policy parameters would be implemented. Not every means-testing policy is though necessarily the most effective way of reducing poverty. This dissertation shows that a mix of meanstested and categorical benefits, sensitive to the characteristics of the poor families, act as the most powerful poverty combat tools. The desired design features of Lithuanian family support system could include a high reach of, for example, large families, a non-age dependent benefits' size calculation, a relatively generous means-testing threshold and a benefit size, calculated in relation to the actual family income (rather than of the uniform size for any family type). These precise policy parameters seem to be driving the most successful child poverty reduction scenario - a reform along the lines of the Slovenian system. Under the latter policy, both the design (i.e. keeping state expenditures constant) and the size (i.e. increasing state expenditures to the relative levels as observed in the corresponding country) effects are actually of equal importance for large families each effect achieves around a 12 percentage points reduction from the baseline poverty rate. This reveals a big poverty reduction capacity.

Our simulations further show that child poverty among single parent families would not noticeably improve if Lithuania were to apply the systems in place in a series of other transition countries- especially under budget neutral conditions. 
This reveals the specificity of Lithuanian socio-demographic conditions, as the analysed foreign policies have much higher poverty effectiveness in their original settings. It also reveals that cash support to single parent families is an effective poverty improving tool, though caveats apply and other support measures could be explored additionally.

\subsection{Conclusions on the use of methodologies in public policy studies}

From a methodological point of view this study is innovative in several ways.

First, this study shows that incorporation of the social risk management theory could provide the so needed structure in understanding and analysing various levels of influences in healthcare use studies. Following this theory, we suggest distinguishing between the two types of contextual influences in healthcare use: institutional and external factors. The explicit separation of the institutional factors enables a clear(-er) recognition that healthcare use is not only related to individual choices or needs and healthcare system organization, but also is as a result of other public policies, such as educational policies, tax-benefit structure of the country, or even migration and economic policies, as observed in the case study of the Luxembourg labour market.

The developed conceptual framework of employment-related influences in healthcare use depicts the ways individual and contextual factors interact with each other, and what the pathways of employment-related influences are. Our findings show that employment affects healthcare use in both positive and negative ways via its impact on health status, income effects, non-materials returns to work, workplace rules, work related social networks, etc. The developed conceptual framework, when applied to the analysis of empirical micro-data, could provide a more detailed explanation of inequality sources in healthcare utilisation.

Second, this dissertation provides evidence that the microsimulation modelling (MSM) is insufficiently used not only in Lithuania, but also in other European transition countries. We confirm a big gap with respect to the diversity and number of MSM applications in European transition countries compared to the economically advanced countries. We record (at least) 113 MSM applications in 19 OECD countries, while we find 36 records of MSM applications in 23 European transition countries. Furthermore, information on MSMs within the transition region is much scarcer in comparison to relative information abundance on MSMs (i.e. technical description and use) in the advanced economies. 
Our study also reveals an outstanding gap in MSM development between the upper income EU member states, often referred as "beyond transition" countries, and (most often) the lower income non-EU countries. Income level is, though, not the only criterion associated with the MSM development. If it were not for the EU or the international development agencies, the gap in MSM development among these two sub-groups of transition countries would be even larger. Overall, international initiatives dominate the MSM development in the entire European transition region - about $75 \%$ of all recorded resources. In Lithuania - the country with the highest number of recorded MSMs (i.e. 6) - no "pure" national initiatives are registered at all. The only full-fledge tax-benefit MSM in Lithuania is actually related to the EUROMOD project - an EU-wide research activity.

Actually, relatively few studies have explored the question of disproportionate lack of use of microsimulation techniques in transition economies, especially taking into consideration the huge need for this type of analysis in the light of the regions' experiences with acute and sudden distributional changes. This dissertation shows that a number of multiplicative factors are responsible for the underdevelopment and lag of microsimulation exercises in transition countries: low political interest in distributional policy analysis, rapid policy changes, low research funding and empirical research capacity, poor quality or limited access to micro-data. Many of these factors are changing, explaining the higher intensity of MSM applications in the recent years.

Third, it is the first time in Lithuania that public policy effects are studied in an integrated and coherent approach allowing evaluating the entire package of related government policies. The developed family benefit microsimulation model LitFAMOD is the first MSM application for the in-depth distributional evaluation purposes of the Lithuanian family cash support and social assistance systems. The model is actually a forerunner of a higher number of tax-benefit policies encompassing model, the EUROMOD. The use of the latter model is actually the first application of a tax-benefit microsimulation model being utilised in testing family transfers' effectiveness within a comparative setting of five new EU member states, and particularly given a focus on the Lithuanian settings.

\subsection{Conclusions on the data needs for distributional public policy studies}

This dissertation relies on diverse micro and macro, survey and administrative data sources. Some common patterns in the use of such data types for policy analysis can be observed: 
1. Household surveys offer a valuable source of information and provide an opportunity to construct tax-benefit microsimulation models or to analyse healthcare use patterns. Nevertheless, they also pose a number of challenges for empirical studies. For example, previous studies on healthcare use are restricted to a very small range of reported frequencies, which limits a more precise analysis of healthcare utilisation patterns. This study utilised administrative social security records escape this limitation. We do rely on the EU-SILC, a household income survey, for the analysis of family cash support measures though. An alternative and more suitable information source has not yet been available given the policy question and the selection of countries. The latter survey has a number of its own limitations, ranging from differences in time reference points for income and demographics information to highly aggregated information on family allowance or social exclusion variables. This implies that other information must be utilised additionally in order to ensure a policy question suitable information pool.

2. Micro level administrative records, such as social security data, offer a rich, but still under-developed source of information for distributional policy studies:

a. To study healthcare utilisation in Luxembourg, we use an extremely rich set of cross-sectional social security data of the Luxemburgresident population. The data were specifically assembled for this project from various public institutions by the Inspection Générale de la Sécurité Sociale. It is the first application of a kind. The dataset could be further developed - a major task on its own - to analyse the presented healthcare use questions in more detail or for exploring other healthcare and public policy questions.

b. In Lithuania, social security records are not yet utilised for the purpose of distributional public policy studies. Nevertheless, we find some evidence on the efforts of policy making institutions in collecting and constructing such a social security micro-database. This could be used in future policy studies: construction of a full tax-benefit microsimulation model, healthcare use studies, etc.

3. Macro information could and is utilised as a source of complementary but highly valuable information in studies primarily relying on (survey or administrative) micro-data. For example:

a. We validate the microsimulation results using annual external administrative social security information on the number of state transfers' beneficiaries or total state expenses.

b. Aggregate administrative records or other macro level information is also used to test how well survey included (observed) information aligns with external estimates, especially if information of interest pertains to smaller population sub-groups. 
c. We use macro level information (i.e. municipal level) is in order to capture healthcare supply and other area socio-economic descriptive factors within our empirical study of healthcare utilisation.

4. The pooled information from survey and administrative social security records would highly enhance the scope of policy analysis and the understanding on the causality of observed behaviours. Such pooled data sources are still rarely obtainable, often due to privacy concerns.

5. Availability of panel data, either survey or administrative records, would permit a better description of policy functioning, i.e. healthcare utilization, over time. It would also allow highlighting the influence of career information on health status and healthcare use. Such data sources become more readily available, at least in some (EU) countries. Their availability is also often related to corresponding public institutions' interest and capacity in supporting evidence based public policy analysis.

\subsection{Lessons for Public Policy Design}

The evidence on the impact of policy interventions presented in this study can be used to evaluate new policy initiatives, ex ante or ex post.

The obtained evidence on how employment characteristic relate to healthcare use point both to potential policy responses and to the supreme benefits of analysing rich social security administration datasets. Actually, such empirical micro data could also be used for the analysis of other public policies, ranging from the family benefit system in Luxembourg to social insurance or income taxation system. Three direct policy lessons also emerge from this dissertation conducted empirical study on Luxembourg:

1. Given that our study points to business and construction sectors' workers as the less frequent users of the healthcare services, one should expect people with the occupational history from these particular sectors to accumulate health problems in a longer run. These occupational profiles therefore should be a target of further studies on potential causes of low(-er) utilisation of healthcare services.

2. The policy makers aiming at improving population health in Luxembourg should pay a closer attention at healthcare utilisation patter of certain sociooccupational population sub-groups. For example, special attention should be paid to non-Luxembourg origin, poorer and part-time working employees - all three attributes are associated with a below average use of healthcare services. 
3. Though the analysed Luxembourg socio-economic settings are rather unique, ethnically diverse labour markets are more and more present in many other countries. The results from this study therefore are applicable in a wider international context, and particularly call for a more accurate capturing of the roles of nationality and employment characteristics.

The results of the dissertation can also be used to understand the effects of various family policy reforms, both in Lithuania and abroad. For example, as recently as 2009, as part of the massive budgetary cuts, family benefits' eligibility in Lithuania has once again been reformed and restricted to lower incomes families. The policy is considered as a temporary austerity measure, and no evaluation of its distributional impacts yet exists. Certain wider and this particular reform related policy lessons could be drawn:

1. The full distributional effects of the new means-testing would go beyond the single policy boundaries, and should be evaluated in relation to the social assistance rules, as well as the general tax-benefit environment and other sociodemographic changes in the country.

2. Depending on the specific parameters of the implemented means-testing, large families could become relative "winners" in comparison to other vulnerable household types, such as single parents.

3. The Lithuanian EUROMOD tax-benefit module with the underlying EU-SILC micro data for Lithuania is readily available to analyse the first-order effects of both family cash support and other policy measures.

4. This dissertation performed family policy evaluation could be extended by evaluating the poverty effectiveness of the other countries policies too - the exercise highly in demand by many national and transnational (i.e. EU Commission) policy making institutions. Given numerous budgetary restrictions, the budget neutral simulations are of particular value when striving to find the most efficient and effective policy designs.

5. The dissertation also suggests that a wider and more effective use of comprehensive policy analysis could be achieved by a more active exchange of knowledge across the national borders. As in the case of Lithuania, a number of microsimulation models have already been developed or are on the way of construction. However, unless a more active engagement in the utilisation of the current models by both national researchers and policy makers is obtained, their potential value is going to be limited.

Overall, the thesis suggests that a comprehensive analysis of empirical micro data is particularly needed and useful in order not to make over-simplistic or biasing conclusions with respect to the distributional impacts of a single public policy. As we show in this dissertation, the design and evaluation of public policies is 
dependent on many inter-linked factors, of which our knowledge is still limited. And even though construction of complex models, which could answer all policy questions, is not possible, the only way to better understand policy effects is by using comprehensive approaches and quality datasets in order to better grasp complexities of reality. 


\section{Samenvatting}

Dit proefschrift bestaat uit essays over de ex-ante en ex-post evaluatie van de herverdelende impact van overheidsbeleid. In een context van steeds toenemende druk op nationale begrotingen, van betere data en groter rekenvermogen, groeit de interesse voor analyse van overheidsbeleid. Hierbij gaat de aandacht in het bijzonder naar de doeltreffendheid, de efficiëntie en de herverdelende impact van het beleid. Een dergelijke beleidsanalyse stelt echter een aantal uitdagingen. Zo kan relevante informatie vaak enkel worden afgeleid uit de analyse van diverse, complexe, gegevensbronnen. De beschikbaarheid van recente data en van gebruiksklare analyse-instrumenten is hierbij van groot belang - zeker wanneer een dringende beleidsvraag voorligt. Het beleid is in de meeste gevallen ook specifiek voor een bepaald land, waarbij nationale instituties en de socio-demografische context een belangrijke invloed hebben op de uiteindelijke impact van een beleidsinstrument. Daarom zijn analyses op nationaal niveau zeer belangrijk. Deze en andere uitdagingen komen aan bod in dit proefschrift.

In ruime zin is het doel van dit proefschrift het beleidsadvies te ondersteunen, opdat beleidsdoelen doeltreffend en efficiënt vervuld kunnen worden. Meer specifiek zal het nieuwe empirisch onderbouwde inzichten leveren over de herverdelende impact van beleid. Het gaat hierbij om één beleidsinstrument gebaseerd op monetaire transfers (namelijk inkomenssteun aan gezinnen door de overheid) en één beleidsinstrument dat voordelen in natura biedt (namelijk het gebruik van publieke gezondheidszorg). De analyse van het gebruik van gezondheidszorg wordt toegepast op de Luxemburgse casus. Het gezinsbeleid wordt onderzocht voor de nieuwe lidstaten van de Europese Unie, met bijzondere aandacht voor Litouwen. Deze landen en regio's werden geselecteerd omdat ze ieder een bijzonder interessant sociaal-economisch en beleidskader bieden, dat tot op heden onvoldoende in kaart werd gebracht.

De analyse van de geselecteerde beleidsinstrumenten houdt rekening met de nationale en internationale context en betreft ex-ante, ex-post en hypothetische beleidsanalyse. Dit proefschrift beperkt zich niet tot empirische analyse, maar verkent ook relevante methoden voor het intensief benutten van empirische microdata voor beleidsondersteuning.

Twee hoofdstukken zijn gewijd aan gezondheidszorgbeleid. In hoofdstuk 2 verkennen we multidisciplinaire inzichten, met name de 'social risk management theory' en de bestaande conceptuele kaders met betrekking tot het gebruik van 
gezondheidszorg. Op basis hiervan stellen we een kader voor dat de determinanten van het gebruik van gezondheidszorg op een meer omvattende wijze in kaart brengt.In hoofdstuk 3 presenteren we empirische resultaten die aantonen hoe verschillende arbeidsgerelateerde factoren het individuele gebruik van gezondheidszorg beïnvloeden. Deze studie steunt op een ex-post analyse (voor het jaar 2006) van administratieve gegevens van de Luxemburgse sociale zekerheid. De data werden specifiek gestructureerd voor deze bepaalde analyse.

Dit proefschrift bevat drie hoofstukken met betrekking tot microsimulatie van de herverdelende (armoedebestrijdende) effecten van monetaire inkomenssteun aan gezinnen. Hierbij komen zowel uitkeringen als belastingvoordelen aan bod. In hoofdstuk 4 gaan we na in welke mate microsimulatiemodellen voor uitkeringen en belastingen verspreid zijn in de Europese transitielanden (dit zijn de 10 nieuwe EU-lidstaten, plus 13 landen uit Zuidoost-Europa en het Gemenebest van Onafhankelijke Staten). Microsimulatiemodellen zijn voor het beleid bijzonder nuttige analyse-instrumenten. Ze maken het immers mogelijk om complexe en vaak onderling gerelateerde uitkeringen en belastingvoordelen te bestuderen. Hoofdstuk 5 onderzoekt in welke mate de recente hervorming (in 2004) van de Litouwse gezinsuitkeringen de armoede bij gezinnen met kinderen vermindert. Dit is immers één van de belangrijkste doelstellingen van het systeem (de graad van armoederisico is bijzonder hoog in bepaalde gezinstypes, zoals bijvoorbeeld gezinnen met alleenstaande ouders of grote gezinnen). Voor deze analyse ontwikkelen we een eigen 'partial static' microsimulatiemodel, aangezien bestaande modellen niet geschikt zijn voor deze vraag. Uit de analyse blijkt dat de beleidshervorming die werd doorgevoerd in Litouwen weinig doeltreffend was op het vlak van armoedebestrijding, zeker in vergelijking met de prestaties van andere nieuwe lidstaten van de EU, zoals Estland, Hongarije, Tsjechië en Slovenië. Deze internationale vergelijking vormt het onderwerp van hoofdstuk 6. Hier evalueren we de armoede-uitkomsten van het Litouws stelsel voor gezinsuitkeringen na een hypothetische hervorming naar het voorbeeld van de voornoemde nieuwe EU-lidstaten.

Dit proefschrift levert een aantal belangrijke bijdragen aan verschillende aspecten van publieke beleidsanalyse. In ruime zin ontwikkelen en bespreken we methodologische concepten en benaderingen die waardevol zijn voor de empirisch onderbouwde analyse van het herverdelend beleid. Verder presenteren we ook nieuwe empirische resultaten met betrekking tot de uitkomsten van de gekozen beleidsinstrumenten.

Een aantal bijdragen willen we hier in het bijzonder noemen. Eén van de bijdragen op conceptueel vlak is dat we de 'social risk management theory' toepassen om de 
verschillende institutionele determinanten voor het gebruik van gezondheidszorg beter in kaart te brengen. Op methodologisch vlak stellen we vast dat er nog steeds een kloof bestaat in de ontwikkeling van microsimulatiemodellen voor uitkeringen en belastingen, met name tussen EU-lidstaten met een hoger inkomen enerzijds, en anderzijds landen met een lager inkomen, die meestal geen deel uitmaken van de EU. Het inkomensniveau is echter niet het enige criterium dat verbonden is met de ontwikkeling van microsimulaties. De empirische bijdragen bestaan uit resultaten voor Luxemburg enerzijds en anderzijds voor Litouwen in een vergelijkend perspectief. Bij het gebruik van gezondheidszorg in Luxemburg stellen we vast dat het effect van de arbeidssituatie van een individu, in al haar diversiteit, sterk verweven is met andere socio-economische factoren, zoals etnische achtergond. Bovendien toont het onderzoek aan dat de arbeidskenmerken vooral een goede verklaring bieden voor de toegang tot diensten van gezondheidszorg, eerder dan voor de frequentie van het gebruik. De analyse van het Litouwse systeem van inkomensondersteuning voor gezinnen onderzoekt het effect van de hervorming van een systeem met middelentoets naar een universeel systeem. Het onderzoek wijst uit dat deze hervorming een gunstig maar beperkt effect heeft op armoede en ongelijkheid in Litouwen. Bovendien tonen we aan dat het ontwerp van de gezinsuitkeringen (in het jaar 2008) een sterker armoedereducerend effect zou kunnen hebben dan nu het geval is, in het bijzonder voor grotere gezinnen. Anderzijds tonen we aan dat bij elk van de onderzochte hypothetische hervormingen, het effect voor gezinnen met alleenstaande ouders veel minder gunstig is dan voor grotere gezinnen. Dit geldt bij uitstek wanneer het volume van de uitkeringen, en dus de overheidsuitgaven, niet wordt verhoogd. Deze conclusie moet worden beschouwd binnen een Litouws kader, met zijn specifieke economische en socio-demografische kenmerken. We vinden immers sterkere armoedereducerende effecten wanneer we deze beleidsontwerpen toepassen binnen hun eigen context (namelijk Estland, Hongarije, Slovenië en Tsjechië).

Samenvattend stelt dit proefschrift dat er een een omvattende analyse van empirische microdata nodig is om te eenzijdige of onevenwichtige conclusies met betrekking tot de herverdelende werking van één enkel beleidsinstrument te vermijden. Zoals we hier aantonen, is het ontwerp en de evaluatie van overheidsbeleid afhankelijk van vele onderling gerelateerde factoren, waarover onze kennis nog altijd beperkt is. Een complex model ontwerpen dat in staat is alle beleidsvragen te beantwoorden, is echter onmogelijk. Desalniettemin is het gebruik van veelzijdige benaderingen en hoogwaardige datasetsde enige manier om de complexe realiteit beter te vatten en beleidseffecten te verhelderen. 



\section{Biography}

Lina Salanauskaite was born in Utena, Lithuania, in 1978. She has studied in Lithuania, the USA and the Netherlands. Lina holds a BA degree in Economics from Rollins College, USA, and an MSc degree in Social Protection Financing from the University of Maastricht, the Netherlands.

Lina has diverse work experience both in the private and public sectors. In 1999, she did a business administration internship in Freeze Frame, USA; in 2000 she worked as the associate assistant in the International Council of Central Florida, USA; in 2003-2004 - she was working as an analyst in the investment banking company, JSC Zabolis and Partners, Lithuania; from 2005 to 2009 she was a parttime coordinator of the various modules of the $\mathrm{PhD} /$ Master programmes at Maastricht Graduate School of Governance (MGSoG), the Netherlands; since 2010 she works as a researcher at the Herman Deleeck Centre for Social Policy, the University of Antwerp, Belgium.

Lina joined the PhD Programme in the European Social Protection Policy at the MGSoG in September 2005. Her PhD research has focused on the distributional impacts of public policies. During the PhD studies, she wrote and co-authored a number of articles, which were presented in numerous summer schools, conferences and research workshops. She has also participated in a number of international research projects, which directly or indirectly influenced the writing of this PhD thesis: EC project on the "Assessment of the labour market impact of the pension reform, the Russian Federation" (2005-2006); Essex University project "EUROMODUpdate" on implementation of the Lithuanian tax-benefit system into the EU-wide microsimulation model EUROMOD (2009-2011); a joined CEPS/INSTEAD and Inspection Générale de la Sécurité Sociale project REDIS on the "Coherence of social transfer policies and microsimulation", etc.

Numerous international research visits have also contributed tremendously to Lina's experience. Of special note are research visits at the Institute for Social and Economic Research (ISER/ECASS programme) of the University of Essex (2008), the Social Research Institute in Vilnius (2008) and the Centre of Social Policy of the University of Antwerp (2007). Lina also has teaching experience at various universities: "Public Economics" at the University of Mauritius (2010); "Social Welfare Research Methods" at Vilnius University (2009); “Using Microsimulation for Poverty and Inequality Analysis" at Maastricht University (2009), etc. 


\section{Selected publications}

- Salanauskaite, L., \& Verbist, G. (2012). Is the Neighbour's Grass Greener? Comparing Family Support in Lithuania and Four Other New Member States. Journal of European Social Policy (forthcoming).

- Salanauskaite, L. (2012). Tax-Benefit Microsimulation in European Transition Countries: a Review of Issues and Applications. The NISPACEE Journal of Public Administration and Public Policy (forthcoming).

- Ivaškaitè-Tamošiūnè, V., \& Salanauskaite, L. (2012). Lietuvos Statistinių Duomenų Panaudojimas Mokesčių-Išmokų Mikrosimuliaciniuose Modeliuose. Social Technologies, 2(1), 156-171.

- Ivaškaitè-Tamošiūnė, V., Kazakevičiūtè, J., Lazutka, R., Navickè, J., \& Salanauskaitė, L. (2011). EUROMOD Country Report: Lithuania (2005-2009).

- Salanauskaite, L. \& Verbist, G. (2010). Broadening The Income Concept: How And Why To Construct Non-Cash Resource Needs Adjusted Equivalence Scales? FLEMOSI project Discussion paper No. 2.

- Salanauskaite, L. \& Verbist, G. (2009). Reforming Child Allowances In Lithuania: What Does Microsimulation Tell Us? Chapter 7, in Lelkes, O. \& Sutherland, H. (Eds), Tax and Benefit Policies in the Enlarged Europe: Assessing the Impact with Microsimulation Models (pp. 155-186). European Centre Viena: Ashgate Press.

\section{Academic Awards}

Marie Curie Fellowship (2005-2008), Maastricht University, the Netherlands

\section{Languages}

Lithuanian (native), English (fluent), Russian (fluent), German (intermediate), Dutch (basic). 


\section{MGSoG Dissertation Series}

Schuering, Esther

To Condition or Not - Is That the Question? An Analysis of the Effectiveness of Ex-Ante and Ex-Post Conditionality in Social Cash Transfer Programs

MGSoG Dissertation Series, nr 29 (2012)

Joe Abah

Strong Organisations in Weak States

Atypical Public Sector Performance in Dysfunctional Environments

MGSoG Dissertation Series, nr 28 (2012)

Zina Samih Nimeh

Social Citizenship Rights: Inequality and Exclusion

MGSoG Dissertation Series, nr 27 (2012)

Lenka Eisenhamerová

Legitimacy of 'Humanitarian Military Intervention'

MGSoG Dissertation Series, nr 26 (2011)

Sonila Tomini

Informal Payments for Health Care Services in Albania

MGSoG Dissertation Series, nr 25 (2011)

Jinjing Li

Dynamic Microsimulation in Public Policy Evaluation

MGSoG Dissertation Series, nr 24 (2011)

Aziz Atamanov

Rural Nonfarm Employment and International Migration as Alternatives to Agricultural Employment:

The Case of Kyrgyztan

MGSoG Dissertation Series, nr 23 (2011)

Frieda Vandeninden

Poverty Alleviation: Aid and Social Pensions

MGSoG Dissertation Series, nr 22 (2011) 
Juliana Nyasha Tirivayi

The Welfare Effects of Integrating AIDS Treatment with Food Transfers:

Evidence from Zambia

MGSoG Dissertation Series, nr 21 (2011)

Agnieska Ewa Sowa

Who's Left Behind? Social Dimensions of Health Transition and Utilization of Medical Care in Poland

MGSoG Dissertation Series, nr 20 (2011)

Emmanaouil Sfakianakis

The Role of Private Actors in the Provision of Public Goods with Applications to Infrastructure and Financial Stability

MGSoG Dissertation Series, nr 19 (2011)

Siu Hing Lo

White Collars Green Sleeves

An Interonganizational Compariso of Deteminants of Energie-Related Behaviors among Office Workers

MGSoG Dissertation Series, nr 18 (2011)

Treena $\mathrm{Wu}$

Constraints to Human Capital Investment in Developing Countries:

Using the Asian Financial Crisis in Indonesia as a Natural Experiment

MGSoG Dissertation Series, nr 17 (2011)

Henry Espinoza Peña

Impact Evaluation of a Job-Training Programme for Disadvantaged Youths:

The Case of Projoven

MGSoG Dissertation Series, nr 16 (2011)

Florian Tomini

Between Family and Friends

Understanding the Interdependency of Private Transfers

MGSoG Dissertation Series, nr 15 (2010)

Michał Polalowski

The Institutional Transformation of Social Policy in East Central Europe:

Poland and Hungary in comparative and historical perspective

MGSoG Dissertation Series, nr 14 (2010) 
Maha Ahmed

Defining, Measuring and Adressing Vulnerability:

The Case of Post Conflict Environments

MGSoG Dissertation Series, nr 13 (2010)

Pascal Beckers

Local Space and Economic Success

The role of spatial segregation of migrants in the Netherlands

MGSoG Dissertation Series, nr 12 (2011)

Victor Cebotari

Complicting Demands in Ethnically Diverse Societies

Ethnopolitical Contention and Identity Values in Europe

MGSoG Dissertation Series, nr 11 (2010)

Dennis Gyllensporre

Competing and Complementary Perspectives on the EU as a Crisis Management Actor:

An Examination of the Common Security and Defence Policy through the Lenses of Idealism and Realism

MGSoG Dissertation Series, nr 10 (2010)

Judit Vall Castello

Business Cycle and Policy Effects on Labour Market Transitions of Older and Disabled Workers in Spain

MGSoG Dissertation Series, nr. 9 (2010)

Keetie Roelen

False Positives or Hidden Dimentions: the definition and measurement of child poverty MGSoG Dissertation Series, nr. 8 (2010)

Denisa Maria Sologon

Earning Dynamics in Europe

MGSoG Dissertation Series, nr. 7 (2010)

Melissa Siegel

Money and Mobility: Migration and Remittances

MGSoG Dissertation Series, nr. 6 (2010)

Jessica S. Hagen-Zanker

Modest Expectations: Causes and effects of migration on migrant households in source countries

MGSoG Dissertation Series, nr. 5 (2010) 
Mirtha R. Muniz Castillo

Human Development and Autonomy in Project Aid: Experiences from four bilateral projects in Nigaragua and El Salvador MGSoG Dissertation Series, nr. 4 (2009)

Christiane Arndt

Governance Indicators

MGSoG Dissertation Series, nr. 3 (2009)

Britta Augsburg

Microfinance - Greater Good or Lesser Evil?

MGSoG Dissertation Series, nr. 2 (2009)

Geranda Notten

Measuring and Managing Poverty Risks

MGSoG Dissertation Series, nr. 1 (2008) 